
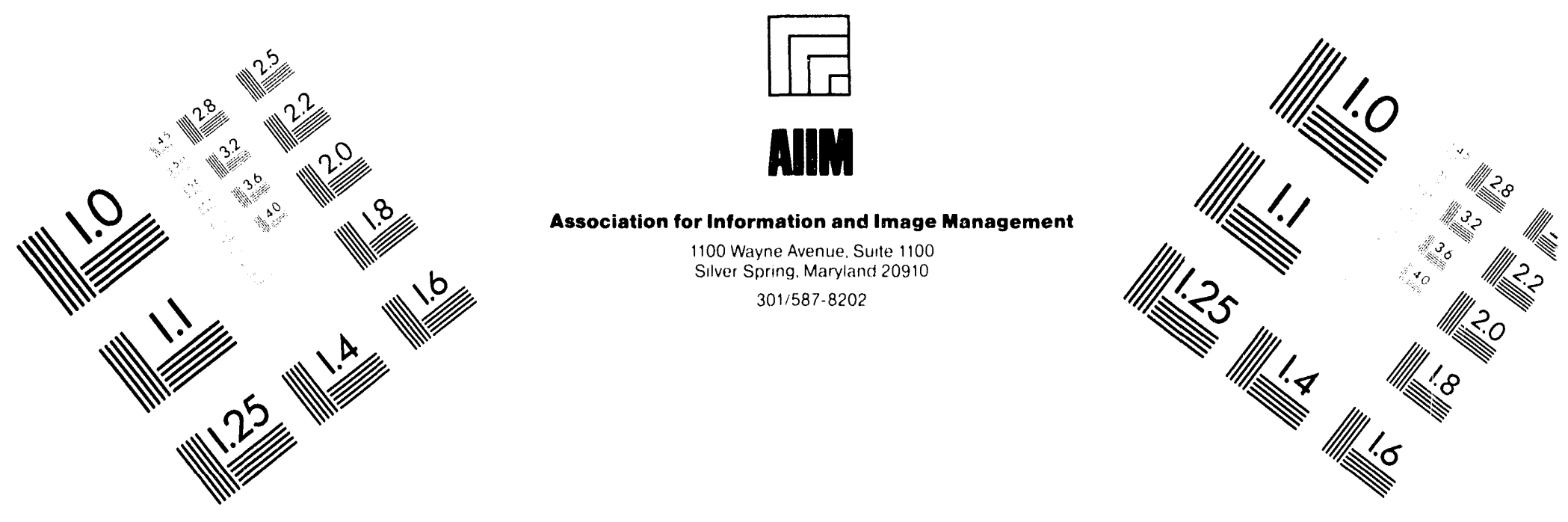

\title{
Centimeter
}

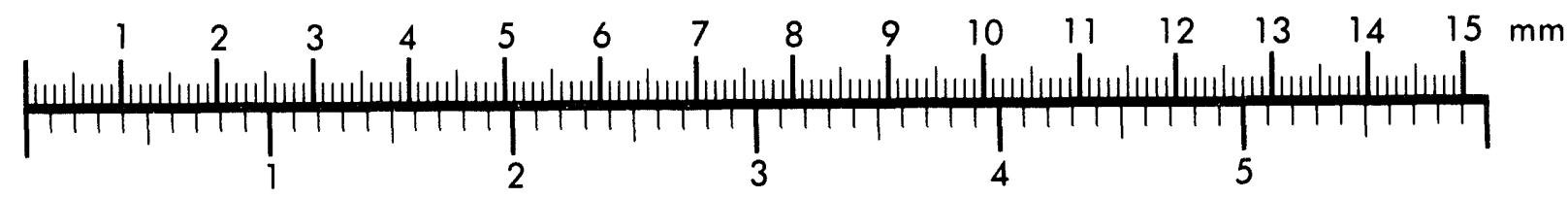
Inches
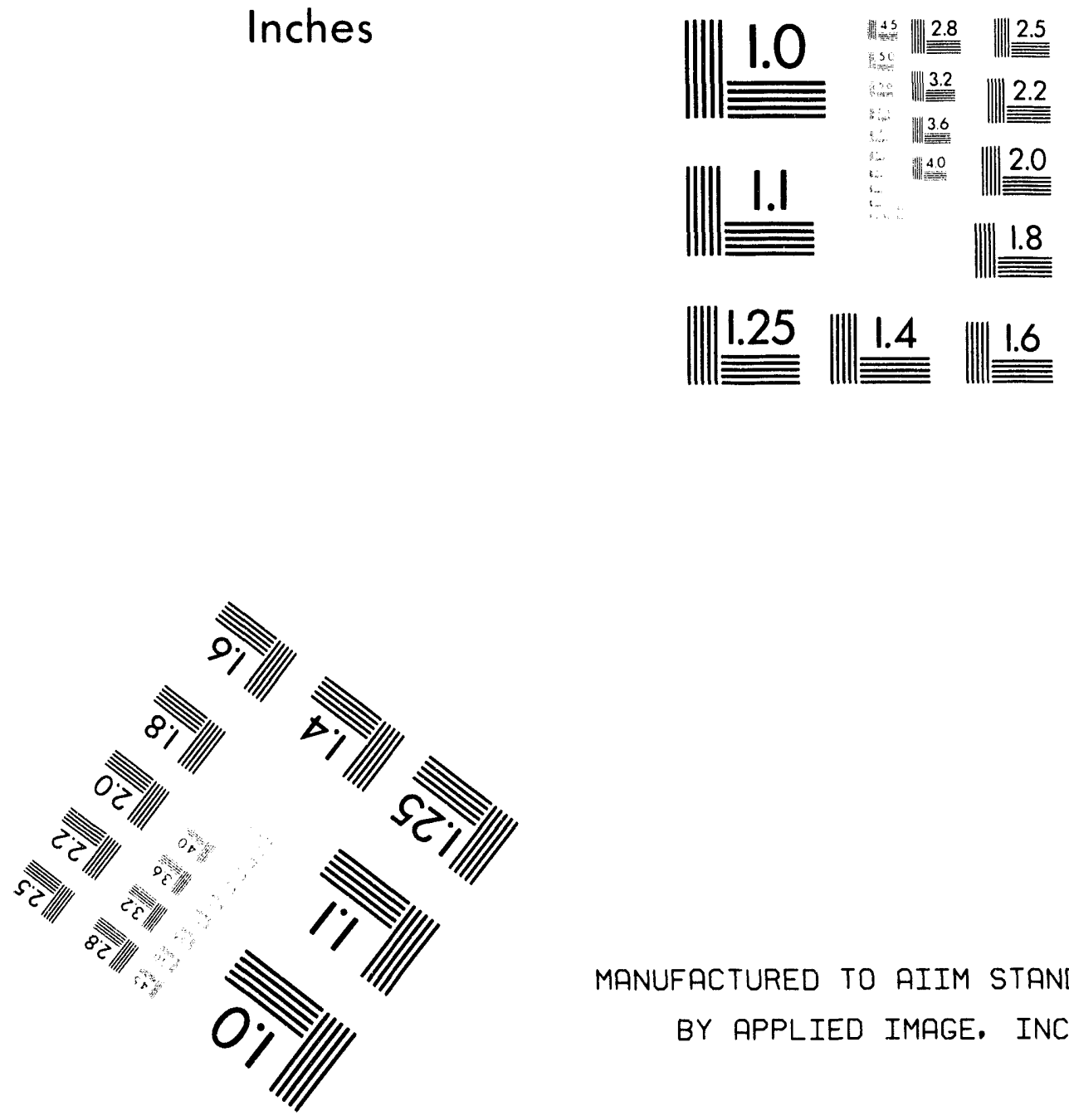

MANUFACTURED TO AIIM STANDARDS

BY APPLIED IMAGE. INC.

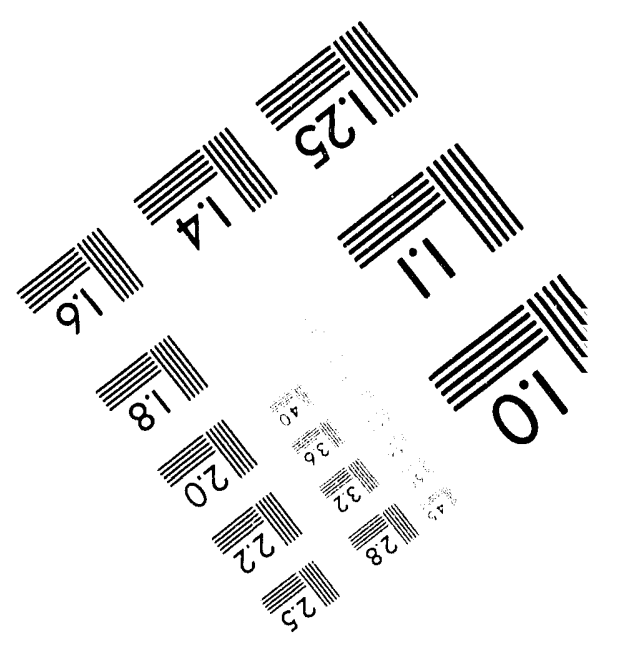



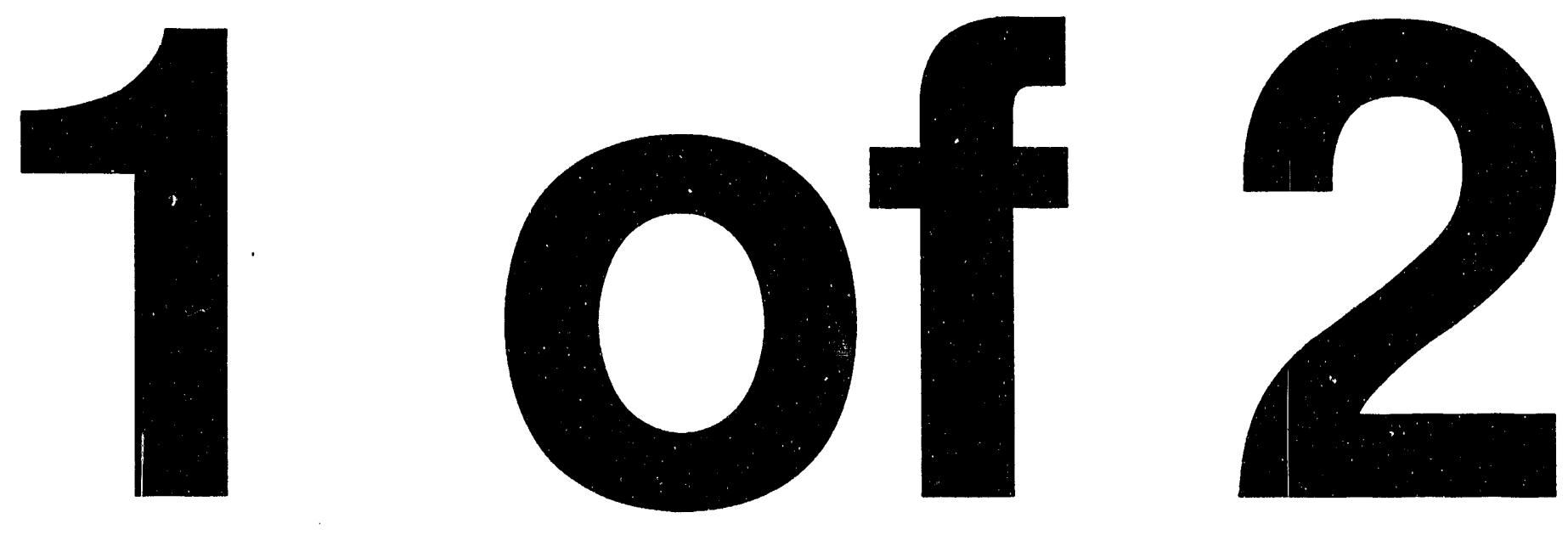
NUREG/CR-6232

PNL-9750

\section{Assessing the Environmental Availability of Uranium in Soils and Sediments}

Manuscript Completed: May 1994

Date Published: June 1994

Prepared by

J. E. Amonette, G. R. Holdren, Jr., K. M. Krupa, C. W. Lindenmeier

Pacific Northwest Laboratory

Richland, WA 99352

\section{Prepared for}

Division of Waste Management

Office of Nuclear Material Safety and Safeguards

U.S. Nuclear Regulatory Commission

Washington, DC 20555-0001

NRC FIN J5019 


\begin{abstract}
Soils and sediments contaminated with uranium pose certain environmental and ecological risks. At low to moderate levels of contamination, the magnitude of these risks depends not only on the absolute concentrations of uranium in the material but also on the availability of the uranium to drinking water supplies, plants, or higher organisms. Rational approaches for regulating the clean-up of sites contaminated with uranium, therefore, should consider the value of assessing the environmental availability of uranium at the site before making decisions regarding remediation. The purpose of this work is to review existing approaches and procedures to determine their potential applicability for assessing the environmental availability of uranium in bulk soils or sediments.
\end{abstract}

Environmental availability is a complex issue involving not only solubility, but also factors such as particle size, kinetics, and the geochemical environment in which the material is reacting. As a result, assessment methodologies can be designed to focus on any of a rumber of specific aspects of uranium chemistry. For example, there are analytical methods for total uranium, for uranium oxidation states, for uranium solid phase speciation, and for the different isotopes of uranium. Each addresses valid issues relating to environmental availability. For this project we have selected aqueous solubility of uranium as the surrogate for estimating availability.

Two major classes of approaches could be used in this type of assessment. Direct empirical approaches provide estimates of the solubility of operationally defined components of a soil. The procedures involve extractions by aqueous solutions of various compositions. Alternately, indirect approaches can be used to identify specific forms or phases of uranium; the contribution of each phase to the solubility is inferred from geochemical models based on thermodynamic and/or kinetic data.

For the present state of the technologies, direct empirical approaches are most likely to provide useful estimates of environmentally available uranium at reasonable costs. The indirect methods offer a range of information not obtainable using the empirical approaches; however, costs, availability of the measurement hardware, and uncertainty regarding the interpretation of the results currently place these technologies more appropriately in the realm of research tools. This situation should be re-evaluated periodically. We recommend testing and development of a wet-chemical procedure based on a combination of standard and nonstandard methods for an interim procedure. We believe that, eventually, methodologies must incorporate kinetic data as a crucial part of a rigorous assessment. For this reason, we recommend the evaluation of a flow-cell methodology for incorporation into an approach that would use kinetic information in the determination of environmental availability. Both the interim and rigorous procedures require laboratory testing and correlation with field data before being used for regulatory purposes.

In addition to making the recommendations regarding methodology, we have tabulated data from the literature on the aqueous complexes of uranium and major uranium minerals, examined the possibility of predicting environmental availability of uranium based on thermodynamic solubility data, and compiled a representative list of analytical laboratories capable of performing environmental analyses of uranium in soils and sediments. 


\section{Contents}

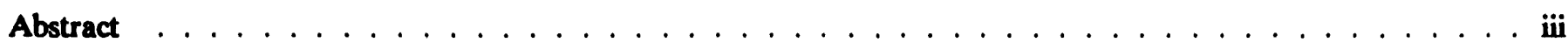

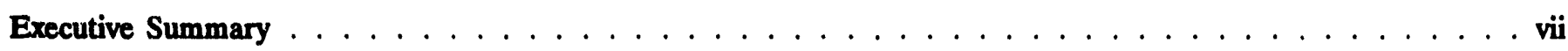

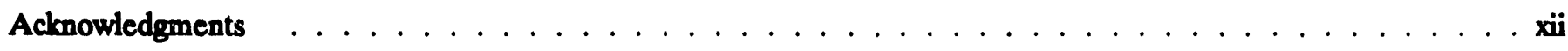

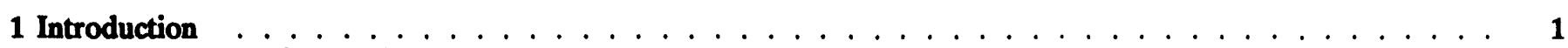

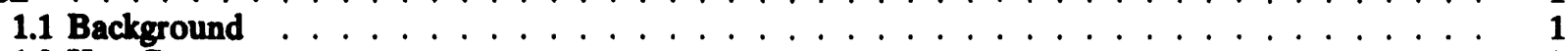

1.2 Key Concepts . . . . . . . . . . . . . . . . . . . . . . . . . . . . . . 2

1.2.1 Environmental Availability . . . . . . . . . . . . . . 2

1.2.2 Correlation . . . . . . . . . . . . . . . . . . . . 2

1.2.3 Decision Trees . . . . . . . . . . . . . . . . . . . . . . . 3

1.3 Forms of Uranium in Soils and Sediments . . . . . . . . . . . . . . . . . . . . . . . 5

1.4 Analytical Chemistry of Uranium . . . . . . . . . . . . . . . . . . . . . . . 6

1.4.1 Assay for Total Uranium . . . . . . . . . . . . . . . . . . . . . . 6

1.4.2 Assay for Uranium Oxidation States . . . . . . . . . . . . . . . . . . 6

1.4.3 Speciation of Solid-Phase Uranium . . . . . . . . . . . . . . . . 7

1.4 .4 Speciation of Uranium Isotopes . . . . . . . . . . . . . . . . . . . . . . . 7

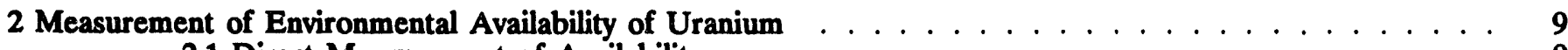

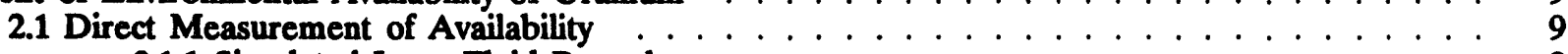

2.1.1 Simulated Lung Fluid Procedure . . . . . . . . . . . . . . . . . . . . . . . . . . 9

2.1.1.1 Background ... . . . . . . . . . . . . . . 9

2.1.1.2 Current Procedure and Limitations . . . . . . . . . . . . . . . . 9

2.1.2 Extraction Procedures . . . . . . . . . . . . . . . . . . . . . . 11

2.1.2.1 Background . . . . . . . . . . . . . . . . . . 11

2.1.2.2 Standard Methods . . . . . . . . . . . . . . . . . . . . . . 13

2.1.2.3 Sequential Extraction Methods . . . . . . . . . . . . . . . . . . . 16

2.1.2.4 Technical Applicability of Extractions . . . . . . . . . . . . . 18

2.1.2.5 Summary and Recommendations . . . . . . . . . . . . . . . . . . 20

2.1.3 Bioavailability Studies . . . . . . . . . . . . . . . . . . . . . . 21

2.1.4 Selection of Direct Measurement Approach . . . . . . . . . . . . . . . 24

2.2 Inferred Measurement of Availability _. . . . . . . . . . . . . . . . 25

2.2.1 Phase Identification Procedures . . . . . . . . . . . . . . . . . . . 25

2.2.1.1 X-ray Absorption Spectroscopy . . . . . . . . . . . . . . . . . . . . . 25

2.2.1.2 Analytical Electron Microscopy _. . . . . . . . . . . . . . . . 26

2.2.1.3 Laser-Based Spectroscopies . . . . . . . . . . . . . . . . . . . . . . . 26

2.2.1.4 Preconcentration Techniques . . . . . . . . . . . . . . 26

2.2.1.5 Assessment of Phase Identification Procedures . . . . . . . . . . . . . . 26

2.2.2 Geochemical Modeling . . . . . . . . . . . . . . . . . . . 27

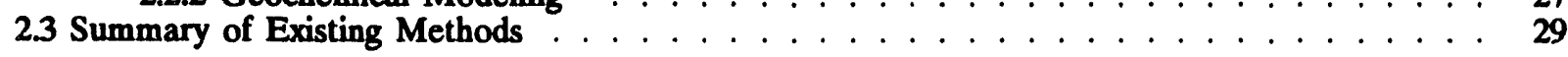

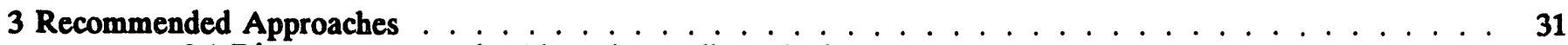

3.1 Rigorous Approach Using Flow-Cell Methodology . . . . . . . . . . . . . . . . . . . . . . 31

3.1.1 Background . . . . . . . . . . . . . . . . . . . . . . . 33

3.1 .2 Assumptions . . . . . . . . . . . . . . . . . . . . . . . . . . 33

3.1.3 Specialized Equipment $\ldots \ldots \ldots \ldots$

3.1.4 Procedure Outline . . . . . . . . . . . . . . . . . . . . . . . . . . . . . . . 33

3.1.5 Development Needs . . . . . . . . . . . . . . . . . . . . . . . . . . . . . . . . . 34

3.2 Interim Procedure Using Standard Methods . . . . . . . . . . . . . . . . . . . . . . . 34

3.2.1 Background . . . . . . . . . . . . . . . . . . . . . . . . . . . . . . . . . . 34

3.2.2 Assumptions . . . . . . . . . . . . . . . . . . . . . . . . . . . . . . . . . . . . . . 36

3.2.3 Modifications . . . . . . . . . . . . . . . . . . . . . . . . . . . 36

3.2.4 Integration with Risk Assessment Models . . . . . . . . . . . . . . . . . . . . . 37

3.2 .5 Development Needs . . . . . . . . . . . . . . . . . . . . . . . . . . . . . . . . . . . . . . 37 
Contents

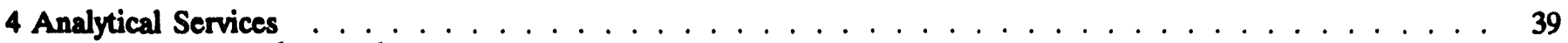

4.1 Background . . . . . . . . . . . . . . . . . . . . . . . . . 39

4.2 Cost, Batch Size, and Turnaround Time Estimates . . . . . . . . . . . . . . . . . . . . 39

4.3 Laboratory-Specific Information . . . . . . . . . . . . . . . . . . . . . . 39

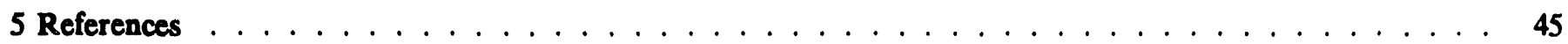

\section{Appendices}

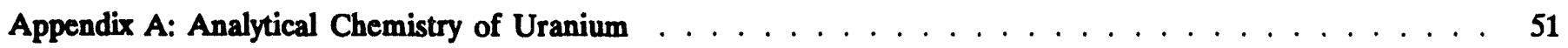

Appendix B: Draft Wet-Chemical Methods for Oxidation-State Determination of Uranium in Soils . . . . . . 63

Appendix C: Draft Interim Method for Estimating Environmentally Available Uranium in Soils . . . . . . 67

Appendix D: Draft Quality Control Procedures for Determining Environmentally Available Uranium in

Soils $\ldots \ldots \ldots \ldots \ldots \ldots$

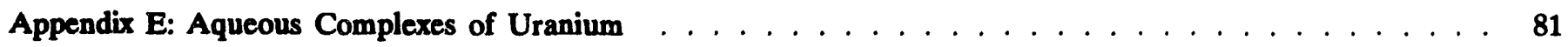

Appendix F: A Solubility-Ranking System to Describe the Relative Availability of Major Uranium Minerals and Uranium-Bearing Soil Phases . . . . . . . . . . . . . . . . . . . . . 87

Figures

Figure 1. Example of a Decision Tree for Assessing Environmental Availability of Uranium in Soils and Sediments .

Figure 2. Decision Tree for the Rigorous Approach for Assessing Environmental Availability of Uranium in Soils and Sediments

Figure 3. Draft Interim-Procedure Decision Tree for Assessing Environmental Availability of Uranium in Soils

\section{Tables}

Table 1. Pure Uranium Compound Samples Used to Calibrate the SLF Procedure (Kalkwarf, 1980b) . . . 9

Table 2. Weight Fractions (f), Dissolution Half-Lives $(\tau)$, and ICRP Dissolution-Rate Classifications of Pure Uranium Compounds Obtained with the Batch SLF Procedure (Kalkwarf, 1980b)

Table 3. Compositions of Simulated Lung Fluid (Kalkwarf, 1980b) and Typical Hanford-Site Groundwater

Table 4. Calculated Aqueous Concentrations of Uranium in Equilibrium with Schoepite $\left(\mathrm{UO}_{3} \cdot 2 \mathrm{H}_{2} \mathrm{O}\right)$ at Specified pH Values and Total Inorganic Carbon (TIC) Concentrations

Table 5. Standard Methods for the Extraction of Metals and Their Calculated Effectiveness in Extracting Uranium from a Soil Contaminated with $100 \mathrm{mg} \mathrm{U} \mathrm{kg}$ as Schoepite $\left(\mathrm{UO}_{3} \cdot 2 \mathrm{H}_{2} \mathrm{O}\right)$

Table 6. Summary of Analytical Characteristics of Selected Standard Soil Extraction Procedures

Table 7. Summary of Methods for Measurement of Environmental Availability of Uranium 


\section{Executive Summary}

Soils and sediments contaminated with uranium pose certain environmental and ecological risks. At low to moderate levels of contamination, the magnitude of these risks depends not only on the absolute concentrations of uranium in the material but also on the availability of the uranium to drinking water supplies, plants, or higher organisms. Rational approaches for regulating the clean-up of sites contaminated with uranium, therefore, should consider the value of assessing the environmental availability of uranium at the site before making decisions regarding remediation. The purpose of this work is to review existing approaches and procedures to determine their potential applicability for assessing the environmental availability of uranium in bulk soils or sediments.

\section{Concepts}

An understanding of three concepts is critical to assessing the environmental availability of uranium in soils and sediments. The first of these is "enrironmental availability" itself. We define environmental availability with respect to uranium as "the ability of a soil to supply uranium to organisms." Because the major pathways by which uranium moves from the soil to organisms involve an initial solubilization step, we can implement the definition of environmental availability by considering "the ability of a soil to maintain an aqueous concentration of uranium in the soil solution." Environmental availability can be described in terms of two primary parameters, capacity and intensity. Capacity describes the mass of uranium in a soil that can eventually become soluble. Intensity describes the amount of uranium that is soluble at any particular moment, i.e., the aqueous concentration of uranium. Although capacity is more easily measured, intensity has a greater bearing on environmental availability because, to a large extent, it is the concentration of aqueous uranium that determines how much is taken up by organisms. From the standpoint of risk assessment, we are interested in the time-resolved intensity of uranium, i.e., what aqueous concentrations of uranium will be maintained by the soil over a certain time. Thus, a determination of environmental availability requires a conceptual model that correlates easily measured parameters (e.g., capacities) with baseline observations of aqueous uranium concentrations in field soils (e.g., intensities).

The second concept critical to assessing environmental availability is that of correlation. Correlation involves evaluating any operational measure of availability, such as extracted concentration, mass, or kinetic data obtained from soil extraction procedures, and interpreting the results in the context of other data describing a particular soil or sediment. The correlation is used to obtain an overall estimate of the expected aqueous concentration of uranium present in a particular environmental situation. Examples of data other than immediate uranium concentration that are considered in the correlation process include rainfall patterns, temperature regimes, soil $\mathrm{pH}, \mathrm{p}_{\mathrm{CO} 2}$, iron oxide content, organic carbon content, texture, mineralogy, and hydraulic conductivity. Several riskbased objectives can be pursued for the correlation. Each of them requires the parameterization of a model that takes into account important factors controlling solubility or availability of uranium in soils. This correlation model serves as a useful guide for selecting the most important environmental parameters to be measured and for assessing risk levels associated with different degrees of remediation.

The third key concept used in the context of assessing environmental availability is that of a decision tree. Quite simply, a decision tree is a prioritization of the steps required to reach a remediation decision. At some point a decision must be made to remediate or to take no action, based on the assessment of environmental availability that is made. The criteria on which the decision is made must include both the results of a soil uranium analysis and their interpretation in terms of a correlation model that takes into account the other factors influencing environmental availability. For example, if one were to compare 1) a sandy soil on a flood plain in a humid zone with 2) a clayey soil on a plateau in an arid zone, each soil having the same uranium analytical results, clearly the first soil would pose a greater environmental risk and require remediation before the second. The important point to remember is that the decision tree approach offers a recipe for making remediation decisions, but the criteria employed must have sound technical bases that take into account factors other than the immediate analytical concentration of uranium.

\section{Forms in Soils}

In uranium ore deposits, the most common forms of uranium are in the reduced and mixed oxides (uraninite and pitchblende), silicates (coffinite and uranophane), uranothorite, and various phosphate and vanadate minerals (autunite series, carnotite). In soils and other near-surface environments, uranium and uranium-bearing minerals weather to form a range of phases, typically oxides, carbonates, phosphates, and 
adsorbed species. Uranium is most mobile in oxidizing, carbonate-rich waters that are high in divalent cations such as calcium and magnesium. Iron and manganese oxide phases act as effective adsorbents for oxidized uranium ions.

\section{Analytical Methods}

A variety of methods can be used to determine the total amounts of uranium present in a soils as well as the amounts of U(IV) and U(VI), the types and amounts of solid-phase uranium, and the isotopic composition of the uranium. Total uranium can be measured by decomposition of the sample in strong acid solutions and analysis of the uranium released by pulsed laser phosphorimetry, inductively coupled plasma mass spectroscopy, inductively coupled plasma atomic emission spectrometry, stripping voltammetry, spectrophotometry, X-ray spectrometry, epithermal neutron activation, and prompt gamma emission spectroscopy. The selection of method depends largely on practical considerations rather than clear technical differences.

Determination of the amounts of uranium in each oxidation state [i.e., U(IV) and U(VI)] is more difficult because of the relatively low reduction potential of $U(V)$ in aqueous solution and the consequent ease with which U(IV) can be oxidized to $\mathrm{U}(\mathrm{VI})$. Direct spectroscopic techniques such as $\mathrm{X}$-ray absorption, laser photoacoustic, laser luminescence, and laser Raman spectroscopies minimize the potential for changes in oxidation state during analysis, but generally sample only small portions of the soil and thus require many measurements to have statistical significance. Wet-chemical techniques involving ionexchange, polarography, or specific precipitation processes have been used in pure systems, but may not work well in soils because of interferences from other redox-sensitive species, notably iron.

Nevertheless these procedures can be applied to soils to gain some information about the relative oxidative or reductive capacity of the soil as a whole.

Solid-phase uranium in soils can occur as an exchangeable cation on minerals, as an organically bound constituent, as a pure or mixed-valence oxide, or as a structural constituent of various silicates, phosphates, and vanadates. Because soils and sediments are heterogeneous systems, the dominant form of uranium may change from one soil particle to the next. Speciation of the solid-phase uranium, therefore, is typically done by assessing its tendency to dissolve in different aqueous solutions ranging from deionized water to strong acid solutions. These selective extractions give rise to operational definitions of speciation for solid-phase uranium rather than strict crystallographic or thermodynamic phases. As with oxidation state determinations, direct spectroscopic techniques can identify some of the solid-phase uranium as can analytical electron microscopy, but quantification is limited by the cost of the methods and the number of samples required to obtain the desired degree of statistical certainty.

Determination of the uranium isotopic distribution is done by mass spectrometry or by nuclear spectroscopy, generally after a preconcentration step. The mass spectrometric techniques include ionization of solid samples directly as well as from aqueous or organic solutions. Nuclear spectroscopic techniques include the counting of either alpha particles from an electroplated specimen or gamma rays after irradiation of the specimen with epithermal neutrons.

\section{Techniques for Measurement of Environmental Availability}

Because the environmental availability of uranium is related to the amount of aqueous uranium maintained in the soil solution over time, measurement techniques generally involve determination of both the total capacity of the soil to release uranium and the rate at which the uranium is released to maintain a certain concentration.

Two major approaches have been taken to estimate these parameters. The first involves direct contact of the soil with a solution that simulates in a short time period the soil environmental conditions expected over a much longer time interval. Included under this broad umbrella are 1) the simulated lung fluid procedure in which aerosol particles are equilibrated for different time periods at $37{ }^{\circ} \mathrm{C}$ in an aqueous solution having a composition similar to that in human lungs, 2) chemical extraction procedures using a variety of solutions and approaches, and 3) bioavailability studies in which uptake of uranium from soils or soil solutions by plants or organisms is measured. Sequential extraction procedures in which the soil is treated by successively harsher solutions have been developed for other environmentally related assessments and several standard methods designed for particular situations are available.

The second major approach for estimating environmental availability of uranium involves inferring the aqueous concentrations of uranium based on a 
determination of the solid phases in contact with the solution and geochemical modeling of the solubilities of these phases for the particular soil solution composition. Phase identification procedures include X-ray absorption spectroscopy, analytical electron mieroscopy, and the laser-based spectroscopies. Geochemical modeling includes calculations of the thermodynamic equilibria of ions in aqueous solutions, the kinetics of solid dissolution and precipitation, and the transport of ions in soils and sediments. Of these, the equilibrium codes are well developed, whereas attempts to couple equilibrium calculations with kinetic and transport processes in soils are still in their infancy. These codes rely on large databases containing information about thermodynamically distinct phases, reaction stoichiometries, and other factors affecting reaction kinetics and transport.

In our assessments of these two major approaches we considered the technical factors (i.e., is the information obtained sufficient to establish a defensible estimate of environmental availability?) as well as the practical factors (i.e., how much time and money are required to obtain the information and how many facilities are available to perform the analyses?). Of the three direct approaches considered, two were eliminated for either technical or practical reasons. The simulated lung fluid test was clearly not specific or relevant to a soil environment and required 60 days and numerous analyses to obtain the information. The bioavailability tests, while the most relevant of all the procedures, also required lengthy periods before the information could be obtained and had not been developed sufficiently to warrant their adoption for regulatory purposes. The phase identification procedures for the inferred measurement approach, while providing unique information, generally did not provide complete information (e.g., amounts of amorphous uranium or adsorbed uranium dispersed through the soil), were expensive, and because of their small specimen size required many specimens to be analyzed before a statistically valid estimate could be obtained. In turn, the geochemical modeling for the phases identified by these techniques was focused on thermodynamic equilibrium and not sufficiently developed to handle the kinetic aspects of the problem.

We concluded that an approach based on direct extraction of the soil offered the best combination of information quality, low cost, and rapid turnaround. None of the standard or research methods examined, however, yielded both the capacity and intensity data needed to make a sound assessment of environmental availability. We decided, therefore, to identify the characteristics of an ideal rigorous extraction method as well as one that might be suitable for interim use pending the development of the rigorous approach.

\section{Recommended Approaches}

A technically rigorous procedure for use in estimating the environmental availability of uranium in a soil would provide information about the amount of exchangeable uranium present, the concentration of uranium found in the soil solution, the mineral forms from which the exchangeable and soluble uranium originated, the amounts of U(IV) and $U(V I)$ present, the total amount of uranium present, and the time rate of release of uranium from the solid phase into the soil solution. With the exception of the total uranium measurement, this wealth of information could best be collected, using a flow-through cell containing a single soil sample subjected to a sequence of treatments with successively harsher solutions and treatment conditions over a time period ranging from a few hours to days. Analysis of the uranium concentrations in the effluent would provide kinetic information about the operationally defined forms of uranium present and their relative amounts. Data from the flow-through-cell approach, when correlated with long-term field studies of uranium behavior in a variety of soils, would provide the best possible estimate of environmental availability at a relatively low cost and short turnaround time.

Because previous examples of the flow-through-cell approach were primarily for research applications and not focused on the determinations of uranium availability for regulatory purposes, several years might be needed to develop the approach in an appropriate manner. Certainly, several years would be required to perform the field correlation studies needed, although some of the natural analog studies of uranium behavior in sediments might be of use. In the absence of a rigorous procedure, an interim procedure drawn largely from standard methods is needed.

Our proposed interim procedure involves a combination of extractions that measures the total uranium in the sample and then subdivides this into four separate fractions: readily available, slowly available, very slowly available, and unavailable. The readily available fraction consists of uranium leached by a modified EPA/SWP 846 Method 1311 (TCLP) extraction procedure in which 5 successive treatments with pH 2.9 acetic acid are applied to the same sample. These repetitive treatments allow some 
estimate of the kinetics of release of the readily available uranium. The slowly available fraction consists of the additional uranium leached from the sample previously treated by the TCLP procedure when it is leached with an oxidizing, $\mathrm{pH} 8.3$, carbonate buffer solution. The very slowly available fraction is determined by the difference between the sum of the readily available and slowly available fractions and the total available uranium fraction. The total available fraction is determined by overnight extraction of uranium from a fresh soil sample with a $0.6 \mathrm{M} \mathrm{HCl}$ solution. Total uranium is determined by an appropriate method selected by the analyst and the difference between this value and the total available uranium determination is classified as the unavailable uranium fraction. We also developed a protocol specifying practices to ensure that high-quality data were obtained for the proposed interim procedure.

Both the rigorous and the interim procedures are easily incorporated into a staged decision-tree approach to making a remediation decisions. This staged approach is designed to keep the number and cost of analytical determinations to the minimum needed to make sound remediation decisions. In each procedure, a determination of total uranium would be made first. If the uranium were below a certain level, no further tests would be needed and a "no action" decision on remediation would be made. Likewise, if the uranium were above a second, much higher level, a "remediate" decision would be made and no further analysis would be needed. Samples having total uranium values between the two limits would then be subjected to the additional testing to classify the uranium as to its availability. Appropriate site-specific risk assessment models would be used to set the two limits for the decision tree.

For the rigorous approach, remediation decisions would be made based on the total solubility of the uranium, on the rate at which it was released, and on the other site-specific factors included in the risk assessment model. For the interim approach, remediation decisions would be based on the amounts of total available uranium-with intermediate values, the additional testing for readily available and slowly available uranium would be performed and a final decision based on these values. An optional oxidation state determination of uranium in the total available uranium extract could also be used to make a remediation decision, with the caveat that if the test yielded predominantly hexavalent uranium, the additional tests for readily and slowly available uranium would need to be performed. Lastly, we outlined the means by which the analytical values for uranium obtained in the proposed interim procedure can be converted to values for "soluble" and "insoluble" uranium for use in risk assessment models.

Neither the rigorous nor the interim procedures we propose have been tested in a laboratory or field setting, nor have their results been correlated with long-term soil uranium availability. In our judgement, laboratory testing and correlation must be done before either procedure can be considered technically defensible.

\section{Analytical Services}

During the project we obtained information from 26 analytical laboratories ( 3 government and 23 private) about their analytical capabilities for uranium testing of soils and their estimated costs, batch sizes, and turnaround times for the proposed interim procedure. The response for a particular procedure required that the laboratory be currently or potentially capable of performing the procedure. Although we expected to find a cost difference between these two groups (i.e., private and government), no clear trend could be distinguished.

The procedures for total available uranium and slowly available uranium were single-step extraction methods, and the laboratories gave similar estimates for them. The mean costs were \$200-225 per sample, with a two-week turnaround time and average weekly output of about 120 samples. About $80 \%$ of the laboratories gave a cost reduction on batches of samples. The cost reduction per sample averaged 13-14\% (\$25-30) for batch sizes of 13-15 samples.

The procedures for readily available uranium and uranium oxidation state determinations involved multiple steps, and this was reflected in higher costs, longer turnaround times, and smaller weekly sample output. These two procedures averaged about \$410$\$ 430$ per sample, with 16- to 19-day turnaround times and weekly outputs of 50-60 samples. The batch-costreduction and batch-size results were similar to those for the total available uranium and slowly available uranium procedures.

\section{Supplemental Information}

As part of our review of uranium chemistry in soils we assembled lists of the known or suspected aqueous complexes of uranium and the known uranium minerals. We also attempted to develop a solubility 
ranking system (similar to that developed for the synthetic lung fluid test) that could be used to estimate the environmental availability of uranium based on thermodynamic solubility data alone. The calculated ion activity products obtained for a representative group of uranium minerals equilibrated in a typical soil solution showed little correlation with the solubility classifications obtained for the same minerals in the synthetic lung fluid test. We concluded that there was no technically defensible method for estimating the kinetic dissolution behavior of hexavalent uranium phases for which only thermodynamic solubility data were available, and that there was no substitute for kinetic dissolution studies under conditions representative of soil environments.

\section{Conclusions}

We conclude by stating that no proven method for estimation of the environmental availability of uranium in soils or sediments currently exists. We recommend immediate testing of an interim procedure drawn from standard soil extraction methods and the development of information that correlates the results of the interim procedure with other properties of soil known to influence environmental availability. For the long term, we recommend development of a rigorous flowthrough-cell approach to measure speciation, solubility, and kinetic information about the uranium present in soils and to correlate this with other soil properties. Neither the proposed interim procedure nor the rigorous procedure should be used to make remediation decisions without adequate laboratory testing and establishment of a correlation database. 


\section{Acknowledgments}

This project benefited greatly from the assistance and technical interactions we had with many individuals. Specifically, we wish to single out Dr. Rateb (Boby) Abu-Eid, U. S. Nuclear Regulatory Commission, Office of Nuclear Material Safety and Safeguards (NRC-NMSS), who served as NRC Technical Monitor, and Mr. Daniel T. Huang, NRC-NMSS, who served as NRC Project Manager, for their financial and technical support and for their patience. We thank Mr. R. Jeff Serne, Pacific Northwest Laboratory (PNL), for a technical review and Ms. Laurel Grove (PNL) for an editorial review of the report. Ms. Julie L. Eliason (PNL) served as the administretive specialist for the project and Ms. Betty A. Lamar
(PNL) provided secretarial assistance. We benefitted from technical discussions with Dr. Paul M. Bertsch, Savannah River Ecology Laboratory; Dr. David E. Morris and Dr. Michael H. Ebinger, Los Alamos National Laboratory; Dr. Mark P. Elless, Dr. Chet W. Francis, and Dr. Gary T. Jacobs, Oak Ridge National Laboratory; Dr. Henry R. Westrich, Sandia National Laboratories; and Dr. Larry E. Thomas, Mr. O. Tom Farmer, Dr. James P. McKinley, Mr. Khris B. Olsen, and Dr. Eric J. Wyse, PNL. Lastly, we thank the many individuals at analytical laboratories across the country who supplied us with information about their laboratory capabilities and estimates of costs and turnaround times for the proposed interim procedure. 


\section{Introduction}

\subsection{Background}

The U. S. Nuclear Regulatory Commission's (NRC) existing guidance on interim remediation criteria for sites and facilities having soils and other materials contaminated with uranium is contained in a 1981 Branch Technical Position (BTP) entitled Disposal or Qnsite Storage of Thorium or Uranium Wastes from Past Qperations, Under Option 2 of the BTP, two sets of criteria are provided for soluble and insoluble uranium that has been enriched and depleted with respect to ${ }^{20} \mathrm{U}$. Although $\mathrm{NRC}$ has a rulemaking under way that is expected to eventually replace the criteria in the 1981 BTP, this rulemaking will not be completed until at least 1995. In the interim, NRC will continue to require licensees and responsible parties to remediate facilities having uraniumcontaminated soil following the criteria in the BTP.

This document summarizes the results of a project funded by NRC with the objective of identifying candidate promadures for the determination of the environmental availability of uranium in soils and sediments. To date, no procedures acceptable for regulatory purposes are available for determining the environmental availability of uranium in soil even though differences in availability can have a large impact on environmental migration and dose to humans. NRC has adopted NUREG/CR-1428 (Kalkwarf, 1980b) to classify solubilities of airborne uranium particulates. The method described in NUREG/CR-1428 requires determination of the rates at which uranium particulates dissolve in simulated lung fluid media. Although the method is considered adequate for airborne particulates, it bas never been employed by NRC staff for determining uranium solubility in soil. The candidate procedures identified in this document have not been subjected to laboratory or field evaluation. Such evalution must be performed before implementing these procedures.

The project involved five tasks. Task 1 identified possible solubility-based procedures (e.g., NUREG/CR-1428) and speciation-based procedures (i.e., based on the identification of specific compounds and forms of uranium) for assessing the environmental availability of uranium in soils. Task 2 involved detailed technical assessments of these two types of procedures. Task 3 provided detailed practical assessments of the two approaches along with a recommendation as to which approach to pursue for regulatory purposes. Task 4 involved the compilation of a list of uranium species possibly present in contaminated soils, along with guidance regarding their environmental availability and the impact of soil properties on this availability. Task 5 involved the compilation of a list of analytical facilities capable of performing the testing procedures being assessed.

We began by assessing the different analytical methods for total uranium, for uranium oxidation states, for uranium in solid phases, and for the different isotopes of uranium. We then examined the ways of assessing the environmental availability of uranium. This effort focused on the aqueous concentrations of uranium in water bathing the soil or sediment particles (i.e., the soil solution) because the mobility of uranium (and hence its environmental availability) in the solid phase is, by comparison, negligible. The two major approaches identified were 1) the direct empirical approach involving various types of extractions by aqueous solutions, and 2) the indirect approach in which the solubility-controlling phases of uranium are identified and their contributions to the soil solution inferred from geochemical models based on known thermodynamic solubility and/or kinetic data. Throughout this study we have had to infer much of the information about uranium analysis in soils from sources in which soil was not a factor. In short, although the analytical chemistry of uranium is well developed, the determination of the environmental availability of uranium in soils and sediments is not. Such a determination not only requires sound analytical chemistry, but also a clear understanding of the complex chemical processes that can occur in a soil system and their relative importance in controlling the availability of uranium to the soil solution and, eventually, the organisms that live off the soil.

Our approach was to canvass individuals with experience in the analysis of uranium in soils, sediments, and natural waters and to augment this effort with a literature search of technical articles and reports related to the subject. Our technical assessment, therefore, is based on published data as well as on the cumulative experience of ourselves and other individuals familiar with the issue. Although all the procedures that were given technical evaluations were also given a practical evaluation in this task, we focussed on 1) the analytical procedures for uranium, 2) the best direct procedure for assessing the environmental availability of uranium in soils, and 3) the best inferred procedure for uranium availability. Practical factors that were assessed include cost, accessibility and number of facilities capable of performing the analyses, and turnaround time for the analysis. After completing the practical assessment, it was clear that a procedure yielding a rigorous determination of the environmental availability of uranium in soils did not exist. We therefore identified an interim procedure based on standard methods that could be used until a more rigorous procedure could be developed. 


\subsection{Key Concepts}

Three fundamental concepts underlie our approach to the project. Environmental availability encompasses all the processes by which soil uranium becomes available for uptake by organisms. Correlation involves the process by which analytical concentration data for uranium are converted into meaningful assessments of risk. Decision trees provide mechanisms for streamlining remediation decisions based on analytical determinations of uranium species in soils. In the next three sections we expand on our definitions of these three concepts.

\subsubsection{Environmental Availability}

The environmental impact of uranium is largely determined by its effect on the biological functions of animals and, secondarily, plants. Fundamentslly, environmental availability can be defined as the auility of the soil to supply uranium to organisms. Uptake and accumulation of uranium by animals typically occurs by ingestion of water or food containing uranium, although inhalation of dust particles can be an important pathway in some situations. Because incorporation of uranium in food involves uptake of uranium by plants from an aqueous solution (i.e., the soil solution), both of the major pathways by which uranium is taken up by animals involve soluble uranium. (This simplification ignores the active uptake of uranium and other ions by plant species.) In a general sense, the environmental availability of soil uranium can be redefined in terms of the ability of a soil to maintain an aqueous concentration of uranium in the soil solution.

Environmental availability can be described in terms of two primary parameters, capacity and intensity. Capacity describes the mass of uranium in a soil that can eventually become soluble. Intensity describes the amount of uranium that is soluble at any particular moment, i.e., the aqueous concentration of uranium. Although capacity is more easily measured, intensity has the greater bearing on environmental availability because, to a large extent, it is the concentration of aqueous uranium that determines how much is taken up by plants or animals. From the standpoint of risk assessment, we are interested in the time-resolved intensity of uranium, i.e., what aqueous concentrations of uranium will be maintained by the soil over a certain time.

Procedures that measure uranium capacity and intensity data for soil systems include the following:

- Single-step and sequential soil extraction procedures, which measure the soil's uranium capacity (c.g., the amount releassd by EPA/SW 846, Method 3050A) or fractions thereof (e.g., exchangeable uranium).

- Kinetic soil extraction procedures, which measure the rate at which the soil approaches a given soluble uranium concentration (intensity) or, alternatively, the rate at which a particular solid uranium form (capacity) is exhausted under a well-defined set of conditions.

- Analytical electron microscopic identification of crystalline uranium phases (capacity).

- Geochemical modeling, which is aimed at quantifying the concentration of uranium in the soil solution (intensity) from a knowledge of the uranium solids present (capacity) and other soil properties.

- Measurements of aqueous uranium concentrations in the soil solution or groupdwater (intensity).

In a rough sense, the last measurement cau be considered a direct measurement of the instantaneous environmental availability of uranium. However, we must predict whether the environmental availability will go up, go down, or stay the same, for relatively long periods. Such predictions require an understanding of the processes that affect uranium chemistry in soils, measurement of the parameters that describe these processes, and the incorporation of these parameters into some kind of model that allows accurate predictions to be made. A determination of environmental availability requires a model that correlates easily measured parameters (e.g., capacities) with baseline observations of aqueous uranium concentrations in field soils (e.g., intensities).

\subsubsection{Correlation}

Uranium solubility and mobilization potential in soils will be determined by more than the intrinsic properties of the contaminant. It is true that the properties of the uranium solids involved (e.g., equilibrium solubility, particle size, or surface area) will always be cruciul components of the characterization. However, this information alone is not sufficient-climatological, landscape, and soilgenesis factors are central to determining the availability of uranium. Climatological factors, such as seasonal rainfall patterns, average annual rainfall, and seasonal temperature regimes, influence land use, native vegetation, and related factors, and more directly contribute to setting the environmental pathways along which a contaminant will migrate. 
The physical and chemical properties of a soil (e.g., soil pH, Eh, soil gas $\mathrm{CO}_{2}$, the iron or organic contents of a soil, the texture, mineralogy, and the consequent hydraulic conductivity) can all influence the apparent solubility and mobilization of uranium. Given the diversity of factors influencing availability, one technically defensible approach for establishing the relationship between the results obtained from one or a series of standard measurement procedures and the actual risk is to undertake a correlation study involving a range of the relevant parameters.

Correlation involves evaluating any extracted concentration, mass, or kinetic data obtained from soil extraction procedures in the context of other data describing a particular soil in the field. The correlation is used to arrive at an overall estimate of the expected concentration of uranium present in comparable environmental situations. Several riskbased objectives might be pursued for the correlation. For example, one could target maximum attainable closed-system uranium solubilities. Alternately, average growing-season uranium concentrations in soil solution would be a viable objective. Regardless of the risk target, correlations require the parameterization of a model that takes into account the important factors controlling the solubility or availability of uranium in soils. Once the model is constructed, it serves as a useful guide for determining what environmental parameters must be measured, and provides guidance concerning risk levels associated with different degrees of remediation.

In the area of soil fertility, these types of correlations have been built up over many decades, based on experience gained from the analysis of thousands of samples. While an effort of this magnitude is not appropriate for the uranium problem, one defensible approach for building a correlation model involves testing several dozen soils from a variety of representative sites. The soils would be characterized for the relevant soil properties (c.g., hydraulic conductivity, texture, $\mathrm{pH}$, $\mathrm{Eh}$, exchange capacities, mineralogy, organic carbon) and specific site factors, such as temperature and precipitation regimes, would be determined. Each soil would be extracted using several evaluation procedures, for example the TCLP, a sequential procedure (e.g., Yanase et al., 1991), a kinetic procedure, and, perhaps one or more shortterm batch equilibrium and column-leaching procedures using water similar in composition to the soil solution from the test site. Other detailed characterization procedures, for example determination of the $U(I V) / U(V I)$ ratio, would also be completed. A few (3-5) field lysimeters would be deployed at each field location (or literature values from relevant studies would be examined) to correlate the behavior observed in the extraction and column-leaching studies with that observed in the field. Statistical analysis of these data would determine the relative importance of the specific forms of wanium present, and of the environmental factors specific to the soil and site. This approach would produce a technically defensible selection of an appropriate soil extraction procedure for conducting the risk assessment. The product would be an easily parameterized model having general applicability to soils and requiring input data that are relatively inexpensive and easily obtained, The input data would include results from an extraction proredure and small amount of ancillary information regarding the soil and the site.

\subsubsection{Decision Trees}

The third key concepr used in the context of environmental availability is that of a decision tree (Fig. 1). Quite simply, a decision tree is a prioritization of the steps required to reach a remediation decision. At some point a decision must be made to remediate or to take no action, based on the assessment of environmental availability that is made. The criteria on which the decision is made should include both the results of a soil uranium analysis and their interpretation in terms of a correlation model that takes into account the other factors influencing environmental availability.

The decision-tree approach can accomodate rigid criteria (e.g., the $35 \mathrm{pCi} \mathrm{g}^{-1}$ limit set by the U. S. Department of Energy for uranium concentrations in bulk soil at the Fernald Site) or flexible criteria that incorporate other information about the soil and the site. For example, if one were to compare 1) a sandy soil on a flood plain in a humid zone with 2) a clayey soil on a plateau in an arid zone, each soil having the same uranium analytical results, clearly the first soil would pose a greater environmental risk and require remediation before the second.

The important point to remember is that the decision tree approach offers a recipe for making remediation decisions. To the maximum extent possible, the criteria employed should have sound technical bases that take into account factors other than the immediate analytical concentration of uranium. 


\section{Introduction}

Stop 1: Bulk Uranium

Analyoio

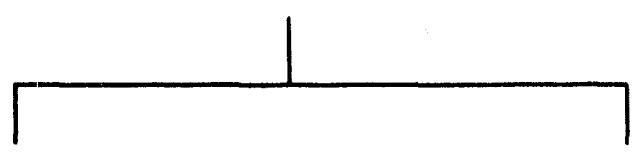

$0,<\mathrm{AB}$ pCl $\mathrm{g}^{-1}$

1

No Action

Required
U, > AB pCi $g^{-1}$

$\mid$

Step 2: Selective Extraction Procedure
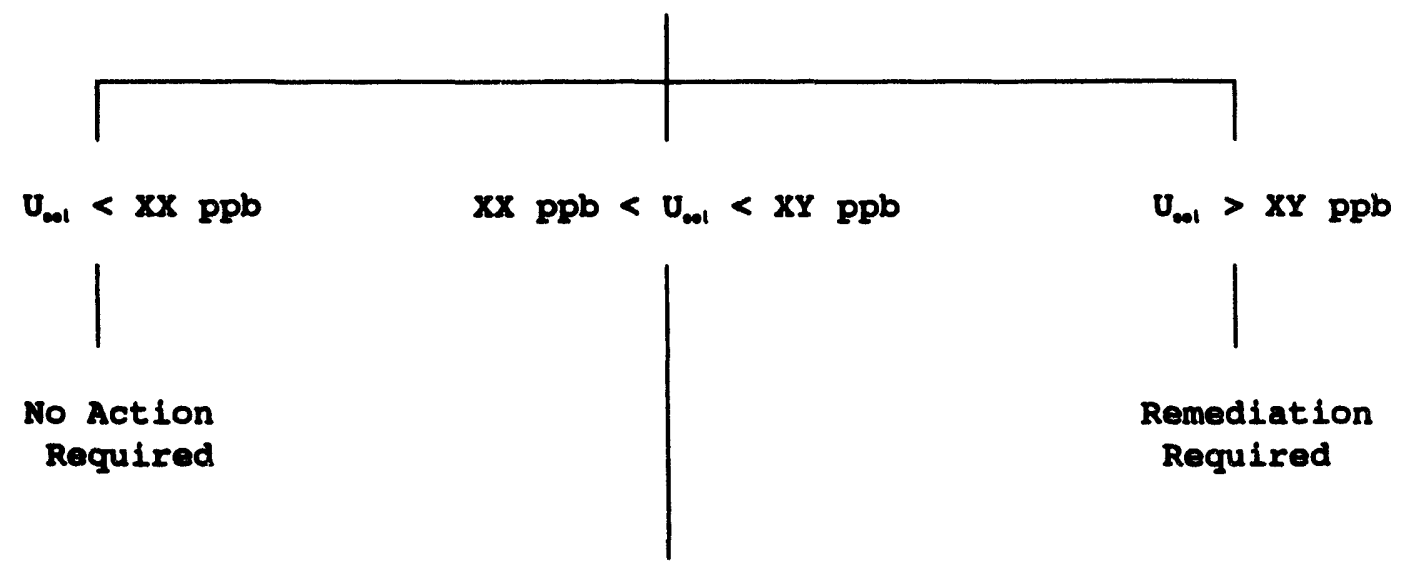

Step 3: Rinetic study

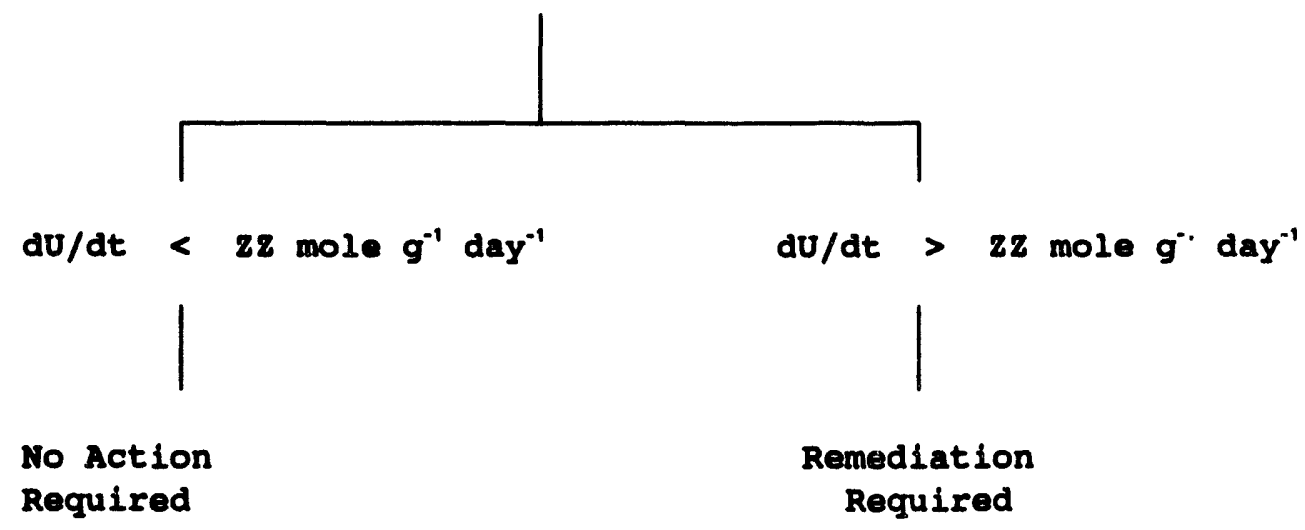

Figure 1. Example of a Decision Tree for Assessing Environmental Availability of Uranium in Soils and Sediments 


\subsection{Forms of Uranium in Soils and Sediments}

Uranium is a naturally occurring element; as such, it is found in a wide range of minerals and rock types and its concentrations can span many orders of magnitude. The average crustal abundance of uranium is on the order of $3.4 / \mathrm{g} \mathrm{g}^{-1}$. Typical concentrations in common rock types vary considerably; in carbonates, uranium concentrations are typically 0.1 to several $\mu \mathrm{g} \mathrm{g}^{-1}$. Granites and other sialic rocks commonly have concentrations ranging from a few to about $12 \mu \mathrm{g} \mathrm{g}^{-1}$. Individual minerals within these rock types can, similarly, have widely varying uranium concentrations. For example, in granites, uranium tends to concentrate in amphibole phases (e.g., hornblende) or as minor intergranular oxide phases.

Although some 187 different minerals have been identified in which uranium is an essential component, only a few minerals make up the vast majority of uranium ore deposits. The most common minurals are the reduced and mixed oxides (uraninite, $\mathrm{UO}_{2}$, and pitchblende, a mixed oxide), silicates (coffinite and uranophane), uranothorite, and various phosphate and vanadate minerals (e.g., autunite-series minerals, carnotite).

In soils and other near-surface environments, uranium and uranium-bearing minerals weather to form a range of phases. Although not a great deal of information on the speciation of uranium, in soils and sediments is available, the information reviewed indicates that a few common processes control the distribution and mobility of uranium in soils. In most soils, uranium-bearing phases are subjected to oxidative weathering. Under these conditions, uranium exposed at mineral-solution interfaces becomes oxidized to the U(VI) form. At this point, the fate of the metal depends on a number of factors including the quantity of uranium that is available to solution, the composition (e.g., $\mathrm{pH}, \mathrm{Eh}$, carbonate content) of the weathering solutions, and the composition of the soil or sediment.

Uranium is most mobile under oxidizing, carbonatebearing conditions. Therefore, under these conditions, one would anticipate that uranium would be most soluble. However, other secondary factors may affect the mobility as well. For example, in the presence of low-ionic-strength solutions (i.e., "soft waters"), the uranyl ion concentrations will probably be regulated in part by exchange processes. The uranyl ion will adsorb onto clays, organics, and oxides, and this will limit its mobility. As the ionic strength of the solution increases, other ions, notably $\mathrm{Ca}^{2+}, \mathrm{Mg}^{2+}$, and $\mathrm{K}^{+}$, will displace the uranyl ion, forcing it into solution. For this reason, the uranyl ion is particularly mobile in "hard" waters. Not only will other cations "outcompete" the uranyl ion for exchange sites, but carbonate ions will form strong soluble complexes with the uranyl ion, further lowering its activity while increasing the total amount of uranium in solution.

Some of the sorption processes to which the uranyl ion is subjected are not completely reversible. Sorption onto iron and manganese oxides can be a major process for extracting uranium from solution. These oxide phases act as a short-term, irreversible sink for uranium in soils. Uranium bound in these phases is not generally in isotopic equilibrium with dissolved uranium in the same system, suggesting that the reaction mediating the transfer of the metal between the two phases is slow.

Staff from the Oak Ridge National Laboratory [e.g., Trabalka et al. (1987) and Bondietti et al. (1979)] have conducted long-term investigations of the solution chemistry of actinide elements present in an alkaline freshwater pond $(\mathrm{pH}=9.1)$. The pond, ORNL Pond 3513 , is a former final low-level-radioactive-waste settling basin used at the Oak Ridge facilities.

Although the site studies included uranium, which was present in the +6 valence state, most of studies focused on other actinides present in this pond. Total uranium was analyzed by a fluorimetric method, and its individual isotopes were determined by alpha spectrometry. The results of these studies indicated that adsorption by sedimentary materials in the pond was the dominant factor controlling effective actinide concentrations in solution. The researchers believed that this may partly explain the absence of any strong positive correlation between the concentrations of dissolved carbonate and uranium species. Solubility calculations, which were based on the assumption of solubility equilibrium between the soluble uranium and solid $\mathrm{UO}_{2}(\mathrm{OH})_{2}$, predicted uranium concentrations that were 100 times higher than those measured at the pond (Bondietti et al. 1979).

Organics are another possible sink for uranyl ions in soils and sediments. The mechanisms for uranium sequestration have not been worked out in detail, although several different processes may be involved. One possible process may involve sorption of the ion onto exchange sites, such as carboxylic acid groups. These groups can coordinate with the uranyl ion, displacing waters of hydration, and form stable complexes. A process such as this probably accounts for a significant fraction of the organically bound uranium in soils, and, perhaps, in sediments. Alternatively, sedimentary organics may participate in 
axidation-reduction (redox) processes. For this type of process, the organics would act to reduce the uranium to a U(IV) species. These species are notoriously low in solubility, and many remain associated with the organic phase after precipitation as a reduced oxide. Little seems to actually be known about the nature of organic-uranium associations in soils or sediments, although several different types of interactions may be taking place.

If uranium is abundant in the sample, it is possible for it to form its own distinct soil mineral phases. Reduced uranium ores will weather in a step-wise manner to form a series of increasingly oxidized intermediates with the final products being schoepite or one of its polymorphs. In the presence of sufficient dissolved silica $\left(\mathrm{H}_{4} \mathrm{SiO}_{4}\right)$, weathering processes seem to favor the formation of coffinite or similar silicate phases, although, based on the information reviewed to date, the factors favoring the formation of sihoepite or coffinite have not been worked out in detail. Rates of the reactions involving the weathering and alteration of the diffetent uraniumbearing phases have not been studied in any detail. Surface oxidation of uraninite and other reduced uranium oxides appears to occur rapidly in pH-neutral, oxygen-bearing aqueous solutions. However, we also infer that the oxidized layer may form a protective surface layer that inhibits further reaction under certain conditions. Further study is needed to determine the role of protective oxide layers in regulating the bioavailability of different forms of uranium.

Systematic studies regarding the availability of the different forms of uranium to solution or to biota have been limited. Most of the studies develop correlations between availability and some nominal, operationally defined fraction of the metal such as "acid extractable." Details regarding the accessibility of the different forms of uranium, as discussed above, are limited.

\subsection{Analytical Chemistry of Uranium}

At some point in the process, determination of the environmental availability of uranium requires quantitative determinations of the amounts of uranium present in a sample. Because the quality of the environmental availability determination depends heavily on the quality of the analytical data, we list, in the four sections that follow, the major analytical techniques used to estimate total uranium, uranium oxidation states, solid-phase species, and isotopic species. A more detailed description and assessment of each technique is given in Appendix A.

\subsubsection{Assay for Total Uranium}

The methods for determining total uranium in soil can be grouped by whether the sample is destroyed during the analysis or remains essentially intact. Wetchemical techniques, by definition, involve a conversion of uranium from the solid phases to a solute in the liquid phase and, thus, are considered sampledestructive. On the other hand, several nondestructive methods of analysis can also be used, which involve exciting the sample with high-energy radiation and measuring the energy flux given off by the sample as a result of fluorescence or radioactive decay.

Detection limits are generally lower for the wetchemical techniques, but recent advances in X-ray sources (i.e., synchrotrons) have allowed higher incident fluxes to be focussed on the samples and hence lower detection limits. The selection of which methods to use for determination of total uranium, therefore, is largely based on practical considerations rather than on clear technical differences.

The wet-chemical techniques we surveyed include acid digestion, pulsed laser phosphorimetry, inductively coupled plasma mass spectrometry, inductively coupled plasma atomic emission spectrometry, adsorptive stripping voltammetry, and spectrophotometry. Nondestructive techniques surveyed include X-ray spectrometry neutron activation analysis, and promptgamma emission spectrometry.

\subsubsection{Assay for Uranium Oxidation States}

In general, the oxidation state of uranium has a direct bearing on its solubility and, hence, its environmental availability. Uranium in the +4 state is usually less soluble than that in the other common oxidation state $(+6)$, and, as a consequence, much less of an environmental risk. However, $U(I V)$ is oxidized to $\mathrm{U}(\mathrm{VI})$ rather easily $\left(\mathrm{E}^{\circ}=+0.25 \mathrm{~V}\right.$, Bruno et al., 1985) and the kinetics of this reaction will be crucial to any assessment of environmental availability. Thus, a determination of the oxidation state of uranium in both the aqueous and the solid phases is needed, along with some way of estimating the kinetics of U(IV) oxidation in a particular soil, in order to properly assess the potential risk associated with the uranium contamination. This type of measurement can be done either by wet-chemical techniques (e.g., ion exchange, precipitation, or polarography) or by direct spectroscopic techniques [e.g., X-ray absorption near-edge structure (XANES), laser photoacoustic, laser Raman, optical luminescence]. 


\subsubsection{Speciation of Solid-Phase Uranium}

Like other trace metals, the solid-phase uranium in soils can occur as an exchangeable cation on minerals, as an organically bound constituent, as a pure or mixed-valence oxide, and as a structural constituent of various silicates, phosphates, or vanadates. Because soils and sediments are heterogeneous anisotropic systems, even at a microscopic scale, the dominant form of a trace metal may change from one region to the next. Attempts to speciate the solid forms of uranium in a large body of soil, therefore, face a nearly impossible task. Because these attempts are often predicated on how the uranium will react, operational definitions of uranium speciation have been used, rather than absolute definitions based on identification and quantification of specific mineral phases. Since we are interested in the "environmental availability" of uranium in soils, i.e., in its reactivity towards the soil solution, this type of operational classification is reasonable.

The literature is replete with extraction and leaching procedures ranging from single-step extractions, through multistep, single-fluid procedures, to multiextractant, sequential procedures. All the extraction procedures are essentially wet-chemical methods and yield estimates of the mass of uranium associated with some specific operationally defined soil component. Direct spectroscopic speciation of solid-phase uranium is also possible by a variety of techniques including $\mathrm{X}$ ray absorption (XAS) and optical luminescence spectroscopies and analytical electron microscopy. The direct analyses quantify the forms of uranium, but do not necessarily provide information about the availability of the uranium and, because of small sample sizes, require a larger number of analyses to achieve the same degree of statistical certainty as the extraction techniques.

\subsubsection{Speciation of Uranium Isotopes}

The specific activity of the uranium in a sample depends on its isotopic composition. Three natural isotopes of uranium contribute to the element's activity: ${ }^{24} U,{ }^{25} U$ and ${ }^{25} U$. In closed, natural systems, uranium has a specific activity of $0.68 \mathrm{pCi}$ $\mathbf{H B}^{-1}$. The percentage of this activity originating from each isotope is $48.93 \%, 2.14 \%$, and $48.93 \%$, respectively. In near-surface environments (e.g., soils), however, the ${ }^{24} \mathrm{U}$ isotope tends to have a slightly higher mobility than the other two isotopes. This stems from the fact that $24 \mathrm{U}$ derives from the decay of ${ }^{2 x} \mathrm{U}$, and hence, tends to reside in mineral sites that have been damaged by the decay process. Solutions passing through soils, therfore, will leach a disproportionately larger amount of the ${ }^{24} U$ isotope, resulting in specific activities several times higher than $0.68 \mathrm{pCi}_{\mathrm{gg}} \mathrm{g}^{-1}$. Currently, the EPA uses a specific activity of $1.3 \mathrm{pCi}_{\mathrm{NB}}^{-1}$ as the nominal activity of uranium in surface waters. This value is based on a geometric mean of activities measured on water samples collected during a nationwide radon survey (U. S. Environmental Protection Agency, 1985, 1991d). Because much of the environmental hazard associated with uranium is due to its specific activity, which is known to vary in weathered systems, this factor, or one derived from a direct measurement of the isotopic ratios, should be part of any estimate of environmental availability.

The isotopic composition of a uranium-bearing sample can be determined in a number of ways. The most straightforward of these is mass spectrometry, whereby all the isotopes of uranium can be determined regardless of their specific activity. Two types of nuclear spectroscopy (alpha, and gamma after epithermal neutron irradiation) also can be used. Because the data from these techniques are generally comparable, the choice of method for isotopic composition largely depends on individual circumstances. 


\section{Measurement of Environmental Availability of Uranium}

\subsection{Direct Measurement of Availability}

\subsubsection{Simulated Lung Fluid Procedure}

\subsubsection{Background}

This presentation is a summary of the work of Kalkwarf (1979, 1980a, 1980b). The general purpose of using a Simulated Lung Fluid (SLF) test is to evaluate the potential health risk associated with the inhalation of airborne uranium products. Essentially, the health risk (i.e., radiation dose) is inversely proportional to the rate of dissolution and subsequent expulsion from the lung of a given uranium species (or species composite). As noted by Kalkwarf (1979), "maximum dissolution rates are sought because the lung is expected to be the site for efficient dissolution and because the values are to approximate clearance rates that included contributions from endocytosis and ciliary-mucus transport."

The dissolution rate model used for this type of test was developed by the International Commission on Radiological Protection (ICRP, 1975, 1979ab, 1980, 1981ab, 1982abc) and establishes three components of classification for lung-deposited uranium-containing material. These classifications represent half-lives for the residence time of the material in the lung where $D$ (days) denotes 0 to 10 days, $W$ (weeks) denotes 10 to 100 days, and $Y$ (years) denotes $>100$ days. If clearance of the material from the lung is not strictly exponential with time, it is approximated by a sum of the exponentials and the material is classified according to the fractions of $D, W$, and $Y$ components. The model used for uranium dissolution classification is represented by the equation:

$$
F=\Sigma_{i} f_{i} \exp \left(-0.693 t / \tau_{i}\right)
$$

where $F$ is the fraction of uranium remaining undissolved as a function of time, $f_{i}$ is the initial weight fraction of component $i$, and $\tau_{i}$ is the dissolution half-time of component $i$. Values for $F$ are calculated by subtracting the amount of uranium dissolved during any sampling period from the amount undissolved at the beginning of that period and dividing this quantity by the total amount of uranium in the sample.

The dissolution rate classification results for five pure uranium compounds are shown in Tables 1 and 2 (Kalkwarf, 1980b). These data show the differences in solubility of U(VI) and U(IV) compounds. Since dissolution in the lung fluid is desirable for elimination of the uranium from the lung, it is the U(IV) compounds that are the most hazardous from the inhalation standpoint. In soils, on the other hand, U(IV) is of the least concern because it is not soluble and thus is much less likely to contaminate groundwater. Kalkwarf (1979) also applied the dissolution-rate classification test using synthetic lung fluid to other uranium compounds associated with a variety of uranium processing plant and mining operations. In each case, the samples were fully characterized, the major uranium solids identified, and their dissolution rates determined. From a determination of the dissolution half-times as shown in Table 2, ICRP dissolution rate classifications could be assigned.

\subsubsection{Current Procedure and Limitations}

The three methods used to determine dissolution-rate classification in simulated lung fluid are the "batch method," the "sandwich method," and the "mini-batch method" (Kalkwarf, 1979). The methods are distinguished by the quantity of sample analyzed and/or the uranium concentration of the sample. The batch method has been applied to 0.6-g samples or greater, while the sandwich method has been applied

Table 1. Pure uranium compound samples used to calibrate the SLF procedure (Kalkwarf, 1980b)

\begin{tabular}{llllll}
\hline Sample & Color & $\begin{array}{l}\text { Particle } \\
\text { Size Range }\end{array}$ & $\begin{array}{l}\text { Expected } \\
\text { Compenents }\end{array}$ & $\begin{array}{l}\text { Valence } \\
\text { State }\end{array}$ \\
\hline Ammonium diuranate & Yellow & $0-45 \mu \mathrm{m}$ & $\left(\mathrm{NH}_{4}\right)_{2} \mathrm{U}_{2} \mathrm{O}_{7}$ & $\mathrm{U}(\mathrm{VI})$ \\
Uranium trioxide & Yellow & $0-45 \mu \mathrm{m}$ & $\mathrm{UO}_{3}$ & $\mathrm{U}(\mathrm{VI})$ \\
Uranium octoxide & Greenish black & $0-45 \mu \mathrm{m}$ & $\mathrm{U}_{3} \mathrm{O}_{8}$ & $\mathrm{U}(\mathrm{IV}+\mathrm{VI})$ \\
Uranium dioxide & Brownish black & $0-45 \mu \mathrm{m}$ & $\mathrm{UO}_{2}$ & $\mathrm{U}(\mathrm{IV})$ \\
Uranium tetrafluoride & Green & $0-45 \mu \mathrm{m}$ & $\mathrm{UF}_{4}$ & $\mathrm{U}(\mathrm{IV})$ \\
& & & & &
\end{tabular}


Measurement of Environmental Availability

Table 2. Welent fractions (f), dissolution half-lives ( $\tau$ ), and ICRP dissolution-rate classifications of pure uranium compounds obtained with the batch SLF procedure (Kalkwarf, 1950b)

\begin{tabular}{|c|c|c|c|c|c|}
\hline Sample & $t_{1}$ & $\tau_{1}$ & $f_{2}$ & $\boldsymbol{T}_{2}$ & Classification \\
\hline $\begin{array}{l}\text { Ammonium diuranate }{ }^{1} \\
\text { Uranium trioxide }\end{array}$ & 1.00 & $5.0 \mathrm{~d}$ & - & - & D \\
\hline $\begin{array}{l}\text { Batch method } \\
\text { Mini-batch method }\end{array}$ & $\begin{array}{l}0.45 \\
0.51\end{array}$ & $\begin{array}{l}0.5 d \\
0.7 d\end{array}$ & $\begin{array}{l}0.55 \\
0.49\end{array}$ & $\begin{array}{l}123 d \\
184 d\end{array}$ & $\begin{array}{l}45 \% \mathrm{D}, 55 \% \mathrm{Y} \\
51 \% \mathrm{D}, 49 \%, \mathrm{Y}\end{array}$ \\
\hline Uranium octoxide & 1.00 & $\infty$ & - & -- & $\mathbf{Y}$ \\
\hline Uranium dioxide & 1.00 & $\infty$ & - & $\cdots$ & $\mathbf{Y}$ \\
\hline Uranium tetrafluoride & 1.00 & $\infty$ & - & $\cdots$ & $\mathbf{Y}$ \\
\hline
\end{tabular}

'Reported values from 1980 analyais.

to small sample sizes $(50 \mathrm{mg})$ of high uranium concentration (e.g, pure oxides) sealed between two membrane filters that are separated by a tetrafluoroethylene ring. Most of the recent work conducted at the Pacific Northwest Laboratory (PNL) has used the mini-batch method, which targets small sample sizes (ca. 100-500 mg) at fairly low uranium concentrations (e.g., 30-100 $\mathrm{NB} \mathrm{B}$ ).

The general procedure for any of the three methods is essentially a variation of the mini-batch method currently used at PNL. This method begins with the collection of airborne dust on ashlese $20-\mu \mathrm{m}$-porosity filter paper under high-volume air flow (40 cfm). These filters are then placed in a desiccator with anhydrous calcium sulfate pellets overnight to remove residual moisture. After drying, the filtered particulates are vacuumed onto a 25-mm-diameter membrane filt ?, composited, and subdivided into four fractions. One fraction is used for XRF analysis while the other three are used for the leach test as triplicate samples having $125 \mathrm{mg}, 250 \mathrm{mg}$, and $500 \mathrm{mg}$ of sample. These fractions are placed into separate 10$\mathrm{ml}$ reaction vials with $5 \mathrm{ml}$ of synthetic lung fluid and maintained at $37^{\circ} \mathrm{C}$ for the duration of the leach test. After each of eight sampling intervals $(0.17,0.33,1.0$, $3.0,10.0,20.0,30.0$, and 60.0 days), the samples are centrifuged to yield a clear supernate, the supernate is collected and saved for total uranium analysis, and a fresh 5-ml aliquot of synthetic lung fluid is added to the solid remaining in the reaction vial. The supernate samples are acidified with concentrated $\mathrm{HNO}_{3}$ and analyzed for total uranium by ICP-MS. At the end of the 60-day test, the undissolved solid in the vial is digested in an HF-HCl-HNO, matrix and also analyzed for total uranium. The sum of the uranium in all fractions including the residual material should equal the total uranium concentration of the original sample as determined on a separate unreacted specimen.

The primary technical limitation to the use of the uranium dissolution trial with synthe ${ }^{*}$ ic lung fluid to estimate the environmental availability of uranium in soils and sediments is its focus on single set of conditions (i.e., lung fluid at body temperature) and a limited number of well-defined solid phases. In view of the different compositions of lung fluid and of soil solutions (Table 3), and of the more complicated chemistry of uranium in soils, extrapolation of the results of this specific test to a different set of conditions (e.g., the soil solution at $20^{\circ} \mathrm{C}$ ) is not technically defensible. However, the test classifies the uranium in an operationally defined way, which may prove useful for an environmental availability assessment.

While the SLF test is considered an appropriate procedure for evaluating the potential health effects of airborne particulates, it has not been employed by NRC staff to determine the solubility in soils or sediments. The SLF test addresses a well-constrained environmental situation, i.e., the environment found in the human lung. The exposure pathway is well defined (i.e., inhalation of partirles), the exposure conditions are well known (i.e., pir, $\mathrm{pCO}_{2}$, fluid composition) and vary only within small ranges, and the exposure hazard has been characterized (i.e., particle residence time in the lungs). For soils and sediments, virtually none of these aspects have been addressed in the literature. The major practical drawbacks associated with this method are that it requires 1) long equilibration times (i.e., a total of 60 days) and 2) many analyses. Both of these factors contribute to a high per-sample cost and a long turnaround time. 
Table 3. Compositions of simulated lung fiuld (Kalkwarf, 1980b) and typical Hanford-site groundwrater

\begin{tabular}{|c|c|c|}
\hline Ion & Lung Fluid & Groundwater \\
\hline & \multicolumn{2}{|c|}{ meq $\mathrm{L}^{-1}$} \\
\hline $\begin{array}{l}\text { Calcium, } \mathrm{Ca}^{2+} \\
\text { Magnesium, } \mathbf{M g}^{2+} \\
\text { Potassium, } \mathbf{K}^{+} \\
\text {Sodium, } \mathrm{Na}^{+}\end{array}$ & $\begin{array}{r}5.0 \\
2.0 \\
4.0 \\
145.0\end{array}$ & $\begin{array}{l}2.4 \\
1.2 \\
0.3 \\
1.4\end{array}$ \\
\hline Total Cations & $\overline{156.0}$ & $\overline{5.3}$ \\
\hline $\begin{array}{l}\text { Bicarbonate, } \mathrm{HCO}_{3}{ }^{\circ} \\
\text { Chloride, } \mathrm{Cl}^{-} \\
\text {Citrate, } \mathrm{H}_{5} \mathrm{C}_{6} \mathrm{O}_{7}{ }^{3} \\
\text { Acetate, } \mathrm{H}_{3} \mathrm{C}_{2} \mathrm{O}_{2} \cdot \\
\text { Phosphate, } \mathrm{HPO}_{4}{ }^{2} \\
\text { Sulfate, } \mathrm{SO}_{4}{ }^{2}\end{array}$ & $\begin{array}{r}31.0 \\
114.0 \\
1.0 \\
7.0 \\
2.0 \\
1.0\end{array}$ & $\begin{array}{l}2.3 \\
7.8 \\
- \\
- \\
-- \\
1.6\end{array}$ \\
\hline Total Anions & $\overline{156.0}$ & $\overline{4.7}$ \\
\hline pH & 7.3-7.4 & 8.14 \\
\hline
\end{tabular}

In spite of these drawbacks, the SLF test has some features that make it uniquely pertinent to investigating uranium solubility in soils. In Section 3 and Appendix C, we discuss an analogous method that might serve as an adequate surrogate for this procedure for soil systems if extensive correlation with long-term leaching tests is made.

\subsubsection{Extraction Procedures}

\subsubsection{Background}

Within soils and sediments, metals, nutrients and many contaminants are typically present in several coexisting phases. The different forms and phases can have widely varying solubilities and/or availabilities. Even for a single, well-defined phase, its solubility or the rate at which it releases the contaminant to the environment can depend on the chemical environment within the soil. As a result, one of the challenges confronting regulatory agencies is to accurately and economically assess the availability of a contaminant in a particular soil or sediment. Frequently, this type of assessment is made using a soil extraction procedure. Soil extraction measurements fall into three broad categories. Single-step chemical extractions are procedures that typically use a single solution to extract the contaminant of interest. This type of procedure is the mainstay of standard methods, and has been frequently used in both regulatory and assessment applications. The second broad category includes multistep or sequential chemical extractions, in which the soil is reacted with a series of different extraction liquors, each more chemically aggressive than the previous, with the intent of quantifying the distinct chemical forms of the contaminant in the sample. Sequential extractions have been used primarily in research applications. The third type of soil extraction measurement is designed to measure the rate of release of the contaminant under a specific set of conditions that can be correlated with field conditions. Kinetic extractions involve either sequential extractions of a single soil sample using fresh aliquots of the same extraction liquor or a single-step extraction carried out on several replicate soil samples for different periods of time, and often find applications for environmental and regulatory purposes. All three types of prucedures are designed to extract and measure specific, chemically defined components. The primary distinctions among them are the specificity with which one attempts to define 1) the number of distinct phases in the sample, and 2) 
the rate at which these phases dissolve to yield aqueous ions.

Uranium may be present as an exchangeable ion adsorbed to organic matter, carbonates, or clay minerals; as a constituent of amorphous and crystalline iron and aluminum (hydrous) oxides; as a discrete uranium-oxide [which may contain U(IV), $\mathrm{U}(\mathrm{VI})$, or both], silicate, phosphate or vanadate mineral; and as an accessory component in common silicate minerals. The goal of a sequential chemical extractior is to determine the partitioning of uranium among these fractions. When used carefully, the sequential procedures will provide qualitative to semiquantitative information pertaining to the chemical form and oxidation state of the uranium in the sample. In contrast, single-step and kinetic chemical extractions attempt to assess only avcilability of the uranium from the soil, regardless of the specific chemical form. These approaches make no attempt to distinguish from which forms the soluble uranium originates. All three types of procedure provide the user with operationally defined results.

Soil extraction procedures rely on the proposition that uranium bound in different phases will react, or fail to react, with the extraction solutions to different extents and at different rates. For example, high-ionicstrength, near-neutral-pH solutions can be used to extract exchangeable forms of uranium effectively. In addition, uranium oxides, silicates, etc. will be slightly soluble in these solutions. If the soil has little uranium resident on exchange sites, then the bulk of the metal released to solution may have been released from other discrete phases. Because the procedures rely on chemical methods to separate and identify the different phases, there will always be a certain amount of overlapping reactivity among the presumably discrete phases. Thus, the phase separation is rarely definitive.

Although single-step and kinetic extractions are not saddled with the difficulty of delineating specific forms of uranium (or other contaminants) in soils or sediments, relating the results to concentrations in the field may be difficult. Any form of uranium exhibits a range of solubilities in different soil environments. For example, Table 4 lists the solubilities of schoepite, a hydrous uranyl oxide, for ranges of $\mathrm{pH}$ and total inorganic carbon (TIC) concentrations that span those commonly found in soils. These values were computed using $\mathbf{G M}$, an in-house equilibrium geochemistry code. At any given $\mathrm{pH}$, the solubility of schoepite can vary by as much as two orders of magnitude for a factor-of-10 change in TIC. Similarly, varying the $\mathrm{pH}$ significantly influences the soluivility, especially at higher TIC values. Because most
Table 4. Calculated aqueous concentrations of uranium in equilibrium with schoepite $\left(\mathrm{UO}_{3} \bullet^{2} \mathrm{H}_{2} \mathrm{O}\right)$ at specified pH values and total inorganic carbon (TIC) concentrations

\begin{tabular}{lllc}
\hline pH & TIC & \multicolumn{2}{c}{ Uranium } \\
\hline & mol L $^{-1}$ & mol L & $\mathrm{mg} \mathrm{L}^{-1}$ \\
5.0 & 0.01 & $7.82 \mathrm{E}-05$ & 18.6 \\
5.0 & 0.001 & $2.17 \mathrm{E}-05$ & 5.2 \\
6.0 & 0.01 & $2.19 \mathrm{E}-04$ & 52.1 \\
6.0 & 0.001 & $6.73 \mathrm{E}-06$ & 1.6 \\
7.0 & 0.01 & $1.07 \mathrm{E}-03$ & 256. \\
7.0 & 0.001 & $1.29 \mathrm{E}-05$ & 3.1 \\
8.0 & 0.01 & $1.95 \mathrm{E}-03$ & 463. \\
8.0 & 0.001 & $1.97 \mathrm{E}-05$ & 4.7 \\
9.0 & 0.01 & $2.57 \mathrm{E}-03$ & 611. \\
9.0 & 0.001 & $4.34 \mathrm{E}-05$ & 10.3 \\
\hline
\end{tabular}

selective chemical extractions rely on the use of a single, well-defined extraction liquor (e.g., distilled water, acetic acid buffer), the solubility measured by the procedure may or may not be representative of the conditions found in the soil.

The range of conditions encountered in soils differs considerably from that presented by the SLF test. In the human lung, the factors controlling uranium solubility, i.e., temperature, $\mathrm{pH}, \mathrm{PcO}_{2}$, bulk fluid composition, and humidity, are, effectively, invariant. As a result, more or less direct correlations can be made between SLF dissolution measurements and the flushing rate of the metal from the lungs. The wide range of conditions that will be encountered in the soils, even at a single facility, will generally preclude the drawing of universal conclusions from a limited set of extraction measurements. As a result, the claim made for most soil extraction procedures is not that they can provide estimates of environmentally realistic concentrations or mobilities for uranium or other metals, but rather that they provide a uniform foundation from which decisions of a regulatory nature can be made.

Because most chenical extraction procedures have been designed to accomplish specific goals, the analyst selects among them according to the intended use of the information. These goals do not necessarily carry 
over from one study to others. For example, certain procedures have been developed for the separation of U(IV) species from U(VI) species and are different from those that have been developed to determine which uranium-bearing phases are most closely associated with controlling the mobility and groundwater concentrations of uranium. Some modification and/or merger of these techniques might bu required if one were interested in attempting to isolate or identify the bioavailable fractions of uranium in a soil.

In spite of the operational nature of the defined phases, chemical extractions have found a range of applications in both environmental and agricultural fields. Soil fertility tests for "plant-available" nitrogen, phosphate, potassium, and other nutrients have been used for decades to deturmine proper fertilizer application rates with great success (Black, 1968; Tisdale and Nelson, 1975; Walsh and Beaton, 1973; Mortvedt et al., 1972). Tessier et ai. (1979) and Sheppard and Thibault (1992) have used the more rigorous sequential extractions to i.jentify the phases that transition metals become associated with in sedimentary environments. These types of information have been used to estimate the bioavailability and fate of metals in these systems.

The next section presents brief descriptions of some of the standard procedures that are available to determine extractable metals from environmental media. In addition to the extraction media and test conditions, we include a short discussion of the purpose of each test.

\subsubsection{Standard Methods}

Chemical extraction procedures, as used in the past, have found both regulatory and research applications. In the context of environmental metals, several methods have been designed to determine the predominant metal-bearing phases in solids and ores, or simply to provide estimates of availability (Table 5). More detail for each of these methods is presented in the paragraphs following.

For each method in Table 5, the major components of the extracting liquor, the initial $\mathrm{pH}$, the solution:soil ratio $\left(\mathrm{ml} \mathrm{g}^{-1}\right)$, the temperature at which the extraction is carried out, and whether single or multiple extractions are performed, as well as the calculated extraction efficiency for removal of schoepite from a soil are listed. Although the composition of the liquor will change as the liquor reacts with the contaminated soil or sediment, the initial composition provides a rough idea of how chemically aggressive the liquor is towards the soil. For all the procedures except those with extremely acidic liquors, the final $\mathrm{pH}$ of the extracting fluid will, in most cases, be significantly different from the initial value. Soils and sediments have significant $\mathrm{pH}$-buffering capacities and, in most procedures, this is taken into account by measuring the $\mathrm{pH}$ at the end of the extraction as well as at the start. Several of the procedures use distilled water as the extracting liquor, in which case, the $\mathrm{pH}$ will be essentially that of the natural soil. For the purposes of calculating the schoepite extraction efficiency, we assumed a $\mathrm{pH}$ of 6.0 for such procedures. Additional assumptions in the calculation were 1) that the soil is contaminated with $100 \mathrm{ppm}$ of uranium deposited as schoepite $\left(\mathrm{UO}_{3} \boldsymbol{2}^{\mathrm{H}} \mathrm{H}_{2} \mathrm{O}\right.$ ) and no other forms of uranium, 2) that the extraction solution maintains the initial $\mathrm{pH}$ value, 3 ) that the extraction solution attains equilibrium with the schoepite, 4) that the TIC concentration in the system is equal to $10^{-3} \mathrm{M}$ (the lower concentration listed in Table 4), and 5) that there are no kinetic constraints limiting the release of the metal from the solid phases. In some cases listed in Table 5, the extraction would require many volumes to be able to extract the uranium, whereas in others (e.g., the TCLP method employing the acetate buffer) the extraction is just sufficient to dissolve the available uranium, and in still others (e.g., the D3974-81 procedure) the procedure is capable of solubilizing many times the amount of uranium listed.

\section{ANSI/ANS-16.1-1986}

\section{Summary of the Procedure}

This procedure was designed to measure the leaching rate of nuclides from various stabilized forms (e.g., glasses and grouts) of low-level wastes. The standard calls for placing the sample in demineralized water for specified periods of time, those times being after 2,7 , $24,48,72,96,120$, and 144 hours from the start of the procedure. The sampling intervals can be extended to days 19,47 , and 90 from the initiation of the procedure if desired. A unique aspect of the procedure is the determination of leachate volumes. The procedure assumes that the sample is a compact solid (e.g., vitrified), and that one can obtain an estimate of its geometrical surface area. (This requirement precludes the use of unconsolidated soils or sediments in the procedure.) The analyst places the solid waste (preferably a cylindrical shape, but it is also acceptable to use a sphere or parallelepiped) in a quantity of demineralized water whose voliume is equal to ten times $(10 \mathrm{x})$ the geometrical surface area of the solid. The leaching is allowed to occur for the specified period, and then the solution is completely changed to fresh, demineralized water. The leachate is analyzed for the desired analytes at the termination 
Messurement of Environmental Availability

Table 5. Standard methods for the extraction of metals and their calculated effectiveness in extracting uranium from a soll contaminated with $100 \mathrm{mg} \mathrm{U} \mathrm{kg}^{-1}$ as schoepite $\left(\mathrm{UO}_{3} \mathrm{e2H}_{2} \mathrm{O}\right)$

\begin{tabular}{|c|c|c|c|c|c|c|}
\hline Method & $\begin{array}{l}\text { Solution } \\
\text { Composition }\end{array}$ & $\begin{array}{c}\text { Solution } \\
\text { pH }\end{array}$ & $\begin{array}{l}\text { Solution: } \\
\text { Soil Ratio }\end{array}$ & $\begin{array}{l}\text { Extraction } \\
\text { Temperature }\end{array}$ & $\begin{array}{l}\text { Time } \\
\text { Sertes? }\end{array}$ & Extracted \\
\hline ANSI/ANS-16.1-1986 & dist $\mathrm{H}_{2} \mathrm{O}$ & $6.0^{1}$ & $-m^{2}$ & room & yes & $-m^{2}$ \\
\hline ASTM D $3974-81$ & $\begin{array}{l}\mathrm{HCl} / \mathrm{HNO}_{3} \\
\mathrm{HCl}\end{array}$ & $\begin{array}{l}<0.1 \\
\sim 0.2\end{array}$ & $\begin{array}{l}27.8 \\
100 .\end{array}$ & $\begin{array}{l}95^{\circ} \mathrm{C} \\
\text { room }\end{array}$ & $\begin{array}{l}\text { no } \\
\text { no }\end{array}$ & $\begin{array}{l}100 \% \\
100 \%\end{array}$ \\
\hline ASTM D $3987-85$ & dist $\mathrm{H}_{2} \mathrm{O}$ & $6.0^{1}$ & 20.0 & room & no & $32 \%$ \\
\hline ASTM D $4793-93$ & dist $\mathrm{H}_{2} \mathrm{O}$ & $6.0^{1}$ & 20.0 & room & yes & $32 \%$ per batch \\
\hline ASTM D $4874-89$ & dist $\mathrm{H}_{\mathbf{2}} \mathrm{O}$ & $6.0^{1}$ & $--^{3}$ & room & yes & $\begin{array}{c}1.4 \% \text { per pore } \\
\text { volume }\end{array}$ \\
\hline $\begin{array}{l}\text { EPA/SW } 846 \\
\text { Method } 1311 \text { (TCLP) }\end{array}$ & $\begin{array}{l}\text { NaOAc } \\
\text { HOAc }\end{array}$ & $\begin{array}{l}4.9 \\
2.9\end{array}$ & $\begin{array}{l}20.0 \\
20.0\end{array}$ & $\begin{array}{l}22 \pm 3^{\circ} \mathrm{C} \\
22 \pm 3^{\circ} \mathrm{C}\end{array}$ & $\begin{array}{l}\text { no } \\
\text { no }\end{array}$ & $\begin{array}{l}100 \% \\
100 \%\end{array}$ \\
\hline $\begin{array}{l}\text { EPA/SW } 846 \\
\text { Method 3050A }\end{array}$ & $\underset{\mathrm{HCl}}{\mathrm{HNO}_{3} / \mathrm{H}_{2} \mathrm{O}_{2} /}$ & $<0.0$ & $\sim 15$ & $95^{\circ} \mathrm{C}$ & no & $100 \%$ \\
\hline
\end{tabular}

soll pH ansumed to be 6.0
'teat deaigned for monolithic compacted wate forms, not appropriate for soils
'flow-through column leaching test

of each period. Data from the study are combined to develop a single "Leachability Index" for the sample.

\section{Nominal Applications}

As indicated above, this procedure was developed to measure and index the release of radionuclides from solid waste forms (not unconsolidated soils and sediments) as a result of leaching in demineralized water. Results from the procedure should be used to infer leaching behavior for periods less than 1 year; however, extrapolation to longer periods can be made from assumptions about diffusion rates and the morphology of the waste form. The procedure is not intended to mimir conditions to which the waste form might be exposed in the field; rather, the procedure is designed with the intention of using reproducible conditions that are readily achievable.

\section{ASTM D 3974-81 (Reapproved 1990)}

\section{Summary of the Procedure}

This standard procedure provides two alternatives for leaching metals from soils or sediments. The first procedure is the more complex and more vigorous, and extracts a larger fraction of the metals from the solids. The procedure calls for adding $4 \mathrm{~g}$ of soil to a beaker, to which is then added $100 \mathrm{ml}$ of distilled water, $1 \mathrm{ml}$ of concentrated nitric acid, and $10 \mathrm{ml}$ of concentrated hydrochloric acid. The mixture is heated to $95^{\circ} \mathrm{C}$ and held at that temperature until the total solution volume is reduced to between 10 and $15 \mathrm{ml}$. The leachates are separated from any remaining solids by filtration, and the solution is diluted to an appropriate volume and analyzed for the desired analytes. The alternate procedure calls for placing $1 \mathrm{~g}$ of soil or sediment in an appropriate reaction vessel, adding $95 \mathrm{ml}$ of distilled water and $5 \mathrm{ml}$ of concentrated hydrochloric acid. The reaction vessel is sealed, and the mixture is shaken at room temperature overnight (ca. 16 hours). The solution is filtered to remove solids, and is analyzed for the desired analytes.

\section{Nominal Applications}

Both procedures are sufficiently vigorous to effect dissolution of most of the environmentally available forms of uranium from a soil or sediment. The first procedure will have greater efficiency at solubilizing reduced oxides and, perhaps, some silicates. However, 
the first procedure employs an oxidizing acid $\left(\mathrm{HNO}_{3}\right)$ and is thus not suitable for measurements in which one wished to determine the oxidation state distribution of the uranium in the sample. The secund procedure uses a non-axidizing acid, and so is appropriate for axidation-state determinations.

Neither procedure provides information regarding the specific forms binding the uranium nor do they provide estimates of rates at which the uranium would be released from these phases.

\section{ASTM D 3987-85}

\section{Summary of the Procedure}

This procedure is designed to perform a shaker extraction of solid wastes in distilled water. For the procedure, a sample of known weight (e.g., $70 \mathrm{~g}$ ) is added to an appropriate-sized vessel. A volume of distilled water equal to twenty times the weight of the sample in grams is added to the vessel (e.g., for the $70-\mathrm{g}$ sample, $1400 \mathrm{ml}$ of distilled water is added). The vessel is sealed and placed in an agitator, and the sample agitated for $18 \pm 0.25$ hours at room tempezature. The vessel is opened, and solids are allowed to settle. The supernatant is then decanted and filtered, the $\mathrm{pH}$ is measured, and the bulk of the solution is preserved for the analytes of interest.

\section{Nominal Applications}

This test is basically designed to give an indicator of the water solubility of a contaminant in a soil or sediment. The test is short-term and does not yield any time-dependent indication of the dissolution behavior.

\section{ASTM D 4793-93}

\section{Sumumary of the Procedure}

This procedure is similar to procedure D $3987-85$, except that it provides for the measurement of the time rate of release of the contaminant from the sample. In essence, a sample of known weight is added to a reaction vessel, and a volume of distilled water equal to 20 times the mass of the dry solid (in grams) is added. The vessel is sealed and then agitated for $18 \pm 0.25$ hours at room temperature. After separation of the leachate by pressure filtration, all solids are returned to the reaction vessel quantitatively, and the procedure is repeated nine additional times. The first four extraction sequences must be completed without a break of more than a few hours between runs. The test requires two weeks for completion.

\section{Nominal Applications}

Because of its similarity to D $3987-85$, this procedure provides essentially the same type of phase-specific information. The primary difference between the methods is that Method D $4793-93$ does provide some additional information about the time rate of release of the contaminant from the solid.

\section{ASTM D 487489}

\section{Sumumary of the Procedure}

This is a standard method for leaching solid wastes in a column apparatus. The solid material is packed into a soil column. The physical characteristics of the column (e.g., density, porosity, permeability, soil texture) should mimic those expected in the field. One then determines the pore volume (i.e., void volume) of the column. The column is saturated with distilled water (or other fluid, if required by the test requirements), and the analyat begins continuous pumping of the leaching solution through the column. Pumping rates should be equal to about one pore volume per 24-hour ( $\pm 10 \%)$ period. The effluent is collected, the $\mathrm{pH}$ measured, and the solution preserved according to the analyses to be conducted. The test can be continued for any period of time, although tests are typically run for at least 10 pore volumes.

\section{Nominal Applications}

The test provides information about the rates of release of a contaminant from a soil or sediment. Of the standard methods, in form and information generated, this procedure is the closest environmental equivalent of the SLF Test. Because of the low solution:solid ratio used in the test, the procedure has a limited ability to provide estimates of the quantities of uranium that might be associated with specific forms. For example, if the soil were contaminated with $50 \mathrm{ppm}$ schoepite, and if the kinetics of schoepite dissolution in the soil were such that the leachate attains equilibrium with each void volume (a generous assumption), then the procedure would need to be run for at least a month to deplete the schoepite. Thus, the procedure is not suitable for determining the oxidation state of uranium in the soil.

EPA/SW 846, Method 3050A

\section{Summary of the Procedure}

This method is a wet-chemical digestion procedure to determine the total concentration of a metal contaminant in a particular soil, sediment, or waste. To perform the procedure, a 1- to 2-g sample is 
added to a conical beaker. Five $\mathrm{ml}$ of distilled water and $5 \mathrm{ml}$ of concentrated nitric acid are added to the solid and mixed to form a paste. The mixture is heated to $95^{\circ} \mathrm{C}$ and maintained for $10-15$ minutes. The sample is cooled and an additional $5 \mathrm{ml}$ of concentrated nitric acid is added. This is then heated to $95^{\circ} \mathrm{C}$ and maintained for about 30 minutes. This last series of steps is repeated one additional time, and then the nitric acid solution is reduced to ca. 5 $\mathrm{ml}$. At this point, the sample is cooled, and $2 \mathrm{ml}$ of distilled water are added along with $3 \mathrm{ml}$ of $30 \%$ hydrogen peroxide. This mixture is heated to initiate the peroxide reaction. Peroxide is added in 1-ml increments until all apparent reactions cease, or until a total of $13 \mathrm{ml}$ of peroxide have been added, whichever occurs first. After the mixture has cooled, the analyst adds $5 \mathrm{ml}$ of concentrated hydrochloric acid, $10 \mathrm{ml}$ of distilled water, and the mixture is once again heated to about $95^{\circ} \mathrm{C}$ and refluxed for an additional 15 minutes. The mixture is cooled, the extraction liquor is filtered, and the total solution diluted to $100 \mathrm{ml}$ with distilled water. The solution is now ready for analysis by ICP, ICP/MS, or a related method.

\section{Nominal Applications}

This method yields a measure of the total potentially reactive metal associated with the soil or sediment. The only fractions of the metal that should not be extracted by this procedure are those that are bound within the crystalline lattice structure of refractory silicates. Because oxidizing acids and peroxide are used in the first portions of the procedure, the method is not suitable for estimating the distribution of uranium between the two oxidation states, nor is the method suitable for making estimates of mineral speciation.

\section{EPA/ SW 846, Method 1311 (TCLP)}

\section{Summary of the Procedure}

This procedure, also known as the Toxicity Characteristic Leaching Procedure or TCLP, provides the analyst with two alternative extraction procedures, the selection of which depends on the acid-neutralizing capacity of the sample. The first extraction liquor is a pH $4.93 \pm 0.05$ sodium acetate solution; the second solution is a dilute acetic acid solution with a $\mathrm{pH}$ of $2.88 \pm 0.05$. To determine which of the two extraction liquors to employ, a $5-\mathrm{g}$ sample is added to a beaker to which $96.5 \mathrm{ml}$ of distilled water is added. This slurry is stirred vigorously for 5 minutes, and the $\mathrm{pH}$ of the suspension determined. If the $\mathrm{pH}$ is less than 5.0, use extraction liquor \#1. If not, then $3.5 \mathrm{ml}$ of $1.0 \mathrm{~N} \mathrm{HCl}$ is added to the slurry, and the mixture is heated to $50 \mathrm{C}$ for 10 minutes. After the suspension has cooled, the $\mathrm{pH}$ is once again measured. If the $\mathrm{pH}$ is less than 5.0, extraction liquor \#1 is used for the procedure; otherwise, use extraction liquor $\# 2$.

Once the appropriate extraction liquor has been determined, $100 \mathrm{~g}$ of soil or sediment is added to the reaction vessel, and $2 \mathrm{~L}$ of the extraction liquor are added. The vessel is sealed tightly and placed on a rotary agitation device. The vessel is agitated at 30 rpm for $18 \pm 2$ hours at room temperature (22 \pm $\left.3^{\circ} \mathrm{C}\right)$. The liquid portion of the extraction liquor is separated from the solids using a glass fiber filter. The $\mathrm{pH}$ of the extraction fluid is recorded, and the fluid preserved for subsequent analysis.

\section{Nominal Applications}

This procedure, which is widely used for regulatory purposes, was originally designed to assess the potential mobility of metals in an organic-acid-rich landfill environment. The method has several advantages relative to other procedures discussed. The extraction liquor has a high enough ionic strength to "encourage" the release of exchangeable uranium to solution; at the same time, the medium is not so aggressive toward the solids as to effect significant dissolution of solid phases that are only slightly soluble under environmental conditions. As a result, the method forges a compromise between those procedures that attempt to measure all available forms of the contaminant, and those that seek to estimate some quasi-steady-state level of contaminant that might be observed. However, the TCLP does not mimic the natural conditions of the environment, nor does it provide information about the rate at which different phases in the sample react.

\subsubsection{Sequential Extraction Methods}

Extraction procedure of Yanase et al. (1991)

The goal of the study conducted by Yanase et al. (1991) was to describe the distribution and secondary mobilization (i.e., changes that have taken place in the emplacement of the ore deposit) of uranium at the major ore deposit near Koongarra, Australia. The site has been studied as a natural analog for processes affecting disposal of high-level nuclear waste.

\section{Summary of the Procedure}

To prepare the sample, $50 \mathrm{~g}$ of rock or soil is crushed and homogenized. Note that at the end of each extraction step that sample is centrifuged and the supernatant is filtered through a $0.45-\mu \mathrm{m}$ filter prior to sample preservation and storage. 1) A 1-g aliquot of sample is shaken in $40 \mathrm{ml}$ of $1.0 \mathrm{M} \mathrm{Na}$-acetate 
(adjusted to pH 5.0 with acetic acid) for 4 hours at room temperature. This step nominally removes exchangeable and carbonate-bound uranium. 2) The reaidue from step 1 is shaken with $40 \mathrm{ml}$ of Tamm's eolution (10.9 $\mathrm{g} \mathrm{L}^{-1}$ oxalic acid plus $16.1 \mathrm{~g} \mathrm{~L}^{-1} \mathrm{NH}_{4}$ oxalate) for 4 hours at room temperature in the dark. This step nominally removes amorphous hydrous coides of iron, aluminum and silicon in addition to secondary [presumably U(VI)] uranium minerals. The residue from step 2 is shaken with $40 \mathrm{ml}$ of CDB solution $(1 \mathrm{~g}$ of Na-dithionite added to $60 \mathrm{ml}$ of a 0.3 $\mathrm{M} \mathrm{Na}_{3}$-citrate $+0.2 \mathrm{M} \mathrm{NaHCO}_{3}$ solution immediately before use) at $85^{\circ} \mathrm{C}$ for 30 minutes. This step nominally removes the crystalline iron minerals. 4) The residue from step 3 is shaken with $60 \mathrm{ml}$ of 6.0 N HCl for 2 hours at $85^{\circ}$ C. This step nominally removes nonexchangeable uranium associated with clay minerals and some refractory minerals. 5) The residue from step 4 is put into a platinum crucible, and $5 \mathrm{ml}$ of perchloric acid and $25 \mathrm{ml}$ of HF are added. The sample is heated to $60^{\circ} \mathrm{C}$ overnight, and then evaporated to dryness. One gram of $\mathrm{Na}_{2} \mathrm{CO}_{3}$ and $2 \mathrm{~g}$ of Na-tetraborate are added to the sample and the sample is fused. The resulting cake is dissolved in $6.0 \mathrm{~N} \mathrm{HCl}$ and the solution analyzed. This step measures all remaining uranium in the sample.

The procedure is fairly elaborate; even so, it cannot be used to address all issues that might be raised with regard to a soil or sediment. The primary focus of the procedure is to provide information about the partitioning of uranium among some of the major mineral forms in the soil. In spite of this, the investigators did not allow for steps that might permit one to distinguish different oxidation states of uranium. Furthermore, it is not clear at what point in the procedure phosphate phases (e.g., torbernite, autunite, salceite) would be leached to the extraction solution. They might dissolve during steps 2,3 , or 4 in the nrocedure. Since uranyl phosphates can be a major alteration product of reduced uranium oxides (e.g, uraninite, gummite), it would be useful to have information on this topic. Finally, the procedures focus on determining the partitioning of the uranium among the different mineral species; it does not addiress either the rates at which the different mineral might react with natural waters, nor does it address what the "equilibrium" concentrations of uranium in contact with the soil might be. These pieces of information would be useful in a regulatory context.

\section{Paturactica Precedure of Tesaler et al. (1979)}

Tessier et al. (1979) recognized that a contaminant, once deposited in a soil or sediment, will partition itself among a number of different fractions or phases. Furthermore, the mobility and environmental availability of the contaminant have the potential to be dramatically different for the different fractions. Tessier et al. suggested that the use of a sequential extraction procedure might provide detailed information about the origin, form, biological and environmental availability, and susceptibility for mobilization and transport. The goal of their study, therefore, was to identify a series of procedures that would allow an analyst to determine the partitioning of transition metals into operationally defined, but environmentally relevant fractions.

\section{Summary of the Procedure}

The procedure purports to separate metals into five distinct fractions: exchangeable, bound to carbonates, bound to $\mathrm{Fe}$ and Mn oxides, bound to organics, and residual metals. The procedure is carried out using a 1-g sample of sediment or soil. To estimate the exchangeable fraction of the metal, the sediment is extracted for 1 hour with $8 \mathrm{ml}$ of a $1.0 \mathrm{M}$ magnesium chloride solution that has a $\mathbf{p H}$ adjusted to 7.0. The slurry is centrifuged, and the solution decanted, filtered, and saved for analysis. The sediment pellet resulting from the treatment is washed with $8 \mathrm{ml}$ of distilled water, and this slurry is centrifuged. The water from this step is discarded. Tessier et al. had some concern about the efficiency of this step. Transition metal concentrations released during this step were generally small to undetectable, suggesting that the sorption of the metals to the exchange sites might be sufficiently strong to prevent quantitative removal by this step.

To measure the carbonate-bound fraction, the sediment or soil pellet is suspended in $8 \mathrm{ml}$ of a 1.0 M Na-acetate solution whose pH is adjusted to 5.0. This suspension is maintained at room temperature and agitated constantly for the 5-h period of the extraction. Tessier et al. recommend that if the sample contains coarse-grained carbonates, the duration of the extraction should be extended, and the analyst must check the pH of the suspension occasionally to maintain it at about 5.0. At the end of this step, the suspension is centrifuged, the solution is decanted, and the pellet is washed as in the first step. This procedure will release metals from carbonates and, because of the slightly lower pH, will effectively complete the desorption of any metals bound on exchange sites.

For metals bound to iron and manganese oxides, Tessier et al. recommend the use of $0.04 \mathrm{M}$ hydroxylamine- $\mathrm{HCl}$ in a $25 \%(\mathrm{v} / \mathrm{v})$ acetic acid solution. The pellet from the second step is suspended in $20 \mathrm{ml}$ of the reagent, heated to $96 \pm$ $3^{\circ} \mathrm{C}$, and agitated occasionally. The suspension is maintained at this temperature for 6 hours. At the 
end of this step, the suspension is cooled and centrifused, the solution decanted, and the pellet washed as in the first step. An investigation of the use of other reagents, specifically a citrate-dithionite solution that is commonly employed in other studies, suggested that these reagents lead to the loss of metals through their precipitation as sulfide minerals.

Organically bound metals are extracted using an acidic peroxide solution. The pellet from the third step is wetted with $3 \mathrm{ml}$ of $0.02 \mathrm{~N}$ nitric acid and $5 \mathrm{ml}$ of $30 \% \mathrm{H}_{2} \mathrm{O}_{2}$. The $\mathrm{pH}$ is adjusted to 2.0 , and the mixture heated to $85{ }^{\circ} \mathrm{C}$ for $2 \mathrm{~h}$ with occasional agitation. A second 3-ml aliquot of peroxide is added to the vessel, and the mixture is once again heated to $85{ }^{\circ} \mathrm{C}$ for $3 \mathrm{~h}$. After cooling, $5 \mathrm{ml}$ of $3.2 \mathrm{M}$ ammonium acetate in $20 \%$ (v/v) nitric acid is added to the sample, and the suspension is agitated at room temperature for $0.5 \mathrm{~h}$. The suspension is then centrifuged, and the solution decanted. The pellet, as before, is washed.

Finally, the residual solid was dissolved in a mixture of HF and HClO . The pellet is wetted with $2 \mathrm{ml}$ of $\mathrm{HClO}_{4}$ and $10 \mathrm{ml}$ of HF. This is warmed and evaporated to near drynese, at which point a second 1ml addition of $\mathrm{HClO}_{4}$ and $\mathbf{1 0} \mathrm{ml}$ of $\mathrm{HF}$ are added. Again the sample is heated to near dryness. One milliliter of $\mathrm{HClO}_{4}$ is added and the mixture heated until the solution begins to fume. At this point, the residue is dissolved in $12 \mathrm{~N} \mathrm{HCl}$, and the total diluted to $25 \mathrm{ml}$ with distilled water.

The development of this procedure is notable because of the care that was taken to evaluate alternate techniques. At different stages during the development, the authors compared several nominally comparable techniques for a particular step and, based on their observations, they were able to determine the relative strengths and weaknesses of the alternatives.

\section{Other Sequential Extraction Procedures}

In addition to the two extraction procedures described above, the literature contains numerous descriptions of other methods for evaluating the partitioning of transition metals among the possible phases in a soil or sediment. In many cases, these procedures are similar to those described, with only minor modifications in the order of application or in the reagents used. Examples of these procedures can be found in Malo (1977), Jackson (1979), Presley et al. (1972), Brannon et al. (1977), Luoma and Jenne (1976), Gupta and Chen (1975), and Engler et al. (1974).

\subsubsection{Technical Applicability of Extractions}

As illustrated in the previous sections, there are a wide range of extraction procedures available for determining different, operationally defined fractions of uranium or other contaminants in soils and sediments. The procedure one would choose to employ in an application will depend on the goal for the measurement. In the context of site remediation, extraction procedures have some limitations, both in a generic sense and specifically for uranium chemistry.

In the generic sense, all of the extraction procedures, whether the single-step, time-sequence, or sequential extractions, provide only operationally defined components for the contaminant. While information of some type is obtained from each procedure, none of the methods provide data that can be used directly to understand the dynamics of uranium in the soil or sediment to be remediated. One-to-one correlations of extraction results with uranium behavior could be developed on a site by site basis. This would require that an extensive site characterization be completed, including a hydrogeologic model for the mobilization and redistribution of the element in the environment.

The other major limitation of the majority of the extraction procedures is that few of the methods are constructed to take advantage of some of the unique features of uranium chemistry. An important aspect of uranium geochemistry is its redox behavior.

Uranium (IV), a common form in oxide fuels, mineral deposits, and mine tailings, has a limited solubility. Therefore, in this form it is not readily available to the biosphere. However, most uraninite $\left(\mathrm{UO}_{2}\right)$ and gummite $\left(\mathrm{U}_{3} \mathrm{O}_{8}\right)$ phases are susceptible to oxidation to the $(+6)$ state and subsequent mobilization. None of the extraction methods reviewed provide a means for estimating the ratio of U(IV) to $U(V)$ in environmental samples, even though this would be a useful indicator of the quantity of uranium that might be immediately available to the biosphere. Another shortcoming of the extraction procedures reviewed is that none of the methods investigated mechanisms for isolating and identifying the quantity of phosphate minerals present in a soil or sediment. Unlike many other metals, uranium is able to form relatively stable phosphate phases in soils (e.g., saleeite), even when the concentrations of both uranium and phosphorus are at trace levels. Because uranyl [U(VI)] phosphates have low solubilities, relative to uranyl oxides and silicates, it would be useful to have a mechanism for distinguishing these different forms in order to obtain better estimates of uranium mobility and availability in the soil being remediated. 
Given these limitations both with respect to extraction procedures in general and with respect to uranium in particular, it would be useful to decide what characteristics of extraction procedures might be beneficial, and then, using this as a foundation, determine how well the various procedures enable an analyst to address those issues. In this context, we have selected a number of candidate criteria that could be useful for evaluating the applicability of uranium extraction procedures. This list is not a definitive list, but rather is constructed with the intent of demonstrating how one might go about evaluating available procedures, and, perhaps, defining new procedures that better meet the goals of the specific task.

\section{Erample Evaluation Criteria}

Criterion 1: Does the procedure extract the exchangeable fraction of uranium bound in the soil?

At a minimum, the procedure should produce an estimate of the readily accessible fraction of the uranium. In most cases this will require that the exchangeable fraction plus additional materials will be leached to solution. The exchangeable fraction is a highly mobile and available form of uranium.

Because of the processes regulating exchange, most methods will not provide information regarding the mass of uranium bound on these sites. Methods that attempt to characterize "steady-state" or "equilibrium" concentrations of the contaminant will fail to measure the mass of uranium resident on exchangeable sites. This would lead to a serious underestimation of the quantity of available, or reactive, uranium in the system. Also, any soil or sediment with high concentrations of organic matter or clays will preferentially adsorb uranium. Thus, procedures that aspire to measure "soluble" uranium, for example in distilled water, might actually lose material to adsorption as part of the extraction procedure. Therefore, a reasonable procedure might include a step that extracts the soil with a high-ionic-strength, moderate-pH solution early in the process.

Criterion 2: Does the procedure provide some estimate of the concentration of the contaminant that might be found in a natural soil water?

This is a common criterion used in developing many single-step and sequential procedures, although it is not clear how distilled water extracts of a soil can be related to the dynamies of the contaminant in the field. (Perhaps the best way to obtain estimates of soil water concentrations of a ccntaminant is to measure them in the field using zero-tension lysimeters.) Possible transformation of the contaminant during the extraction procedure, for example dissolving a metastable oxide and depositing the resultant ions onto exchange sites, make interpretation of these measurements suspect for most metals. Nonetheless, the widespread use of these procedures suggests that some investigators have found useful applications for the information.

Criterion 3: Does the procedure allow one to determine from which mineral forms the contaminant originated in the soil?

Although this type of information is not generally of interest for regulatory purposes, remediation efforts at a site might be made more effective if the predominant forms of the contaminates were known so that the treatment technology could be focused to address one or a few phases. Single-step and bulk analyses of soils do not yield the information needed to make these judgements. However, because different forms of uranium will display markedly different mobilities and bioavailabilities, the type of information obtained from this type of measurement could be exceptionally useful.

Criterion 4: Does the procedure, with appropriate adjustments, allow the analyst to obtain estimates of the $U(I V) / U(V)$ ratios in the sample?

Although not as definitive as a thorough mineral speciation measurement, there is a strong correlation between the oxidation state of uranium in a sample and its availability. As already noted, exceptions include the limited solubility of certain U(VI)phosphate and -vanadate minerals and, on the other side, the rapid oxidation and dissolution of certain reduced mineral forms of uranium. This type of measurement generally calls for the extraction of the sample with a non-oxidizing, mildly acidic solution.

Criterion 5: Does the method provide for estimating the total mass of the contaminant at the site?

A common regulatory consideration is the total concentration or activity of uranium at a site. A method that provides this type of informatin will potentially satisfy a number of different requirements. As a modification on this criterion, one might measure the non-residual (i.e., non-natural) forms of the uranium. This type of procedure would employ strong acids in oxidizing solution, although the extraction liquors would probably not be sufficiently vigorous to attack silicate phases. 
Criterion 6: Does the procedure allow the analyst to estimate the time rate of release of uranium from the sample?

One of the strengths of the SLF test is that it provides estimates as to the time rate of release of uranium from a sample. Kinetics of uranium release from environmental samples is an area of incomplete knowledge. Varying organic concentrations in a sample can lead to dissolution rate changes for uranium axidation and dissolution by several orders of magnitude (Grandstaff, 1976). Although dissolution of uranium from scils or sediments is a geochemically complex problem, useful information can still be inferred from measured release rates.

We have developed a table illustrating how well the methods discussed in Sections 2.1.2.2 and 2.1.2.3 meet these six criteria (Table 6). As is evident, none of the methods is capable of addressing all the criteria. Each of the methods provides some information about the system, but clearly data from more than one method are needed to make sound remediation decisions.

\subsubsection{Summary and Recommendations}

The methods discussed above employ diverse sets of reagents and were developed to address different regulatory and research issues. For the most part, methods currently employed as standard methods use either single-step extractions or multistep procedures that employ single extraction media. With the exception of the TCLP (EPA/SW 846-Method 1311), these procedures use either distilled water or strong, and generally oxidizing, acids as the extraction medium. As a result, the methods are best suited to addressing a narrow range of regulatory issues in which specific pieces of information are required. In the context of this type of application, the information users must be careful to match the needs of their programs with the type of information obtained from the procedure(s) being employed.

Table 6. Summary of analytical characteristics of selected standard soil extraction pricedures

\begin{tabular}{|c|c|c|c|c|c|c|}
\hline \multirow[b]{2}{*}{ Method } & \multicolumn{6}{|c|}{ Criterion } \\
\hline & $\begin{array}{c}1 \\
\text { Exchange }\end{array}$ & $\stackrel{2}{\text { Equilibrium }}$ & $\stackrel{3}{\text { Mineral }}$ & $\begin{array}{l}4 \\
U\end{array}$ & $\stackrel{5}{\text { Total U }}$ & $\begin{array}{c}6 \\
\text { Rate }\end{array}$ \\
\hline ANSI/ANS-16.1-1986 & $\mathbf{N}^{1}$ & $\mathbf{Y}$ & $\mathbf{N}$ & $\mathbf{N}$ & $\mathbf{N}$ & $\mathbf{Y}$ \\
\hline $\begin{array}{l}\text { ASTM D } 3974-81\left(\mathrm{HNO}_{3}\right) \\
\text { ASTM D } 3974-81(\mathrm{HCl}) \\
\text { ASTM D } 3987-85 \\
\text { ASTM D } 4793-93 \\
\text { ASTM D } 4874-89\end{array}$ & $\begin{array}{l}\mathbf{Y} \\
\mathbf{Y} \\
\mathbf{N} \\
\mathbf{N} \\
\mathbf{N}\end{array}$ & $\begin{array}{l}\mathbf{N} \\
\mathbf{N} \\
\mathbf{Y} \\
\mathbf{Y} \\
\mathbf{Y}\end{array}$ & $\begin{array}{l}\mathbf{N} \\
\mathbf{N} \\
\mathbf{N} \\
\mathbf{N} \\
\mathbf{N}\end{array}$ & $\begin{array}{l}\mathbf{N} \\
\mathbf{Y} \\
\mathbf{N} \\
\mathbf{N} \\
\mathbf{N}\end{array}$ & $\begin{array}{l}\mathbf{Y} \\
\mathbf{N} \\
\mathbf{N} \\
\mathbf{N} \\
\mathbf{N}\end{array}$ & $\begin{array}{l}\mathbf{N} \\
\mathbf{N} \\
\mathbf{N} \\
\mathbf{Y} \\
\mathbf{Y}\end{array}$ \\
\hline $\begin{array}{l}\text { EPA/SW } 846-1311(\mathrm{pH} 4.93) \\
\mathrm{EPA} / \mathrm{SW} 846-1331(\mathrm{pH} 2.88) \\
\mathrm{EPA} / \mathrm{SW} 846-3050 \mathrm{~A}\end{array}$ & $\begin{array}{l}\mathbf{Y} \\
\mathbf{Y} \\
\mathbf{Y}\end{array}$ & $\begin{array}{l}\mathbf{S} \\
\mathbf{N} \\
\mathbf{N}\end{array}$ & $\begin{array}{l}\mathbf{N} \\
\mathbf{N} \\
\mathbf{N}\end{array}$ & $\begin{array}{l}\mathbf{N} \\
\mathbf{S} \\
\mathbf{N}\end{array}$ & $\begin{array}{l}\mathbf{N} \\
\mathbf{N} \\
\mathbf{Y}\end{array}$ & $\begin{array}{l}\mathbf{N} \\
\mathbf{N} \\
\mathbf{N}\end{array}$ \\
\hline $\begin{array}{l}\text { Yanase et al. (1991) } \\
\text { Tessier et al. (1979) }\end{array}$ & $\begin{array}{l}\mathbf{Y} \\
\mathbf{Y}\end{array}$ & $\begin{array}{l}\mathbf{S} \\
\mathbf{N}\end{array}$ & $\begin{array}{l}\mathbf{Y} \\
\mathbf{Y}\end{array}$ & $\begin{array}{l}\mathbf{N} \\
\mathbf{N}\end{array}$ & $\begin{array}{l}\mathbf{Y} \\
\mathbf{Y}\end{array}$ & $\begin{array}{l}\mathbf{N} \\
\mathbf{N}\end{array}$ \\
\hline
\end{tabular}


Of the research procedures reviewed, only the procedure employed by Yanase et al. (1991) was designed to investigate uranium speciation specifically. Other procedures have been more generally developed to investigate the partitioning of a range of trace metals in soils and sediments. All of these procedures appear to have been developed on the premise that uranium or other trace metals exist primarily as minor components in the soil; they focus on distinguishing the metals that are bound in carbonates from those in iron or manganese oxides, soil organics, or other phases. None of the methods seem to provide mechanisms for evaluating certain chemical characteristics that might be unique to uranium. Specifically, the methods do not provide for ways to determine $U(I V) / U(V I)$ ratios or to distinguish uranyl phosphates (or vanadates) from uranyl hydrous oxides, nor have they addressed the situation where one might wish to distinguish uranium oxides from uranium sequestered in hydrous iron, manganese, or aluminum oxides.

A major limitation of both the standard methods and the sequential extractions is that none of the methods provide results that can be directly correlated to the expected behavior of uranium at the site being studied. Admittedly, uranium dynamics in soils is a complex function of soil hydrology, soil chemistry, regional climate and related factors. As a result, it is not reasonable to expect any single measurement methodology to provide information relevant to the uranium dynamics for all systems. Users of these methods, therefore, either must accept the results of a test as a surrogate or indicator of potential behavior, or must use a combination of existing standard and advanced procedures to obtain more specific data regarding uranium behavior. The standard methods will be relatively easily implemented, and have wellconstrained costs associated with them, although the results will have a degree of uncertainty associated with them. The advanced methodologies, on the other hand, require developmental work. To correlate uranium behavior in a soil with the results obtained using a measurement methodology, long-term studies must be undertaken on dissolution and transformation processes. The specific goal of these studies should be to learn what measures provide the best estimates of uranium soil dynamics in a representative range of "typical" soil regimes.

In light of these different goals, there are several options for choosing the procedures to employ for characterizing a uranium-contaminated soil for remedial investigations. If the user is constrained to using standard methods (or modifications thereof), the most appropriate standard method for this purpose is probably the TCLP (EPA/SW 846-Method 1311).
This method has two variations, each of which would yield information pertinent to site clean-up. Extraction at pH 4.9 can yield information about exchangeable, carbonate-bound, and other loosely bound uranyl compounds. The more aggressive $\mathrm{pH}$ 2.9 solution should extract uranium sequestered in poorly crystalline hydrous oxides and some of the organically bound forntinn. Together, these fractions probably constitute must of the uranium in the sample that will be environmentally available over time frames of less than several years. The method does not yield time-rate of release information, nor does it provide specific information about the speciation of uranium in the soil. However, the operationally defined "available uranium" is of regulatory interest.

Extraction procedures that provide either kinetic information or more specific information about the forms and partitioning of the uranium at the site are not currently established. Methods and procedures do exist in the literature that would enable an investigator to obtain these types of data in a routine or standard way. However, because of the range of information that is potentially available from different types of extraction procedures, one would need to define the desired product carefully before attempting to develop a new procedure or set of procedures to support site remediation efforts. Sequential extractions used in conjunction with some form of kinetic measurement probably hold the best opportunities for correlating the results of a measurement methodology with the expected short-term behavior of uranium in a soil. However, procedures for such applications remain to be developed.

We have reviewed a range of standard procedures and research methodologies that qualify as selective or sequential extraction procedures. Currently, these methods seem to be the most practical for estimating the environmental availability of uranium directly. The methods are almost universally rapid and provide reproducible operational definitions of uranium reactivity classes. Extraction results can be correlated with long-term studies of availability performed on a matrix of different soil types and environmental conditions. The techniques are easily performed in most wet-chemistry laboratories with a minimum of capital cost.

\subsubsection{Bioavailability Studies}

Ingestion of plants that have assimilated uranium from contaminated soils and direct ingestion of uraniumcontaining soils are important pathways leading to the uptake of uranium by humans and animals. Although these processes are important, the results of our literature search indicate very few data exist regarding 
field and laboratory studies of the bioavaiiability of uranium from soils and sediments. Moreover, identification and characterization, including valencestate determinations, were not conducted or reported in the few studies identified in our review.

Cannon (1952) studied the effect of uranium-vanadium deposits on the vegetation of the Colorado Plateau. For plants rooted in uranium-bearing rock, Cannon found the highest concentrations of uranium in the roots and seeds. The results indicated that the availability of uranium to plants was strongly influenced by soil clay content, organic matter content, soil acidity, and depth of the root system.

Miera (1980) evaluated the bioavailability of uranium to a single species of small mammal, the white-footed deer mouse [Peromyscus maniculatus nufinus (Merriam)] in two different environments: uraniumcontaminated soils at a weapons-testing site near Los Alamos, New Mexico, and an inactive uranium milltailings pile located near Grants, New Mexico. The objective of the study was to determine whether uranium concentrations in tissues and organs of white footed deer mice could be related to soil uranium concentrations. The concentrations of uranium were determined for various soil size fractions and whole (i.e., unfractionated) soil samples. The uranium analyses of the soil samples from the Grants and the Los Alamos sites were done by a neutron assay and an instrumental epithermal neutron activation analysis technique, respectively. The mineralogical form and valence state of the uranium in the soils were not characterized. The study indicated a high variation in uranium distributions at the Los Alamos site, which Miera concluded to be a result of the uranium dispersal patterns from the explosive test shots. At the Grants site, the relatively homogeneous distribution of uranium was attributed to the solubility of uranium resulting from the refining process and the uniformity of soil particle sizes that optimizes the soil mixing processes. More ingested uranium was metabolically assimilated in the white-footed deer mouse at the Grants site, a result that Miera attributed to a more soluble form of uranium at this site.

Dreesen et al. (1982) examined the enrichment of potentially toxic constituents (e.g., uranium) in uranium mill residues and the aqueous mobility and bioavailability of these contaminants in the environment. The investigation included laboratory studies involving the leaching of tailings with water and the plant uptake of contaminants. $A$ greenhouse experiment was conducted to evaluate contaminant uptake from the alkaline tailings by native plant species. A grass (Sporobolus airoides) and a shrub
(Atriplex canescens) were grown in two environmental settings: 1) soil-covered tailings and 2) soil alone. The results of the laboratory studies were also compared to contamination measured near an actual tailings pile. Water extractions of trace constituents from the tailings, sediment, and soil samples were completed by mixing the air-dried solids with deionized water for $\mathbf{3 0}$ days at a solid-to-liquid mass ratio of 1:5. No additional characterization of the solids was reported. Uranium was analyzed by delayed neutron counting after thermal neutron irradiation of the tailings, soil, vegetation, extract, and water samples. The analyses indicated that uraniur: concentrations in the tailings extracts were at least 25 times greater than those in the soil extracts. On the other hand, the mean concentrations of uranium in the shrubs grown in tailings were 15 times greater than in those grown in soils, indicating that the waterextract concentrations of uranium did not necessarily correspond to the quantity of that element in the above-ground portion of the plant.

Chassard-Bouchaud and Galle (1988) studied the cellular and subcellular distribution of ${ }^{288} U$ in several organisms using microanalytical techniques. The organisms included oysters, mussels, shrimps, crabs, and sea spiders collected from the French coastal waters. Isotopic measurements and cellular images of the radionuclide distribution were obtained using secondary ion mass spectrometry (SIMS). X-ray spectrometry was also used to study radionuclide distribution at the subcellular level. ChassardBouchaud and Galle were able to detect ${ }^{238} \mathrm{U}$ bioaccumulations in every species, target organism, cell, and organelle. Although Chassard-Bouchaud and Galle discussed the possible physiological strategies for the uptake, storage, and elimination of uranium by these organisms, no specific information was provided. Since this short paper was included in the proceedings of an international conference, the issue of uranium bioavailability may have been discussed in their oral presentation.

Linsalata et al. (1989) conducted a field study of adult steers in an area in Orange County, New York, that has elevated background radioactivity. The objectives of the study were to assess tissue concentrations, soil-to-tissue concentration ratios, and the comparative bioavailability of isotopic $\mathrm{Th}, \mathrm{U}, \mathrm{Ra}$ and light rareearth elements in adult steers. The elements chosen for study display some physical, chemical, and biological properties that are similar to those for transuranic actinide elements present in high-level nuclear waste.

Linsalata et al. (1991) conducted a field study in the Poços de Caldas plateau, Brazil. This area has 
elevated natural background radioactivity. The purpose of the study was to assess tissue concentrations and the comparative bioavailability of isotopic $\mathrm{Th}$ (IV), $\mathrm{U}(\mathrm{IV}, \mathrm{VI}), \mathrm{Ra}$ (II) and light rare-earth elements in adult steers, pigs and chickens. The field study showed that the isotopic ratios in the farm animals' tissue resemble closely, with few exceptions, those in soils over which the animals forage. These results indicated the importance of the soil component in the biouptake of these elements by animal tissues.

Garten et al. (1981) conducted a study of comparative uptake of ${ }^{25} \mathrm{U},{ }^{202} \mathrm{Th}$, and ${ }^{200} \mathrm{Pu}$ from soil by fescue, grasshoppers, and small mammals at the contaminated White Oak Creek floodplain in east Tennessee. The floodplain, which is near the Oak Ridge National Laboratory, was originally the site of a liquid retention pond for radioactive waste, and was contaminated with plutonium and fission products in 1944. Samples used in this study included carcasses from shrews, mice, and rats and bone samples from raccoon, opossum, woodchuck, and rabbit. Radionuclides were extracted from 10-g soil samples using $8 \mathrm{M} \mathrm{HNO}_{3}$ for 48 hours. The authors considered $8 \mathrm{M} \mathrm{HNO}_{3}$ to be effective in extracting total actinides, because the radionuclides in this soil were expected to be present as surfaceadsorbed forms as opposed to some refractory form. Analyses of ${ }^{20} \mathrm{U},{ }^{232} \mathrm{Th}$, and ${ }^{200} \mathrm{Pu}$ in the supernatant were completed using alpha spectrometry. Radionuclides in the plant and animal tissue samples were analyzed by thermal emission isotope dilution mass spectrometry. The results indicated that the pattern of uptake of these radionuclides by biota from the soil was $U>T h \approx P u$. This pattern of accumulation corresponded to the authors' previous studies regarding the extractability of these radionuclides from soil using $1 \mathrm{M} \mathrm{HNO}_{3}$ and $10 \% \mathrm{Na}_{2} \mathrm{CO}_{5} 5 \% \mathrm{NaHCO}_{3}$. Garten et al. considered the pattern of extractability from soil to be probably related to the valence states of these radionuclides [U(VI), Pu(IV), and Th(IV)].

Sheppard et al. (1984) used field lysimeters to study plant growth, plant uptake, and redistribution of uranium and chromium in soil. The investigations included studies of two plant species [alfalfa (Medicago sativa) and Swiss chard (Beta vulgaris cicla)] in two soil types (loam and sand) that were spiked with uranium. The uranium was added at two depths (15 and $30 \mathrm{~cm}$ ) in the form of the uranyl [U(VI)] ion using uranyl nitrate solution. Analysis of uranium was completed using activation analysis/delayed neutron counting. The SOLMNQ chemical speciation computer model was used to estimate the uranium speciation in both soils. The speciation calculations indicated that the uranium under these conditions should behave as an anion, with the dominant species being $\mathrm{UO}_{2}\left(\mathrm{HPO}_{4}\right)_{2}^{2-},\left(\mathrm{UO}_{2}\right)_{3}(\mathrm{OH})_{7}, \mathrm{UO}_{2}\left(\mathrm{CO}_{3}\right)_{2}^{2}$, and $\mathrm{UO}_{2}\left(\mathrm{CO}_{3}\right)_{3}^{4}$. Sheppard et al. found that the total uptake of uranium increased significantly as more uranium was applied to the soil. Plant uptake of uranium was determined to be independent of plant species and the placement depth of uranium contamination in the loam soil. In sandy soil, however, the uptake of uranium by plants was greater where the uranium placement was near the soil surface. Sheppard et al. attributed this increased uptake to the presence of more roots in the shallow zone. They reasoned that the lower uranium uptake with deep placement might reflect less root activity or a reducing environment that altered the initial U(VI) to less soluble forms of uranium. The studies also indicated that the uranium did not migrate significantly in the loam soil. Sheppard et al. speculated that uranium was immobilized by organic matter in the loam soil. In the sandy soil, uranium placed near the surface migrated predominantly upward, whereas, with deep placement, some uranium might have been lost to the water table.

Sheppard and Evenden (1985) studied the uptake of uranium and several other metals (technetium, phosphorus, and iron) by barley (Hordeum vulgare) grown in field lysimeters. The purpose of the investigation was to examine metal uptake and mobility at the water table interface between the unsaturated, usually aerated soil and water-saturated, often anaerobic soil. The study included

measurements of plant uptake, plant root distribution, and soil profiles of total and extractable concentrations of uranium and the other metals. The soil was treated with uranyl ion in the form of uranyl nitrate solution. Soil sampling included the extraction of uranium from the soil using $0.02 \mathrm{M} \mathrm{CaCl}_{2}$ and $0.5 \mathrm{M}$ $\mathrm{NaHCO}_{3}(\mathrm{pH} \mathrm{8.5)}$. Analysis of uranium was completed using neutron activation/delayed-neutron counting. Results indicated that uranium was most mobile in the aerated soil. The migration was predominantly upward and particularly from the shallow treated layer when the water table was fixed. The greatest retention of uranium occurred in the anaerobic treated layers. The measured concentrations of uranium in the plants were approximately a factor of $\mathbf{1 0}$ higher than background, but were statistically different from background only in the case of shallow uranium placement with a fixed water table. The plant uptake of uranium reflected the mobility of uranium at these conditions and plant root activity. The studies showed that the mobility of some metals changes as they migrate from anaerobic to aerobic zones. This transition zone occurs at the boundary of oxygen depletion and not the water table interface. 
Sheppard and Thibault (1988) investigated the vertical migration of uranium, technetium, iodine, and neptunium in peat from two types of mires typical of the Canadian Precambrian Shield. Both mire deposits were located within the area of the Whiteshell Nuclear Research Establishment in Pinawa, Canada. To study uranium migration, core samples of peat material were spiked with uranyl [U(V)] ion using uranyl nitrate solution. Analysis of $x U$ was conducted using neutron activation. The studies included measurements of seasonal groundwater level fluctuations and chemical composition changes in the mires. Uranium analyses of peat and pore water samples from the cores indicated that uranium sorbed effectively to the peat and was quickly immobilized. The concentrations of uranium in the surface peat were very low, with the uranium concentrated near the spike location. The results indicated that the mobility of uranium is retarded in this reducing environment.

None of the studies we reviewed approached the subject from the standpoint of trying to predict the environmental availability of uranium from a particular soil. Rather, they were conducted to explore some of the possible pathways that bioaccumulation of uranium might follow. A bioassay for regulatory purposes might involve germination of bean sprouts, or some other rapidly growing plant or microorganism, in an agar containing the soil of interest. The rate of uptake by the test organism would then be correlated with long-term studies of uranium release to groundwater and/or to plants and mammals to estimate the risk factors. A complete assessment of environmental availability for surface soils would include some sort of a bioassay to account for terrestrial movement of the uranium not associated with groundwater. To our knowledge, no such investigation has been undertaken by any research group or regulatory agency.

Procedures to determine the bioavailability and toxicity of contaminants fall into two broad categories: aquatic tests and terrestrial tests. The aquatic tests have been the standard-bearer for these types of measurements. Standard test organisms [e.g., fat head minnows, daphnia (a zooplankton), various algae species] are exposed to the contaminated water or an extract of the soil, for a defined period (Poston et al., 1984). For acute exposure assessments, the tests usually last four days. Chronic exposure tests can be run for up to 28 days. A general limitation with the aquatic tests is their lack of specificity. The organisms react to all contaminants present in the sample, so unless one has a detailed characterization of the materials being tested and is aware of synergistic interactions among those contaminants, it is virtually impossible to assign a specific organism response to the presence of a single contaminant.

The terrestrial tests (Linder et al., 1992) are relatively new, having been developed within the last decade. The terrestrial tests encompass a battery of measurements, including seed-germination tests, rootelongation tests, greenhouse tests, and earthwormtoxicity tests. These tests are generally more applicable to situations in which the contaminants are partitioned onto soil solid phases. As with the aquatic tests, these procedures tend to be broad-spectrum tests; that is, it is difficult to assign observed toxicity to a specific contaminant unless additional work is undertaken.

Costs for the aquatic and terrestrial tests vary. There are several dozen commercial laboratories in the United States that are currently capable of conducting the aquatic toxicity tests with nonradionuclides. We have not been able to determine how many laboratories also are equipped to handle uranium and other radionuclides, although we expect the number to drop by more than an order of magnitude. Costs for these tests are expected to be several thousands of dollars per test. For the terrestrial testing, about six laboratories in the United States are capable of performing the evaluations. Of these, only one currently is set up to handle radionuclides. Costs for the tests also vary. Seed-germination and rootelongation tests will be available for about $\$ 1,500$ to $\$ 2,000$ per test. Greenhouse testing is considerably more expensive. We have not obtained exact figures, but anticipate the costs to be on the order of $\$ 10,000$ to $\$ 12,500$ per test.

\subsubsection{Selection of Direct Measurement Approach}

Clearly, the SLF procedure cannot be used directly to estimate the environmental availability of uranium in soils. It does, however, incorporate an estimate of the release rate of uranium, something that is lacking in most of the other procedures we have examined. The bioassay approach also has some appeal, but has not been developed sufficiently to be used for regulatory purposes. The only direct approach that has been developed to a degree that would make adaptation for regulatory purposes possible is one based on a rapid chemical extraction procedure. The ideal procedure would directly measure the rates of release of uranium from the soil solid phase to the soil solution and would take into account the variety of uranium-bearing solid phases present in soils, as well as the different solution compositions and flow rates that may be encountered. 


\subsection{Inferred Measurement of Availability}

The inferred measurement approach does not measure the rate of uranium release from each soil directly, but rather estimates it based on quantification of the thermodynamically identifiable phases of uranium associated with the soil solids. This information is then coupled with fundamental thermodynamic, kinetic, and hydrologic data to estimate the environmental availability of uranium. The success of the approach relies on 1) the ability to correctly and economically quantify the important uranium-bearing phases in a soil, and 2) the integrity and applicability of the fundamental data that are used to predict uranium availability. Rather than being operationally defined, as the direct availability measurements tend to be, the inferred approach is based on absolute data and offers the potential of being both simpler and more precise.

\subsubsection{Phase Identification Procedures}

\subsubsection{X-ray Absorption Spectroscopy}

With the advent and continued development of dedicated synchrotron facilities, X-ray absorption spectroscopy (XAS) has emerged as an important and accessible technique for the determination of local structure (nearest-neighbor identity and distance, and coordination number) and oxidation state of atoms. This information is located in two portions of the Xray spectrum and obtained by scanning across the absorption edge for a particular inner-shell electronic transition (e.g., the $K$ edge or the $L_{m}$ edge). The actual position of the edge varies slightly with the oxidation state of the atom, generally shifting to lower energirs as the oxidation state decreases. In addition, pre-edge features often appear in spectra for the higher oxidation states as a result of transitions of electrons from inner shells to outer valence shells that are unoccupied as a result of the oxidation state. Thus, from a combination of absolute edge position and features near the edge (i.e., within $40 \mathrm{eV}$ on both sides) much can be deduced about the oxidation state of the atom. Examination of this portion of the absorption spectrum is termed X-ray absorption near edge structure (XANES) spectroscopy and requires little or no computer modeling to extract the information. An electron is ejected from the atom as a result of X-ray absorption and will produce features in the spectrum $40 \mathrm{eV}$ to about $1000 \mathrm{eV}$ above the absorption edge that contain information about the identity, interatomic distance, and coordination number of the nearest atomic neighbors to the absorbing atom. This portion of the spectrum is referred to as the extended X-ray absorption fine spectrum (EXAFS), and elaborate computer modeling is required to extract the information.

Because the technique is relatively new, only a few examples of its use for characterization of uranium in soils have been published. Dent et al. (1992) compared the EXAFS spectra of uranyl ions in solution and adsorbed to silica and montmorillonite. Using the X-ray microprobe (XRM) with a beam size of $50 \times 50 \mu \mathrm{m}$, Bertsch et al. (1993) collected XANES spectra of uranium-contaminated soil samples from Fernald, Ohio, and the Savannah River Site, South Carolina, and were able to determine the average oxidation state of the uranium in the samples. They noted that most of the U(IV) was present in the sand size fraction, presumably from airborne particle deposition, whereas uranium adsorbed to the clay fraction was essentially all hexavalent. They did not specify, however, whether precautions were taken during separation of the clay fraction to prevent the oxidation of colloidal and adsorbed uranium in these soils. The highest concentration of uranium in the samples studied was about $1000 / \mathrm{B} \mathrm{g}^{-1}$, and they estimated that concentrations as low as $10 / \mathrm{Bg}^{-1}$ could be studied with the microprobe technique.

The application of XAS for identification of uranium solid species in soils can reveal information about average oxidation state and with XRF can quantify the total uranium present. Use of the XRM can extend the resolution of the method to as low as a few microns, and this resolution is expected to improve as the development of the XRM continues.

Furthermore, XAS allows the examination of hydrated samples in their natural state since it does not require a high vacuum. However, these techniques reveal the local structure rather than identifying specific thermodynamic phases that can be treated in a geochemical equilibrium model. Extraction of phase information (e.g., nearest neighbor distances) requires considerable time and expertise with a sophisticated computer model. However, one can imagine an automated elaborate XRM set-up that would systematically scan a sample for uranium, collect an XANES spectrum, an XRF spectrum, and an XRD spectrum at each point of interest (say where uranium concentrations above a certain threshold level were found), and use this information to estimate the amounts and forms of uranium in the sample. Obviously, representative sampling would be required and there would always be some concern about extrapolating the results from the XRM analyses to a whole soil. Such a system does not currently exist, but may become possible in the next 5 to 10 years. 


\subsubsection{Analytical Electron Microscopy}

Electron microscopy combines the ability to image samples on a very small scale with other analytical techniques for identification and quantification of composition [energy-dispersive X-ray analysis (EDX)] and structure [electron diffraction (ED)]. The entire package of techniques is often refered to as analytical electon microscopy (AEM) and is a powerful tool for the detailed examination and characterization of soils (Gilkes, 1994). The technique can identify particles on the order of a few nanometers in diameter on the basis of chemical composition and, if crystalline, crystal structure. However, the measurements must be made under a high vacuum and, for diffraction, must be from very thin specimens that allow transmission of the electrons. The technique, thus, is best suited for examination of uranium that is in discrete crystalline phases that are not readily altered by desiccation. Because of the high resolution attainable, this technique can also be used, in conjunction with image analysis software, to quantify the sizes and shapes of the individual particles for later use in estimates of absolute dissolution rates. Unlike XAS, AEM does not offer a capability for determination of oxidation states. The sample preparation requirements are also more restrictive than those for XAS. On the other hand, the resolution and imaging capabilities are far superior and may offset these limitations.

\subsubsection{Laser-Based Spectroscopies}

The phase-identification approach taken by one group at Los Alamos National Laboratory involves integrating the information from XAS with that from several laser-based techniques (D. E. Morris, Los Alamos National Laboratory, 1993, personal communication). The laser spectroscopies employed include optical luminescence, Raman, and photoacoustic. In general, luminescence is more sensitive to $U(V I)$, whereas photoacoustic is more sensitive to U(IV). The Raman technique samples vibrations of functional groups and has roughly equivalent sensitivity to compounds of either valence. The integrated approach offers the ability to characterize uranium in soils with a minimum of pretreatment and thus has the potential of being highly accurate from a phase-identification standpoint. Analytical costs, however, are in the neighborhood of $\$ 5000$ per specimen, and about $\$ 500,000$ in capital is needed to purchase the instrumentation.

\subsubsection{Preconcentration Techniques}

Although identification and quantification are not accomplished directly by preconcentration, phase identification is often enhanced by various solid-phase preconcentration procedures that rely on differences in particle-size, density, surface charge, and other physical properties to separate the phuses of interest from the soil matrix (Laird and Dowdy, 1994). Because of the high density of uranium relative to the minerals that make up the bulk of the soil minerals, a preconcentration technique relying on density fractionation would seem to have great promise for increasing the concentration of uranium in specimens, thereby lowering the effective detection limits for the various phases present. We are not aware of any work in which this approach has been taken specifically for the isolation of uranium phases in soils.

\subsubsection{Assessment of Phase Identincation Procedures}

Phase identification generally requires a combination of information about the elemental composition of the specimen and its structure. As such, X-ray and particle-beam techniques are the main ways of identifying individual phases and identification is much easier for crystalline phases than for amorphous phases. In soils, uranium concentrations are low enough to require microbeam techniques, in which individual particles are identified and then characterized. As a result, the direct phaseidentification approach requires minimal quantities of soil for each specimen, but, in analogy to sand-grain analysis in classical petrography, sampling of very large numbers of individual particles from a particular soil in order for the results to be statistically meaningful.

XRM and AEM are two techniques that can acquire both compositional and structural information about small particles. One limitation to the XRM is that it requires a synchrotron $X$-ray source to obtain enough $X$-ray flux on the specimen for analytical purposes. The AEM, on the other hand, is a relatively common instrument and accessibile to many laboratories. Of the two instruments, then, the AEM is clearly the more practical and offers structural, compositional, morphological, and spatial information about the uranium in soils.

The main drawback of AEM is due to its being a microbeam technique. A large number of individual characterizations may have to be performed before an average composition for the whole soil can be deduced. Furthermore, extensive sample preparation (i.e., thin sections) is required if spatial information is desired. Lastly, the technique does not lend itself to oxidation state determinations (even by quantification of oxygen and stoichiometric calculations). As noted by Nash (1992), "the standards and unknowns must be well polished and clean, have the same thickness of $C$ coating, and have surfaces perpendicular to the 
electron beam. These procedures are particularly critical for $O$ because the signal is derived from very near the surface, and $C$ has a high mass absorption coefficient for OK. radiation." Thus, oxidation state analyses by oxygen quantification can be done only on thin sections and may be subject to considerable error if not properly performed.

In short, the AEM technique, though powerful, does not identify amorphous phases readily, nor adsorbed uranium, nor coprecipitated uranium at small mole fractions, and thus may ignore a considerable fraction of the available uranium present in soils. This, in combination with the tedious and labor-intensive nature of the data collection, makes it not particularly practical for routine determination of environmental availability of uranium. It may better serve as an ancillary technique to help identify phases extracted by wet-chemical methods and aid in the correlation of reactivity and availability.

\subsubsection{Geochemical Modeling}

Geochemical modeling is a broad term that may include calculations of the thermodynamic equilibria of ions in aqueous solutions, the kinetics of solid dissolution and precipitation, and the transport of ions in soils and sediments. Of these, the equilibrium codes are well developed, whereas attempts to couple equilibrium calculations with kinetic and transport processes in soils are still in their infancy. We refer here only to the equilibrium calculations, recognizing at the same time both the importance of the other processes and the difficulty of combining them into meaningful tools for predicting contaminant behavior.

Calculation of equilibrium species distributions of dissolved major and trace constituents, including radionuclides such as uranium, may be used to understand the processes that control the chemistry of surface- and groundwater systems and, to some extent, the chemical mobility in these systems and bioavailability to humans. Such processes as aqueous complexation, oxidation/reduction, adsorption/desorption, and mineral precipitation/dissolution will control the thermodynamic activities of radionuclide species in solution. Both the diversity and interdependency of research efforts associated with chemical reaction modeling are effectively demonstrated by the papers cited in the literature review of Serne et al. (1990) and those published in Jenne (1979), Jacobs and Whatley (1985), Jackson and Bourcier (1986), and Melchior and Bassett (1990).

The distribution of aqueous species at equilibrium in a multicomponent system can be reliably calculated only with a combination of accurate analyses of water compositions and a competent geochemical reaction model. A geochemical reaction model is defined here as the integration of mathematical expressions describing theoretical concepts and thermodynamic relationships on which the aqueous speciation, solubility, adsorption, and mass transfer calculations are based. A geochemical reaction code refers to the translation of a geochemical reaction model into a sequence of statements in a particular computer language. A competent geochemical reaction model is a model that contains all the necessary submodels and important aqueous complexes, solids and gases for the important elements of interest required to adequately interpret a given data set.

Geochemical reaction models may be used to predict the maximum concentration of elements, such as uranium, that may be present in an aqueous solution. This type of modeling calculation requires the user to select either a solubility or an adsorption reaction to constrain the maximum concentration limit of a radionuclide or any other dissolved constituent. The modeling process is based on the following assumptions and needs for the environment of interest:

- For a concentration limit based on a solubility reaction, the mineral phase selected as the solubility control for the radionuclide of interest must have known thermodynamic data (e.g., solubility constant) and be technically defensible (e.g., known to exist in nature and have rates of precipitation and dissolution that are not limited by kinetics).

- For a concentration limit based on a sorption reaction, the substrate (e.g., an iron-oxyhydroxide coating' selected as the sorption control for the radionuclide of interest must be technically defensible relative to the soil or sediment being modeled, and sorption parameters must be known for the radionuclide of interest and its major competing ions for the substrate and the range of appropriate environmental conditions.

- The reactions or conditions that control the $\mathrm{pH}$, redox conditions, and concentrations of complexing ligands (e.g., dissolved carbonate) for the derived aqueous solution must be assumed and technically defensible.

- The model must have a competent thermodynamic database that includes all the necessary aqueous species, redox reactions, minerals, and sorption substrates for the radionuclide of interest and for the other constituents of environmental importance. 
- The componition of water (in particular, $\mathrm{pH}, \mathrm{Eh}$, and alkalinity) contacting the radionuclidecortaining phases must be known.

- Moat geochemical modeling calculations will be limited to equilibrium conditions, because of the general abeence of kinetic rate values for the aqueous speciation, solubility, and/or sorption reactions involving the radionuclide of interest and other constituents of environmental importance.

The results of the modeling calculations provide the total concentrations of dissolved radionuclide and other elements included in initial aqueous solution; distributions (total concentrations and percentages) of dissolved radionuclide in each valence state included in the model [e.g, U(VI), U(V), and U(IV)]; diatributions (concentrations and percentages) of different uranium aqueous species [e.g., $\mathrm{UO}_{2}^{+}$, $\mathrm{UO}_{2}(\mathrm{OH})_{2}^{\circ}(\mathrm{aq}),\left(\mathrm{UO}_{2}\right)_{2} \mathrm{CO},(\mathrm{OH})_{3} \mathrm{j}$. Without information or assumptions regarding the rate of release of the radionuclide of interest from its source term, such as contaminated soils or a low-levelradioactive-waste (LLW) site, modeling calculations cannot provide an eatimate of the total mass (i.e., mass present in aqueous solution plus associated mineral phases) of a radionuclide in the environment under review. Because thermodynamic data typically do not have the resolution to distinguish among different isotopic forms of radionuclide-containing aqueous species or solids, seochemical modeling calculations do not provide any information on the distribution of the different radionuclide isotopes present in the aqueous or associated solid phases.

Geochemical reaction codes have been used to model a variety of problems associated with the behavior of uranium-containing phases in natural environments. A few examples of applications related to the geochemical behavior of uranium include the following:

- Prediction of the interaction of groundwater and compacted bentonite and the resulting effects on the maximum solubilities of diseolved uranium at a potential nuclear waste repository (Wanner, 1987)

- Eatimation of the effects of ionic strength, groundwater composition, and temperature on calculated solubilities of dissolved uranium (Lemire and Garisto, 1992)

- Prediction and analysis of water-rock interactions and aseociated uranium mineralization and mobility at natural analogue study sites for radioactive waste disposal systems [e.\&., Alligator River Analogue Project in the Northern Territory of Australia (Sverjensky, 1992); Pogos de Caldas Project in the State of Minas Gerais, Brazil (Nordstrom et al., 1990; Bruno et al., 1991; Cross et al., 1991) ${ }^{1}$; Palmottu Analogue Project in southern Finland (Ollila 1992)]

- Assessment of the geochemical behavior of radionuclides, such as uranium, at candidate sites for high-level radioactive waste repositories (Meyer et al., 1986; SAIC, 1985; Kelmers et al., 1984)

- Validation of thermodynamic and solubility data for uranium-containing aqueous systems (Krupka et al., 1983)

- Prediction and analysis of interactions of acidic uranium mill tailings solutions with sediments (Felmy et al., 1987; Peterson et al., 1983)

- Analysis and derivation of mechanistic constants for the adsorption of uranium (Turner et al, 1993)

- Performance assessment of a radionuclide source term and transport involving uranium (Muller et al., 1986)

- Analysis of the release of uranium from borosilicate glass incorporating nuclear waste (Grambow et al., 1991)

Geochemical modeling of maximum concentration limits provides valuable information for input to performance assessment analyses. These results may have some limitations. For example, even if the input parameters are technically defensible, the conceptual model may be too conservative and predict concentrations that are unrealistic. This situation might result from 1) selection of an ultra-conservative solubility or adsorption reaction constraint, 2) the absence of kinetic rate data for key reactions, or 3) inadequate thermodynamic and sorption constant data, including those for organic-complexing ligands and associated radionuclide reactions. Although the calculations could guide further site characterization and analysis, the conceptual model on which the modeling calculations are based would have to be reassessed relative to its degree of conservatism, and refined for the environment of interest.

However, the equilibrium codes are well established and simple to operate. With the appropriate user

1. It should be noted that the U. S. Nucienr Regulatory Comminaion wa a participant in the Allightor River Analogue and Pogos de Caldas projects. 
interface, essentially anyone with a chemical background can input the parameters needed to calculate the equilbrium assemblage of uranium species in a soil solution. Whereas the codes themselves are reasonably robust, the quality of their predictions is only as good as the quality of the input data. As shown in Table 4, failure to input the values for $\mathrm{PCO}_{2}$ (i.e., TIC) or $\mathrm{pH}$ can have a dramatic effect on the equilibrium concentrations predicted for a single phase. It is not enough just to identify the compounds present-to assess their environmental availability, some estimate of their solubility is needed, and this can come only from a geochemical code or an empirical determination. In the absence of empirical determinations, geochemical modeling is cesential.

Equilibrium geochemical codes are readily available and not difificult to use. However, they do not incorporate all the information that is needed (i.e., kinetics, transport) to determine environmental availability. Thus, the inferred approach to measuring environmental availability is not suitable for regulatory purposes. With further developments in phase identification procedures (c.g., automation of AEM analyses) and increased sophistication of geochemical codes (i.e., incorporation of kinetics and transport modules), this approach may become more practical.

\subsection{Summary of Existing Methods}

Because the environmental availability of uranium is related to the amount of aqueous uranium maintained in the soil solution over time, measurement techniques generally involve determination of both the total capacity of the soil to release uranium and the rate at which the uranium is released to maintain a certain concentration.

Two major approaches have been taken to estimate these parameters. The first involves direct contact of the soil with a solution that simulates in a short time period the soil environmental conditions expected over a much longer time interval. Included under this broad umbrella are 1) the simulated lung fluid procedure in which acrosol particles are equilibrated for different time periods at $37{ }^{\circ} \mathrm{C}$ in an aqueous solution having a composition similar to that in human lunge, 2) chemical extraction procedures using a variety of solutions and approaches, and 3) bionvailability studies in which uptake of uranium from soils or soil solutions by plants or organisms is measured. Sequential extraction procedures in which the soil is treated by successively harsher solutions have been developed for other environmentally related asessments and several standard methods designed for particular situations are available.
The second major approach for estimating environmental availability of uranium involves inferring the aqueous concentrations of uranium based on a determination of the solid phases in contact with the solution and geochemical modeling of the solubilities of these phases for the particular soil solution composition. Phase identification procedures include $\mathrm{X}$-ray absorption spectroscopy, analytical electron microscopy, and the laser-based spectroscopies. Geochemical modeling includes calculations of the thermodynamic equilibria of ions in aqueous solutions, the kinetics of solid dissolution and precipitation, and the transport of ions in soils and sediments. Of these, the equilibrium codes are well developed, whereas attempts to couple equilibrium calculations with kinetic and transport processes in soils are still in their infancy. These codes rely on large databases containing information about thermodynamically distinct phases, reaction stoichiometries, and other factors affecting reaction kinetics and transport.

We have summarized many of the features of the direct and inferred approaches in Table 7. In our assessments of these two major approaches we considered the technical factors (i.e., is the information obtained sufficient to establish a defensible estimate of environmental availability?) as well as the practical factors (i.e., how much time and money are required to obtain the information and how many facilities are available to perform the analyses?). Of the three direct approaches considered, two were eliminated for either technical or practical reasons. The simulated lung fluid test is clearly not specific or relevant to a soil environment and requires 60 days and numerous analyses to obtain the information. The bioavailability tests, while the most relevant of all the procedures, also require lengthy periods before the information could be obtained and have not been developed sufficiently to warrant their adoption for regulatory purposes. The phase identification procedures for the inferred measurement approach, while providing unique information, generally do not provide complete information (e.g., amounts of amorphous uranium or adsorbed uranium dispersed through the soil), are expensive, and because of their small specimen size require many specimens to be analyzed before a statistically valid estimate can be obtained. In turn, the geochemical modeling for the phases identified by these techniques is focused on thermodynamic equilibrium and not sufficiently developed to handle the kinetic aspects of the problem.

We conclude that an approach based on direct extraction of the soil offers the best combination of information quality, low cost, and rapid turnaround. None of the standard or research methods examined, 
Measurement of Environmental Availability

Table 7. Summa y of methods for measurement of environmental availability of uranium

\begin{tabular}{|c|c|c|c|c|c|c|c|c|}
\hline Method & $\begin{array}{l}\text { Number } \\
\text { of U } \\
\text { Det'n' }\end{array}$ & $\begin{array}{l}\text { Cost } \\
\text { per } \\
\text { Sample }\end{array}$ & $\begin{array}{l}\text { Set-up } \\
\text { Cost }\end{array}$ & $\begin{array}{l}\text { Turn- } \\
\text { around } \\
\text { Time }\end{array}$ & $\begin{array}{l}\text { Lab } \\
\text { Avall- } \\
\text { abllity }\end{array}$ & $\begin{array}{l}\text { Kinetic } \\
\text { Data }\end{array}$ & $\begin{array}{l}\text { Specinc } \\
\text { to U }\end{array}$ & Comments \\
\hline Direet $^{2}$ & & $-\$-$ & $-\$-$ & $--d--$ & & & & \\
\hline $\begin{array}{l}\text { Simulated Lung Fluid } \\
\text { and sediments }\end{array}$ & 29 & $15-20 \mathrm{~K}$ & $50-200 \mathrm{~K}^{3}$ & 70 & Medium & Yes & Yes & Not applicable to soils \\
\hline \multicolumn{9}{|l|}{ Batch Extractions } \\
\hline Single-Step & 6 & 675 & $50-200 \mathrm{~K}$ & 14 & High & No & Yes & \\
\hline Sequential & $12-36$ & 2,580 & $50-200 \mathrm{~K}$ & $16-19$ & High & Yes & Yes & \\
\hline \multicolumn{9}{|l|}{ Bioassays } \\
\hline Aquatic & $12-24 ?$ & 2,000 & $<50 \mathrm{~K}$ & $7-30$ & Medium & No & No & Labor intensive \\
\hline Terrestrial & $12-48 ?$ & $12 \mathrm{~K}$ & $<50 \mathrm{~K}$ & $30-60$ & Low & No & No & Labor intensive \\
\hline \multicolumn{9}{|l|}{ Inferred 4} \\
\hline \multicolumn{9}{|c|}{ X-ray Absorption Spectroscopy } \\
\hline Bulk & 3 & 100 & $<50 \mathrm{~K}^{5}$ & $7-30$ & Low & No & Yes & $\begin{array}{l}\text { Requires access to } \\
\text { synchrotron; cost is for } \\
\text { average oxidation state } \\
\text { data (i.e., XANES) only }\end{array}$ \\
\hline Microprobe & $>100 ?$ & $>2000 ?$ & $<50 K^{5}$ & $7-30$ & Low & No & Yes & $\begin{array}{l}\text { Requires numerous } \\
\text { analyses of single grains } \\
\text { for statistical certainty }\end{array}$ \\
\hline $\begin{array}{l}\text { Analytical Electron } \\
\text { Microscopy }\end{array}$ & $>100 ?$ & $>2000 ?$ & $200-900 \mathrm{~K}$ & $7-30$ & Medium & No & Yes & $\begin{array}{l}\text { Does not identify } \\
\text { amorphous } U \text { phases or } \\
\text { detect adsorbed } U\end{array}$ \\
\hline $\begin{array}{l}\text { Laser-based } \\
\text { Spectroscopy }\end{array}$ & $10-100$ & $<5000$ & $500 \mathrm{~K}$ & $7-30$ & Low & No & Yes & $\begin{array}{l}\text { Identifies functional } \\
\text { groups and oxidation } \\
\text { states }\end{array}$ \\
\hline
\end{tabular}

serumes triplicate determinations

requires correlation with other fectors to estimate environmental availability to organisms

3 depends on instruments used for total uranium determinations-\$50K for phosphorimetry and alpha/gamma spectrometry, $250 \mathrm{~K}$ for ICP-MS

requires geochemical modeling to obtain solubility estimates and then correlation with other factors for environmental availability estinates

soes not include cost of synchrotron facility

however, yield both the capacity and intensity data needed to make a sound assessment of environmental availability. In the following section, therefore, we identify the characteristics of an ideal rigorous extraction method as well as one that might be suitable for interim use pending the development of the rigorous approach. 


\section{Recommended Approaches}

Our brief review of standard procedures and research literature addressing questions about the determination of the forms and distributions of uranium in soils and sediments identified no widely accepted techniques for determining the "availability" of uranium in natural environments. Techniques are available and are routinely used for assessing the potential "leachability" of hazardous components associated with specific wastes, but the applicability of these methods to the remediation of soils contaminated with uranium wastes has not been tested.

Any procedure applicable to the NRC's needs must address a number of questions. First, the procedure should provide estimates of the "solubility classification" of the aggregate uranium forms in the soil being tested. That is, the results from the procedure should indicate if one or more forms of the uranium in the contaminated soil are readily soluble. Because equilibrium concentrations of uranium in soluble phases may vary by several orders of magnitude depending on environmental conditions, either "soluble" will have to be defined for specific conditions, or the definition will have to be sufficiently flexible to encompass a range of conditions. Second, the procedure should provide information regarding the relative masses of uranium that might be associated with each of the different solubility fractions of uranium. Finally, the procedure should indicate the relative reactivity of uranium in the soil. "Refractory" forms of uranium (as measured by the SLF tests, for example) will be reactive and accessible to the biosphere on time scales longer than those provided for by currently available tests. An ideal test procedure would allow one to distinguish truly refractory forms from those that are reactive but kinetically slow to solubilize.

For the long term, we recommend that the NRC investigate methods and procedures that supply both speciation and kinetic information about the uranium as a rational and rigorous basis for completing an environmental assessment. Much of this information could be obtained using a continuous leaching procedure.

Pending development of a technically rigorous procedure, we suggest an interim procedure that is largely derived from standard test methods and follows the three-level decision-tree approach. First, a bulk uranium analysis of the soil or sediment is completed. If the measured concentrations exceed specified limits, the analyst may begin a series of extractions that include the ASTM D 3974-81 acid-leach method, a modified EPA/SW 846 Method 1311 (TCLP) procedure, and an oxidizing extraction in a carbonate buffer. After the bulk uranium analysis, a decision to remediate, to take no action, or to perform the next level of testing would occur midway through in the procedure and, if further testing were selected, a final decision point would occur at the end of the testing. The decision to remediate or to take no action would depend on whether the analytical data fell above or below limits to "soluble" uranium concentrations established by an appropriate risk assessment model and would be site-specific.

This interim approach has several drawbacks. First, because of the conditions specified for the extractions, the approach will not provide useful kinetic information about the rates of release of uranium from the contaminated soil. Second, "action levels," the uranium concentrations that determine which branch of the decision tree to follow, are not defined. These values must be specified in conjunction with experts in health and safety and with consideration of the site-specific remediation goals.

Applicability of either the rigorous or the interim procedure to setting remediation action levels at contaminated sites must be verified by correlation studies. The procedures recommended here are those that we believe have the highest probability for providing useful guidance in the remediation of contaminated sites. However, full testing of the procedures and a comparison with a wider selection of possible approaches prior to implementation is recommended.

\subsection{Rigorous Approach Using Flow- Cell Methodology}

The interim procedure does not provide critical pieces of information that would be useful for risk assessment. For the long term, we recommend that methods and procedures that supply both speciation and kinetic information about uranium be developed and that these methods be correlated with the expected dynamics of uranium in contaminated soils and sediments. This type of information would provide a more rational and rigorous basis for environmental remediation decisions.

The rigorous approach follows the decision-tree concept described in Section 1.2.3 but uses a continuous flow-cell procedure to obtain both the solubility data of Step 2 and the kinetic data of Step 3 (Fig. 2). Applicability of the procedure to setting remediation action levels at contaminated sites must still be verified by correlation studies. The procedures outlined here are those that have the highest 
Recommended Approaches

Stop 1: Bulk Uranium

Analysis

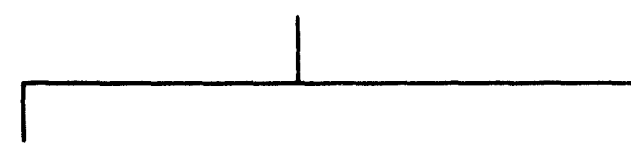

$U_{\mathrm{r}}<\mathrm{AB} \mathrm{pCI} \mathrm{g}^{-1}$

$U_{1}>\mathrm{AB} \mathrm{pCi} \mathrm{g}^{-1}$

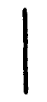

No Action

Required

Step 2: Flow-Cell Procedure

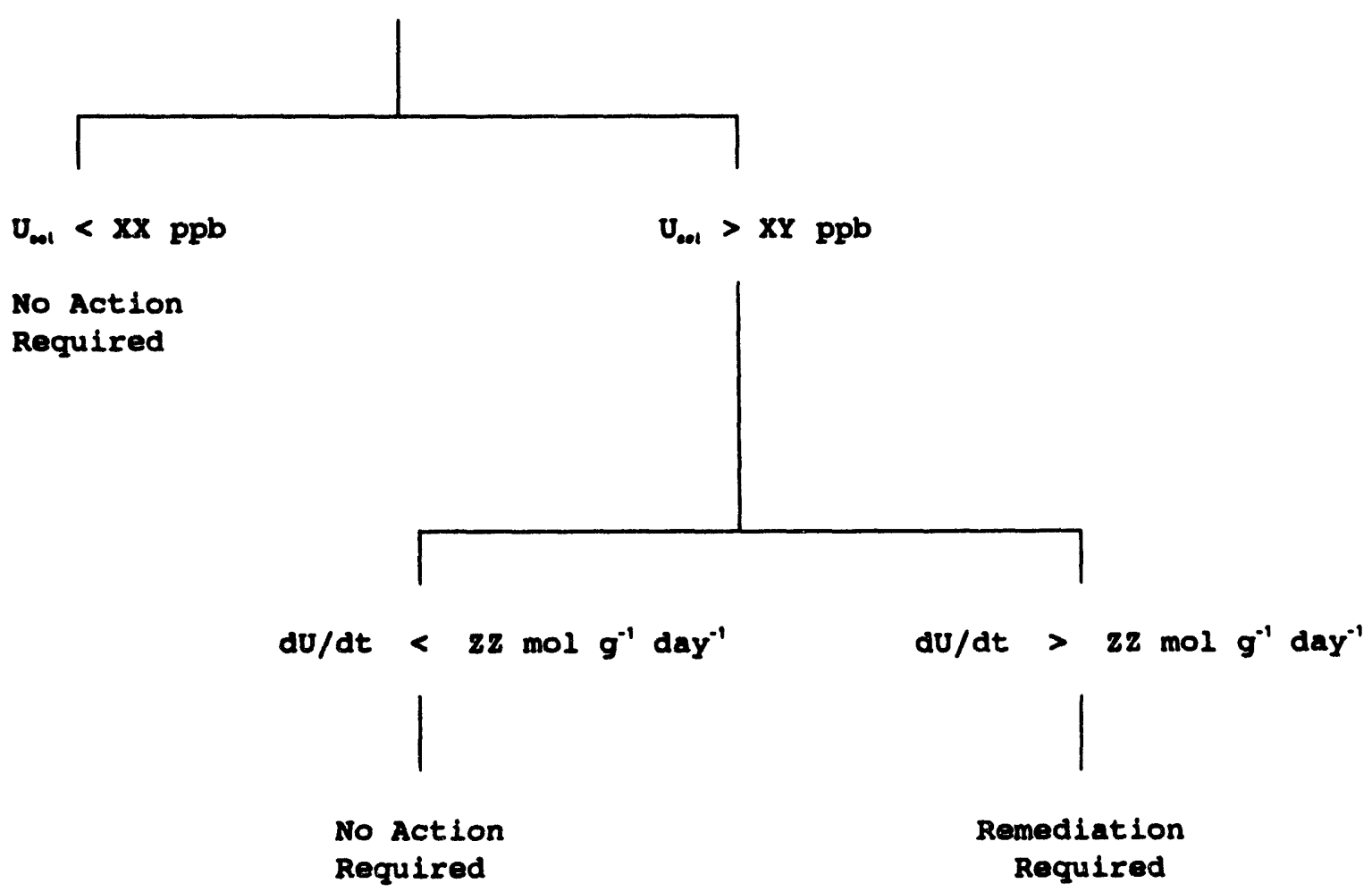

Figure 2. Decision Tree for the Rigorous Approach for Assessing Environmental Availability of Uranium in Solls and Sediments 
probability for providing useful guidance in the remediation of contaminated sites. However, a full testing of the procedures and a comparison with a wider selection of possible approaches is recommended prior to implementation.

\subsubsection{Background}

The flow-cell measurements are based on methodologies that have evolved over the last decade to measure the rates of retction of minerals under well-defined conditions. Various flow-cell apparatus have been designed and used in kinetic studies of mineral dissolution (e.g., Wollast and Chou, 1985; Holdren and Speyer, 1985; Knauss and Wolery, 1986; Amonette, 1988; Casey et al., 1989). Conceptually, the flow-cell measurements provide a type of information that is closer to that provided by the SLF measurements than it is to any of the other procedures reviewed. The method yields masses of uranium released to solution under given environmental conditions, and determination of the different solubility classes is straightforward. The equipment allows the analyst to regulate the composition of both the extraction fluid and the gas phase in equilibrium with the solution, allowing for a more realistic simulation of leaching processes in soils.

The flow-cell reactor approach has two disadvantages. First, this type of equipment has not been used in regulatory applications in the past, to the best of our knowledge. Consequently, the hardware and analytical expertise required to use the method are not generally available, although they are easily acquired. Second, the flow-cell approach tends to generate a large number of samples requiring analysis, thus creating a fairly heavy analytical burden for the laboratory. However, recent developments in automated on-line analysis techniques should lessen this load to a manageable level. Despite these limitations, the flowcell technology has attained a degree of maturity that makes it potentially suitable for regulatory applications.

\subsubsection{Assumptions}

Certain assumptions are made in the outlining of this procedure:

1) Uranium is the contaminant of primary concern;

2) Uranium in the soil/sediment exists in watersoluble, nonvolatile forms;

3) The samples being tested are not contaminated with non-aqueous phase liquids (NAPLs); and
4) The saturated conditions in the flow cell adequately mimic conditions in the soil, even though soils are typically unsaturated.

\subsubsection{Specialized Equipment}

Implementation of a flow-cell measurement of uranium solubility requires certain equipment including

1) A reciprocating syringe pump to inject and simultaneously withdraw controlled volumes of leaching solution at a controlled rate;

2) Flow cells capable of accomodating soils having a wide range of particle sizes (these are not commercially available to the best of our knowledge, but several designs that can be readily constructed have been described in the literature);

3) Water bath with temperature controller to maintain extractions at a constant temperature.

\subsubsection{Procedure Outline}

Because this is neither an established procedure, nor a modification of an established procedure, we describe the general procedure with limited operational details:

1) Prime all solution-transfer lines and saturate the filter in the bottom of the reaction chamber with the initial extraction solution.

2) Add a known mass of soil/sediment to the reaction chamber. In general, the mass of the soil should be equal to $10 \%$ of the volume of solution expected to be resident in the chamber under operating conditions.

3) Set the flow rates on the pump to maintain a solution-residence time in the reaction chamber of between 8 and 24 hours, depending on the expected reactivity of the sample. Higher flow rates should be used for the more reactive samples.

4) Fill the reaction chamber to its operational level with the initial leaching solution (probably a pH 5.0 $\mathrm{HCl}$ solution with an ionic strength of about 0.005 developed from $\mathrm{CaCl}_{2}$; this is a mild, nonoxidizing, non-complexing acid selected to mimic soil solutions). Initiate stirring with a paddle stirrer, and maintain the suspension for a period equal to the solution-residence time.

5) Initiate solution pumping. Solution is added and withdrawn from the reaction chamber simultaneously and at equal rates. 
6) Collect effluent in suitably sized aliquots, usually ranging from 0.5 chamber volumes to 2.0 chamber volumes. Measure the pH and total dissolveduranium concentration of each fraction collected (an automated on-line procedure for these analyses could be readily developed).

7) Continue operation of the reaction chamber using the initial leaching solution until the rate of uranium release has become constant (usually at a very low level). Drain the chamber.

8) Repeat steps 1), 4), 5), 6), and 7) using a $0.1 \mathrm{M}$ $\mathrm{HCl}$ solution.

9) Preserve the effluent from the acid leaching of the sample in $4 \mathrm{M} \mathrm{HCl}$ and analyze the solutions for $U(I V) / U(V I)$ ratios using ion-exchange methodologies (see Appendix B).

This procedure could present laboratories with extended measurement periods and numerous analyses to be conducted for each sample. Leaching times can be shortened, however, by increasing the flow rates, the cell temperature, and/or the strength of the leaching solutions. Likewise, the analytical burden would be minimal if an automated on-line set-up is used. This procedure has the potential to yield significantly more detailed and rigorously defined information about the forms and reactivities of uranium species in a soil in a short time than any of the other procedures we have investigated. However, some development work is needed to define the practical working conditions before the procedure can be implemented.

\subsubsection{Development Needs}

Previous efforts employing flow-cell reactors have had primarily research applications. This approach for measuring uranium solubility offers regulators a vehicle for obtaining detailed reactivity estimates for a material undergoing remediation, and it should also provide information about how the contaminant might leach under a broad range of environmental conditions (e.g, various precipitation regimes, hydrologic regimes). However, it does not yet have an established "track record" from which to judge its performance.

We recommend development of the flow-cell methodology for the purpose of assessing the environmental availability of uranium in soils, along with a concerted effort to correlate the flow-cell data with long-term leaching studies carried out with a variety of soils under a range of realistic

environmental conditions. At the same time, one or more batch leaching procedures [e.g., a modified EPA/SW 846 Method 1311 (TCLP)] should also be evaluated and correlated with realistic field soil data. Based on a technical assessment of how well the flowcell and batch methods correlate with field data, and a practical assessment of the relative costs required for a certain degree of correlation, an informed and technically defensible decision regarding the best method for determining environmental availability of uranium can be made. Clearly a fast, economical, and rigorous procedure must be developed if sound remediation decisions are to be made.

\subsection{Interim Procedure Using Standard Methods}

\subsubsection{Background}

The interim procedure we recommend (Fig. 3) combines standard and nonstandard methods to allow some flexibility in setting regulatory limits. The procedure is structured to offer a staged response to the problem in the hopes of eliminating unnecessary analyses. Thus, the first stage involves a determination of the total uranium (TU) present in the soil. The second stage involves a determination of the total environmentally available uranium (TAU) in the soil. The third stage involves a more intensive classification of the environmentally available uranium into reactivity subclasses [i.e., readily available (RAU), slowly available (SAU), and very slowly avallable (VSAU) uranium, or two subclasses on the basis of oxidation state). At the completion of the analyses for the first or second stages, a decision to remediate, to take no action, or to go on to the next stage of testing can be made using criteria based on appropriate risk-assessment models and site-specific information. If the third stage of testing is necessary, then a final decision to remediate will be made based on the analytical results, the appropriate riskassessment models, and other site information.

Specifically, the initial step in the procedure involves a determination of TU as part of a screening test. If the levels of TU are less than an action level set by risk assessment methods (i.e., XX in Fig. 3), no further testing is needed. Higher concentrations of TU may require additional testing or, at the discretion of the contractor, a decision to remediate may be made. The second step in the procedure, which is drawn from the ASTM Method D 3974-81, is an overnight extraction of the sample in $0.6 \mathrm{M} \mathrm{HCl}$. This procedure is intended to provide the analyst with an estimate of TAU in the sample. If this quantity of uranium is low (as determined by appropriate risk assessment methods), no further action would be 
Recommended Approaches

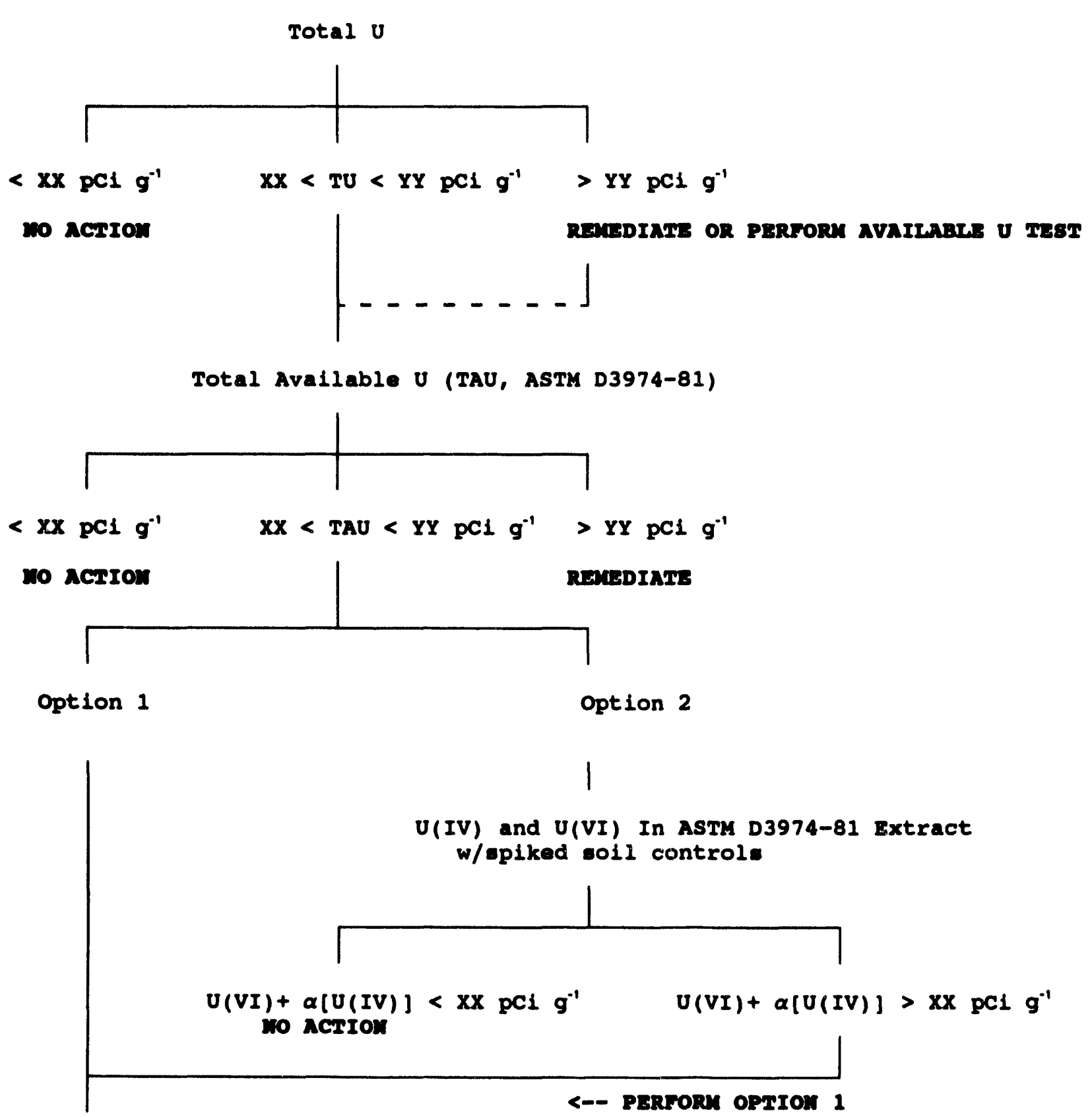

Readily Available U (RAU, Modified TCLP, 5 times epH 2.88)

slowly Available U (SAU, Oxidizing Extraction in $\mathrm{CO}_{3}$ Buffer, pH 8.3)

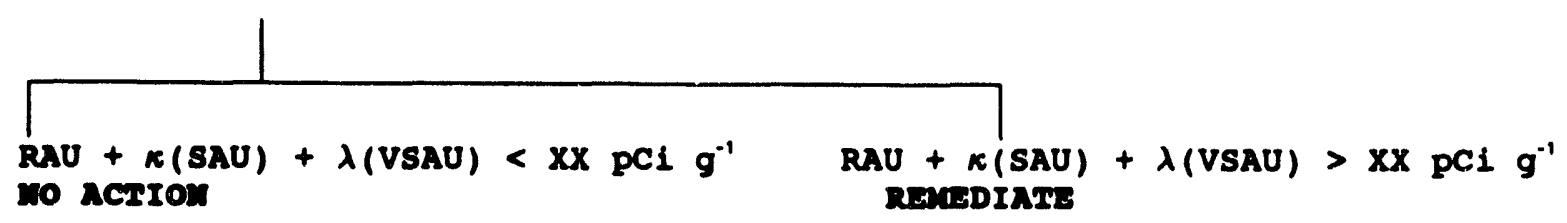

Figure 3. Draft Interim-Procedure Decision Tree for Assessing Environmental Avallability of Uranium in Solls 
required. If TAU exceeds an upper action level set by risk assessment methods (i.e., $Y Y$ in Fig. 3), remediation is required. At intermediate levels, however, the analyst would select one of two options in the third stage of the procedure for further testing.

Option 1 involves sequential measurements of RAU and SAU on the same sample and the estimation of VSAU by the difference between TAU and the sum of RAU and SAU, i.e.,

$$
\text { VSAU }=\text { TAU }-(R A U+S A U) \text {. }
$$

Option 2 involves determination of the relative amounts of uranium present as U(IV) or U(VI) in the extract obtained in the determination of TAU. If the sum of the $U(V I)$ and a fraction of the $U(I V)$ present (i.e., $\alpha$ in Fig. 3 ) is less than a lower action level prescribed by appropriate risk assessment models, then no action is required. Otherwise, the full test described in Option 1 must be performed.

The analytical tests performed in Option 1 include EPA/SW 846 Method 1311 (modified to consist of five sequential batch extractions with $0.1 \mathrm{M}$ acetic acid) for estimation of RAU, and an oxidizing extraction in a carbonate buffer for estimation of SAU. The RAU procedure is designed to estimate the exchangeable, carbonate-bound, and part of the organically complexed and iron- and aluminum-oxidebound uranium fractions in soil. The SAU procedure focuses on the U(IV) species present plus the remainder of the organically bound uranium. The uranium in the soil that is not removed by these two treatments (i.e., the VSAU) is present in iron and aluminum oxides and oxyhydroxides, in phosphates, or as part of silicate minerals and is not expected to be of much concern from an environmental viewpoint.

As originally designed, EPA/SW 846 Method 1311, known as the Toxicity Characteristic Leaching Procedure or TCLP, determines the mobility of organic and inorganic contaminants in liquid, solid, and multiphase wastes buried in a municipal landfill. The method, thus, involves an organic-acid-rich extraction liquor (acetic acid) that is harsher than would be expected in most soils. If the acidneutralizing capacity of the waste is low, the material is leached using a $0.1 \mathrm{M}$ sodium acetate solution with an initial $\mathrm{pH}$ of about 4.9. If the acid-neutralizing capacity is high (as defined by the method), $0.1 \mathrm{M}$ acetic acid with an initial pH of about 2.9 is used as the extraction liquor. All extractions are conducted in suspensions having a 20:1 solution:soil ratio. Although we are reasonably confident that our modified procedure involving successive extractions with the 0.1 M (pH 2.9) acetic acid solution will measure all exchangeable and carbonate-bound uranium, it is not clear what proportions of the organically and oxidebound uranium fractions in soils will be measured. We expect the modified method to overestimate the RAU fraction in soils, but this expectation must be confirmed by careful experimentation and correlation with long-term uranium leaching studies under realistic soil environmental conditions.

Detailed draft outlines of the proposed interim procedure and of proposed quality control procedures are given in Appendices $\mathbf{C}$ and $\mathbf{D}$. The proposed interim procedure has not been tested in the laboratory nor have the results of the procedure been correlated with actual release of uranium into the environment by soils. Both of these steps are necessary before it can be used to make regulatory decisions.

\subsubsection{Assumptions}

In developing the interim procedure, a number of assumptions have been made. These assumptions have not been evaluated in the laboratory or on field samples and may require additional refinement.

The proposed interim procedure assumes

1) uranium is the primary contaminant of concern;

2) uranium is present only in non-volatile forms [e.g., $\mathrm{UF}_{\sigma}(\mathrm{g})$ is not a contaminant of concern];

3) samples being tested are soils or sediments, and these samples are not contaminated with NAPLs;

4) soils and sediments being tested are primarily mineral soils (i.e., total organic-carbon content should not exceed $10 \mathrm{wt} \%$ of the air-dried soil);

5) the risk associated with the uranium in soils is primarily due to those forms that can dissolve in the soil solution.

\subsubsection{Modifications}

For the determination of TAU, we recommend that ASTM Method D3974-81 (Digestion Practice B) be employed. For the determination of RAU, we recommend two minor modifications to the EPA/SW 846 Method 1311 (TCLP):

1) Five sequential extractions by the $0.1 \mathrm{M}(\mathrm{pH}$ 2.9) acetic acid solution for $18 \pm 2 \mathrm{~h}$ at room 
temperature (ca. $22^{\circ} \mathrm{C}$ ). The five extracts are combined and the cumulative amount of uranium released is measured on the combined extract. If kinetic information is desired, separate analyses of each extract can be made and summed to obtain the cumulative amount of uranium released;

2) Smaller sample masses and solution volumes are recommended for the procedure outlined here than are provided for in EPA/SW 846 Method 1311. These recommendations are made to contribute toward the goal of waste minimization as part of laboratory practices. If the analyst is concerned that the sample masses provided for are insufficient to allow representative sampling of the soil or sediment, the procedure should be modified to allow for larger sample sizes.

\subsubsection{Integration with Risk Assessment Models}

For use in some risk assessment models and for regulatory purposes, the analytical results of the proposed interim procedure may have to be converted to amounts of "soluble" and "insoluble" uranium. In order to do this, however, data from the first stage and either the second or third stage of the procedure must be available. If data from the first two stages are available, the value for TAU can be used for "soluble" uranium, that is,

$$
\text { "Soluble U" = TAU }
$$

If data from the first and third stages are used, then two options are possible. For Option 1,

$$
\text { "Soluble } U^{\prime \prime}=\mathrm{RAU}+\alpha(\mathrm{SAU})+\lambda(\mathrm{VSAU}) \text {, }
$$

where $\alpha$ and $\lambda$ are scaling factors that account for the lower probability of the uranium in these two fractions contributing to the concentration of uranium in solution. Values for $x$ and $\lambda$ would most likely be site-specific and certainly between 0 and 1 .
For Option 2,

$$
\text { "Soluble } U^{n}=U(V I)+\alpha[U(I V)],
$$

where $\alpha$ is a scaling factor similar to $x$ and $\lambda$ and falling in the same range. In all instances,

$$
\text { "Insoluble } \mathbf{U}^{n}=\mathbf{T U} \text { - "Soluble } \mathbf{U}^{n} \text {. }
$$

\subsubsection{Development Needs}

The proposed interim procedure was developed .. use existing standard methods to as great a degree as possible. The procedure does not take advantage of some of the pecularities of uranium geochemistry. Prior to implementation of the method, several aspects of the behavior of uranium in natural soil and sediments should be investigated so that the results from the procedures might be better interpreted.

Specific recommendations for additional modifications or studies are as follows:

1) Assess the leachability of uranyl phosphate phases during the first step (acid digestion) of the interim procedure. Uranium weathering products tend to partition into soil phosphate phases such as saleeite. These phases tend to be relatively refractory, even though they are a uranyl [U(VI)] species. An investigation into the leachability of these forms is warranted to better assess soil uranium dynamics and the risks associated with remediating (or not remediating) uranium bound in these forms.

2) Assess the rates of uranium dissolution under relevant environmental ccáditions and correlate these results with both physical and chemical information pertinent to the soil environment. A potentially major shortcoming of the interim procedure is that it does not provide mechanisms for assessing how quickly uranium might be released from soils under realistic environmental conditions. 


\section{Analytical Services}

\subsection{Background}

One task in this project involved assembling a representative list of laboratories capable of conducting environmental availability analyses for uranium in soils and sediments. We contacted about 170 private and government laboratories and received responses from 32. Six of these 32 laboratories did not have a current or potential capability in uranium analysis and are therefore not included in the listing. The private laboratories contacted were identified as having environmental-analysis capabilities in the Directory of Testing Labonatories, 1992 Edition (American Society for Testing and Materials, 1991).

We focussed on wet-chemical methods and obtained information about the laboratories' capabilities to

1) perform several standard methods [ASTM D397481, ASTM D4793-93, EPA/SW846-3050A, EPA/SW846-1311 (TCLP), and NUREG/CR1428];

2) receive radioactive samples with more than 200 $\mathrm{nCi}$ radioactivity $\mathbf{~}^{-1}$;

3) receive samples classified as hazardous waste (40 CFR); and

4) perform the analyses for TAU, RAU, SAU, and oxidation states of uranium as outlined in Appendices A and B.

We also obtained information about each laboratory's analytical instrumentation used for uranium determinations and their estimates of typical detection limits for liquid and solid specimens.

Lastly, we obtained a pooled estimate of the laboratories' cost, batch size, turnaround time, and weekly sample output for the TAU, RAU, SAU, and oxidation-state procedures described in Appendices A and $B$.

\subsection{Cost, Batch Size, and Turnaround Time Estimates}

Of the 26 laboratories listed, 23 were privately owned and 3 were government facilities. The response for a particular procedure required that the laboratory be currently or potentially capable of performing the procedure. Although we expected to find a cost difference between these two groups (i.e., private and government), no clear trend could be distinguished and the data reported are pooled for all the laboratories contacted.

The procedures for TAU and SAU were single-step extraction methods, and the laboratories gave similar estimates for them. The mean costs were \$200-225 per sample, with a two-week turnaround time and average weekly output of about 120 samples. About $80 \%$ of the laboratories gave a cost reduction on batches of samples. The cost reduction per sample averaged 13-14\% (\$25-30) for batch sizes of 13-15 samples.

The procedures for RAU and uranium oxidation states involved multiple steps, and this was reflected in higher costs, longer turnaround times, and smaller weekly sample output. These two procedures averaged about $\$ 410-\$ 430$ per sample, with 16 - to 19 day turnaround times and weekly outputs of 50-60 samples. The batch-cost-reduction and batch-size results were similar to those for the TAU and SAU procedures.

\subsection{Laboratory-Specific Information}

Laboratory names, addresses, contact people, methods capabilities, uranium analytical instrumentation, uranium liquid and solid detection limits, and sampletype information are listed below. The laboratories are listed in order of their ZIP codes (going from east to west in the United States, i.e., from 00000 to 99999) to make it easier to find a laboratory by geographical location. Categories for which no response was given by the laboratory are shown by "NR." 
Ledoux and Co.

359 Alfred Avenue

Teaneck, NJ 07666

Contact: Paul Blumberg

Phone: 201/837-7160

FAX: 201/837-1235

Standard Methods: D3974-81, D4793-93, 3050A, 1311

Radianctive Samples $>200 \mathrm{nCl} / \mathrm{g}$ Yes

Hazardous Waste Samples (40 CFR): NR

Analytical Instrumentation: UV-Vis, Fluorimeter

Lquild Detection Lmit: $100 / 8 \mathrm{~L}^{-1}$

Solld Detection Limit: $100 \mathrm{mg} \mathrm{kg}$

Current Capabilities: TAU, RAU, SAU, Redox

Potential Capabilities: TAU, RAU, SAU, Redox

Industrial \& Environmental Analysts, Inc.

P. O. Box 12864

Research Triangle Park, NC 27709

Contact: Donald J. Goeivel

Phone: 919/677-0090

FAX: $\quad 919 / 677-0427$

Standard Methods: NR

Radioactive Samples $>200 \mathrm{nCl} / \mathrm{g}:$ No

Hazardous Waste Samples (40 CFR): Yes

Analytical Instrumentation: ICP-MS, Alpha

Lquild Detection Limit: $0.50 \mathrm{pg} \mathrm{\textrm {L } ^ { - 1 }}$

Solld Detection Limit: $\mathrm{mg} \mathrm{kg}^{-\mathrm{I}}$

Current Capabilities: NR

Potential Capabilities: TAU, RAU, SAU, Redox

Analytical Services, Inc.

390 Trabert Avenue, N.W.

Atlanta, GA 30309

Contact: Dr. Roy-Keith Smith

Phone: 404/892-8144

FAX: $\quad 404 / 892-2740$

Standard Methods: 3050A, 1311

Radioactive Samples $>200 \mathrm{nCl} / \mathrm{g}$ : No

Hazardous Waste Samples (40 CFR): Yes

Analytical Instrumentation: FAAS, GFAAS

Lquid Detection Limit: 20,000 ig $L^{-1}$

Solid Detection Limit: $100 \mathrm{mg} \mathrm{kg}$

Current Capabilities: TAU, RAU, SAU

Potential Capabilities: TAU, RAU, SAU, Redox
Environmental Science and Engineering, Inc.

Attn: Analytical Services

P. O. Box 1703

Gainesville, FL 32602-1703

Contact: Kenneth U. Erondu

Phone: 904/333-1609

FAX: $\quad 904 / 333-6622$

Standard Methods: D3974-81, D4793-93, 3050A, 1311

Radioactive Samples $>200 \mathrm{nCl} / \mathrm{g}:$ No

Hazardous Waste Samples (40 CFR): Yes

Analytical Instrumentation: ICP-MS

Liquid Detection Limit: $0.10 \mathrm{~kg} \mathrm{\textrm {L } ^ { - 1 }}$

Solid Detection Limit: $0.10 \mathrm{mg} \mathrm{kg}^{-1}$

Current Capabilities: TAU, RAU, SAU, Redox

Potential Capabilities: TAU, RAU, SAU, Redox

Center For Applied Engineering, Inc.

10301 9th Street N.

St. Petersburg, FL 33716

Contact: Chris Given

Phone: 813/578-4331

FAX: $\quad 813 / 576-0318$

Standard Methods: 3050A, 1311

Radioactive Samples $>200 \mathrm{nCl} / \mathrm{g}$ : Maybe

Hazardous Waste Samples (40 CFR): Yes

Analytical Instrumentation: ICP-MS

Liquid Detection Limit: $0.010 \mathrm{rg} \mathrm{\textrm {L } ^ { - 1 }}$

Solid Detection Lmit: $0.030 \mathrm{mg} \mathrm{kg}$

Current Capabilities: NR

Potential Capabilities: TAU, RAU, SAU, Redox

Metallurgical Services Co.

4102 Bishop Lane

Louisville, KY 40218

Contact: David Brown

Phone: 502/968-5000

FAX: $\quad 502 / 964-5000$

Standard Methods: NR

Radloactive Samples >200 nCi/g: No

Hazardous Waste Samples (40 CFR): No

Analytical Instrumentation: ICP-MS, XRF

Lquid Detection Limit: NR

Solid Detection Limit: NR

Current Capabilities: NR

Potential Capabilities: TAU, RAU, SAU, Redox 
Bri-Mar International Laboratories, Inc.

Suite 101-105

2901 Finley Road

Downers Grove, IL 60515

Contact: Mark Boese

Phone: 708/932-1166

FAX: NR

Standard Methods: NR

Radioactive Samples $>200 \mathrm{nCl} / \mathrm{F}$ No

Harardous Waste Samples (40 CFR): No

Analytical Instrumentation: NR

Uquid Detection Limit: NR

Solld Detection Limit: NR

Curreat Capabillities: SAU

Potenthal Capabillities: TAU, RAU, SAU, Redox

PDC Laboratories, Inc.

4349 Southport Road

P. O. Box 9071

Peoria, IL 61612-9071

Coutact: John LaPayne

Phone: 309/676-4893

FAX: $309 / 672-2726$

Standard Methods: D3974-81, D4793-93, 3050A, 1311

Radioactive Samples $>200 \mathrm{nCl} / \mathrm{g}$ : Maybe

Hazardous Waste Samples (40 CFR): Yes

Analytical Instrumentation: ICP-AES, UV-Vis

Lquid Detection Limit: $1 \mathrm{~g} \mathrm{~L}^{-1}$

Solid Detection Limit: $\mathbf{m g ~} \mathbf{~ g g}^{-1}$

Current Capabilities: NR

Potential Capabilities: TAU, SAU, Redox

IT Analytical Services

13715 Rider Trail N

Earth City, MO 63045

Contact: Donald Dihel

Phone: 314/298-8566

FAX: $\quad 314 / 298-8757$

Standard Methods: D4793-93, 3050A, 1311

Radioactive Samples >200 $\mathrm{nCi} / \mathrm{g}$. Yes

Hazardous Waste Samples (40 CFR): Yes

Analytical Instrumentation: Laser Phosphorimeter,

Alpha

Uquid Detection Limit: $1.0 \mathrm{Ng} \mathrm{\textrm {L } ^ { - 1 }}$

Solid Detection Limit: $0.01 \mathrm{mg} \mathrm{kg}^{-1}$

Current Capabilities: TAU, RAU, SAU, Redox

Potential Capabilities: TAU, RAU, SAU, Redox
A \& L Mid West Laboratories

13611 B Street

Omaha, NE 68144

Contact: Dr. Jerome J. King

Phone: 402/334-7770

FAX: $\quad 402 / 334-9121$

Standard Methods: 3050A, 1311

Radioactive Samples $>200 \mathrm{nCl} / \mathrm{g}$ NR

Hazardous Waste Samples (40 CFR): Yes

Analytical Instrumentation: ICP-AES

Lquid Detection Limit: $100 / \mathrm{g} \mathrm{L}^{-1}$

Solid Detection Limit: $10 \mathrm{mg} \mathrm{kg}$

Current Capabillties: TAU, RAU, SAU

Potential Capabilities: TAU, RAU, SAU

USPCI Analytical Services

4322 S 49th West Avenue

Tulsa, OK 74107-6121

Contact: Gerald Holmes

Phone: 918/446-1162

FAX: 918/445-0945

Standard Methods: D3974-81, D4793-93, 3050A, 1311

Radioactive Samples $>200 \mathrm{nCl} / \mathrm{g}$. No

Hazardous Waste Samples (40 CFR): Yes

Analytical Instrumentation: ICP-AES

Liquid Detection Limit: 500 pg L $\mathrm{L}^{-1}$

Solld Detection Limit: $50 \mathrm{mg} \mathrm{kg}$

Current Capabilities: TAU, RAU, SAU

Potential Capabilities: TAU, RAU, SAU, Redox

Accu-Labs Research, Inc.

4663 Table Mountain Drive

Golden, CO 80403-1650

Contact: Bud Summers

Phone: 303/277-9514

FAX: $\quad 303 / 277-9512$

Standard Methods: 3050A, 1311

Radioactive Samples >200 nCl/g: Yes

Hazardous Waste Samples (40 CFR): Yes

Analytical Instrumentation: Laser Phosphorimeter, Alpha, Fluorimeter

Lquid Detection Uimit: $0.10 / \mathrm{B} \mathrm{L}^{-1}$

Solid Detection Limit: $0.01 \mathrm{mg} \mathrm{kg}$

Current Capabillties: RAU

Potential Capabilities: TAU, RAU, SAU, Redox 
Hazen Research, Inc.

4601 Indiana Street

Golden, CO 80403

Contact: NR

Phome: NR

FAX: NR

Standard Methoda: D3974-81, 3050A, 1311

Radloactive Samples >200 „Cl/E: Yes

Hasardous Waste Samples (40 CFR): Yes

Anslytical Instrumentation: Fluorimeter

Uquild Detection Limiti 200 is $\mathrm{L}^{-1}$

Solld Detection Lmit: $1.0 \mathrm{mg} \mathrm{kg}$

Current Capabllities: TAU, RAU

Potential Capabilities: TAU, RAU

Pace Inc.

5930 Mclntyre St.

Golden, CO 80403

Contact: Bill Sandberg

Phome: 303/278-3400

FAX: $303 / 278-2121$

Standard Methoda: 1311

Radloastive Samples $>200 \mathrm{nCl} / \mathrm{s}$ No

Harardous Waste Samples (40 CFR): Yes

Analytical Instrumentation: Laser Phosphorimeter,

Alpha

Uquild Detection Umit: $1.0 \mathrm{mg} \mathrm{L}^{-1}$

Solld Detection Limit: $1.0 \mathrm{mg} \mathrm{kg}$

Current Capabilitiea: NR

Potential Capabilities: TAU, RAU, SAU, Redox

DataChem Laboratories, Inc.

$960 \mathrm{~W}$. LeVoy Drive

Salt Lake City, UT 84123

Contact: Lee Harris

Phone: 801/266-7700

FAX: 801/268-9992

Standard Methods: D3974-81, 3050A, 1311

Radloactive Samples $>200 \mathrm{nCl} / \mathrm{g}$ : Yes

Hazardous Waste Samples (40 CFR): Yes

Analytical Instrumentation: Laser Phosphorimeter

Uquid Detection Limit: $0.10 \mathrm{~kg} \mathrm{~L}^{-1}$

Solid Detection Limit: $0.01 \mathrm{mg} \mathrm{kg}^{-1}$

Current Capabilities: TAU, RA.U, SAU, Redox

Potential Capabilities: TAU, RAU, SAU, Redox
Western Technologies, Inc.

3737 E. Broadway

P. O. Box 21387

Phoenix, AZ 85036

Contact: M. English

Phone: 602/437-1080

FAX: 602/437-8706

Standard Methoda: 3050A, 1311

Radloactive Samples $>200 \mathrm{nCl} / \mathrm{z}$. No

Hazardous Waste Samples (40 CFR): Yes

Amalytical Instrumentation: ICP-AES

Uquild Detection Umits is $\mathrm{L}^{-1}$

Solld Detection Umit: $\mathrm{mg} \mathrm{kg}^{-1}$

Current Capabilitiea: TAU, RAU

Potential Capabillitea: TAU, RAU, SAU, Redox

Sandia National Laboratories

P. O. Box 5800

Albuquerque, NM 87185-0975

Contact: James L. Krumhansl

Phone: 505/844-9093

FAX: 505/8447354

Standard Methods: NR

Radloactive Samples $>200 \mathrm{nCl} / \mathrm{E}$ Yes

Hazardous Waste Samples (40 CFR): No

Analytical Instrumentation: Neutron Activation, DCP

Liquid Detection Umit: $10,000 / \mathrm{KL}^{-1}$

Solld Detection Umit: $1.0 \mathrm{mg} \mathrm{kg}^{-1}$

Current Capablilites: NR

Potential Capabilities: TAU, RAU, SAU, Redox

C. E. P. Laboratories

1925 Rosina

Santa Fe, NM 87501

Contact: James J. Mueller

Phone: 505/982-9841

FAX: $\quad 505 / 982-9289$

Standard Methods: D3974-81, D4793-93, 3050A, 1311, CR-1428

Radioactive Samples $>200 \mathrm{nCl} / \mathrm{g}:$ Yes

Hazardous Waste Samples (40 CFR): Yes

Analytical Instrumentation: Laser Phosphorimeter, ICP-AES, Alpha, UV-Vis, Radiometric

Uquid Detection Limit: $0.10 \mu \mathrm{g} \mathrm{L}$

Solid Detection Limit: $0.10 \mathrm{mg} \mathrm{kg}^{-1}$

Current Capablities: TAU, RAU, SAU, Redox

Potential Capabilities: TAU, RAU, SAU, Redox 
U. S. Environmental Protection Agency

Radiological Analyais Branch

P. O. Box 93478

Los Veom, NV 89193-3478

Contact Robert Holloway

Pleses 702/798-2325

FAX: NR

Standard Methodur NR

Radleaction 8amples $>200 \mathrm{aCl} / \mathrm{e}$ No

Hamenton Wate Samplew (40 CFR): No

Anshyteol inotorumeatadion: Alpha

Uefld Devection Umite $18 \mathrm{~L}^{-1}$

Solld Dotaction Unalte mg kg ${ }^{-1}$

Curreat Capabilltien: NR

Potential Capabsllitieas NR

Weat Conat Amalytical Service, Inc.

9840 Alburtis Avenue

Santa Fo Springe, CA 90670

Contect: D. J. Northington

Fromer 310/948-2025

FAX: 310/948-5850

Standard Methoda: 3050A, 1311

Badloactive Samples $>200 \mathrm{nCl} / \mathrm{E}$. Yes

Haxardoes Warte Samples (40 CFR): Yes

Analytical Instrumentation: ICP-MS

Uquild Detection Limitt: $0.01 \mathrm{sB} \mathrm{L}^{-1}$

Solid Detection Limit: $0.003 \mathrm{mg} \mathrm{kg}^{-1}$

Curreat Capabilltica: TAU, RAU, SAU, Redox

Potential Capabulltiea: TAU, RAU, SAU, Redox
Teledyne Wah Chang Albany,

Analytical Labs Svcs.

P. O. Box 460

1600 Old Salem Road

Albany, OR 97321

Contact: Gary L. Beck

Phoue: 503/967-6939

FAX: $503 / 967-6986$

Standard Methods: D3974-81, D4793-93, 3050A, 1311, CR-1428

Radlonctive Sumples $>200 \mathrm{nCl} / \mathrm{s}$ Yes

Haxardous Waste Samples (40 CFR): Yes

Analytical Instrumentation: Laser Phosphorimeter, ICP-AES, ICP-MS

Uquild Detection Umit: $0.01 / 8 \mathrm{~L}^{-1}$

Solld Detection Umit: $0.01 \mathrm{mg} \mathrm{kg}^{-1}$

Current Capabillities: TAU, RAU, SAU, Redox

Potential Capabillties: TAU, RAU, SAU, Redox

Laucks Testing Labortories, Inc.

940 S. Harney Street

Seattle, WA 98108

Contact: Mike Nelson

Phone: 206/767-5060

FAX: 206/767-5063

Standard Methoda: 3050A, 1311

Radloactive Samples $>200 \mathrm{nCl} / \mathrm{e}$ No

Hazardous Waste Samples (40 CFR): Yes

Analytical Instrumentation: ICP-MS, UV-Vis

Uquild Detection Lmitt is $\mathbf{L}^{-1}$

Solld Detection Limit: $\mathrm{mg} \mathrm{kg}^{* 1}$

Current Capabilities: TAU, RAU, SAU, Redox

Potential Capabilitiea: TAU, RAU, SAU, Redox
Montgomery Labs

555 Walnut

Pasadena, CA 91101

Contact: Andy Eaton

Phone: 818/568-6425

FAX: $818 / 568-6324$

Standard Methods: D3974-81, 3050A, 1311

Radioactive Samples $>200 \mathrm{nCl} / \mathrm{F}$ No

Hazardous Waste Samples (40 CFR): Yes

Analytical Instrumentation: ICP-MS

Uquid Detection Limit: $2.0 \mathrm{~kg} \mathrm{L^{-1 }}$

Solld Detection Umit: $200 \mathrm{mg} \mathrm{kg}$

Current Capabilitiea: NR

Potential Capablitiles: NR
Columbia Analytical Services

1317 South 13th Avenue

P. O. Box 479

Kelso, WA 98626

Contact: Jeff Christian

Phone: 206/565-8496

FAX: 206/636-1068

Standard Methods: D3974-81, D4793-93, 3050A, 1311

Radioactive Samples $>200 \mathrm{nCi} / \mathrm{g}$ No

Hazardous Waste Samples (40 CFR): Yes

Analytical Instrumentation: ICP-MS

Uquild Detection Limit: $0.005 / \mathrm{g} \mathrm{L}^{-1}$

Solld Detection Lmit: $0.003 \mathrm{mg} \mathrm{kg}^{-1}$

Current Capabilities: TAU, RAU, SAU

Potential Capabilities: TAU, RAU, SAU, Redox 
Pacific Northwest Laboratory

P. O. Box 999

Richland, WA 99352

Contact: Eric J. Wyse

Frome: 509/376-3074

FAX: $509 / 376-7475$

Standard Methodas NR

Radioactive Samples $>200 \mathrm{nCl} / \mathrm{F}$. Yes

Harardows Waste Samples ( 40 CrR): Yes

Analydical Instrumentation: ICP-MS

Uquald Detaction Umit: $0.01 \mathrm{~kg} \mathrm{L^{-1 }}$

Solld Detection Umit: $0.03 \mathrm{mg} \mathrm{kg}^{-1}$

Curremt Capabllitiea: TAU, RAU, SAU, Redox

Potential Capabillties: TAU, RAU, SAU, Redox
IT Analytical Services

2800 George Washington Way

Richland, WA 99352

Contact: Van Pettey

Phone: 509/375-3131

FAX: NR

Standard Methoda: D3974-81, 3050A

Radioactive Samples $>200 \mathrm{nCl} / \mathrm{g}$ Yes

Hazardous Waste Samples (40 CFR): No

Analytical Instrumentation: Laser Phosphorimeter, ICP-MS, Alpha

Lquid Detection Limit: 1.0 /g $\mathrm{L}^{-1}$

Solld Detection Umit: NR

Current Capabilities: NR

Potential Capabilities: TAU, RAU, SAU, Redox 


\section{References}

Amorican Society for Testing and Materials, Directory of Testing Labonatories, 1992 Edition, ASTM, Philadelphia, Pennsylvania, 1991.

Amonette, J. E., The Role of Structural Iron Oxidation in the Weathering of Trioctahedral Micas by Aqueous Solutions, Ph.D. Dissertation, Iowa State University, Ames, Iowa, Dissertation Abstracts *DA8825372, 1988.

Atomic Enery Act, P.L. 79-585, as amended, 42 USC 2011 et seq. (1946).

Black, C. A., Soll-Plant Relationships, John Wiley \& Sons, New York, 1968.

Bondietti, EA., M.A. Bugle, J.N. Brantley, F.S. Brinkley, M.S. Delar.ey, C.T. Garten, Jr., C.W. Francis, T.G. Scott, M.H. Shanks, A.R. Smiddy, J.R. Trabalke, and R.L. Walker, ORNL-5508, "Section 5. Actinide Elernents in Aquatic and Terrestrial Environments," Environmental Sciences Division, Annual Progress Report, Period Ending September 30, 1978, Oak Ridge National Laboratory, Oak Ridge, Tennessee, 1979.

Brannon, J. M., R. M. Engler, J. R. Rose, P. G. Hunt, and I. Smith, Dredged Material Reseanch Program, Technical Repon D-76-7, Office Chief of Engineers, U. S. Army, Washington, D.C., 1977.

Bruno, J., A. Sandino, J.E. Cross, J. Eikenberg, I. G. Mckinley, D. Read, and P. Sellin, NAGRA-NTB-90-29 (SKB-TR-90-20 and UK-DOE-WR-90-051), Testing of Geochemical Models in the Pocos de Caldas Analogue Study," Poços de Caldas Report No. 11, Nationale Genossenschaft fuer die Lagerung Radioaktiver Abfaelle (NAGRA), Baden, Switzerland, 1991.

Cannon, H.L., The Effect of Uranium-Vanadium Deposits on the Vegetation of the Colorado Plateau," American Joumal of Science, 250: 735-770, 1952.

Casey, W. H., H. R. Westrich, G. W. Arnold, and J. F. Banfield, The Surface Chemistry of Dissolving Labradorite Feldspar," Geochimica Cosmochimica et Acta, 53: 821-832, 1989.

Chassard-Bouchaud, C., and P. Galle, "Cellular and Subcellular Distribution of Uranium and Transuranic Radionuclides in Marine Organisms," Radiation Protection Practice. Volume II (IRPA 7. Seventh International Congress of the Intemational Radiation Protection Association), pp. 656-659, Pergamon Press, New York, 1988.
Cross, J.E., A. Haworth, I. Neretnieks, S.M. Sharland, and C.J. Tweed, "Modelling of Redox Front and Uranium Movement in a Uranium Mine at Pocos de Caldas," Radiochimica Acta, 52/53(2): 445-451, 1991.

Dent, A. J., J. D. F. Ramsay, and S. W. Swanton, "An EXAFS Study of Uranyl Ion in Solution and Sorbed onto Silica and Montmorillonite Clay Colloids," Joumal of Colloid and Interface Science, 150:45-60, 1992.

Dreesen, D.R., J.M. Williams. M.L. Marple, E.S. Gladney, and D.R. Perrin, "Mobility and Bioavailability of Uranium Mill Tailings Contaminants," Envinonmental Science and Technology, 16(10): 702709, 1982.

Enerzy Reorganization Act, P.L. 93-438, as amended, 42 USC 5811 et seq. (1974).

Engler, R.M., J.M. Brannon, J. Rose, and G. Bigham, "A Practical Selective Extraction Procedure for Sediment Characterization," Chemistry of Marine Sediments, Proc. ACS Symp., Atlantic Ciry, NJ, 8-13 Sept. 1974, pp. 293-296, American Chemical Society, Washington, D.C., 1974.

Felmy, A.R., S.R. Peterson, and R.J. Serne, "Interactions of Acidic Uranium Mill Tailings Solution with Sediments: Predictive Modeling of Precipitation/Dissolution Reactions," Uranium, 4: 2541, 1987.

Fowler, K. M., G. R. Bilyard, S. A. Davidson, R. J. Jonas, and J. Joseph, DOE/RL/01830-H15, Federal Environmental Standards of Potential Importance to Operations and Activities at U.S. Department of Energy Sites (Draft Report). Pacific Northwest Laboratory, Richland, Washington, 1993.

Garten, C.T., Jr., E.A. Bondietti, and R.L. Walker, "Comparative Uptake of Uranium, Thorium, and Plutonium by Biota Inhabiting a Contaminated Tennessee Floodplain," Joumal of Environmental Quality, 10(2): 207-210, 1981.

Gilkes, R. A., Transmission Electron Microscope Analysis of Soil Materials," Quantitative Methods in Soil Mineralogy, J.E. Amonette and L. W. Zelazny (eds.), pp. 177-204, Soil Science Society of America, Madison, Wisconsin, 1994.

Grambow, B., R. Mueller, A. Rother, and W. Lutze, "Release of Rare Earth Elements and Urauium from Glass in low pH High Saline Brines," Radiochimica Acta, 52/53(2): 501-506, 1991. 
Grandstafi, D. E, "A Kinetic Study of the Dissolution of Uraninite," Economic Geology 71: 1493-1506, 1976.

Gupta, S. K, and K. Y. Chen, "Partitioning of Trace Metals in Selective Chemical Fractions Near Shore Sediments," Envirommental Letters, 10: 129-151, 1975.

Holdren, G. R, and P. M. Speyer, "pH Dependent Changes in the Rates and Stoichiometries of Diseolution of an Alkali Feldspar at Room Temperature," American Joumal of Science, 285: 994 1026, 1985.

International Commission on Radiological Protection (ICRP), ICRP Publication 23, Report of the Task Group on Refenence Man, Pergamon Press, Oxford, 1975.

International Commission on Radiological Protection (ICRP), ICRP Publication 30, Part 1, Limits for Intakes of Redionuclides by Workers, Annals of the ICRP Vol. 2, Pergamon Press, Oxford, 1979a.

International Commission on Radiological Protection (ICRP), ICRP Publication 30, Supplement to Part 1, Limits for Intakes of Radionuclides by Workers, Pergamon Prese, Oxford, 19796.

International Commission on Radiological Protection (ICRP), ICRP Publication 30, Part 2, Limits for Intakes of Radionuclides by Workers, Annals of the ICRP Vol. 4, Pergamon Press, Oxford, 1980.

International Commission on Radiological Protection (ICRP), ICRP Publication 30, Supplement to Part 2, Limits for Intakes of Radionuclides by Workers, Pergamon Preas, Oxford, 1981a.

International Commission on Radiological Protection (ICRP), ICRP Publication 30, Part 3, Annals of the ICRP Vol. 6, Limits for Intakes of Radionuclides by Workers, Pergamon Press, Oxford, 1981b.

International Commission on Radiological Protection (ICRP), ICRP Publication 30, Supplement A to Part 3, Limits for Intakes of Radioniclides by Workers, Pergamon Press, Oxford, 1982a.

International Commission on Radiological Protection (ICRP), ICRP Publication 30, Supplement B to Part 3 Including Addendum to Supplements to Parts 1 and 2, Limits for Intakes of Radionuclides by Workess, Pergamon Press, Oxford, 1982b.
International Commission on Radiological Protection (ICRP), ICRP Publication 30, Index, Limits for Intakes of Radionuclides by Workers, Pergamon Press, Oxford, 1982c.

Jackson, M. L., Soil Chemical Analysis--Advanced Course, published by the author, Madison, Wisconsin, 1979.

Jackson, KJ., and W.L. Bourcier (tech. orgs.), CONF-8609134, "Proceedings of the Workshop on Geochemical Modeling," National Technical Information Service, Springfield, Virginia, 1986.

Jacobs, G.K, and S.K. Whatley, eds., NUREG/CP-0062 (ORNL/TM-9585), "Conference on the Application of Geochemical Models to High-Level Nuclear Waste Repository Assessment," Oak Ridge National Laboratory, Oak Ridge, Tennessee, 1985.

Jenne, E.A., ed., Chemical Modeling in Aqueous Systems. Speciation, Sorption, Solubility, and Kinetics, American Chemical Society Symposium Series 93, Washington, D.C., 1979.

Kalkwarf, D. R., NUREG/CR-0530, "Solubility Classification of Airborne Products from Uranium Ores and Tailings Piles," Pacific Northwest Laboratory, Richland, Washington, 1979.

Kalkwarf, D. R., NUREG/CR-1316, "Solubility Classification of Airborne Uranium Products Collected at the Perimeter of the Allied Chemical Plant, Metropolis, Illinois," Pacific Northwest Laboratory, Richland, Washington, 1980a.

Kalkwarf, D. R., NUREG/CR-1428, "Solubility Classification of Airborne Uranium Products from LWR-Fuel Plants," Pacific Northwest Laboratory, Richland, Washington, $1980 \mathrm{~b}$.

Kelmers, A.D., J.H. Kessler, W.D. Arnold, R.E. Meyer, N.H. Cutshall, G.K. Jacobs, S.Y. Lee, and R.J. Clark, NUREG/CR-3851-Vol.2

(ORNL/TM-9191-Vol.2), "Progress in Evaluation of Radionuclide Geochemical Information Developed by DOE High-Level Nuclear Waste Repository Site Projects. Report for January-March 1984," Oak Ridge National Laboratory, Oak Ridge, Tennessee, 1984.

Knauss, K. G., and T. J. Wolery, "Dependence of Albite Dissolution Kinetics on pH and Time at $25^{\circ} \mathrm{C}$ and $70{ }^{\circ} \mathrm{C}$," Geochimica et Cosmochimica Acta, 50: 2481-2498, 1986. 
Kraus, K. A, and F. Nelson, "Metal Separations by Anion Exchange," Proceedings of a Symposium on Ion Exchange and Chromatography in Analytical Chemistry, ASTM Special Publication No. 195, pp. 27-57, American Society for Testing and Materials, Philadelphia, Pennsytvania, 1956.

Krupka, K.M., E.A. Jenne, and WJ. Deutsch, PNL4333, "Validation of the WATEQ4 Geochemical Model for Uranium," Pacific Northwest Laboratory, Richland, Washington, 1983.

Laird, D. A., and R. H. Dowdy, "Preconcentration Techniques in Soil Mineralogical Analyses," Quantilative Methods in Soil Mineralogy, J.E. Amonette and L. W. Zelarany (eds.), pp. 236-266, Soil Science Society of America, Madison, Wisconsin, 1994.

Lemire, R.J., and F. Garisto, The Effect of Ionic Strength, Groundwater Composition and Temperature on Calculated Radionuclide Solubilities," Radiochimica Acta, 58-59(1): 37-44, 1992.

Linder, G, E. Ingham, C. J. Brandt, and G. Henderson, EPA/600/R-92/183, Evaluation of Temestrial Indicators for Use in Ecological Assessments at Hezandous Waste Sites, U. S. Environmental Protection Agency, Washington, D. C., 1992.

Linsalata, P., R. Morse, H. Ford, M. Eisenbud, E. Penna Franca, M.B. Castro, N. de Lobao, I. Sachett, and M. Carlos, Transport Pathways of Th, U, Ra and La from Soil to Cattle Tissues," Joumal of Envinonmental Radioactivity, 10(2): 115-140, 1989.

Linsalata, P., R. Morse, H. Ford, M. Eisenbud, E. Penna Franca, M.B. Castro, N. de Lobao, I. Sachett, M. Carlos, Th, U, Ra and Rare Earth Element Distributions in Farm Animal Tissues from an Elevated Natural Radiation Background Environment," Joumal of Envionmental Radioactivity, 14(3): 233-257, 1991.

Lowson, R.T., S.A. Short, B.G. Davey, and D.J. Gray, ${ }^{204} \mathrm{U} /{ }^{26} \mathrm{U}$ and ${ }^{200} \mathrm{Th} /{ }^{24}$ Th Activity Ratios in Mineral Phases of a Lateritic Weathered Zone," Geochimica et Cosmochimica Acta, 50: 1697-1702, 1986.

Luoma, S. No and E. A. Jenne, "Estimating Bioavailability of Sediment-Bound Trace Metals with Chemical Extractants," Trace Substances in Environmental Health, 10: 343-351, 1976.

Malo, B. A., "Partial Extraction of Metals from Aquatic Sediments," Envinonmental Science and Technolozy, 11: 277-282, 1977.
Martin Sanchez, A., F. Vera Tome, and J. Diaz Bejarano, "Natural Isotopic Separation of Uranium in the Guadina Basin," Joumal of Radioanalytical Chemistry, Letters, 118: 291-298, 1987.

Melchior D.C., and R.L. Bassett, eds., Chemical Modeling of Aqueous Systems II, American Chemical Society Symposium Series 416, Washington, D.C., 1990.

Meyer, R.E., W.D. Arnold, J.G. Blencoe, G.K. Jacobs, A.D. Kelmers, F.G. Seeley, and S.K. Whatley, NUREG/CR-4236-Vol.4 (ORNL/TM-9614-Vol.4), "Progress in Evaluation of Radionuclide Geochemical Information Developed by DOE High-Level Nuclear Waste Repository Site Projects. Annual Report, October 1984-September 1985. Volume 4," Oak Ridge National Laboratory, Oak Ridge Tennessee, 1986.

Mortvedt, J. J., P. M. Giordano, and W. L. Lindsay (eds.), Micronutrients in Agriculture, Soil Science Society of America, Madison, Wisconsin, 1972.

Muller, A.B., D.L. Parkhurst, and P.W. Tasker, NUREG/CP-0079, "Use of the PHREEQE Code in Modelling Environmental Geochemical Problems Encountered in Performance Assessment Modelling." Proceedings of the Symposium on Groundwater Flow and Transpont Modeling for Performance Assessment of Deep Geological Disposal of Radioactive Waste: $A$ Critical Evaluation of the State of the At, 10 May 1985, Abuquerque, New Mexico, pp. 303-322, Pacific Northwest Laboratory, Richland, Washington, 1986.

Nash, W. P., "Analysis of Oxygen with the Electron Microprobe: Applications to Hydrated Glass and Minerals," American Mineralogist, 77: 453-457, 1992.

Nightingale, T., NUREG/CR-5040, AAEC/C55, "Distribution of Uranium Series Nuclides Throughout the Koongarra Deposit," Radionuclide Migration Around Uranium Ore Bodies - Analogue of Radioactive Waste Repositories, P.L. Airey, et al. (eds.), pp. 41-64, Australian Atomic Energy Commission, Lucas Heights, Australia, 1987.

Nordstrom, D.K., I. Puigdomenech, and R.H. McNutt, NAGRA-NTB-90-32 (SKB-TR-90-23 and UK-DOE-WR-90-054), "Geochemical Modelling of Water-Rock Interactions at the Osamu Utsumi Mine and Morro do Ferro Analogue Study Sites, Poços de Caldas, Brazil," Poços de Caldas Report No. 14, Nationale Genossenschaft fuer die Lagerung Radioaktiver Abfaelle (NAGRA), Baden, Switzerland, 1990. 
Nuclear Waste Policy Act, P.L. 97-425, as amended, 42 USC 10101 et seq. (1982).

Ollila, K., GTK-YST-78, "Natural Colloids, and Uranium and Thorium Equilibrium in Groundwater of Palmottu Natural Analogue Study Site. Part 2: Uranium and Thorium Equilibrium in Groundwater," The Palmottu Analogue Project, pp. 127-133, Geological Survey of Finland, Espoo, Finland, 1992.

Payne, T., NUREG/CR-5040, AAEC/C55, "Extraction and Desorption of Accessible Uranium," Radionuclide Migration Around Uranium Ore Bodies - Analogue of Radioactive Waste Repositories, P.L. Airey, et al. (eds.), pp. 161-167, Australian Atomic Energy Commission, Lucas Heights, Australia, 1987.

Peterson, S. R., A.R. Felmy, R.J. Serne, and G.W. Gee, NUREG/CR-3404 (PNL-4782), Predictive Geochemical Modeling of Interaction between Uranium Mill Tailings Solutions and Sediments in a FlowThrough System: Model Formulation and Preliminary Results, Pacific Northwest Laboratory, Richland, Washington, 1983.

Poston, T. M., R. W. Hanf, Jr., and M. A. Simmons, Taxicity of Uranium to Daphnia magna," Water, Air, and Soil Pollution, 22: 289-298, 1984.

Presley, G. J., Y. Kolodny, A. Nissenbaum, and D. R. Kaplan, "Early Diagenesis in a Reducing Fjord Saanich Inlet, British Columbia-II. Trace Element Distribution in Interstitial Water and Sediment," Geochimica et Cosmochimica Acta, 36: 1073-1090, 1972.

SAIC (Science Applications International Corporation), NVO-196-43, "Nevada Nuclear Waste Storage Investigations. Quarterly report, January 1, 1984-March 31, 1984," Science Applications International Corporation, Las Vegas, Nevada, 1985.

Serne, R.J., R.C. Arthur, and K.M. Krupka, NUREG/CR-5548 (PNL-7285), Review of Geochemical Processes and Codes for Assessment of Radionuclide Migration Potential at Commercial LLW Sites, Pacific Northwest Laboratory, Richland, Washington, 1920.

Sheppard, S.C. and W.G. Evenden, "Mobility and Uptake by Plants of Elements Placed Near a Shallow Water Table Interface," Joumal of Environmental Quality, 14(4): 554-560, 1985.

Sheppard, M.I., and D.H. Thibault, "Migration of Technetium, Iodine, Neptunium, and Uranium in the Peat of Two Minerotrophic Mires," Joumal of Envinonmental Quality, 17(4): 644-653, 1988.
Sheppard, M. I., and D. H. Thibault, "Desorption and Extraction of Selected Heavy Metals from Soils," Soil Science Society of America Joumal, 56: 415-423, 1992.

Sheppard, M.I., S.C. Sheppard, and D.H. Thibault, "Uptake by Plants and Migration of Uranium and Chromium in Field Lysimeters," Joumal of Envinonmental Quality, 13(3): 357-361, 1984.

Sverjensky, D. A., "Geochemical Modelling of the Koongarra Uranium Deposit," Alligator Rivers Analogue Projech, Annual Repon 1990-1991, P. Duerden (ed.), pp. 25-55, Australia Nuclear Science and Technology Organisation (ANSTO), Menai, Australia, 1992 .

Tessier, A., P.G.C. Campbell, and M. Bisson, "Sequential Extraction Procedure for the Speciation of Particulate Trace Metals," Analytical Chemistry, 51: 844-853, 1979.

Tisdale, S. L., and W. L. Nelson, Soil Fertility and Fertilizers, 3rd edition, Macmillan, New York, 1975.

Trabalka, J.R., M.A. Bogle, E.A. Bondietti, and T.G. Scott, CONF-841142, "Actinide Behavior in a Freshwater Pond," Symposium on Environmental Reseanch for Actinide Elements, Hilton Head Island, South Carolina, 7 November 1984, pp. 341-369, U.S. Department of Energy Office of Scientific and Technical Information, Oak Ridge, Tennessee, 1987.

Turner, D.R., T. Griffin, and T.B. Dietrich, "Radionuclide Sorption Modeling Using the MINTEQA2 Speciation Code," Scientific Basis for Nuclear Waste Management XV, C. G. Interrante and R. T. Pabalan (eds.), pp. 783-789, Materials Research Society, Pittsburgh, Pennsylvania, 1993.

U. S. Department of Energy, DOE/EH-0071, "Internal Dose Conversion Factors for Calculation of Dose to the Public," 1988.

U. S. Department of Energy, "Radiation Protection of the Public and the Environment." DOE 5400.5, 1989.

U. S. Environmental Protection Agency, "National Primary Drinking Water Standards," U.S. Code of Federal Regulations, 40 CFR 141, 1991a.

U. S. Environmental Protection Agency, "Standards for Protection Against Uranium Mill Tailings," U.S. Code of Federal Regulations, 40 CFR 192, $1991 \mathrm{~b}$. 
U. S. Environmental Protection Agency, "Protection Standards of Managing and Disposing of Spent

Nuclear Fuel, High-Level and Transuranic Radioactive Wastes," U.S. Code of Federal Regulations, 40 CFR 191, 1991c.

Walsh, L. M., and J. D. Beaton (eds.), Soil Testing and Plant Analysis, Soil Science Society of America, Madison, Wisconsin, 1973.

Wanner, H. "Modeling Interaction of Deep Groundwaters with Bentonite and Radionuclide Speciation," Nuclear Technology, 79(3): 338-347, 1987.
Wollast, R., and L. Chou, "Kinetic Study of the Dissolution of Albite with a Continuous Flow-Through Fluidized Bed Reactor," The Chemistry of Weathering, J. I. Drever (ed.), NATO ASI Series, C 149, pp. 7596, Reidel, Dordrecht, Holland, 1985.

Yanase, N., T. Nightingale, T. Payne, and P. Duerden, "Uranium Distribution in Mineral Phases of Rock by Sequential Extraction Procedure," Radiochimica Acta, 52/53: 387-393, 1991. 


\section{Appendix A: Analytical Chemistry of Uranium}

\section{A.1 Assay for Total Uranium}

The methods for determining total uranium in soil can be grouped by whether the sample is destroyed during the analysis or remains essentially intact. Wet-

chemical techniques, by definition, involve a conversion of uranium from the solid phases to a solute in the liquid phase and, thus, are considered sampledestructive. On the other hand, several nondestructive methods of analysis can also be used, which involve exciting the sample with high-energy radiation and measuring the energy flux given off by the sample as a result of fluorescence or radioactive decay. Detection limits are generally lower for the wetchemical techniques, but recent advances in X-ray sources (i.e., synchrotrons) have allowed higher incident fluxes to be focussed on the samples and bence lower detection limits. The selection of which methods to use for determination of total uranium, therefore, is largely based on practical considerations rather than on clear technical differences.

\section{A.1.1 Wet-Chemical Techniques}

The measurement of total uranium in soils and sediments, using wet-chemical methods, is a relatively straightforward procedure. Although we were unable to locate any digestion procedures that had been designed specifically for the determination of uranium, there are numerous studies available that address the digestion of soil, rock or sediment samples for the purpose of determining total metal compositions (Johnson and Maxwell, 1989; Lim and Jackson, 1982).

In general, the procedures call for digesting the sample by exposure to mixtures of hydrofluoric acid (HF) and either perchloric ( $\left.\mathrm{HClO}_{4}\right)$ or nitric $\left(\mathrm{HNO}_{3}\right)$ acid and heating the samples (e.g., to $60^{\circ} \mathrm{C}$ overnight) to promote decomposition. Some methods then evaporate the solution to near dryness, thus concentrating the inorganic constituents and volatilizing silica and fluoride. This cycle of acidification and evaporation may be repeated as many as three times. The HF is included to break down silicate minerals, and the mineral acids maintain the metals in a soluble form. Depending on the nature of the starting material, transition metals, including uranium, may be resolubilized simply by leaching the residue from the HF treatments to a mildly acidic hydrochloric acid (HCl) solution. If there are concerns that a fraction of the metal remains bound in the refractory solids, then the residue is usually mixed with a flux (e.g., Nametaborate) and the sample is fused. The sample bead produced by this fusion is then crushed, and the resulting powder dissolved in a mildly acidic solution. Other methods (e.g., Lim and Jackson, 1982) require only a single dissolution step in HF and retain the full starting volume of the sample. In these methods, the excess HF remaining after sample decomposition is then neutralized by addition of boric acid $\left(\mathrm{H}_{3} \mathrm{BO}_{3}\right)$ before analysis of the uranium.

Numerous variations on these sample decomposition procedures exist. Analysts have employed highpressure reaction vessels (i.e., bombs) in which to conduct the sample digestion in order to speed up the process. Digestions completed in bombs are frequently completed in 24 hours or less, whereas other digestion techniques generally require longer time periods, with two to five days being a typical range. In almost all cases, laboratories are set up to allow for the simultaneous preparation of multiple samples. Recently, microwave digestion systems using bombs constructed from tetrafluoroethylene and other resistant polymers have come into general usage and offer quick reliable digestions using a minimum of sample and reagent.

Once the sample has been decomposed into soluble constituents, transition-metal concentrations, including those for uranium, are determined on the resulting aqueous solution, using any of a wide range of possible analytical techniques. The major techniques specifically used for uranium determinations include pulsed-laser phosphorimetry, inductively-coupledplasma mass spectrometry (ICP-MS), stripping voltammetry, and spectrophotometry. When using these wet-chemical procedures, the analyst must be fully aware of all potential interferences, quenchers, and similar problems that affect this sort of analysis. The procedures do, generally, provide excellent information regarding the total uranium content of a sample. However, because of the severity of the digestion treatment, information concerning speciation, oxidation state, or mineralogy is lost in the analysis.

\section{Pulsed-Laser Phosphorimetry}

This is the baseline technique for uranium determinations in solutions. It has excellent detection limits (ca. $50 \mathrm{ng} \mathrm{L}^{-1}$ in clean solutions), but suffers from various types of interferences [e.g., organic substances, $\mathrm{Fe}$ (II), $\mathrm{Fe}$ (III), $\mathrm{NO}_{3}^{-1}, \mathrm{Mn}$ (II), $\mathrm{HCl}$, which are largely overcome by a combination of oxidation to remove organics, dilution, and complexation of the uranium with phosphate-based ligands.

The method (ASTM, 1992; Robbins et al., 1985) relies on the luminescent properties of the uranyl (UO ${ }_{2}{ }^{2+}$ ) ion when irradiated in the UV region $(337 \mathrm{~nm})$. The lifetime of the luminescence is extended by complexation of the uranyl ion with phosphoric acid or proprietary polyphosphate compounds. These 
complexing agents prevent quenching of the luminescence by minimizing interactions between the uranyl ion and other molecules in solution such as alcohols, halides other than fluoride, and many metal ions. Other substances such as humic acids, Fe(III), and $V(V)$ also absorb radiation at this wavelength and thus can yield low results. When these interferences are avoided, detection limits as low as $50 \mathrm{ng}^{-1}$ (i.e., $0.05 \mathrm{ppb}$ ) are obtained. A multilaboratory test of the ASTM method yielded excellent accuracy at low concentrations (within $0.5 \%$ of the given value at $2 / \mathrm{kg}$ $L^{-1}$ ) with a slight bias towards high results as the given concentration of uranium increased (ASTM, 1992). Precision was also very good, with singleoperator relative errors of $2-4 \%$ reported.

Recently, the phosphorescence technique was modified for use on a UV-Vis spectrophotometer with a fluorescence adaptor (Rajec, 1992). Preconcentration of the sample was performed by a selective extraction process and detection limits of about $200 \mathrm{ng} \mathrm{mL}^{-1}$ and relative errors of $1-5 \%$ were obtained for a $10-\mathrm{mL}$ sample.

Laser-phosphorescence instruments are available in several laboratories around the country (one of the two major manuf_cturers has placed about 100 instruments in the U.S.A., of which a third are in private testing laboratories) and can be purchased at a relatively low price (i.e., \$30-45K, depending on the degree of automation). Once the sample is in liquid form, the time required for analysis is on the order of a few minutes, assuming no major interferences are present (this can be verified by the addition of a small, known amount of uranium to the sample after the initial analysis and reanalyzing). Aside from the potential interferences, the method is eminently practical and considered to be the standard against which other methods are compared.

\section{Inductively-Coupled-Plasma Mass Spectrometry}

In the fourteen years since it was first developed (Houk et al., 1980) the linkage of an inductively coupled plasma ion source to a mass spectrometer has proven to be an exceptional analytical tool for trace metals in difficult matrices. The interferences are few and largely due to the composition of the atmosphere used to generate the plasma rather than stemming from the sample matrix.

In this technique, a continuous stream of sample is ncbulized into a plasma (usually argon ions generated by a rapidly oscillating electromagnetic field), which is directed into a quadrupole mass spectrometer. Only a very small fraction of the sample reaches the highvacuum portion of the mass spectrometer, but the sensitivity and linear range of the instrument are superb. This technique is isotope specific, so that, in principle, uranium concentrations can be expressed in terms of both mass and radioactivity units by summing the mass concentrations of the different isotopes and multiplying each by their specific activity. Thus, the technique eliminates the reliance on the analysis of a single nuclide and use of a fixed conversion factor for the determination of specific activity.

Analytical detection limits of $10 \mathrm{ng} \mathbf{L}^{-1}$ (corresponding to $10 \mathrm{ng} \mathrm{\textrm {g } ^ { - 1 }}$ for the original solid) are routinely obtained for samples fused in $\mathrm{Na}_{2} \mathrm{O}_{2}$, but are 100 to 1000 times higher for acid-digested samples (E. J. Wyse, 1993, personal communication). In relatively clean low-ionic-strength water samples, sub-ng $\mathbf{L}^{-1}$ detection limits are possible. An in-house comparison $\left(n=15, U\right.$ concentration range $\left.=1-2000 \mathrm{ng} \mathrm{mL}^{-1}\right)$ of ICP-MS with pulsed-laser phosphorimetry for the analysis of uranium extracted from soils by $8 M$ $\mathrm{HNO}_{3}$ showed very good agreement (K. B. Olsen, 1993, personal communication). The ICP-MS values were $17 \%$ higher on average than the phosphorimetric values, possibly as a result of luminescence quenching by organic substances in the soil extracts. Elimination of one outlier lowered this average difference to $13 \%$.

The ICP-MS instrument, however, is expensive to purchase (\$200-250K) and to maintain, and is not as robust as could be hoped. On the other hand, it can be used to measure the quantities of nearly every element in the periodic table rather than being dedicated to $U$ analysis, and this feature decreases the net cost for a multielement testing laboratory.

Furthermore, measurement times are on the order of a few minutes per sample, and automated sampling and data reduction are standard. ICP-MS is rapidly gaining acceptance among environmental analytical laboratories and may supplant the ICP-atomic emission spectrometer as the "workhorse" instrument for trace metal analysis in the coming decade. In our opinion, the ICP-MS technique is ideally suited for the analysis of $U$ in soils because it combines high sensitivity and ease of sample introduction with the ability to measure isotopic ratios. Our only reservation is the high initial cost associated with its purchase.

\section{Inductively-Coupled-Plasma Atomic Emission Spectrometry}

This instrument was originally developed approximately 30 years ago and the first commercial units were produced in 1970 (Greenfield et al., 1964; Wendt and Fassel, 1965; Soltanpour et al., 1982). The technique, therefore, is mature and the instrumentation robust. The method is similar to the 
ICP-MS method discussed except that light emitted by excited ions in the plasma is sent into a UV-Vis spectrometer for identification of the elements present and quantification of their concentrations. Detection limits for uranium are on the order of $10 \mathrm{ng} \mathrm{mL}^{-1}$, i.e., roughly 3 orders of magnitude higher than those for the ICP-MS technique.

Depending on spectrometer resolution and measurement sequence (i.e., sequential elemental analysis vs. simultaneous analysis of several elements), the instrument may be purchased for about $\$ 60-130 \mathrm{~K}$. The multielemental capabilities and moderately low detection limits coupled with automated sampling and data reduction have made ICP-AES the dominant instrument for trace metal analysis in most laboratories. Because of the isotopic analysis capability and lower detection limits of its sister technique ICP-MS, however, we expect ICP-AES to yield some of its dominance to ICP-MS, especially for elements such as $U$ where isotopic ratios are important.

\section{Stripping Voltammetry}

Adsorptive stripping voltammetry is an emerging technique that may prove quite useful for uranium determinations in soil extracts (Wang et al., 1992ab; Wang and Setiadji, 1992) and shows great promise for automated analysis of aqueous samples in the field. The strengths of the method are that it can determine oxidation states directly on a single specimen and the detection limits are on the order of $1 \mathrm{ng} \mathrm{mL}^{-1}$.

The technique involves adsorption of a $\mathrm{U}(\mathrm{VI})$ cupferron or $\mathrm{U}(\mathrm{VI})$-oxine complex at the surface of a mercury electrode. The potential of the electrode is then varied to reduce the $U$. The amount of current measured during the reduction process is directly proportional to the amount of U present. Detection limits of $1 \mathrm{~kg} \mathrm{^{-1 }}$ or lower were reported with relative errors of 3-5\% being reported for groundwater samples. With soil extracts $\left(8 \mathrm{M} \mathrm{HNO}_{3}\right.$ ), however, lower precision is obtained ( $50-60 \%$ relative error, $K$. B. Olsen, 1993, personal communication). Development work is continuing on this technique, and these results may improve.

The cost of the instrument is relatively low $(\$ 20-30 \mathrm{~K})$, it may be automated, and sample analysis times on the order of a minute or two are normal. Current implementations of the method, however, have yielded lower precision than hoped for soil extracts (K. B. Olsen, 1993, personal communication). Once the problems with soil extracts have been resolved, the technique can be considered quite robust and practical for $U$, especially where oxidation state information is needed.

\section{Spectrophotometry}

Numerous spectrophotometric methods exist for the determination of uranium in aqueous solution (Silfwerbrand-Lindh et al., 1984; Kojima and Shigetomi, 1989; Pavon et al., 1989, 1992;). These methods generally rely on the complexation of uranium by a chromophoric ligand [e.g., 1-(2pyridylazo)-2-naphthol (PAN), 2-(5-bromo-2pyridylazo)5-diethylaminophenol (5-Br-PADAP), or $2,2^{\prime}-(1,8-$ dihydroxy-3,6-disulfo-2,7-naphthalenebis(azo))dibenzenearsonic acid (Arsenazo III)] and then measuring the absorbance at the optimum wavelength for the uranium-chromophore complex. Other ions can form chromophoric complexes [e.g., $\mathrm{Fe}$ (III) and $\mathrm{Zr}$ (IV)] and these are masked by complexation with oxalic acid or DCTA [(trans-1,2cyclohexylenedinitrilo)tetraacetic acid]. Solubility of the chromophoric reagents is often limited in aqueous solutions and so extractions into nonpolar phases (or onto ion exchange resins) are often used to preconcentrate the analyte and eliminate interferences. These methods are also easily adapted to automated flow-injection analysis. Absolute detection limits, therefore, depend on preconcentration factors and on the molar absorptivity of the chromophore-uranium complex. Values for the detection limit of as low as $0.51 \mathrm{H} \mathrm{L} \mathrm{L}^{-1}$ have been reported, with relative errors of $2 \%$ or less.

The costs of materials and instrumentation are relatively low for this technique when compared with the others and, as a consequence, it can be performed in almost any wet chemistry laboratory. The technique is robust, but the instrumental detection limits are comparable to those of the ICP-AES. As with all the wet-chemical techniques, flow-injection analysis allows oxidation-state determinations to be made on splits of the samples using separate reaction loops, and preconcentration techniques can enhance the detection limits. The method is practical and inexpensive, but not used as widely as the more instrumentation-intensive techniques, perhaps because it seems tedious.

The leading features of the wet-chemical techniques for total uranium are summarized in Table A.1.

\section{A.1.2 Nondestructive Techniques}

\section{X-ray Spectrometry}

Analytical X-rays can be excited in the sample by irradiation with photons having energies greater than 
Appendix A: Analytical Chemistry

Table A.1. Summary of avallable analytical methods for the determination of uranium by wet-chemical or nondestructive techniques

\begin{tabular}{|c|c|c|c|c|c|}
\hline Method & $\begin{array}{l}\text { Detection } \\
\text { Limit }\end{array}$ & $\begin{array}{l}\text { Relative } \\
\text { Precialon }\end{array}$ & $\begin{array}{l}\text { Cost per } \\
\text { Analysis's }\end{array}$ & $\begin{array}{l}\text { Instrument } \\
\text { Cost }\end{array}$ & Comments \\
\hline Wet-Chemical & BB L $L^{-1}$ & $-\%-$ & $-\$-$ & $-\$-$ & \\
\hline $\begin{array}{l}\text { Laser } \\
\text { Phosphorimetry }\end{array}$ & 0.05 & $<4$ & $50-100$ & $\sim 45 \mathrm{~K}$ & $\begin{array}{l}\text { Good precision at low concentrations } \\
\text { but numerous interferences ( } \mathrm{Fe}, \mathrm{Mn} \text {, } \\
\mathrm{HCl}, \mathrm{NO}_{3} \text { ) }\end{array}$ \\
\hline $\begin{array}{l}\text { ICP-MS } \\
\text { instrument of choice }\end{array}$ & for commer & $\sim 10$ & 100 & $\sim 250 \mathrm{~K}$ & $\begin{array}{l}\text { High ionic strength solutions suppress } \\
\text { sensitivity; excellent for multielement } \\
\text { and isotopic analyses; becoming the } \\
\text { labs }\end{array}$ \\
\hline ICP-AES & 10.0 & $\sim 10$ & 100 & $\sim 50-100 \mathrm{~K}$ & $\begin{array}{l}\text { Currently instrument of choice for } \\
\text { metals analyses; not as sensitive as ICP. } \\
\text { MS and no isotopic capabilities }\end{array}$ \\
\hline $\begin{array}{l}\text { Stripping } \\
\text { Voltammetry }\end{array}$ & 1.0 & $5-50$ & 100 & $-30 \mathrm{~K}$ & $\begin{array}{l}\text { Shows promise, but still in development; } \\
\text { direct determination of oxidation states; } \\
\text { can be automated }\end{array}$ \\
\hline Spectrophotometry & $0.5-10$ & 2-10 & $50-100$ & $\sim 10 \mathrm{~K}$ & $\begin{array}{l}\text { Relatively preparation intensive but } \\
\text { otherwise comparable to ICP-AES; } \\
\text { flow-injection analysis allows oxidation } \\
\text { state determinations }\end{array}$ \\
\hline Noadestructive & ng $\mathbf{8}^{-1}$ & $-\%-$ & $-\$-$ & $-\$-$ & \\
\hline $\mathbf{X R F}$ & $>1000$ & $\sim 10$ & $50-150$ & $\sim 250 \mathrm{~K}$ & $\begin{array}{l}\text { Most common nondestructive technique; } \\
\text { multielemental capability }\end{array}$ \\
\hline Synchrotron XRF & $1-50$ & $\sim 10$ & $50-150$ & $--^{2}$ & $\begin{array}{l}\text { Has greatest sensitivity but requires } \\
\text { access to a synchrotron; microprobe } \\
\text { allows determination of elemental } \\
\text { composition, average oxidation state and } \\
\text { structure of crystalline uranium particles }\end{array}$ \\
\hline $\begin{array}{c}\text { PIXE } \\
\text { elements }\end{array}$ & $>10,000$ & $\sim 10$ & $50-150$ & - & $\begin{array}{l}\text { Requires small particle accelerator; } \\
\text { multielemental capability best for light }\end{array}$ \\
\hline Neutron Activation & 500 & c.s. $^{3}$ & $50-100$ & - & $\begin{array}{l}\text { Limited number of facilities available; } \\
\text { turn around time of } \sim 1 \text { week }\end{array}$ \\
\hline PIGE & $>1000$ & c.s. & $50-150$ & - & Requires heavy-ion accelerator; \\
\hline
\end{tabular}


the absorption edge of the inner-shell electronic transition of interest (e.g., U- $\left.\mathrm{L}_{\mathrm{m}}\right)$ or by irradiation with charged particles of high energy (e.g., protons, electrons, and alpha particles). In both instances, the probabilities associated with X-ray production in the sample, and with attenuation of the incident photons/particles and of the emitted X-rays, are well understood (Amonette and Sanders, 1994). In general, the efficiency of X-ray production falls off with increasing atomic number and much more rapidly for particle excitation than for photon excitation. Thus, X-ray fluorescence (XRF) is more suited to uranium determinations than proton-induced X-ray emission (PIXE) based purely on physical principles. Because attenuation of $\mathrm{X}$-rays by the sample is important, the detection limits for uranium by X-ray spectrometry will vary by as much as an order of magnitude depending on the matrix. For example, they will be significantly higher for uranium in an iron oxide matrix than in an aluminosilicate matrix. With conventional equipment and routine counting times, detection limits on the order of $1 \mathrm{~KB} \mathrm{~B}^{-1}$ ranging up to about $5018 \mathrm{~g} \mathrm{~g}^{-1}$ are obtained with XRF. Synchrotron $X$-ray sources, however, offer incident fluxes that are several orders of magnitude greater than can be achieved by conventional X-ray tubes. With these sources, detection limits into the sub-ng $g^{-1}$ realm are possible. The $\mathrm{X}$-ray microprobe, currently under development at several institutions, offers the possibility of obtaining concentration maps of elements in undisturbed samples at submicron resolution and ng $\mathrm{g}^{-1}$ sensitivity.

Because of its ability to analyze solid specimens and relatively few spectral interferences, X-ray spectrometry has always been an important technique for the elemental characterization of soils and sediments (Amonette and Sanders, 1994). The technique finds application in a variety of instruments in which specimens may be probed by characteristic $X$-rays, electrons, protons, and, most recently, synchrotron-generated X-radiation. The cost and availability of these instruments vary considerably, as do their analytical capabilities. Most analytical laboratories will have access to an X-ray fluorescence (XRF) spectrometer and, possibly, to an electron microprobe (EM). A few will have access to a proton accelerator for proton-induced X-ray emission (PIXE) spectroscopy, whereas the number of synchrotron facilities available to commercial analytical laboratories can probably be counted on one hand. Costs for a total uranium determination by XRF on a bulk sample are on the order of $\$ 50$ to $\$ 150$ per sample depending on the laboratory, the sample matrix, and the detection limit desired ( $1 / \mathrm{B} \mathrm{g}^{-1}$ is typical). Electron microprobe costs are similar per determination, but require many analyses to achieve statistical certainty regarding the bulk sample. Analyses by PIXE are comparable in cost to XRF, at a sacrifice of approximately 1 order of magnitude in the detection limit. The best detection limits (ca. 1 ng $\mathrm{g}^{-1}$ ) for total uranium are achieved with synchrotron radiation for bulk samples. The ongoing development of the X-ray microprobe promises to allow structural and oxidation-state determinations of uranium-bearing particles present at $18 \mathbf{g}^{-1}$ levels, in addition to total uranium concentration maps at $\mathrm{ng} \mathbf{g}^{.1}$ levels. Nevertheless, synchrotrons are primarily research tools and are not generally used for routine analytical measurements of soils. This situation may change in the future, if dedicated analytical synchrotrons are built. In the meantime, the use of synchrotron radiation for regulatory purposes can be considered impractical, if only because of the limited number of facilities, and the planning, travel, and inconvenience involved in collecting the data. Thus, XRF and, in some instances, PIXE, remain the only practical X-ray spectrometric techniques for analysis of uranium in soils.

\section{Gamma-Ray Spectrometry}

\section{Neutron Activation}

Neutron activation analysis is isotope-specific, relying on the reaction between a neutron of energy above a certain threshold value and a specific atomic nucleus to potentially yield a nucleus having a higher energetic state (Steinnes, 1971; Helmke, 1982). For ${ }^{234} \mathrm{U}$, the reaction with epithermal neutrons (i.e., neutrons having energies $>0.5 \mathrm{eV}$ ) results in the production of ${ }^{200} \mathrm{U}$. This isotope of uranium is radioactive and decays to ${ }^{209} \mathrm{~Np}$ with the release of a beta particle and a gamma ray having an energy of $74.7 \mathrm{keV}$. The ${ }^{209} \mathrm{U}$ nuclide has a half-life of about 24 minutes. The ${ }^{209} \mathrm{~Np}$ nuclide then decays by beta-gamma emission $\left(E_{r}=\right.$ 106,228 , and $278 \mathrm{keV}$ ) to ${ }^{20} \mathrm{Pu}$, with the half-life of the ${ }^{209} \mathrm{~Np}$ nuclide being about 2.4 days. Thus, measurements can be taken soon after irradiation at $74.7 \mathrm{keV}$ or after several days at 106,228 , or 278 $\mathrm{keV}$, depending on which nuclear transition is selected. The requirements for neutron activation analysis are a source of neutrons (typically a small research nuclear reactor or a Van de Graaff particle accelerato:), a sample that is reasonably transparent to the neutrons, and a detection system for counting gamma rays emitted by the sample after it is irradiated. Detection limits depend on the length of irradiation, the energy of the neutrons relative to a resonance energy where neutron capture is favorable, the efficiency of the gamma detector, the sample size, and the length of time after irradiation and before counting. Sample sizes ranging from $50-500 \mathrm{mg}$ are typical, although samples much smaller can be 
accomodated. Miera (1980) reported a uranium detection limit of 500 ng $\mathrm{g}^{-1}$ for soils irradiated with epithermal neutrons. Other workers have reported values from about 5 to $40 \mathrm{ng} \mathrm{g}^{-1}$ for uranium, depending on the neutrons used (Zielinski and McKown, 1984; Landsberger and Wu, 1993). Uncertainty of the analysis depends largely on counting statistics (i.e., error decreases as the square root of the number of counts) with the contribution from other factors being less than $1 \%$ relative (Helmke, 1982).

Zielinski and McKown (1984) reported on a method that gave much lower detection limits for liquid samples. Briefly, the method involved a preconcentration step in which the uranium was complexed by an exchange resin dissolved in kerosene. This organic phase was then analyzed as a liquid and yielded results in the $1-20 \mathrm{ng} \mathrm{L}^{-1}$ range that agreed well with phosphorimetric measurements of the same samples.

Neutron activation analysis for ${ }^{20} \mathrm{U}$ using epithermal neutrons affords excellent detection limits, comparable to those obtained with synchrotron radiation. On a practical basis, however, it shares one limitation with synchrotron radiation, in that the number of neutron sources is small and those that are available are heavily subscribed. The analytical costs can be quite low (one lab outside the U.S. apparently can analyze samples for $\$ 10$ each, although a typical cost domestically is in the \$50-\$100 range. Adding to its practicality is the minimal sample preparation requirement and rapid turnaround (ca. 1 week under optimal cunditions). Thus, the only factor limiting its use is the limited number of facilities. If an arrangement can be made with one of these facilities, this method is eminently practical.

\section{Particle-Induced Gamma Emission}

The impact of high-energy ( $>0.2 \mathrm{MeV}$ ) charged particles on a sample will result in a few particlenucleus collisions with the nucleus being left in an excited state. As with neutron irradiation, some characteristic gamma rays will be released as these nuclei decay, and their measurement allows quantification of nuclides in the sample. Most of these excited nuclei have very short half-lives (i.e., fractions of a second), and the gamma rays emitted are termed "prompt gammas" because they must be measured while the sample is being irradiated. The cross sections for particle-induced gamma emission (PIGE) decrease with increasing atomic number and decreasing mass of the incident particle. The best cross sections for uranium, therefore, are obtained with heavy ion bombardment of the sample.
Particle-induced gamma emission spectrometry has minimal sample preparation requirements and can provide data very rapidly. For uranium determinations, it requires a small particle accelerator capable of generating a heavy-ion beam. These instruments are not as scarce as synchrotrons but neither are they as common as XRF spectrometers. Because of the low cross section for uranium, the detection limits are comparable to those for XRF and, consequently, the PIGE technique has seen little use. In view of the relatively limited sources and lackluster detection limits, this method is not very practical.

The salient features of the analytical techiques for nondestructive determination of uranium in solids are summarized in Table A.1.

\section{A.2 Assay for Uranium Oxidation State}

In general, the oxidation state of uranium has a direct bearing on its solubility and, hence, its environmental availability. Uranium in the +4 state is usually less soluble than that in the other common oxidation state (+6), and, as a consequence, much less of an environmental risk. However, U(IV) is oxidized to $\mathrm{U}(\mathrm{VI})$ rather easily $\left(\mathrm{E}^{\circ}=+0.25 \mathrm{~V}\right.$, Bruno et al., 1985) and the kinetics of this reaction will be crucial to any assessment of environmental availability. Thus, a determination of the oxidation state of uranium in both the aqueous and the solid phases is needed, along with some way of estimating the kinetics of U(IV) oxidation in a particular soil, in order to properly assess the potential risk associated with the uranium contamination. This type of measurement can be done either by wet-chemical techniques or by direct spectroscopic techniques [e.g., X-ray absorption near-edge structure (XANES), laser photoacoustic, laser Raman, optical luminescence].

\section{A.2.1 Direct Spectroscopic Techniques for Oxidation State}

Direct spectroscopic measurement of the uranium oxidation state in solids or liquids is possible using XANES spectroscopy. This technique measures small (0.1-eV resolution) shifts in the position and shape of the X-ray absorption spectrum of an element as one scans in energy across the absorption edge. In a crude sense, the more reduced an atom is (i.e., the greater the number of valence-shell electrons), the less energy it needs to eject an inner-shell electron and a slight shift (ca. 2-3 eV per unit difference in oxidation number) to lower energy is seen in the position of the absorption edge. The effect is confounded by coordination number (e.g., tetrahedral vs. octahedral), 
but the theory is well enough developed to allow prediction of the shape and location of the absorption edge.

Although several groups in the U. S. Department of Energy (DOE) complex and university community have been pursuing XANES spectroscopy of $U$ in soils, we are aware of only one manuscript concerning the XANES spectrum of U solids in soils (Bertsch et al., 1994). The data presented clearly show a 4.5-eV shift in the position of the $\mathrm{L}_{\mathrm{m}}$ absorption edge for uranium in going from $U(I V)$ to $U(V)$ ). Moreover, the shift is linearly proportional to the fraction of $U(V)$ present in soveral samples having mixtures of the two oxidation states, making possible a quantitative analysis of the average oxidation state of $\mathrm{U}$ in the sample. The beauty of the technique is that it is non-destructive to the sample and that data can be collected from field-moist specimens if desired. Xray absorption near-edge structure spectroscopy requires an intense tunable $X$-ray source that is available, for practical purposes, only at a synchrotron. Consequently, XANES is not practical for routine analytical purposes (at least until a dedicated analytical synchrotron facility can be built).

Other direct spectroscopic techniques (i.e., laser photoacoustic, laser Raman, and optical luminescence spectroscopies) interrogate the sample by monochromatic laser light and measure the optical absorption (laser Raman), optical emission (luminescence), or thermal emission (laser photoacoustic) properties of the sample. The intensities of thermal and optical emissions for a specific atomic transition are generally inversely related. Thus, laser photoacoustic signal is strong where the optical luminescence signal is weak. In general, then, laser photoacoustic spectroscopy is more sensitive to U(IV) species and optical luminescence to U(VI) species. Laser Raman spectroscopy measures the vibrational spectra of functional groups and shows roughly equal sensitivity to the two oxidation states of U. Because of their small highly collimated light sources, these three laser-based techniques generally sample small portions of a soil and many measurements are needed to gain a statistically certain estimate of the average $U$ oxidation state in the bulk soil. They yield solid-speciation information that can be critical to the design of remediation technologies, but at much higher expense than wet-chemical procedures.

\section{A.2.2 Wet-Chemical Techniques for Oxidation States}

The literature provides a number of examples in which wet-chemical procedures are used to estimate the distribution of uranium oxidation states among reactive phases in soils or sediments. In general, these procedures call for the leaching of uranium from a sample using a mild, nonoxidizing acid-usually $\mathrm{HCl}$. Under these acidic conditions, both U(IV) and U(VI) are relatively stable and do not undergo significant interconversion over the time scales of most laboratory measurement (i.e., < days). It should be noted that the leaching of a sample is done using much milder conditions than those used to complete a total sample dissolution. As a result, the procedures used in these determinations of uranium oxidation state do not extract all of the uranium from the sample. Uranium locked in refractory phases (e.g., silicate and some phosphate minerals) will not be included in the estimates of the oxidation-state distributions of this metal in the sample. Of critical concern in this leaching step is the release of $\mathrm{Fe}$ (III) that could react with U(IV) to yield U(VI) and thus, potentially, give a false estimate of the initial U(IV):U(VI) ratio in the soil.

Once in solution, a number of different approaches can be used to estimate the relative abundance of the different oxidation states of uranium. One longestablished method is to use exchange resins (O. T. Farmer, 1993, personal communication). These procedures usually involve a number of steps: first, an aliquot of the sample is mixed with a mild oxidizing agent to convert all uranium to the $U(V)$ form, and a total analysis is conducted on this. Then, unoxidized samples are adjusted to a $2 \mathrm{M} \mathrm{HCl}$ concentration, and passed across an exchange bed. Under these conditions, the $U(V I)$ is trapped by the column, whereas the U(IV) species pass through the column. $A$ mild oxidizing agent is added to the elutriate to convert the $U(I V)$ to $U(V)$ and the quantity of uranium measured. Finally, the column holding the $\mathrm{U}(\mathrm{VI})$ is eluted with distilled water, allowing the $U(V I)$ to be released. The elutriate is then analysed for uranium. The sum of the uranium in the two fractions should be equal to the total solubilized uranium measured in the first step. Once the two oxidation states of uranium have been separated any of the wet-chemical techniques described in Appendix A, Section A.1.1 (e.g., pulsed-laser phosphorimetry) can be used to quantify the amounts of uranium present in each solution.

Another approach to the problem, once the $U$ is in solution, is to selectively precipitate the U(IV) by addition of cupferron (Vogel et al., 1989, p. 471-472) or by coprecipitation with $\mathrm{NdF}_{3}$ (Anderson, 1984). After removal of the precipitate by filtration, the supernate is reduced with Ti(III) and the cupferron or $\mathrm{NdF}_{3}$ coprecipitation repeated to obtain the fraction originally present as $\mathrm{U}(\mathrm{VI})$. 
As an alternative to the exchange and precipitation methoda, aridation states of uranium in solution can bo measured directly using polarographic methods. With these methods, all forms of solubilized uranium are plated onto an appropriate electrode (e.g., mercury or gold), and the current generated as a function of voltage applied can be used to estimate the quantity of uranium present in each of the different axidation states.

For soils, most attempts at quantifying oxidation states have been dovoted to those of iron (Amonette et al, 1994). None of these attempts were specifically designed for quantification of uranium oxidation states in soils. The same general sample-handling and ample-decomposition principles hold for both elements, however. The main difficulty is in stabilizing the original ratio of axidized to reduced species during the decomposition/extraction process until they can be quantified. Although oxygen from the air is an obvious source of oxidizing power that can alter this ratio, other components of the soil may act as axidants or reductants during the decomposition process. For example, organic matter and sulfide minerals are known to reduce Fe(III) during decomposition, whereas manganese oxides act as oxidants. Uranium, with its much lower standard reduction potential may not be as susceptible to reduction as $\mathrm{Fe}$ (III) by organic matter and sulfides but, by the same token, it is more likely to be oxidized by $\mathrm{Mn}$ (IV) and perhaps even $\mathrm{Fe}$ (III). Often these effects can be muted if a stable complex of the ion in question can be formed during the decomposition process. The classic example is that of 1,10-phenanthroline, which stabilizes the Fe(II) species towards oxidation by raising its reduction potential 0.4 V. A similar ligand might be found for U(IV) (possibly cupferron).

Ignoring these dificulties for the time being, we have modified other existing methods for uranium oxidation-state determination to come up with a pair of wet-chemical methods, based on ion-exchange and on coprecipitation, that may prove suitable for analysis of uranium oxidation states in soils (see Appendix B). These methods have not been tested in their current form in the laboratory and, almost certainly, will not work for all soils. If nothing else they will give an estimate of the overall redox status of the soil relative to the $\mathrm{U}(\mathrm{VI}) / \mathrm{U}(\mathrm{IV})$ reduction potential (it may also be possible to develop a complexant-based method in which the uranium oxidation states are stabilized until analysis). As described, the methods can be performed rather easily by almost any commercial laboratory for about $\$ 300-400$ a sample, depending on the degree of automation and the method.
Some of the features of analytical methods for oxidation state determinations of uranium are listed in Table A.2.

\section{A.3 Speciation of Solid-Phase Uranium}

Like other trace metals, the solid-phase uranium in soils can occur as an exchangeable cation on minerals, as an organically bound constituent, as a pure or mixed-valence oxide, and as a structural constituent of various silicates, phosphates, or vanadates. Because soils and sediments are heterogeneous anisotropic systems, even at a microscopic scale, the dominant form of a trace metal may change from one region to the next. Attempts to speciate the solid forms of uranium in a large body of soil, therefore, face a nearly impossible task. Because these attempts are often predicated on how the uranium will react, operational definitions of uranium speciation have been used, rather than absolute definitions based on identification and quantification of specific mineral phases. Since we are interested in the "environmental availability" of uranium in soils, i.e., in its reactivity towards the soil solution, this type of operational classification is reasonable.

The literature is replete with extraction and leaching procedures ranging from single-step extractions, through multistep, single-fluid procedures, to multiextractant, sequential procedures. Tessier et al. (1979) for example, used a sequential extraction procedure to classify the trace metals in soils into five fractions: exchangeable, bound to carbonates, bound to manganese and iron oxides, bound to organic matter, and residual. A similar extraction procedure was followed by Yanase et al. (1991) to speciate the uranium in the mineral phases of rock cores from the Koongarra uranium ore body. Other systematic studies regarding the availability of the different forms of uranium to solution or to biota have been limited. Because these categories are arbitrarily defined, absolute standards do not exist, and it is difficult to assess the accuracy of the technique. However, the precision obtained for trace metals in sediment samples by Tessier et al. (1979) was in the neighborhood of $10-30 \%$ relative--clearly not as precise as for total uranium, but still manageable.

Each of these procedures yields an estimate of mass of uranium associated with some specific, operationally defined soil component. These components may be narrowly defined, as is the case for most of the steps outlined in sequential procedures, they may be broadly based, as is found for most acid extractions, or they may lack any well-defined relationship to specific soil phases. This last case is represented by most water 
Table A2. Selected foutures of analytical methods for the determination of uranium oxddation staties and uranlue botopes

\begin{tabular}{|c|c|c|c|c|c|}
\hline Method & $\begin{array}{l}\text { Detaction } \\
\text { Unit }\end{array}$ & $\begin{array}{l}\text { Relative } \\
\text { Procialon }\end{array}$ & $\begin{array}{l}\text { Coet per } \\
\text { Sample' }\end{array}$ & $\begin{array}{l}\text { Instrument } \\
\text { Cost }\end{array}$ & Comments \\
\hline Oddation Statem & $1 L^{-1}$ & $-\infty-$ & $-s-$ & $-s-$ & \\
\hline Ion Exchange & varies $^{2}$ & $\sim 10$ & 400 & $\sim 50-200 \mathrm{~K}$ & $\begin{array}{l}\text { Easily implemented in most labs; } \\
\text { instrument cost depends on method } \\
\text { used for total uranium determination }\end{array}$ \\
\hline Coprecipitation & varies & $\sim 10$ & 400 & $\sim 50-200 \mathrm{~K}$ & $\begin{array}{l}\text { Easily implemented in most labs; } \\
\text { instrument cost depends on method } \\
\text { used for total uranium determination }\end{array}$ \\
\hline $\begin{array}{l}\text { Stripping } \\
\text { Voltammetry }\end{array}$ & 1.0 & $-5-50$ & 100 & $\sim 30 \mathrm{~K}$ & $\begin{array}{l}\text { Promising technique, but not widely } \\
\text { available yet; can be automated }\end{array}$ \\
\hline XANES & $10 \mathrm{~KB} \mathrm{~B}^{-1}$ & $\sim 20$ & $50-150$ & -3 & $\begin{array}{l}\text { Requires access to a synchrotron; } \\
\text { microprobe under development; }\end{array}$ \\
\hline $\begin{array}{l}\text { Laser-based } \\
\text { Spectroscopies }\end{array}$ & $10 / 8^{-2}$ & $\sim 20$ & $<5000$ & $\sim 500 \mathrm{~K}$ & $\begin{array}{l}\text { Emerging techniques; primarily used fo } \\
\text { research }\end{array}$ \\
\hline \multicolumn{6}{|l|}{ Isotopes } \\
\hline \multicolumn{6}{|c|}{ Mass Spectrometry } \\
\hline ICP-MS & 0.01 & $\sim 10$ & 100 & $\sim 250 \mathrm{~K}$ & $\begin{array}{l}\text { High ionic-strength solutions suppress } \\
\text { sensitivity; becoming the instrument of } \\
\text { choice because of multielemental } \\
\text { capabilities; widely available }\end{array}$ \\
\hline Other MS & $10^{12}$ atoms & $\sim 10$ & 100 & $\sim 600 \mathrm{~K}$ & $\begin{array}{l}\text { Limited availability, primarily used for } \\
\text { research applications }\end{array}$ \\
\hline $\begin{array}{l}\text { Alpha } \\
\text { Spectrometry }\end{array}$ & $12 \mathbf{B q}$ & c.s. ${ }^{4}$ & $65-100$ & $-80 \mathrm{~K}$ & Moderate availability \\
\hline $\begin{array}{l}\text { Gamma } \\
\text { Spectrometry }\end{array}$ & $12 \mathbf{B q}$ & c.s. & 100 & $\sim 80 \mathrm{~K}$ & Moderate availability \\
\hline
\end{tabular}

includes eample preparation

'depends on total uranium method uned and on preconcentration factors

3 Iare facility required, capability beyond moat independent laboratoriea

'depends on counting statistics, but generally < $10 \%$

extracts of soils. The multistep, single-fluid extractions are capable of providing a limited amount of kinetic information.

Regardless of the approach, a great deal of caution needs to be used when attempting to relate the results of extraction procedures to field situations. Few of the procedures attempt to mimic field geochemical conditions, so correlating extraction results with the expected geochemical behavior of uranium at specific sites is not a routine undertaking. Extensive correlation work will have to be completed in order to 
min confidence that the output from a specific messurement, or series of messurements, can be meaningfully interpreted.

All the extraction procedures are essentially wetchemical methods. Processing time and per sample coats will depend on a number of factors such as enmples per batch, or the number of samples that a laboratory is able to extract simultaneously. In general, coil pieparation prior to the extraction [drying cleaning (if appropriate), grinding, etc.] will require from 48 to 168 hours total time. Each extraction step, then would normally require approximately 24 hours to complete (typically 18 hours on the agitation device, plus six hours of sample handling solution preparation, centrifugation and/or filtration, etc.). Total solution analytical time will vary, but $\mathrm{pH}$ and dissolved uranium analyses can normally be completed in 4 hours. Sample holding times between completion of an extraction step and the anabyais of the resulting solution will vary with the analytical facility.

Coets per sample per analysis vary from procedure to procedure. Normally, cost will increase as the number of extraction steps increases and as the number and type of extraction liquors employed increases. A rough estimate obtained from one commercial laboratory gave $\$ 75$ per extraction step, $\$ 110$ per analysis of total soluble uranium, and \$150 per uranium digestion/analysis for total uranium. Thus, for a sample requiring three extractions, determinations for both $U(I V)$ and $U(V)$ in each extract, and a total uranium digestion, an estimate of the total cost would

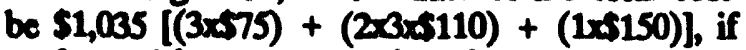
performed by a commercial laboratory. A large number (ca. 160) of commercial laboratories are equipped to perform this type of analyais in the United States.

Direct-spectroscopic speciation of solid-phase uranium is also possible by a variety of techniques. The integrated approach suggested by Morris (D. E. Morris, Los Alamos National Laboratory, 1994, personal communication) and described in Appendix A, Section A.2.1 utilizes X-ray absorption (XAS) and optical luminescence spectroscopies primarily to speciate the uranium in soils. Analytical electron microscopy can also be used to identify uranium in thin sections and individually dispersed particles by a combination of electron dift. action and $\mathrm{X}$-ray emission spectroscopy. The direct analyses tend to quantify the forms of uranium but do not necessarily provide information about the availability of the uranium. Analytical costs tend to be higher also, with a typical sample areting in the neighborhood of $\$ 5000$ by the XAS/optical luminescence approach (D. E. Morris,
Los Alamos National Laboratory, 1994, personal communication). Lastly, the question of the statistical certainty associated with a few measurements of a very small fraction of the soil remains.

\section{A.4 Speciation of Uranium Isotopes}

The specific activity of the uranium in a sample depends on its isotopic composition. Three natural isotopes of uranium contribute to the element's activity: ${ }^{2} U,{ }^{2 x} U$ and ${ }^{2} U$. In closed, natural systems, uranium has a specific activity of $0.68 \mathrm{pCi}$ $1 \mathrm{~B}^{-1}$. The percentage of this activity originating from each isotope is $48.93 \%, 2.14 \%$, and $48.93 \%$, respectively. In near-surface environments (c.g., soils), however, the ${ }^{20} \mathrm{U}$ isotope tends to have a slightly higher mobility than the other two isotopes. This stems from the fact that 2 U derives from the decay of $U$, and hence, tends to reside in mineral sites that have been damaged by the decay process. Solutions passing through soils, therefore, will leach a disproportionately larger amount of the $3 \mathrm{U}$ isotope, resulting in specific activities several times higher than $0.68 \mathrm{pCi}_{\mathrm{Ag}}^{-1}$. Currently, the EPA uses a specific activity of $1.3 \mathrm{pCi}^{\mathrm{Ng}}{ }^{-1}$ as the nominal activity of uranium in surface waters. This value is based on a geometric mean of activities measured on water samples collected during a nationwide radon survey (U. S. Environmental Protection Agency, 1985, 1991d). Because much of the environmental hazard associated with uranium is due to its specific activity, which is known to vary in weathered systems, this factor, or one derived from a direct measurement of the isotopic ratios, should be part of any estimate of environmental availability.

The isotopic composition of a uranium-bearing sample can be determined in a number of ways (Table A.2). The most straightforward of these is mass spectrometry, whereby all the isotopes of uranium can be determined regardless of their specific activity. If the sample is already in liquid form, as in an extract, for example, it can be introduced into the spectrometer via the inductively coupled plasma interface (aqueous extracts) or by electron or chemical ionization (organic extracts). The recent development of direct insertion probe analysis allows placement of a solid sample directly into the ionization chamber of the mass spectrometer, thus avoiding the need for digestion or extraction. However, this technique may not be suitable for soils where uranium is in low concentrations because it does not allow preconcentration of the sample.

Two types of nuclear spectroscopy can be used for determination of uranium isotopes. If the uranium is preconcentrated in solution form and then 
electroplated as a thin layer onto a metal support the alpha-particle energy spectrum can be measured using a surface barrier detector and a multichannel analyzer (Sanchez et al., 1987). This method will detect ${ }^{20} \mathrm{U}$, ${ }^{205} \mathrm{U}$, and ${ }^{200} \mathrm{U}$ (i.e., the naturally occurring isotopes) as well as most of the anthropogenic isotopes. Gamma spectrometry can also be used for isotopic analysis, but is most sensitive to ${ }^{20} \mathrm{U}$, an anthropogenic isotope, and insensitive to ${ }^{20} \mathrm{U}$. If the sample is bombarded with epithermal neutrons, however, ${ }^{20} \mathrm{U}$ will be converted to ${ }^{20} \mathrm{U}$ and can then be measured by gamma spectrometry (Steinnes, 1971; Gladney et al., 1978; Miera, 1980).

Uranium concentrations can also be estimated indirectly in solid samples by gamma spectroscopy of the decay products ${ }^{24} \mathrm{Th}$ and ${ }^{24} \mathrm{~Pa}$, which are established relatively quickly (within 100 days) after purification of $U$ and attainment of secular equilibrium (R. J. Serne, 1994, personal communication).

Analytical costs for alpha spectrometry are about \$65$\$ 100$ per sample and at least one international laboratory offers rapid turnarounds on the order of 1 week. The ICP-MS approach has less sample preparation and, in principle, offers a quicker turnaround time. However, costs and turnaround time vary considerably (as long 60 days in one laboratory). In addition, some problems in quantifying ${ }^{25} U$ have been encountered by at least one laboratory, although these do not seem to be common. Availability of equipment for both methods is comparable and, consequently, the two techniques may be considered equally practical, with the decision as to which one to use depending on individual circumstances.

\section{A.5 References}

American Society for Testing and Materials, ASTM D5174-91, "Standard Test Method for Trace Uranium in Water by Pulsed-Laser Phosphorimetry," Annual Book of ASTM Standards, 11.02:425-427, ASTM, Philadelphia, Pennsytvania, 1992.

Amonette, J. E., and R. W. Sanders, "Nondestructive Techniques for Bulk Elemental Analysis," Quantitative Methods in Soil Mineralogy, J. E. Amonette, and L. W. Zelazny (eds.), pp. 1-48, Soil Science Society of America, Madison, Wisconsin, 1994.

Amonette, J. E., F. A. Khan, H. Gan, J. W. Stucki, and A. D. Scott, "Quantitative Oxidation-State Analysis of Soils," Quantitative Methods in Soil Mineralogy, J. E. Amonette, and L. W. Zelazny (eds.), pp. 83-113, Soil Science Society of America, Madison, Wisconsin, 1994.
Anderson, R. F., "A Method for Determining the Oxidation State of Uranium in Natural Waters," Nuclear Instruments and Methods in Physics Research, 223: 213-217, 1984.

Bertsch, P. M., D. B. Hunter, S. R. Sutton, S. Bajt, and M. L. Rivers, "In Situ Chemical Speciation of Uranium in Soils and Sediments by Micro X-ray Absorption Spectroscopy." Environmental Science and Technology, (1994, in press).

Bruno, J., I. Grenthe, and B. Lagerman, "Redox Processes and $\mathrm{UO}_{2}(\mathrm{~s})$ Solubility: The Determination of the $\mathrm{UO}_{2}{ }^{2+} / \mathrm{U}^{4+}$ Redox Potential at $25^{\circ} \mathrm{C}$ in $\mathrm{HClO}$. Media of Different Ionic Strength," Scientific Basis for Nuclear Waste Management LX, Materials Research Society Symposia Proceedings, 50:299-308, Materials Research Society, Pittsburgh, Pennsylvania, 1985.

Gladney, E. S., W. K. Hensley, and M. M. Minor, "Comparison of Three Techniques for the Measurement of Depleted Uranium in Soils," Analytical Chemistry, 50: 652-653, 1978.

Greenfield, S., I. L. Jones, and C. T. Berry, "High Pressure Plasma as Spectroscopic Emission Sources," Analyst, 89: 713-720, 1964.

Helmke, P. A., "Neutron Activation Analysis," Methods of Soil Analysis, Part 2, Chemical and Microbiological Properties, 2nd Ed. pp. 67-84, American Society of Agronomy, Madison, Wisconsin, 1982.

Houk, R. S., V. A. Fassel, G. D. Flesch, H. J. Svec, A. L. Gray, and C. F. Taylor, "Inductively Coupled Argon Plasma as an Ion Source for Mass Spectrometric Determination of Trace Elements," Anabytical Chemistry, 52: 2283-2289, 1980.

Johnson, W. M., and J. A. Maxwell, Rock and Mineral Analysis, 2nd Edition, Robert Krieger, Malabar, Florida, 1989.

Kojima, T., and Y. Shigetomi, "Spectrophotometric Determination of Uranium(VI) by Solvent Extraction with Trioctylphosphine Oxide and a Molten Mixture of Biphenyl and Napthalene," Talanta, 36: 603-605, 1989.

Landsberger, S., and D. Wu, "Improvement of Analytical Sensitivities for the Determination of Antimony, Arsenic, Cadmium, Indium, Iodine, Molybdenum, Silicon and Uranium in Airborne Particulate Matter by Epithermal Neutron Activation Analysis," Joumal of Radioanalytical and Nuclear Chemistry, Articles, 167: 219-225, 1993. 
Lim, C. H, and M. L. Jackson, "Dissolution for Total Elemental Analysis," Methods of Soil Analysis, Pant 2, Chemical and Microbiological Properties, 2nd Ed, pp. 1-12, American Society of Agronomy, Madison, Wisconsin, 1982.

Miera, F.R., Jr., LA-8624T (Thesis), "Measurements of Uranium in Soils and Small Mammals," Los Alamos National Laboratory, Los Alamos, New Mexicu, 1980.

Pavor, J. L. P., B. M. Cordero, J. H. Mendez, and R. M. I. Agudo, "Application of a Nested-Loop System for the Simultaneous Determination of Thorium and Uranium by Flow Injection Analysis," Analytical Chemistry, 61: 1789-1791, 1989.

Pavon, J. L. P, C. G. Pinto, E. R. Garcia, and B. M. Cordero, "Flow-Injection Determination of Thorium and Uranium after On-Line Ion-Exchange Preconcentration on Dowex 50-X8," Anabytica Chimica Acta, 264: 291-296, 1992.

Rajec, P., "Extraction Fluorimetric Determination of Uranium by Conventional Spectrophotometry," Jownal of Radioanabytical and Nuclear Chemistry, Letters, 166: 413-419, 1992.

Robbins, J. C., C. Castledine, and W. Kostiak, Anatytical Procedures for UA-3 Uranium Analysis, Applications Brief 79-2, Scintrex, Concord, Ontario, 1985.

Sanchez, A. M., F. V. Tome, and J. D. Bejarano, "Natural Isotopic Separation of Uranium in the Guadiana Basin," Joumal of Radioanabytical and Nuclear Chemistyy, Letters, 118: 291-298, 1987.

Silfwerbrand-Lindh, C., L. Nord, L-G. Danielsson, and F. Ingman, "The Analysis of Aqueous Solutions with Ethanol-Soluble Reagents in a Flow Injection System," Anabytica Chimica Acta, 160: 11-19, 1984.

Soltanpour, P. N., J. B. Jones, Jr., and S. M. Workman, "Optical Emission Spectrometry," Methods of Soil Analysis, Part 2, Chemical and Microbiological Properties, 2nd Ed, pp. 29-65, American Society of Agronomy, Madison, Wisconsin, 1982.

Steinnes, E., "Epithermal Neutron Activation Analysis of Geological Material," Activation Analysis in Geochemistry and Cosmochemistry, pp. 113-128, Universitets Forlaget, Oslo, Norway, 1971.
Tessier, A., P.G.C. Campbell, and M. Bisson, "Sequential Extraction Procedure for the Speciation of Particulate Trace Metals," Analytical Chemistry, 51: 844-853, 1979.

U. S. Environmental Protection Agency, EPA 520/585-008, Nationwide Occurrence of Radon and Other Natural Radioactivity in Public Water Supplies (The Nationwide Radon Survey), 1985.

U. S. Environmental Protection Agency, "National Primary Drinking Water Regulations; Radionuclides; Proposed Rules," Federal Register, 56 FR 33050-33127, July 18, 1991d.

Vogel, A. I., G. H. Jeffery, J. Bassett, J. Mendham, and R. C. Denney, Vogel's Textbook of Quantitative Chemical Analysis, 5th Ed., Longman Scientific and Fechnical, Essex, England, 1989.

Wang, J., and R. Setiadji, "Selective Determination of Trace Uranium by Stripping Voltammetry Following Adsorptive Accumulation of the Uranium-Cupferron Complex," Analytica Chimica Acta, 264: 205-211, 1992.

Wang, J., J. Lu, and K. Olsen, "Measurement of Ultratrace Levels of Chromium by AdsorptiveCatalytic Stripping Voltammetry in the Presence of Cupferron," Analyst 117: 1913-1917, 1992a.

Wang, J., R. Setiadji, L. Chen, and J. Lu, "Automated System for On-Line Adsorptive Stripping Voltammetric Monitoring of Trace Levels of Uranium", Electroanalysis, 4: 161-165, $1992 \mathrm{~b}$.

Wendt, R. H., and V. A. Fassel, "Induction-Coupled Plasma Spectrometric Excitation Source," Analytical Chemistry, 37: 920-922, 1965.

Yanase, N., T. Nightingale, T. Payne, and P. Duerden, "Uranium Distribution in Mineral Phases of Rock by Sequential Extraction Procedure," Radiochimica Acta, 52/53: 387-393, 1991.

Zielinski, R. A., and D. M. McKown, "Determination of Uranium Concentration in Water by Liquid Anion Exchange-Delayed Neutron Analysis," Joumal of Radioanalytical and Nuclear Chemistry, Articles, 84: 207-212, 1984. 


\section{Appendix B: Draft Wet-Chemical Methods for Oxidation-State Determination of Uranium in Soils}

\section{B.1 Ion-Exchange Method}

[modified from method given by 0 . T. Farmer based on work by Kraus and Nelson (1956) and an extraction step of Yanase et al. (1991)]

This method, which has not been tested in its complete form in the laboratory, segregates U(IV) from $U(V I)$ and also allows measurement of total available uranium on a single sample of soil.

Available uranium is that which can be dissolved in 6 $\mathrm{M} \mathrm{HCl}$ at $85^{\circ} \mathrm{C}$. The segregation step works by ion exchange on a strong-base anion-exchange resin at a pH that optimizes U(VI) adsorption relative to U(IV). The $U(V I)$ is then eluted from the exchange resin with deionized water. The U(IV) remaining in the initial solution is then oxidized to $U(V I)$, passed through the exchange resin, and the uranium adsorbed is eluted as before. The total available uranium can be estimated by the sum of the uranium in these two fractions, and compared with results obtained by oxidizing a separate aliquot of the sample initially and then performing the ion exchange step.

\section{Reagents}

deionized $\mathrm{H}_{2} \mathrm{O}$

$6 \mathrm{M} \mathrm{HCl}$, preheated to $85^{\circ} \mathrm{C}$ in water bath

$4 \mathrm{M} \mathrm{HCl}$

$10 \% \mathrm{H}_{2} \mathrm{O}_{2}$ solution

high-purity inert gas $\left(\mathrm{N}_{2}, \mathrm{Ar}\right)$ for sparging

(deoxygenation)

\section{Materials}

$85^{\circ} \mathrm{C}$ shaking water bath

$30-\mathrm{ml}$ and $125-\mathrm{ml}$ poly bottles with air-tight seals

$<0.45-\mu \mathrm{m}$ filter membranes (25-mm diameter)

25-mm-diameter filter membrane holder

$\mathrm{Cl}$-saturated strong-base anion-exchange resin (e.g.,

Amberlite 400, Dowex 1)

Ion exchange column, at least $4 \mathrm{~cm}$ long and $0.25 \mathrm{~cm}^{2}$ in cross section

\section{Instrumentation}

Inductively coupled plasma mass spectrometer QR Pulsed-laser phosphorimeter

\section{Sampling}

The soil should be maintained in a field-moist condition, isolated from atmospheric oxygen (preferably under nitrogen), and stored either frozen or at $4^{\circ} \mathrm{C}$ until time for analysis. Immediately before analysis, about $50 \mathrm{~g}$ of soil should be gently ground to a coarse powder (to pass a 60-mesh sieve) under acetone or isopropyl alcohol, homogenized, and stored under nitrogen in an air-tight container. Two 10-g samples of the ground soil should be weighed moist, oven-dried to a constant weight at $105^{\circ} \mathrm{C}$, and reweighed after cooling in a desiccator, to determine moisture content. All analytical results will be reported in terms of the oven-dry weight of the soil.

\section{Method}

Carefully weigh (to $1-\mathrm{mg}$ precision) about $1 \mathrm{~g}$ of the ground and homogenized soil and transfer into a 125ml polypropylene bottle. Tare the bottle and cap, add $60 \mathrm{ml}\left(65.4 \mathrm{~g}\right.$ assuming density of $1.09 \mathrm{~g} \mathrm{ml}^{-1}$ at $20^{\circ} \mathrm{C}$ ) of $6 \mathrm{M} \mathrm{HCl}$ (preheated to $85^{\circ} \mathrm{C}$ in the water bath), cap tightly, reweigh the bottle and cap, and place in the shaking water bath. After digesting for 2 hours, remove the bottle; while it is still hot, centrifuge and then filter the supernate through a $0.45-\mu \mathrm{m}$ filter membrane into a clean $125-\mathrm{ml}$ polypropylene bottle. Wash the solid remaining in the digestion bottle and on the filter paper with two 5-ml aliquots of fresh, $85^{\circ} \mathrm{C}, 6 \mathrm{M} \mathrm{HCl}$.

Tare two 125-ml polypropylene bottles and transfer approximately $20 \mathrm{ml}(21.8 \mathrm{~g}$ assuming density of 1.09 $\mathrm{g} \mathrm{ml}{ }^{-1}$ at $20^{\circ} \mathrm{C}$ ) of the hot $\mathrm{HCl}$ extract into each bottle and reweigh. To the first bottle (hereafter referred to as Bottle $A$ ), add $10 \mathrm{ml}$ of deionized and deoxygenated $\mathrm{H}_{2} \mathrm{O}$. To the second bottle (hereafter referred to as Bottle B), add $1 \mathrm{ml}$ of $10 \% \mathrm{H}_{2} \mathrm{O}_{2}$ solution and then $9 \mathrm{ml}$ of $\mathrm{H}_{2} \mathrm{O}$. Gently stir both bottles to mix (do not cap Bottle B).

Allow the remaining $6 \mathrm{M} \mathrm{HCl}$ extract to cool to room temperature and then determine the density of the extract solution and of the original $6 \mathrm{M} \mathrm{HCl}$ solution (this can be determined at any time on a cool sample) using a $25-\mathrm{ml}$ calibrated volumetric flask. These densities will be used to determine the actual amounts of $\mathrm{HCl}$ that were used to extract the sample and that were transferred into Bottles $A$ and $B$.

Pass the contents of Bottle $A$ through the anion exchange column (the column should be prepared using $4 \mathrm{M} \mathrm{HCl}$ ) and collect the effluent in a clean bottle (hereafter referred to as Bottle $\mathrm{C}$ ). Rinse Bottle $\mathrm{A}$ with one 5-ml aliquot of $4 \mathrm{M} \mathrm{HCl}$ and pass through the column into Bottle C. Add $1 \mathrm{ml}$ of $10 \%$ $\mathrm{H}_{2} \mathrm{O}_{2}$ to Bottle C. Place Bottle B and Bottle C, loosely capped, in the $85^{\circ} \mathrm{C}$ water bath for 30 minutes 63 or until all the $\mathrm{H}_{2} \mathrm{O}_{2}$ has decomposdular fiditared 632 
the absence of air bubbles on the walls of the bottles. (In some instances, overnight incubations may be required to completely remove all the $\mathrm{H}_{2} \mathrm{O}_{2}$.) Meanwhile, pass about $25 \mathrm{ml}$ of deionized $\mathrm{H}_{2} \mathrm{O}$ through the exchange column to elute the $U(\mathrm{VI})$ from Bottle A that was adsorbed to the resin and collect the effluent in a 30-ml polyethylene bottle. This 30$\mathrm{ml}$ bottle contains the $\mathrm{U}(\mathrm{VI})$ that was extracted from the soil.

When the $\mathrm{H}_{2} \mathrm{O}_{2}$ has decomposed in Bottles $\mathrm{B}$ and $\mathrm{C}$, remove them from the water bath and allow them to cool to room temperature. While they are cooling, resaturate the column with $\mathrm{Cl}^{-}$by passing $0.1 \mathrm{M} \mathrm{NaCl}$ solution through and then eluting with deionized $\mathrm{H}_{2} \mathrm{O}$ to the absence of $\mathrm{Cl}^{-}$(as tested by additions of AgNO, solution to the effluent). Pass the contents of Bottle B through the column and rinse the bottle with $5 \mathrm{ml}$ of $4 \mathrm{M} \mathrm{HCl}$ as before. Elute the U(VI) adsorbed to the column with $25 \mathrm{ml}$ of deionized $\mathrm{H}_{2} \mathrm{O}$ and collect the elutriate in a $30-\mathrm{ml}$ polypropylene bottle. This bottle contains the total $U$ that was extracted from the soil.

Resaturate the column with $\mathrm{Cl}^{-}$as before, and then repeat the ion exchange process for Bottle $C$. The third 30-mi bottle contains the U(IV) that was extracted from the soil.

The solutions in the $30-\mathrm{ml}$ bottles may then be made to volume with reagent $\mathrm{H}_{2} \mathrm{O}$ and analyzed directly by pulsed-laser phosphorimetry (ASTM D5174-91). If analysis by ICP-MS is desired the solutions may be diluted with $\mathrm{HNO}_{3}$.

\section{Standards}

With each batch of samples a set of standard U(IV) and $U(V I)$ samples should be run to verify the results. A stock solution of $U(V I)$ in $4 \mathrm{M} \mathrm{HCl}$ should be stable. A U(IV) solution can be prepared from the $\mathrm{U}(\mathrm{VI})$ stock solution by reduction with $20 \% \mathrm{TiCl}_{3}$ (add $1 \mathrm{ml}$ for every $100 \mathrm{ml}$ of stock solution). After the uranium has been reduced, the remaining $\mathrm{TiCl}_{3}$ must be oxidized by the addition of $2 \mathrm{ml}$ of $12 \mathrm{M}$ $\mathrm{HNO}_{3}$ for every $100 \mathrm{ml}$ of stock solution.

\section{B.2 Coprecipitation Method}

[modified from Anderson (1984) and Yanase et al. (1991)]

This method, which has not been tested in its complete form in the laboratory, segregates U(IV) from $U(V I)$ and also allows measurement of total available uranium on a single sample of soil. Available $U$ is that which can be dissolved in $6 \mathrm{M}$ $\mathrm{HCl}$ at $85^{\circ} \mathrm{C}$. The segregation step works by coprecipitation of the uranous ion [U(IV)] with $\mathrm{NdF}_{3}$. The U(VI) remaining is then reduced to U(IV) by Ti(III) and coprecipitated as before. The total available uranium can be estimated as the sum of the uranium in these two fractions, and compared with results obtained by reducing a separate aliquot of the sample initially and performing the coprecipitation step.

\section{Reagents}

deionized $\mathrm{H}_{2} \mathrm{O}$

concentrated $\mathrm{HCl}$

$6 \mathrm{M} \mathrm{HCl}$, preheated to $85^{\circ} \mathrm{C}$ in water bath

$0.6 \mathrm{M} \mathrm{HCl}+0.08 \mathrm{M} \mathrm{HF}$ (in plastic bottle)

$2.5 \% \mathrm{Nd}$ solution as $\mathrm{Nd}\left(\mathrm{NO}_{3}\right)$, sparged

48\% HF

$20 \% \mathrm{TiCl}_{3}$ (prepare fresh)

high-purity inert gas $\left(\mathrm{N}_{2}, A r\right)$ for sparging

(deoxygenation)

\section{Materials}

$85^{\circ} \mathrm{C}$ shaking water bath

30 -, 125-, and $250-\mathrm{ml}$ poly bottles with air-tight seals

$<0.45$ - $\mathrm{mm}$ filter membranes (25-mm diameter)

25-mm-diameter filter membrane holder

Cl-saturated strong-base anion-exchange resin (e.g.,

Amberlite 400, Dowex 1)

Instrumentation

Inductively coupled plasma mass spectrometer QR Pulsed-laser phosphorimeter

\section{Sampling}

The soil should be maintained in a field-moist condition, isolated from atmospheric oxygen (preferably under nitrogen), and stored either frozen or at $4^{\circ} \mathrm{C}$ until time for analysis. Immediately before analysis, about $50 \mathrm{~g}$ of soil should be gently ground to a coarse powder (to pass a 60-mesh sieve) under acetone or isopropyl alcohol, homogenized, and stored under nitrogen in an air-tight container. Two 10-g samples of the ground soil should be weighed moist, oven-dried to a constant weight at $105^{\circ} \mathrm{C}$, and reweighed after cooling in a desiccator, to determine moisture content. All analytical results will be reported in terms of the oven-dry weight of the soil.

\section{Method}

Carefully weigh (to $1-\mathrm{mg}$ precision) about $1 \mathrm{~g}$ of the ground and homogenized soil and transfer into a 125 ml polypropylene bottle. Tare the bottle and cap, add $60 \mathrm{ml}\left(65.4 \mathrm{~g}\right.$ assuming density of $1.09 \mathrm{~g} \mathrm{ml}^{-1}$ at $20{ }^{\circ} \mathrm{C}$ ) of $6 \mathrm{M} \mathrm{HCl}$ (preheated to $85^{\circ} \mathrm{C}$ in the water 
Appendix B: Draft Oxidation-State Methods

bath), cap tightly, reweigh the bottle and cap, and place in the shaking water bath. After digesting for 2 hours, remove the bottle; while it is still hot, centrifuge, and filter the supernate through a $0.45-\mu \mathrm{m}$ filter membrane into a clean $125-\mathrm{ml}$ polypropylene bottle. Wash the solid remaining in the digestion bottle and on the filter paper with two 5-ml aliquots of fresh, $85^{\circ} \mathrm{C}, 6 \mathrm{M} \mathrm{HCl}$.

Tare two 250-ml polypropylene bottles and transfer approximately $20 \mathrm{ml}$ (21.8 g assuming density of 1.09 $\mathrm{g} \mathrm{ml}^{-1}$ at $20{ }^{\circ} \mathrm{C}$ ) of the $\mathrm{HCl}$ extract into each bottle and reweigh. To the first bottle (hereafter referred to as Bottle A) add $1 \mathrm{ml}$ of $2.5 \% \mathrm{Nd}$ solution and then $180 \mathrm{ml}$ of deionized and deoxygenated $\mathrm{H}_{2} \mathrm{O}$. To the second bottle (hereafter referred to as Bottle B) add $2 \mathrm{ml}$ of $2.5 \%$ Nd solution and then $180-\mathrm{ml}$ of $\mathrm{H}_{2} \mathrm{O}$. Shake both bottles to mix. To bottle $A$ add $0.1 \mathrm{ml}$ of concentrated HF. To Bottle B add $0.1 \mathrm{ml}$ of $20 \%$ $\mathrm{TiCl}_{3}$, mix, and then add $0.6 \mathrm{ml}$ of HF. Shake both bottles to mix and allow to stand for at least 1 hour to allow the $\mathrm{NdF}_{3}$ precipitate to form.

Allow the remaining $6 \mathrm{M} \mathrm{HCl}$ extract to cool to room temperature and then determine the density of the extract solution and of the original $6 \mathrm{M} \mathrm{HCl}$ solution (this can be determined at any time on a cool sample) using a $25-\mathrm{ml}$ calibrated volumetric flask. These densities will be used to determine the actual amounts of $\mathbf{H C l}$ that were used to extract the sample and that were transferred into Bottles A and B.

After standing, filter the suspension in Bottle A through a $0.45-\mu \mathrm{m}$ filter membrane, saving both the filtrate and the filter cake. Wash the filter cake with $0.6 \mathrm{M} \mathrm{HCl}-0.08 \mathrm{M} \mathrm{HF}$ and transfer membrane and filter cake to a clean $30-\mathrm{ml}$ poly bottle. The filter cake in this bottle contains the U(IV) that was extracted from the soil. Add $0.1 \mathrm{ml}$ of $\mathrm{TiCl}_{3}$ to the filtrate from Bottle $A$ and mix. Then add $1 \mathrm{ml}$ of the 2.5\% Nd solution, followed by $0.6 \mathrm{ml}$ of HF. Mix and let stand for an hour. Filter as before, wash the filter cake, and transfer the membrane and cake to a separate $30-\mathrm{ml}$ bottle. The filter cake in this bottle contains the $U(V I)$ that was extracted from the soil.

For Bottle B, filter and wash the filter cake as for Bottle $A$, and transfer the membrane containing the filter cake to a third 30-ml polypropylene bottle. The filter cake in this bottle contains the total uranium that was extracted from the soil.

To the contents of each $30-\mathrm{ml}$ bottle, add a minimum amount of concentrated $\mathrm{HCl}$ to dissolve the $\mathrm{NdF}_{3}$ precipitate. The solution then may be diluted to volume with $\mathrm{HNO}_{3}$ for subsequent determination of uranium by ICP-MS. If analysis by pulsed-laser phosphorimetry (ASTM D5174-91) is desired, then the uranium must be oxidized to $U(V)$ by addition of $\mathrm{H}_{2} \mathrm{O}_{2}$ (after dissolution of the filter cake in $\mathrm{HCl}$ ) and the sample purified by passage through a $\mathrm{Cl}$-saturated strong-base anion-exchange resin (e.g., Amberlite 400, Dowex 1) after decomposing the $\mathrm{H}_{2} \mathrm{O}_{2}$ and adjusting the $\mathrm{HCl}$ concentration to $4 \mathrm{M}$. The $\mathrm{U}(\mathrm{VI})$ retained on the exchange resin is then eluted with deionized $\mathrm{H}_{2} \mathrm{O}$ and diluted to volume, and this sample is analyzed by phosphorimetry.

\section{Standards}

With each batch of samples a set of standard U(IV) and $U(V I)$ samples should be run to verify the results. A stock solution of $\mathrm{U}(\mathrm{VI})$ in $4 \mathrm{M} \mathrm{HCl}$ should be stable. A U(IV) solution can be prepared from the $\mathrm{U}(\mathrm{VI})$ stock solution by reduction with $20 \% \mathrm{TiCl}_{3}$ (add $1 \mathrm{ml}$ for every $100 \mathrm{ml}$ of stock solution). After the uranium has been reduced, the remaining $\mathrm{TiCl}_{3}$ must be oxidized by the addition of $2 \mathrm{ml}$ of $12 \mathrm{M}$ $\mathrm{HNO}_{3}$ for every $100 \mathrm{ml}$ of stock solution.

\section{B.3 References}

American Society for Testing and Materials, ASTM D5174-91, "Standard Test Method for Trace Uranium in Water by Pulsed-Laser Phosphorimetry," Annual Book of ASTM Standards, 11.02:425-427, ASTM, Philadelphia, Pennsylvania, 1992.

Anderson, R. F., "A Method for Determining the Oxidation State of Uranium in Natural Waters," Nuclear Instruments and Methods in Physics Research, 223: 213-217, 1984.

Kraus, K. A., and F. Nelson, "Metal Separations by Anion Exchange," Proceedings of a Symposium on Ion Exchange and Chromatography in Analytical Chemistry, ASTM Special Publication No. 195, p. 27-57, American Society for Testing and Materials, Philadelphia, Pennsylvania, 1956.

Yanase, N., T. Nightingale, T. Payne, and P. Duerden, "Urawium Distribution in Mineral Phases of Rock by Sequential Extraction Procedure," Radiochimica Acta, 52/53, 387-393, 1991. 


\section{Appendix C: Draft Interim Method for Estimating Environmentally Available Uranium in Soils}

\begin{abstract}
The method presented is a draft interim procedure developed for the $U$. S. Nuclear Regulatory Commission (NRC) under contract NRC FIN J5019. The method is based on established standard procectures and on results of reseanch being conducted within the DOE complex. The method has not been field-tested to establish its efficacy for estimating envinonmentally available unanium in soils. Users are cautioned to employ approved quality assurance/quality control protocols with this method to maximize the interpretability of the results.
\end{abstract}

\section{C.1 Background}

Uranium occurs in soils both as a naturally occurring element and as a result of certain human activities. The uranium is present in a range of forms, some of which are readily available to the biosphere, some of which are available but slow to be released to the biosphere, and some of which exist in refractory forms.

Uranium has a unique chemistry relative to most metals. Uranium can be highly soluble, especially in oxidizing, carbonate-bearing environments. Under reducing conditions in circumneutral-pH systems, uranium is sequestered. As a result of this unusual chemistry, assessment methods developed for generic environmental concerns may not be applicable for assessing uranium-contaminated sites.

Remediation activities at uranium-contaminated sites are currently being driven by two concerns: total concentrations of uranium, and the amounts of uranium that are available to the biosphere. Assessment methods must provide estimates of both total and available forms of uranium in the soil.

This draft interim method was developed specifically for the NRC to provide a series of procedures that will enable the agency and its regulatees to obtain estimates of the quantities of available uranium present in soils at contaminated sites. It does not provide a procedure for estimating total soil uranium; standard procedures for determining total uranium are available elsewhere, and are not repeated here.

\section{C.2 Purpose}

The purpose of this draft interim method is to provide an analytical protocol for estimating the quantities of uranium present in readily available, slowly available, and very slowly available forms. The protocol is designed for the analysis of individual soil samples, the results of which are to be integrated with test results obtained on other soil samples as well as other types and sources of information. Decisions concerning appropriate remediation decisions should not be based on the results of individual or a small number of tests. However, the integration of the results obtained from multiple tests is beyond the scope of this method.

\section{C.3 Definitions}

TU - Total Uranium - the sum of all fractions of uranium contained in the sample. This includes both available and refractory fractions. The value may be determined instrumentally, for example, using $X$-ray Fluorescence (XRF), or Instrumental Neutron Activation Analysis (INAA), or it may be determined chemically after total dissolution of the sample (typically accomplished using $\mathrm{HF} / \mathrm{HClO}$, digestions, or by fusion of the sample in an appropriate flux). This quantity is not determined by this draft interim method.

RAU - Readily Available Uranium - the fraction of uranium in a soil that is potentially soluble and whose release to soil solutions is not kinetically inhibited. RAU generally includes uranium bound in the following forms: exchangeable uranium, $U(V)$ hydrous oxides, uranium coprecipitated with carbonates, some organically bound forms, and some forms sorbed onto iron or manganese sesquioxides.

SAU - Slowly Available Uranium - This fraction of uranium is not highly soluble in low alkalinity, circumneutral waters, although it can be made available, usually by a transformation reaction [e.g., oxidation from U(IV) to U(VI)]. The fraction generally includes discrete reduced oxide phases, and some portion of the uranium bound in soil organics.

VSAU - Very Slowly Available Uranium - This fraction of uranium can be made available only under certain restrictive conditions. The fraction is generally composed of uranyl phosphate minerals, and of uranium bound in crystalline iron and manganese oxides, refractory soil organics, and some uranyl silicates. 
TAU - Total Available Uranium - the fraction of uranium in a soil that is potentially available to the biosphere. This includes all fractions described for the RAU, SAU, and VSAU forms.

Lower-Limit Action Lovels - a soil concentration specified by the regulating agency. If total uranium or total available uranium concentrations are less than this action level, then, in most cases, remediation of the site will not be required. Also, the regulating agency has the option of not mandating clean-up if readily available uranium concentrations are less than this limit and total available uranium concentrations are less than the Upper-Limit Action Level.

Upper-Limit Action Levels - a soil concentration for total or total available uranium concentrations above which soil remediation is mandated.

\section{C.4 Applications}

This draft interim method has been assembled specifically for the NRC as a protocol for evaluating amounts of environmentally available uranium present in contaminated soils. The procedures contained in this method have been taken from a variety of sources, including both standard methods and research being conducted within the DOE complex. Although the sources for these procedures suggest they should be applicable to NRC concerns, the efficacy of the methods has not been tested in either laboratory or field situations. It is recommended that evaluations of the method be completed before the method is applied to site-specific issues.

C.4.1 Regulatory decisions will be based on the levels of total and available uranium measured relative to the Upper- and Lower-Limit Action Levels, which are set by the NRC.

If total uranium concentrations in soils for a site do not exceed the Lower-Limit Action Levels, then site operators do not need to conduct the available uranium assessments described in this method.

If total uranium concentrations exceed the UpperLimit Action Levels, site operators will probably be required to remediate contaminated soils to levels specified by the NRC. Site operators have the option of completing the assessments described in this method, because the information obtained from the procedures may be useful in establishing applicable remediation levels.

If total uranium levels fall between the two Action Levels, it is recommended that site operators conduct the assessments described in this draft interim method.

If total uranium concentrations have not been measured at the site, it is recommended that the site operators obtain survey information about the concentrations and distributions of uranium in the soils in all contaminated or potentially contaminated areas. Specification of methods or procedures for this activity is beyond the scope of this draft interim method.

C.4.2 This draft interim method is applicable for assessing uranium availability along the following pathways: 1) soils --> soil water -> plants; 2) soil --> soil water --> groundwater; 3) soil --> soil water $\rightarrow>$ surface water; and 4) soil --> direct ingestion.

The method is not applicable for the jathway soil -> suspension of dust $->$ inhalation of respirable particles. If this last pathway poses a regulatory, concern, site operators are directed to the NRC's 1981 Branch Technical Position entitled Disposal or On-site Storgae of Thorium and Uranium Wastes from Past Operations for guidance regarding appropriate assessment methods.

\section{C.5 Summary of the Method}

The draft interim method for estimating available uranium in soils follows a decision-tree approach. After each step in the method, results can be compared with established action levels to determine appropriate next steps.

The first step is to determine the total available uranium concentrations in soils. The procedure is based on the ASTM Method D3974-81, Practice B. Results from this test might suggest that available uranium concentrations are sufficiently low as to warrant no additional action. Conversely, the results might suggest that additional testing is needed. If total available uranium levels exceed specified levels, the analyst has several options.

Initially, the analyst may choose to determine the $\mathrm{U}(\mathrm{IV}) / \mathrm{U}(\mathrm{VI})$ distribution in the total available uranium fraction. If the $U(V I)$ concentrations are less than the Lower-Limit Action Levels and the U(IV) plus $U(V I)$ concentrations are less than the UpperLimit Action Levels, then no further action may be required. However, if these conditions are not met, the analyst is directed to assess the readily available, slowly available, and very slowly available fractions of uranium in the soil. 
As an alternative to the determination of the $\mathrm{U}(\mathrm{IV}) / \mathrm{U}(\mathrm{VI})$ ratios, the analyst may choose to perform the availability assessment of the uranium directly. This assessment is done using a combination of EPA/SW 846 Method 1311 (TCLP) and research protocols. Results from these procedures are not only crucial if remedial actions are needed, but could also provide information that would be useful for determining appropriate remedial technologies.

\section{C.6 Reagents}

C.6.1 Deaxygenated Reagent-Grade Water - Sparge with purified nitrogen or boil vigorously while applying a vacuum for $\mathbf{3 0}$ minutes and store in air-tight container. Should be prepared daily unless storage under an anoxic atmosphere is available.

C.6.2 Concentrated Hydrochloric Acid - (nominally $12 \mathrm{~N})$. This should be reagent-grade acid.

\section{C.6.3 Nitric Acid - reagent grade - nominally $5 \mathrm{~N}$.}

C.6.4 Hydrogen Peroxide - $30 \%$ - reagent grade.

C.6.5 Dow $\times 1 \times 10$ anion exchange resin.

C.6.6 $\mathrm{NaCl}-4.0 \mathrm{M}$ - reagent grade. Dissolve 233.8 $\mathrm{g}$ of reagent-grade $\mathrm{NaCl}$ in $1 \mathrm{~L}$ of reagent water.

C.6.7 Silver Nitrate - $\mathrm{AgNO}_{3}-10 \%$ solution. Dissolve $10 \mathrm{~g}$ of silver nitrate in $100 \mathrm{ml}$ of reagent water. Store in an opaque container, and keep out of direct light.

C.6.8 Acetic Acid Solution - $0.1 \mathrm{M}$ - dilute $5.7 \mathrm{ml}$ of glacial acetic acid in $1.00 \mathrm{~L}$ of reagent water. Check $\mathrm{pH}$ of the solution. If correctly prepared, the solution should have a $\mathrm{pH}$ of $2.88 \pm 0.05$.

C.6.9 Sodium Bicarbonate Solution - $0.1 \mathrm{M}$ Dissolve $52.04 \mathrm{~g}$ of reagent-grade $\mathrm{NaHCO}_{3}$ in $1.00 \mathrm{~L}$ of reagent water.

C.6.10 Oxidized-U Spiking Solution - Prepare a $1000 \mathrm{ppm}$ standard stock solution from appropriate reagents. The analyst needs to be aware of both the chemical form and the isotopic composition of the reagent, because many uranium compounds are prepared from depleted uranium. The following is an example of a standard preparation, although chemical weight: must be adjusted for the chemical form used as the base reagent.
Weigh out $1.353 \pm 0.002 \mathrm{~g}$ of $\mathrm{UO}_{3} \cdot 2 \mathrm{H}_{2} \mathrm{O}$. Place in a clean $500-\mathrm{ml}$ beaker and add ca. $200 \mathrm{ml}$ of reagent water and $100 \mathrm{ml}$ of concentrated, reagent-grade $\mathrm{HCl}$. Slowly add $5.0 \mathrm{ml}$ of $30 \% \mathrm{H}_{2} \mathrm{O}_{2}$. Place suspension on a hot plate, heat to ca. $80^{\circ} \mathrm{C}$, and hold at that temperature for about $\mathbf{3 0}$ minutes. Remove from the hot platu and allow to cool to room temperature. Transfer the solution quantitatively to a $1000-\mathrm{ml}$ volumetric flask. Dilute to volume with $4 \mathrm{~N} \mathrm{HCl}$. This is a stock solution containing 1000 ppm uranium. The activity of the solution will depend on the isotopic composition of the initial reagents.

This solution should be stable for a period of $\mathbf{3 0}$ days.

Working spiking solutions are prepared from the stock standard daily. Dilute $13.3 \mathrm{ml}$ of stock solution to 100 $\mathrm{ml}$ with $4 \mathrm{~N} \mathrm{HCl}$. This solution should be stable for about 7 days. If the initial reagents were prepared from depleted uranium, this should yield an experimental spike of about $50 \mathrm{pCi} \mathrm{ml}^{-1}$.

C.6.11 Reduced-U Spiking Solution - Prepare this fresh daily. In a 100-ml volumetric flask, add $13.3 \mathrm{ml}$ of the U(VI) stock solution, and $0.2 \mathrm{ml}$ of a $20 \%$ $\mathrm{TiCl}_{3}$ solution. Mix and allow to stand at room temperature for 15 minutes. Add $2.5 \mathrm{ml}$ of $12 \mathrm{~N}$ nitric acid. Allow this to stand for 15 minutes. Dilute to $100 \mathrm{ml}$ with $4 \mathrm{~N} \mathrm{HCl}$. This should yield a spiking solution that, if prepared from depleted uranium, will contain about 50 pCi of U(IV) $\mathrm{ml}^{-1}$.

With each batch of samples a set of standard U(IV) and $U(V I)$ samples should be run to verify the results. A stock solution of $U(V I)$ in $4 \mathrm{M} \mathrm{HCl}$ should be stable. A U(IV) solution can be prepared from the $\mathrm{U}(\mathrm{VI})$ stock solution by reduction with $20 \% \mathrm{TiCl}_{3}$ (add $1 \mathrm{ml}$ for every $100 \mathrm{ml}$ of stock solution). After the $U$ has been reduced, the remaining $\mathrm{TiCl}_{3}$ must be oxidized by the addition of $2 \mathrm{ml}$ of $12 \mathrm{M} \mathrm{HNO}_{3}$ for every $100 \mathrm{ml}$ of stock solution. In addition, known amounts of U(IV) and U(VI) solids should be added to an uncontaminated soil sample that is otherwise similar to the contaminated soil sample and carried through the entire TAU and oxidation-state determination.

\section{C.7 Materials and Equipment}

\section{C.7.1 Centrifuge bottles, $125 \mathrm{ml}$, polyethylene .}

C.7.2 Sample bottles - $30 \mathrm{ml}$ (approx.) polyethylene, acid washed.

C.7.3 Mechanical Shaker - as per requirements of ASTM 3974-81. Alternately, one can employ the 
rotary mixer specified in EPA/SW 846 Method 1311 (TCLP).

C.7.4 Glass Fiber filters - acid washed (by rinsing filters with a minimum of $25 \mathrm{ml}$ of $4 \mathrm{~N} \mathrm{HCl}$.) nominal pore size of 0.6 to $0.8 \mathrm{rm}$.

C.7.5 Membrane filters - ca. 0.40 - tó $0.45-\mu \mathrm{m}$ nominal pore size.

\section{C.7.6 Standard laboratory equipment and glassware.}

\section{C.8 Health and Safety}

This method involves the use of hazardous and radioactive materials. The written procedures do not purport to address health and safety issues nor to address issues related to the disposal of radioactive or mixed hazardous wastes. It is the responsibility of the user of this method to establish appropriate health and safety practices; to comply with all local, state, and federal regulations concerning the use and disposal of radioactive and hazardous materials; and to determine any other regulatory limitations of the procedures prior to their use.

\section{C.9 Sample Collection}

Collect a minimum of $1.5 \mathrm{~kg}(1500 \mathrm{~g})$ of sample in the field by appropriate means. Place sample in a suitable air-tight container, such as a zip-locking plastic bag. Without unnecessarily compacting the sample, minimize the dead space (air) volume of the bag. Store on ice, or at approximately $4^{\circ} \mathrm{C}$, and transport to the analytical laboratory. Holding times for the field-moist samples from time of collection to the initiation of the extraction procedure should be less than 21 days.

\section{C.10 Sample Preparation}

C.10.1 Warm the sample to room temperature. Note the presence of any phase separation (e.g., water condensation on the bag) when the bag is removed from refrigeration and on completion of warming.

C.10.2 While the sample is still in the container, gently crush any coarse soil clods (diameter $>3 \mathrm{~cm}$ ). Open bag, and spread sample on a non-coated, lintfree paper. Remove, by'hand, all coarse organic debris (e.g., sticks, twigs, leaves, and leaf fragments) and pebbles (diameter $>5 \mathrm{~mm}$ ) from the sample. Do not destroy soil aggregates (diameter $<3 \mathrm{~cm}$ ) at this point. Return the sample to the plastic bag, minimize the air space within the bag, and reseal the bag.

C.10.3 Homogenize the soil sample by agitating the bag by hand for a minimum of five minutes. Soil aggregates and small clods can be destroyed at this point to facilitate the mixing and homogenization of the sample.

C.10.4 Open the sample bag and split the sample into two approximately equal portions. Rebag one portion, label, and store as an archival sample at $4^{\circ} \mathrm{C}$. Rebag the second portion, and label this the "Working" fraction.

C.10.5 Determine the field moisture. Remove approximately $50 \mathrm{~g}$ of field moist sample from the "Working" fraction bag, place in a tared, uncovered petri dish, and place the dish in a drying oven $(T=$ $105-110^{\circ} \mathrm{C}$ ) overnight. Remove petri dish from the oven, place in a desiccator until cool, and reweigh. Compute the percent moisture content (MC) and the moisture correction lactor $\left(F_{N}\right)$ as follows:

$$
M C=100^{*}\left(\mathrm{M}_{M}-\mathrm{M}_{\mathrm{D}}\right) / \mathrm{M}_{\mathrm{D}}
$$

and

$$
F_{M}=(100-M C) / 100
$$

where $M_{M}$ is the mass of the field-moist sample, and $M_{D}$ is the mass of the oven-dried sample.

C.10.6 Determine the soil $\mathrm{pH}$ of the sample using EPA/SWP-9045.

C.10.7 Determine the soil organic matter content using EPA/SWP-9060.

\section{C.11 Composite Samples}

The method assumes that the analyst is working with individual, unaggregated soil samples. However, conditions at the field location might justify the blending of multiple soils into a single composite sample. Soils can be blended into composite samples if the following conditions are met:

a) Total uranium concentrations in individual samples to be composited vary by less than $20 \%$ from the mean of all samples to be composited.

b) Soil organic matter contents of individual samples to be composited vary by less than $20 \%$ from the mean of all samples to be composited. 
c) Soil pH values of individual samples to be composited vary by less than $0.5 \mathrm{pH}$ unit from the mean of all samples to be composited.

d) Soil samples from different horizons or from different soil classification groups should not be mixed. For example, samples from an Ap horizon should be composited only with other samples collected from Ap horizons. Mixing soils between A, E, B, or C horizons should be avoided. Similarly, soils collected from different soil series should not be composited, nor should soils from different families, subgroups, great groups, suborders, or orders be mixed.

\section{C.12 Procedure}

\section{C.12.1 Total Available Uranium}

This procedure is based on Practice B of ASTM D3974-81. Modifications to the procedure are sugezested based on uranium-specific chemical characteristics. This method has not been laboratory or field tested, and the efficacy of the method should be evaluated prior to its application to a specific site.

C.12.1.1 Into each of three 125-ml, wide-mouth, polyethylene centrifuge bottles, transfer approximately $2 \mathrm{~g}$ of field-moist soil. If the levels of uranium contamination are expected to be low, this mass may be increased up to $10 \mathrm{~g}$, as required to attain the needed sensitivity. Record the weight of the soil in each bottle to the nearest $10 \mathrm{mg}(0.01 \mathrm{~g})$. Label the bottles as $S_{0}, S_{1}$, and $S_{2}$. Label a fourth bottle as $B_{0}$; this bottle will be used to determine the extraction efficiencies for the combined spiking solutions.

C.12.1.2 Calculate the dry weight equivalent $\left(M_{D W B}\right)$ of soil used for the uranium extraction from the relation:

$$
\mathrm{M}_{\mathrm{DWB}}=\mathrm{M}_{M} \boldsymbol{F}_{M}
$$

Record these weights and save for later computations.

C.12.1.3 Add $1.00 \mathrm{ml}$ of the oxidized-U spiking solution to each of the bottles labeled $S_{1}$ and $B_{0}$ Add $1.00 \mathrm{ml}$ of the reduced-U spiking solution to each of the bottles labeled $S_{2}$ and $B_{0}$.

C.12.1.4 Add $95.0 \mathrm{ml}$ of reagent water and $5.0 \mathrm{ml}$ of concentrated reagent-grade $\mathrm{HCl}$ to centrifuge bottle labeled $S_{0}$. Add $94.0 \mathrm{ml}$ of reagent water and $5.0 \mathrm{ml}$ of concentrated reagent-grade $\mathrm{HCl}$ to the bottles labeled $S_{1}$ and $S_{2}$. Finally, add $93.0 \mathrm{ml}$ of reagent water and $5.0 \mathrm{ml}$ of concentrated, reagent-grade $\mathbf{H C l}$ to the bottle labeled $B_{0}$. Cap each bottle tightly and suspend the soil in the solution by shaking vigorously. Loosen the cap and allow the solution to stand for several minutes to permit any $\mathrm{CO}_{2}(\mathrm{~g})$ generated from the reaction of carbonate minerals to escape the system. Recap the bottles tightly.

NOTE: It is crucial that the extraction procedure be completed using $\mathrm{HCl}$. $\mathrm{HNO}_{3}$ and $\mathrm{H}_{2} \mathrm{SO}$, have the potential to oxidize $U(I V)$ to $U(V)$ during the extraction process and must be avoided during this portion of the procedure.

C.12.1.5 Shake the suspensions on a mechanical shaker for $16 \pm 2$ hours (overnight) at room temperature.

C.12.1.6 Centrifuge the suspensions at a minimum of $5000 \times$ g, for 30 minutes. Decant the supernatant from each bottle into a clean beaker. Measure the volume (or mass) of solution recovered from each bottle. Then, filter each solution through a fresh $0.45-\mu \mathrm{m}$ membrane filter. Wash the filtering device and filter with a minimal amount of reagent water, combining the wash water with the supernatant. Dilute combined supernatant and wash from each bottle to $100.0 \mathrm{ml}$ with reagent water, and save the four solutions for uranium analysis by an appropriate procedure (0.g., ICP-MS).

C.12.1.7 Analyze each of the solutions for total dissolved uranium by any appropriate procedure according to the following guidelines:

a) Transfer $20.0 \mathrm{ml}$ of the analytical solutions to a 125-ml beaker. Reserve the remainder of the analytical solutions for two possibilities. First, a portion of the solutions may be required for the U(IV)/U(VI) analyses described in 12.2. Second, it may be necessary to repeat the following steps using different dilutions if the final uranium concentrations fall outside the optimal range for the method of choice.

b) Add $1.0 \mathrm{ml}$ of $30 \% \mathrm{H}_{2} \mathrm{O}_{2}$ to the solution dropwise, with gentle mixing (e.g., with a magnetic stirrer) of the solution. If the effervescence of the solution becomes vigorous, momentarily stop the addition of the peroxide.

c) Once the $\mathrm{H}_{2} \mathrm{O}_{2}$ has been added, cover the beaker with a ribbed watch glass and gently heat the solution to $80^{\circ} \mathrm{C} \pm 5^{\circ}$. Hold at this temperature for 30 minutes.

d) Remove the beaker from the hot plate and allow to cool to room temperature. 
Appendix C: Draft Interim Method

C) Transfer the contents of the beaker quantitatively to a 25-ml volumetric flask. Dilute to volume with reagent water.

f) Use this solution to complete the total dissolved uranium concentration determination on the four samples.

\section{C.12.18 Actions Based on the Results}

Three actions can result, based on the findings from the TAU analysis:

a) If the observed TAU concentrations are less than the Lower-Limit Action Levels specified by the regulating body, no further action is mandated.

b) If the observed TAU concentrations are greater than the Lower-Limit Action Levels but less than the Upper-Limit Action Levels, then the analyst is directed to Section C.12.2 or C.12.3 to continue the procedure.

c) If the TAU concentrations exceed the Upper Limit Action Levels, then several options are available. The analyst may choose to continue with the procedure, at Section C.12.2 or C.12.3, to obtain additional information about the forms and availability of the uranium contamination at the site. Such information might be useful in selecting remediation alternatives. Alternatively, the site operator may be directed by the regulating body to perform certain actions or complete specified clean-up levels.

\section{C.12.2 Distribution of Oxidation States}

The following procedure is undertaken if results of the uranium analyses described in Section C.12.1 exceed the Lower-Limit Action Level.

C.12.2.1 Prepare four ion-exchange columns, one for cach of the four samples $S_{0}, S_{1}, S_{2}$, and $B_{0}$, with a strong-base anion-exchange resin by loading a column, having dimensions approx. $0.6 \mathrm{~cm}$ in diameter $\times 4.0$ $\mathrm{cm}$ in length. Convert the resin to the $\mathrm{Cl}^{-}$form by washing the columns with a minimum of $50 \mathrm{ml}$ of 4 M HCl.

C.12.2.2 For each of the four samples, $S_{0}, S_{1}, S_{2}$, and $B_{0}$, tare two 125-ml polypropylene bottles and transfer $20.0 \mathrm{ml}$ (ca. $21.8 \mathrm{~g}$ assuming density of $1.09 \mathrm{~g}$ $\mathrm{ml}^{-1}$ at $20^{\circ} \mathrm{C}$ ) of the TAU extract into each bottle. To the first bottle in each set of two (referred to as Bottle A), add $2.0 \mathrm{ml}$ of deionized and deoxygenated $\mathrm{H}_{2} \mathrm{O}$ and $8.0 \mathrm{ml}$ of $12 \mathrm{~N} \mathrm{HCl}$. To the second bottle in each set (referred to as Bottle B), add $1 \mathrm{ml}$ of $30 \% \mathrm{H}_{2} \mathrm{O}_{2}$ solution, $1.0 \mathrm{ml}$ of $\mathrm{H}_{2} \mathrm{O}$ and $8.0 \mathrm{ml}$ of 12
$\mathrm{N} \mathrm{HCl}$. Gently stir both bottles to mix (do not cap Bottle B).

C.12.2.3 Pass the contents of Bottle A through an anion exchange column and collect the effluent in a clean, 125-ml bottle (referred to as Bottle C). Rinse Bottle A with $5 \mathrm{ml}$ of $4 \mathrm{M} \mathrm{HCl}$ and pass through the column into Bottle C. Add $1 \mathrm{ml}$ of $10 \% \mathrm{H}_{2} \mathrm{O}_{2}$ to Bottle C.

C.12.2.4 Place Bottle B and Bottle C, loosely capped, in an $85^{\circ} \mathrm{C}$ water bath for 30 minutes or unitil all the $\mathrm{H}_{2} \mathrm{O}_{2}$ has decomposed, as indicated by the absence of air bubbles on the walls of the bottles (in some instances, an overnight incubation may be required). The contents of Bottle $B$ represent the total available uranium concentration in the soil sample. The contents of Bottle C represent the total available U(IV) fraction.

C.12.2.5 Pass $25 \mathrm{ml}$ of deionized $\mathrm{H}_{2} \mathrm{O}$ through the exchange column. Collect this fraction in a bottle labeled D. The contents of this bottle represent the total available $U(V)$ fraction from the soil.

C.12.2.6 If the uranium analyses are to be done using the laser-phosphorimetry method (ASTM D5174 91) or a related method that would have be subject to significant chloride interferences, proceed to step

C.12.2.7. Otherwise go to step C.12.2.11.

C.12.2.7 Recondition the ion-exchange column by washing with a minimum of $50 \mathrm{ml}$ of $4 \mathrm{M} \mathrm{NaCl}$. Then wash the column with $50 \mathrm{ml}$ of reagent water. Test for the presence of $\mathrm{Cl}^{-}$in the final stages of the wash by testing the effluent with $\mathrm{AgNO}_{3}$. Continue to wash column until the $\mathrm{AgNO}_{3}$ test demonstrates the absence of $\mathrm{Cl}^{-}$in the elutriate.

C.12.2.8 Pass the contents of Bottle B through the column and rinse the bottle with $5 \mathrm{ml}$ of $4 \mathrm{M} \mathrm{HCl}$. Elute the $U(V I)$ adsorbed to the column with $25 \mathrm{ml}$ of deionized $\mathrm{H}_{2} \mathrm{O}$ and collect the elutriate in a $30-\mathrm{ml}$ polypropylene bottle. This bottle contains all $U$ extracted from the soil.

C.12.2.9 Repeat steps 12.2 .7 and 12.2.8 but pass the contents of Bottle $\mathbf{C}$ across the exchange resin. This sample contains the U(IV) extracted from the soil.

C.12.2.10 The solutions collected from Bottles B, C, and $D$ can be made to volume in 50-ml volumetric flasks and analyzed directly by pulsed-laser phosphorimetry (ASTM D5174-91).

C.12.2.11 If analysis by ICP-MS is desired, the solutions may be diluted with $\mathrm{HNO}_{3}$. 


\section{C.12.3 Readlly Avallable Uranium}

This procedure is a modification of the EPA/SW 846 Method 1311 (TCLP). It has been modified to address uranium-specific chemistry requirements. The procedure has not been tested in laboratory or field conditions, 80 the efficacy of the method should be evaluated prior to it applical on to a specific site.

C.12.3.1 In a 250-ml, wide-mouth centrifuge bottle (polyethyiene), add the equivalent of ca. $10 \mathrm{~g}$ of dry soil mass to the bottle. Record the weight of moist soil added to the nearest $0.05 \mathrm{~g}$. The mass of field moist soil (MM) is computed as

$$
M_{M}=10.0 / F_{M}
$$

C.1232 Compute the volume of extraction fluid $\left(V_{B}\right)$ that should be added to the sample to bring the total solution:solid ratio to 20:1. This volume is computed as

$$
V_{B}=21^{*}\left(M_{M} * F_{M}\right) \cdot M_{M}
$$

C.12.33 Add the required volume of extraction fluid (0.1 M HOAc, pH 2.9). Cap the bottle, shake the suspension, and loosen the cap to relieve any pressure buildup caused by the dissolution of carbonate minerals that may be present. Make a note of samples that generate easily detectable overpressures of $\mathrm{CO}_{2}$.

C.12.3.4 Recap the vessels and secure in the rotary agitation device. Rotate samples at $30 \pm 2 \mathrm{rpm}$ at room temperature (ca. $22^{\circ} \mathrm{C}$ ) for $18 \pm 2 \mathrm{~b}$. For samples containing carbonate minerals, it may be necessary to relieve excess pressure periodically.

C.123.5 At the end of the agitation period, centrifuge the samples to remove solids. Decant the clear supernatant into a beaker. Separate an aliquot and determine the $\mathrm{pH}$ of the extract. Filter the remainder of the extract through an acid-washed glassfiber filter with nominal pore sizes in the range of 0.6 to $0.8 \mathrm{rm}$. Acidify the filtrate to ca. $0.1 \mathrm{M}$ with nitric acid and save it for analysis.

\section{C.12.3.6 Repeat steps 12.3.3 through 12.3.5 three} more times.

C.12.3.7 Analyze the extracts within 48 hours after the completion of each extraction step, and in no event more than 4 days after the extraction step was completed. If kinetic information is not desired, the four extracts may be combined and a single analysis for total uranium made.
C.12.3.8 Save the soil residue for subsequent determination of SAU.

C.12.3.9 This RAU extraction scheme is designed to measure uranium present in the following forms: exchangeable uranium, uranium bound onto the surfaces of iron and manganese hydrous oxides, hydrous uranyl oxide minerals, and some uranyl silicates. Depending on the buffering capacity of the soil, this extraction may also result in the dissolution of amorphous iron, manganese, and aluminum hydrous oxides, and therefore may release any uranyl species bound in these phases.

The extraction should not measure uranium bound in reduced [uranous, i.e., U(IV)] mineral oxide phases such as uraninite or gummite. The extraction should not be so rigorous that it removes uranyl phosphates, or uranyl species bound in crystalline iron or manganese oxide phases.

As with all operationally defined chemical extractions, many factors affect experimental conditions, and these will have substantial impacts on the effectiveness and selectivity of the extraction procedure. The major factor contributing to the potential variability of the procedure is related to the form and composition of the original soil sample. Care should be taken when using this procedure to employ an approved quality assurance/quality control program to maximize the interpretability of the results.

\section{C.12.4 Slowly Available Uranium}

This procedure is derived from a series of extraction and characterization procedures developed by Oak Ridge National Laboratory (Francis et al., 1992, 1993; Lee and Marsh, 1992). The procedure has not been tested in laboratory or field conditions, so the efficacy of the method should be evaluated prior to its application to a specific site.

C.12.4.1 Using the soil residue and 250-ml bottle from the RAU determination, add $200 \mathrm{ml}$ of the 0.1 $\mathrm{M} \mathrm{NaHCO}_{3}$ solution (pH 8.3) and $1 \mathrm{ml}$ of $30 \%$ $\mathrm{H}_{2} \mathrm{O}_{2}$. Cap the bottle loosely so that any pressure caused by the decomposition of the $\mathrm{H}_{2} \mathrm{O}_{2}$ can be relieved.

C.12.42 Place the bottle in a shaking water bath at $25^{\circ} \mathrm{C}$ and incubate for 6 hours while shaking at $30 \pm 2$ rpm.

C.12.4.3 After the first 3 hours of incubation add another 1-ml aliquot of $30 \% \mathrm{H}_{2} \mathrm{O}_{2}$ to the suspension and again cap the bottle loosely. 
C.12.44 At the end of the incubation period, centrifuge anmples to remove solids. Decant the clear supernatant into an appropriato container and filter it through an acid-washed glass-fiber filter with nomimal pore sizes in the range of 0.6 to $0.8 \mathrm{~m}$.

C.12.45 Acidify the filtrate to ca. $0.1 \mathrm{M}$ with nitric acid and ave for analyais.

C.12.46 This SAU axtraction is designed to measure uranium present in the soil primarily as discrete uranous oxide phases.

The extraction should not be 80 rigorous as to remove uranyl phosphate phases, uranium bound in crystalline silicate phases, or uranyl species bound in crystalline iron or manganese axides.

As with all operationally defined chemical extractions, many factors affect experimental conditions, and these will have subatantial impacts on the effectiveness and selectivity of the extraction procedure. The major factor contributing to the potential variability of the procedure is related to the form and composition of the original soil sample. Care should be taken when using this procedure to omploy an approved quality assuranco/quality control program to maximize the interpretability of the results.

\section{C.12.5 Very Slowly Available Uranium}

The VSAU fraction of soil uranium is defined as the difference between TAU and the sum of the RAU and SAU fractions. Therefore, to compute the VSAU fraction of uranium in a soil, one employs the equation

$$
\text { VSAU = TAU }-(\text { RAU }- \text { SAU })
$$

In general, the VSAU fraction is presumed to consist of uranyl phosphates, uranyl species bound in crystalline iron and manganese oxides, refractory uranyl-organic complexes, and some portion of the uranyl silicate fraction. The actual phase distribution will depend in large part on the forms of uranium that are present at the site, either as natural background or in the form of the contaminant.

\section{C.13 Calculation of Specific Activity}

In natural samples, uranium exists in three isotopic forms: ${ }^{24} U,{ }^{25} U$, and ${ }^{24} U$. Each isotope has a different half-life, and hence, decay rate. The halflives and decay constants for each isotope are

$$
\begin{aligned}
& { }^{20} \mathrm{U} \mathrm{t}_{1 / 2}=4.51 \times 10^{\circ} \mathrm{yrs} ; \quad \lambda=1.537 \times 10^{-10} \mathrm{yr}^{-1} \\
& { }^{20} \mathrm{t}=7.13 \times 10^{2} \text { yrs; } \lambda=9.722 \times 10^{-10} \mathrm{yr}^{-1}
\end{aligned}
$$

26U $t_{1 / 2}=2.48 \times 10^{5} y r ; \lambda=2.795 \times 10^{\circ} \mathrm{yr}^{\cdot-1}$

Using the first-order decay equation

$$
\frac{d N}{d t}=-\lambda N
$$

and, knowing that a picocurie $\left(10^{-12}\right.$ Curies) is equal to 2.2 decays per minute, we can compute the mass of each isotope required to have $1 \mathrm{pCl}$ of material. That is, for $\mathrm{U}, 1 \mathrm{pCi}=2.98 \mathrm{pg}$ of the isotope; for ${ }^{205} \mathrm{U}$, $1 \mathrm{pCi}=0.464 \mathrm{~kg}$ and for ${ }^{24} \mathrm{U}, 1 \mathrm{pCi}=16.1 \mathrm{ng}$. Of course, isotopes never occur in pure form. For naturally occurring uranium that is in secular equilibrium, the isotopic abundances are ${ }^{20} \mathrm{U}=$ $99.274 \%,{ }^{20} U=0.7205 \%$, and ${ }^{214} U=0.0056 \%$. For this material, $1.45 \mathrm{~kg}$ of uranium provides $1 \mathrm{pCi}$. If one is dealing with uranium that is enriched, for example to 2 atom\% ${ }^{20} \mathrm{U}$, the mass required to produce $1 \mathrm{pCi}$ is $0.45 \mathrm{k}$. Conversely, if the contaminant is depleted uranium, and assuming a ${ }^{205} \mathrm{U}$ content of 0.60 atom\% (down from 0.7205 atom\%), the mass required to yield a $\mathrm{pCi}$ is $2.66 \mathrm{Ng}$. Naturally occurring uranium may not be in secular equilibrium. The ${ }^{24} U$ isotope has a tendency to be leached from soile and rock material more easily than the parent isotope, ${ }^{20} \mathrm{U}$. Assuming a ${ }^{2 N} \mathrm{U} /{ }^{20} \mathrm{U}$ activity ratio of 2.0 , the mass required to yield 1 pCi of uranium is about 0.98 rg.

Depending on the type of material contaminating the site, one can develop an appropriate conversion factor to transform the results of chemical analyses, which are usually reported in parts per million (ppm) or parts per billion (ppb), into the required activity units. These conversion factors are as follows: for curiched uranium (2.00 atom\% ${ }^{205} \mathrm{U}$ ) $2.208 \mathrm{pCi}_{1 \mathrm{~B}^{-1}}$, for depleted uranium (0.60 atom\% ${ }^{205} \mathrm{U}$ ) $0.376 \mathrm{pCi}_{\mathrm{Ng}}{ }^{-1}$, for natural uranium (secular equilibrium) $0.691 \mathrm{pCi}$ $1 \mathrm{~S}^{-1}$, and for natural uranium with a ${ }^{204} \mathrm{U} /{ }^{201} \mathrm{U}$ activity ratio of $2.0,1.016 \mathrm{pCi}^{1.1}{ }^{-1}$.

\section{C.14 References}

American Society for Testing and Materials, ASTM D3974-81 (Reapproved 1990), "Standard Practices for Extraction of Trace Elements from Sediments," Annual Book of ASTM Standards, 11.02:593-595, ASTM, Philadelphia, Pennsylvania, 1992.

American Society for Testing and Materials, ASTM D4793-93, "Standard Test Method for Sequential Batch Extraction of Waste with Water," Annual Book of ASTM Standards, 11.02:138-147, ASTM, Philadelphia, Pennsytvania, 1993. 
American Society for Testing and Materials, ASTM D3987-8 (Reapproved 1992), "Standard Test Method for Shake Extraction of Solid Waste with Water," Annual Book of ASTM Standands, 11.02:37-40, ASTM, Philadelphia, Pennoytvania, 1992.

Francis, C.W., A.J. Mattus, L.L. Farr, M.P. Elless, and S.Y. Lee, ORNL/TM-12177, "Selective Leaching of Uranium from Uranium Contaminated Soils: Progress Report L," Oak Ridge National Laboratory, Oak Ridge, Tennessee, 1992.

Francis, C.W., A.J. Mattus, M.P. Elless, and M.E. Timpon, ORNL \#6762, "Selective Leaching of Uranium from Uranium Contaminated Soils Using Carbonate- and Citrate-based Leaching Solutions," , Oak Ridge National Laboratory, Oak Ridge,

Tennessec, 1993.

Lee, S.Y, and J.D. Marsh, Jr., ORNL/TM-11980, "Characterization of Uranium Contaminated Soils from DOE Fernald Environmental Management Project Site: Results of Phase I Characterization," Oak Ridge National Laboratory, Oak Ridge, Tennessee, 1992.
U.S. Environmental Protection Agency, EPA/SWP846, "Method 9060: Total Organic Carbon," Test Methods for Evaluating Solid Waste, Physical-Chemical Methods, 3rd Edition, Vol. I, Pt. I, Section C, Washington, D.C., 1990.

U.S. Environmental Protection Agency, EPA/SWP846, "Method 9045: Solid and Waste pH," Test Methods for Evaluating Solid Waste, Physical-Chemical Methods, 3rd Edition, Vol. I, Pt. I, Section C, Washington, D.C., 1990.

U.S. Environmental Protection Agency, EPA/SWP846, "Method 3050A: Acid Digestion of Sediments, Sludges, and Soils," Test Methods for Evaluating Solid Waste, Physical-Chemical Methods, 3rd Edition, Vol. I, Pt. I, Section A, Washington, D.C., 1990.

U.S. Environmental Protection Agency, "Method 1311: Toxicity Characteristic Leaching Procedure," Test Methods for Evaluating Solid Waste, Physical-Chemical Methods, EPA/SWP-846, 3rd Edition, Vol. I, Pt. II, Section C, Washington, D.C., June 1990. 


\section{Appendix D: Draft Quality Control Procedures for Determining Environmentally Available Uranium in Soils}

\begin{abstract}
The quality control $(Q C)$ protocols outlined below have been developed for the U.S. Nuclear Regulatory Commission (NRC) under contract NRC FIN J-5019. The protocols are based on established procedures, although they have been generally expanded to meet the needs of this specific set of analyses. The $Q C$ requirements being recommended are generally morre demanding than those required for routine testing being done with established, standard methods. These recommendations are being made, in part, because neither the analytical methods nor the $Q C$ protocols been field-tested to establish their efficacy for estimating environmentally available uranium in soils. Users are cautioned to employ approved quality assurance methods, including data verification and validation procedures, with these protocols to maximize the interpretability of the results.
\end{abstract}

\section{D.1 Background}

Appendix $\mathbf{C}$ of this report contains a detailed procedure for the determination of environmentally available uranium as readily available, slowly available, very slowly available, or total available urawium. The methods recommended to complete these determinations have been taken both from standard methods and from the results of research being conducted throughout the DOE complex. At this point, the recommended procedures should be treated as draft procedures. Their efficacy has not been laboratory or field-tested.

Two issues that relate to the quality of the data obtained from the method are not addressed in the procedural write-up. First, the method does not address $\mathrm{QC}$ procedures that must be implemented to assess the quality of the results being obtained. Second, the method does not address sample batching. Clearly, there are significant time and cost savings to be had by analyzing multiple samples concurrently, and these savings can be realized without sacrificing the ability to assess certain aspects of the quality of the results.

The purpose of this appendix is to recommend certain QC procedures to be used in conjunction with the draft interim method for the determination of environmentally available uranium. The recommended procedures depend on the number of samples being analyzed. The procedures are designed to assist in the determination of the precision and accuracy of the data generated. The procedures do not provide vehicles for assessing the completeness, comparability, or representativeness of the sampling. For information regarding these aspects, users are directed to the site manager or oversight officer to obtain information pertaining to a site-wide Quality Assurance Plan, if such a plan exists.

The draft interim method and these QC protocols provide for only operationally defined fractions of soil uranium; assignment of specific phases or soil fractions of bound uranium to an operationally defined fraction is based on theoretical considerations and on a limited amount of field experience. The method is awaiting laboratory and field verification to more accurately portray the specific conditions under which discrete uranium-bearing phases are solubilized during the extraction procedures.

\section{D.2 Field Duplicates}

The draft interim method calls for the collection of individual samples of about $1.5 \mathrm{~kg}$ in mass by appropriate means. The locations at a site from which samples are collected and the means used to collect the samples are important issues. Users are directed to the Site Sampling Plan, if such a document exists, for guidance regarding appropriate procedures and protocols for identifying sampling locations and proper collection techniques. The plan should provide for the collection of samples from both sites known or suspected to contain contamination, and a number of areas in which potential contamination has been minimized. The latter samples are for the estimation of local background levels of uranium.

Field-duplicate samples are soil samples collected to help assess the spatial variability of the contaminant distribution. Soil properties are known to vary markedly on horizontal spatial scales of $1 \mathrm{~m}$. Field duplicates are collected to provide information about the magnitude of this type of variability. Duplicates should be collected regardless of the sampling format, i.e., they apply equally to both individual and composite samples (as defined in Appendix C).

Duplicate samples are usually collected by repeating the complete sampling procedure at a location approximately $1 \mathrm{~m}$ outside any disturbed zone 
associated with the primary sampling site. Typically, a protocol is defined for determining the compass direction away from the primary site to sample for the duplicate. In collecting field duplicates, it is important to repeat the entire sampling procedure. Soils from the two sampling locations should not be commingled.

Once collected, duplicate samples are treated as discrete, individual samples, comparable to other routine samples.

The number of field duplicates to be collected varies depending on the total number of samples to be collected for the program. If ten or fewer samples are to be collected, field duplicates should be collected for a minimum of $50 \%$ of the samples. If between 11 and 50 samples are to be collected, then the greater of 5 or $20 \%$ of the samples should be collected in duplicate. If 51 or more samples are to be collected, then the greater of 10 or $10 \%$ of the samples should be collected in duplicate.

Field duplicates are designed to obtain information regarding the spatial variability of contaminant(s) of interest, both within localized areas and over the site as a whole. Performance of the analytical laboratory is not to be judged based on the results obtained from these samples.

\section{D.3 Sample Batching}

The grouping of samples together into common analytical batches is a common practice. It increases the efficiency of the analytical operation by controlling the number of standards, blanks, duplicates, and related $\mathrm{OC}$ samples that must be analyzed while maintaining the analyst's ability to determine the quality of the results being obtained.

Depending on the types of samples being analyzed and the goals of the analysis program, there are different criteria for determining how samples should be batched. The user is referred to the Site Sampling or Analysis Plans for information, if such plans exist. Generally, samples to be batched together should have similar properties (e.g., levels of uranium contamination). In the absence of other information, samples can generally be batched by soil type, horizon, and geographic location of collection.

Batch sizes will vary, depending on a number of factors. However, for any given series of procedures, there should be a maximum batch size. For the procedures described in the draft interim method, individual batches should not exceed 15 samples, although the maximum size will depend on the facilities available to the laboratory. Small batches (5 samples or fewer) have different QC protocols than do routine analytical batches (6 to 15 samples).

\section{D.4 Preparation Duplicates}

Once soils have been collected and assembled into analytical batches, a number of soil preparation and characterization operations are to be done, including removal of coarse organic debris and pebbles, destruction of soil clods and aggregates, sample homogenization, and determination of soil moisture, pH, and organic content. A number of factors may make it difficult to obtain homogeneous samples. For example, partially decomposed organic matter may be too diffuse to remove from samples and yet coherent enough to prevent effective sample mixing. Similarly, certain samples may experience particle-size separation during shipping and handling. While careful mixing of samples should eliminate the majority of such problems, preparation duplicates are suggested as a means of evaluating the effectiveness of this portion of the procedure.

Preparation duplicates are samples taken from the same soil sample after the removal of coarse organic debris and pebbles, the destruction of clods and aggregates, and soil homogenization. It is recommended that analyses of soil moisture, $\mathrm{pH}$, and organic content, as well as the measures of available uranium, be conducted on the preparation duplicates.

Each batch of samples, regardless of size, should have a minimum of two preparation duplicates.

\section{D.5 Total Available Uranium}

\section{D.5.1 Standards, Blanks, and Spikes}

\section{D.5.1.1 Analytical Standards}

Specific uranium analysis methods are not mandated by the draft interim method. The methods used will depend on the capabilities of the laboratory, the expected concentrations of uranium to be found in the soils, and other factors.

In general, if a wet-chemical method is to be used for each batch of samples, one reagent blank and three analytical standards will be prepared in the same matrices as contained in the samples. The standards will be used to calibrate the instrument at the beginning of the analytical "run," one of the three standards or blanks will be analyzed after every seventh sample, and the complete suite of standards/blanks will be analyzed at the end of the batch. The standards interspersed throughout the run 
and those at the end of the run are included to confirm instrument stability.

\section{D.5.1.2 Blanks}

In addition to the reagent blanks described in Section D.5.1.1, the analyst should prepare procedural blanks by running a sequence of the reagents through the extraction procedure in the absence of soil.

If the analyst is running a small batch ( $\leq 5$ samples), one procedural blank must be completed. If a routine batch is being run $(5<N<15)$, then a minimum of two procedural blanks should be included.

\section{D.S.13 Splkes}

Spikes are the U(IV) or U(VI) solutions that are used in the preparation of samples labeled $S_{1}$ or $S_{2}$ (see Sections C.6.10 and C.6.11) Because these solutions are prepared fresh prior to use, it is essential that the concentrations of total uranium be confirmed for each solution.

Prepare separate bottles of the two spikes by diluting $2.00 \mathrm{ml}$ of each spike with $93 \mathrm{ml}$ of distilled water and $5.0 \mathrm{ml}$ of concentrated $\mathrm{HCl}$. Run these solutions through the entire extraction sequence, and determine the concentration of uranium in each spiking solution. Each spike should have approximately $100 \mathrm{pCi}$ of uranium per sample.

Spike samples should be prepared concurrently with the samples. If changes in the concentrations arise because of processes occurring during the holding of samples, this increases the probability of being able to detect the changes.

\section{D.5.2 Samples and Standard Additions}

\section{D.52.1 Samples}

Routine samples prepared according to the draft interim method are labeled " $S_{0}$." During a normal analytical run, the analyst is directed to measure uranium concentrations in six routine samples and, for the seventh sample, to repeat the analysis of one of the previous six samples. In selecting a sample for repeat analysis, the analyst should attempt to select samples from different relative positions within the group (for example, the re-analysis of the third sample every time should be avoided.) The purpose of the repeat analysis is to provide the laboratory personnel the opportunity to identify potential problems.

\section{D.5.2.2 Standard Additions}

Samples $S_{1}$ and $S_{2}$ are prepared as standard additions for the soil samples. The purpose of these samples is to determine whether analytical interferences, through either quenching or signal enhancement, are arising from the soil solutions.

Sample $B_{0}$ is the combined spiking solution blank. It is included to provide estimates about recovery percentages and the stability of the two oxidation states of uranium in the extraction solutions.

Samples $S_{1}, S_{2}$, and $B_{0}$ should be run for all samples if the analyst is working with individual soil samples or with small batches (i.e., the number of samples is less than or equal to 5 ). If the analyst is running a routine batch, the analyst should pick, randomly, five samples for which standard additions are to be run.

\section{D.6 Distribution of Oxidation States}

If total available uranium concentrations exceed the Lower-Limit Action Level but are lower than the Upper-Limit Action Level, the site operator has several options, including performing a determination of uranium oxidation states, or moving directly to the determination of readily available, slowly available, and very slowly available uranium. If the site operators choose to perform the oxidation-state analyses, they should review this section. Otherwise, they are directed to skip directly to Section D.7.

\section{D.6.1 Standards, Blanks and Spikes}

The procedures described in Section D.5.1 are directly applicable to these analyses. The analyst is directed to follow those procedures for this portion of the analysis.

\section{D.6.2 Samples and Standard Additions}

The procedures described in Section D.5.2 are directly applicable to these analyses. The analyst is directed to follow those procedures for this portion of the analysis.

\section{D.7 Readily Available and Slowly Available Uranium}

The determination of readily available, slowly available, and very slowly available is mandated if the total available uranium concentrations are greater than the Lower-Limit Action Level, but less than the Upper-Limit Action Level, AND the oxidation state determination indicates that the quantity of $U(V I)$ in 
the extract exceeds the Lower-Limit Action Level. In addition, the site operator may elect to' initiate this series of analyses to determine the operationally defined fractions of soil uranium directly after completion of the TAU analyses. This decision negates the requirement to complete the oxidationstate analysis described in Section C.12.2.

\section{D.7.1 Standards, Blanks, and Spikes}

The procedures described in Section D.5.1 are directly applicable to these analyses. The analyst is directed to follow those procedures for this portion of the analysis.

\section{D.7.2 Samples and Standard Additions}

The procedures described in Section D.5.2 are directly applicable to these analyses. The analyst is directed to follow those procedures for this portion of the analysis.

\section{D.8 Very Slowly Available Uranium}

Very slowty available uranium is determined by difference between the total available uranium concentration and the sum of the concentrations from the other fractions. Because this does not involve a specific analytical procedure, no QC requirements are outlined for this determination. However, analytical laboratories completing the analyses of the other fractions are encouraged to compute the VSAU fraction for all samples. The relative contribution of this fraction to the total available uranium should show a consistent pattern across the sample population, and in all cases the value for this fraction should be positive.

\section{D.9 Summary}

The levels of $Q C$ sample analysis being suggested by this appendix are stricter than those of most analytical programs. The motivation for this arises out of the concern that uranium chemistry can be sensitive to a range of conditions, and, given the early stage of development of this interim procedure, the additional burden of QC is not only justified but necessary to assure the analytical laboratory and the site operator that no unexpected interferences or related problems arise during the preparation and analysis of samples. 


\section{Appendix E: Aqueous Complexes of Uranium}

The attached lists present the known or suspected aqueous complexes of uranium. The complexes are presented by major coordinating ion(s) and, within each listing, are presented in order of increasing oxidation state.

For most natural waters, the only stable aqueous complexes will be those of the uranyl ion [U(VI)]. Other species exist either metastably, or, in the case of certain uranous [U(IV)] species, under conditions that are atypical of natural systems, for example at $\mathrm{pH}$ values less than about 4.0 or greater than 11 .

Dominant species in natural systems, which in most cases will be a species derived from the uranyl ion, will depend in large part on the $\mathrm{pH}$ and major and minor ion composition of the water. Under most conditions, halide ion, nitrogen (ammonium or nitrate) ion. selenates, phosphates, and similar complexes will constitute trivial fractions of the total dissolved uranium species. More commonly, the aquo-ions, carbonate complexes, and, to a lesser extent, the sulfate and organic complexes will dominate the aqueous species of uranium in natural waters.

However, because the absolute and relative abundances of these species are dependent on many factors, it is inappropriate to suggest that any specific subset of species will describe the expected speciation in any given sample.

In the lists that follow, the uranium complex is listed in the first column, the oxidation state of uranium in the complex is listed in second column, and a number corresponding to a reference at the end of the section that contains further data about the complex is listed in the third column.

Metal, Oxide, and Aquo-lons

\begin{tabular}{|c|c|c|}
\hline$v^{2}$ & (II) & (3) \\
\hline$u^{n+}$ & (III) & $(2),(3)$ \\
\hline $\mathrm{U}(\mathrm{OH})^{2+}$ & (III) & (3) \\
\hline $\mathrm{U}(\mathrm{OH})_{i}$ & (III) & (3) \\
\hline $\mathrm{U}(\mathrm{OH})_{3}{ }^{\circ}$ & (III) & (3) \\
\hline $\mathrm{U}(\mathrm{OH})_{4}$ & (III) & (3) \\
\hline $\mathrm{U}_{2}(\mathrm{OH})_{2}{ }^{6+}$ & (III) & (3) \\
\hline $\begin{array}{l}\text { U6" } \\
\text { Uo's }\end{array}$ & $\begin{array}{l}\text { (IV) } \\
\text { (IV) }\end{array}$ & $\begin{array}{l}(2),(3) \\
(3)\end{array}$ \\
\hline $\mathrm{U}(\mathrm{OH})^{3 *}$ & (IV) & $(2),(3)$ \\
\hline $\mathrm{U}(\mathrm{OH})_{2}^{20}$ & (IV) & $(2),(3)$ \\
\hline $\mathrm{U}(\mathrm{OH})_{\mathrm{i}}$ & (IV) & $(2),(3)$ \\
\hline $\mathrm{U}(\mathrm{OH}) 4^{\circ}$ & (IV) & $(2),(3)$ \\
\hline
\end{tabular}

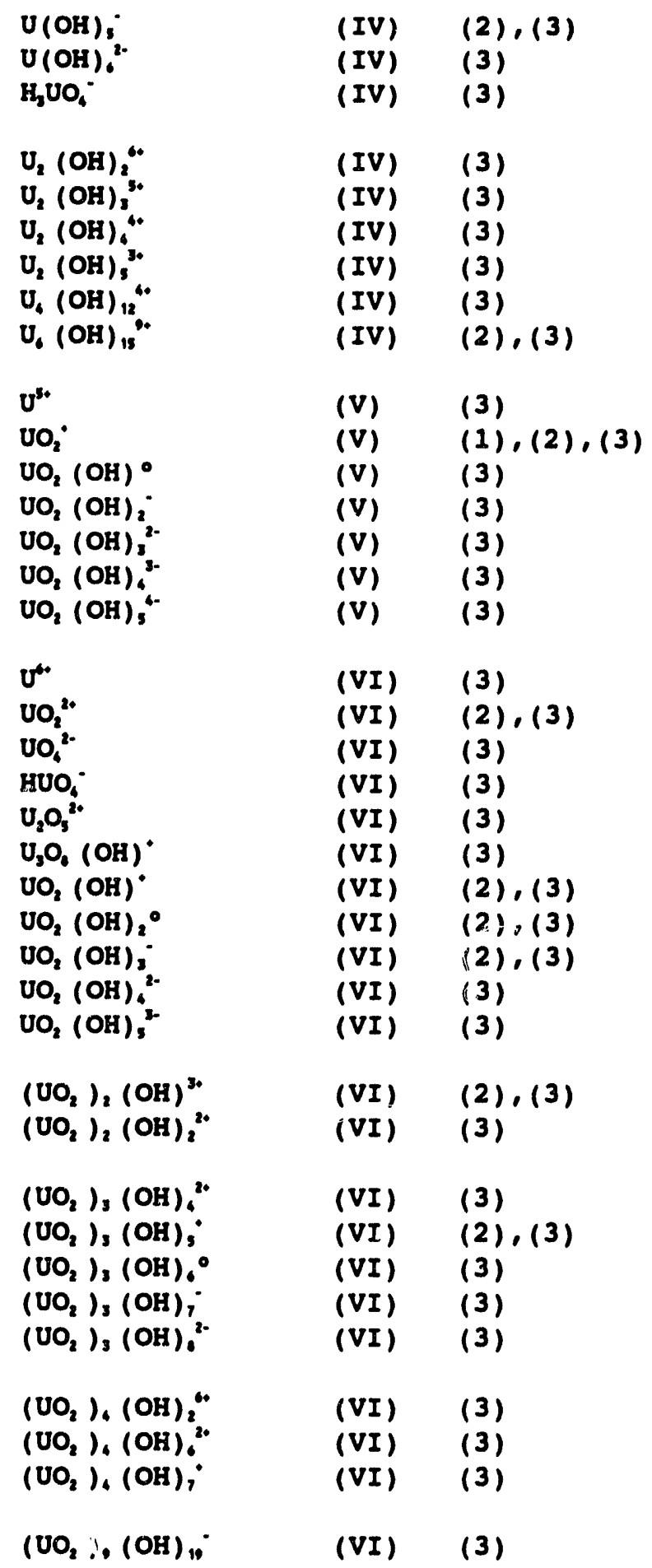

Carbonate and Aguo-Carbonate Complexes

$\begin{array}{ll}\mathrm{U}\left(\mathrm{CO}_{3}\right)^{2 \cdot} & \text { (IV) } \\ \mathrm{U}\left(\mathrm{CO}_{3}\right)_{2}^{\circ} & \text { (IV) } \\ \mathrm{U}\left(\mathrm{CO}_{3}\right)_{3}^{2-} & \text { (IV) } \\ \mathrm{U}\left(\mathrm{CO}_{3}\right)^{4 \cdot} & \text { (IV) }\end{array}$


Appendix E: Aqueous Complexes

\begin{tabular}{|c|c|c|c|c|c|}
\hline \multirow{2}{*}{ 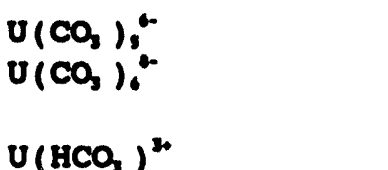 } & $\begin{array}{l}\text { (IV) } \\
\text { (IV) }\end{array}$ & $\begin{array}{l}(1),(3) \\
(3)\end{array}$ & \multicolumn{2}{|c|}{$\begin{array}{l}\left(\mathrm{UO}_{2}\right)_{11}\left(\mathrm{CO}_{3}\right)_{1}(\mathrm{OH})_{1{ }^{2-}}{ }^{2-}(\mathrm{VI}) \\
\left(\mathrm{UO}_{2}\right)_{11}\left(\mathrm{CO}_{2}\right)_{1}(\mathrm{OH})_{23}{ }^{3-} \text { (VI) } \\
\left(\mathrm{UO}_{2}\right)_{13}\left(\mathrm{CO}_{2}\right)_{1}(\mathrm{OH})_{30}{ }^{4-} \text { (VI) }\end{array}$} & $\begin{array}{l}\text { (3) } \\
(3) \\
(3)\end{array}$ \\
\hline & (IV) & (3) & & & \\
\hline $\mathrm{U}\left(\mathrm{HCO}_{3}\right)_{2}{ }^{2+}$ & (IV) & (3) & \multicolumn{3}{|l|}{ Sulfate Complexes } \\
\hline $\mathrm{U}\left(\mathrm{HCO}_{3}\right)_{3}$ & (IV) & (3) & & & \\
\hline $\mathrm{U}(\mathrm{HCO},)^{\circ}$ & (IV) & (3) & $\mathrm{USO}_{4}{ }^{2+}$ & (IV) & (3) \\
\hline $\mathrm{U}(\mathrm{HCO},)^{-}$ & (IV) & (3) & $\mathrm{U}\left(\mathrm{sO}_{4}\right)_{2}^{\circ}$ & (IV) & (3) \\
\hline $\mathrm{U}(\mathrm{HCO},)_{0}^{2-}$ & (IV) & (3) & $\begin{array}{l}\mathrm{U}\left(\mathrm{sO}_{4}\right)_{3}^{2-} \\
\mathrm{U}\left(\mathrm{sO}_{4}\right)^{4-}\end{array}$ & $\begin{array}{l}\text { (IV) } \\
\text { (IV) }\end{array}$ & (3) \\
\hline $\mathrm{U}(\mathrm{OH})_{2}\left(\mathrm{CO}_{3}\right)^{\bullet}$ & (IV) & (3) & $\mathrm{U}\left(\mathrm{SO}_{4}\right)_{8}^{6-}$ & (IV) & (3) \\
\hline $\mathrm{U}(\mathrm{OH}),(\mathrm{CO})^{-}$ & (IV) & (3) & $\mathrm{U}\left(\mathrm{SO}_{6}\right) \mathrm{C}^{\mathrm{a}}$ & (IV) & (3) \\
\hline $\mathrm{U}(\mathrm{OH})_{2}\left(\mathrm{CO}_{1}\right)_{2}^{2-}$ & (IV) & (3) & & & \\
\hline $\mathrm{U}(\mathrm{OH})_{2}\left(\mathrm{CO}_{3}\right)_{3}^{4}$ & (IV) & (3) & $\mathrm{UO}_{2} \mathrm{SO}_{4}^{-}$ & (v) & (3) \\
\hline $\mathrm{U}(\mathrm{OH})_{2}\left(\mathrm{CO}_{3}\right)_{6}^{6-}$ & (IV) & (3) & $\begin{array}{l}\mathrm{UO}_{2}\left(\mathrm{SO}_{4}\right)_{2}^{3-} \\
\mathrm{UO}_{2}\left(\mathrm{SO}_{4}\right)_{3}^{3-}\end{array}$ & $\begin{array}{l}\text { (v) } \\
\text { (v) }\end{array}$ & $\begin{array}{l}\text { (3) } \\
\text { (3) }\end{array}$ \\
\hline $\mathrm{UO}_{2}\left(\mathrm{CO}_{3}\right)^{-}$ & (v) & (3) & $\mathrm{UO}_{2}\left(\mathrm{SO}_{6}\right)_{4}^{7 \cdot}$ & (v) & (3) \\
\hline $\mathrm{UO}_{2}\left(\mathrm{CO}_{3}\right)_{2}^{3-}$ & (v) & (3) & & & \\
\hline $\mathrm{UO}_{2}\left(\mathrm{CO}_{3}\right)_{3}^{3 .}$ & (v) & $(1),(3)$ & $\mathrm{UO}_{2} \mathrm{SO}_{3}^{\circ}$ & (VI) & (3) \\
\hline $\mathrm{UO}_{2}\left(\mathrm{CO}_{3}\right)^{7-}$ & (v) & (3) & $\mathrm{UO}_{2}\left(\mathrm{SO}_{3}\right)_{2}^{2-}$ & (VI) & (3) \\
\hline $\mathrm{UO}_{2}\left(\mathrm{CO}_{1}\right)_{3}$ & (v) & (3) & $\begin{array}{l}\mathrm{UO}_{2}\left(\mathrm{SO}_{1}\right)_{3}^{4-} \\
\mathrm{UO}_{2} \mathrm{~S}_{2} \mathrm{O}_{3}^{\circ}\end{array}$ & $\begin{array}{l}\text { (VI) } \\
\text { (VI) }\end{array}$ & $\begin{array}{l}\text { (3) } \\
\text { (3) }\end{array}$ \\
\hline $\mathrm{UO}_{2}\left(\mathrm{HCO}_{3}\right)^{\circ}$ & (v) & (3) & $\mathrm{UO}_{2} \mathrm{SO}_{4}^{\circ}$ & (VI) & (3) \\
\hline $\mathrm{UO}_{2}\left(\mathrm{HCO}_{3}\right)_{2}^{\circ}$ & (v) & (3) & $\mathrm{UO}_{2}\left(\mathrm{SO}_{1}\right)_{2}{ }^{2-}$ & (VI) & (3) \\
\hline $\mathrm{UO}_{2}\left(\mathrm{HCO}_{3}\right)_{3}^{2-}$ & (v) & (3) & $\mathrm{UO}_{2}\left(\mathrm{SO}_{4}\right)_{3}^{4-}$ & (VI) & (3) \\
\hline \multirow[t]{2}{*}{$\mathrm{UO}_{2}\left(\mathrm{HCO}_{3}\right)_{4}^{3}$} & (v) & (3) & $\mathrm{NO}_{2}\left(\mathrm{SO}_{4}\right)_{4}^{--}$ & (VI) & (3) \\
\hline & & & $\mathrm{UO}_{2}\left(\mathrm{SO}_{6}\right)_{3}^{\mathrm{O}}$ & (VI) & (3) \\
\hline $\mathrm{UO}_{2}\left(\mathrm{CO}_{1}\right)^{\circ}$ & (VI) & $(2),(3)$ & & & \\
\hline $\mathrm{UO}_{2}\left(\mathrm{CO}_{1}\right)_{2}^{2-}$ & (VI) & $(2),(3)$ & $\mathrm{UO}_{2} \mathrm{SO}_{4}^{\circ}$ & (VI) & (2) \\
\hline $\mathrm{UO}_{2}\left(\mathrm{CO}_{3}\right)_{3}^{6-}$ & (VI) & $(2),(3)$ & $\mathrm{UO}_{2}\left(\mathrm{SO}_{6}\right)_{2}{ }^{2-}$ & (VI) & (2) \\
\hline $\mathrm{UO}_{2}\left(\mathrm{CO}_{3}\right)_{6}^{\circ}$ & (VI) & (3) & & & \\
\hline $\mathrm{UO}_{2}\left(\mathrm{CO}_{3}\right)_{3}{ }^{2-}$ & (VI) & (3) & Phosphate Complexes & & \\
\hline $\mathrm{UO}_{2}\left(\mathrm{HCO}_{3}\right)^{\circ}$ & (VI) & (3) & $\mathrm{UP}_{2} \mathrm{O}_{1}^{\circ}$ & (III) & (3) \\
\hline $\mathrm{UO}_{2}\left(\mathrm{BCO}_{3}\right)_{2}^{\circ}$ & (VI) & (3) & $\mathrm{U}\left(\mathrm{H}_{2} \mathrm{PO}_{4}\right)^{20}$ & (III) & (3) \\
\hline $\mathrm{UO}_{2}\left(\mathrm{HCO}_{3}\right)_{3}$ & (VI) & (3) & $\mathrm{U}\left(\mathrm{H}_{2} \mathrm{PO}_{4}\right)_{2}$ & (III) & (3) \\
\hline $\mathrm{UO}_{2}\left(\mathrm{HCO}_{3}\right)_{4}^{2-}$ & (VI) & (3) & $\mathrm{U}\left(\mathrm{H}_{2} \mathrm{PO}_{4}\right)_{3}^{\circ}$ & (III) & (3) \\
\hline \multirow{2}{*}{$\mathrm{UO}_{2}\left(\mathrm{HCO}_{3}\right)_{3}^{3-}$} & (VI) & (3) & & & \\
\hline & & & $\begin{array}{l}\mathrm{U}\left(\mathrm{PO}_{4}\right)^{\circ} \\
\mathrm{U}(\mathrm{PO})^{2-}\end{array}$ & $\begin{array}{l}\text { (IV) } \\
\text { (IV) }\end{array}$ & $\begin{array}{l}\text { (3) } \\
\text { (3) }\end{array}$ \\
\hline $\begin{array}{l}\mathrm{UO}_{2}\left(\mathrm{CO}_{3}\right)(\mathrm{OH})^{2} \\
\mathrm{UO}_{2}\left(\mathrm{CO}_{3}\right)(\mathrm{OH})_{2}{ }^{2-}\end{array}$ & $\begin{array}{l}\text { (VI) } \\
\text { (VI) }\end{array}$ & $\begin{array}{l}(3) \\
(3)\end{array}$ & $\begin{array}{l}\mathrm{U}\left(\mathrm{PO}_{4}\right)_{2} \\
\mathrm{U}\left(\mathrm{PO}_{4}\right)_{3}^{3-}\end{array}$ & (IV) & (3) \\
\hline $\mathrm{UO}_{2}\left(\mathrm{CO}_{2}\right)(\mathrm{OH})_{2}^{\circ}$ & (VI) & (3) & $\mathrm{U}\left(\mathrm{PO}_{4}\right)_{4}^{6-}$ & (IV) & (3) \\
\hline \multirow[t]{2}{*}{$\mathrm{UO}_{2}\left(\mathrm{CO}_{3}\right)_{2}\left(\mathrm{H}_{2} \mathrm{O}\right)_{2}{ }^{2-}$} & (VI) & (3) & $\left.\mathrm{U}\left(\mathrm{PO}_{4}\right)_{3}\right)^{11-}$ & (IV) & (3) \\
\hline & & & $\mathrm{U}\left(\mathrm{PO}_{6}\right)_{6}{ }^{16-}$ & (IV; & (3) \\
\hline$\left(\mathrm{UO}_{2}\right)_{2}\left(\mathrm{CO}_{3}\right)(\mathrm{OH})_{3}^{-}$ & (VI) & $(1),(3)$ & $\mathrm{U}\left(\mathrm{HPO}_{4}\right)^{2+}$ & (IV) & (3) \\
\hline$\left(\mathrm{UO}_{2}\right)_{3}(\mathrm{CO},)_{0}^{\circ}$ & (VI) & $(3),(4)$ & $\mathrm{U}\left(\mathrm{HPO}_{4}\right)_{2}^{\circ}$ & (IV) & (3) \\
\hline$\left(\mathrm{UO}_{2}\right)_{3}\left(\mathrm{CO}_{3}\right)(\mathrm{OH})_{3}$ & (VI) & $(3),(4)$ & $\mathrm{U}\left(\mathrm{HPO}_{4}\right)_{3}^{2-}$ & (IV) & (3) \\
\hline$\left(\mathrm{UO}_{2}\right)_{3}\left(\mathrm{HCO}_{3}\right) \mathrm{O}(\mathrm{OH})_{2}$ & (VI) & (3) & $\mathrm{U}\left(\mathrm{HPO}_{4}\right)_{4}^{4 *}$ & (IV) & (3) \\
\hline \multirow{2}{*}{$\left(\mathrm{UO}_{2}\right)_{3}\left(\mathrm{CO}_{2}\right)(\mathrm{OH})_{3}$} & (VI) & (3) & $\mathrm{U}\left(\mathrm{HPO}_{4}\right) \mathrm{g}^{6-}$ & (IV) & (3) \\
\hline & & & U(HPO, $)_{6}^{\circ-}$ & (IV) & (3) \\
\hline
\end{tabular}


Appendix E: Aqueous Complexes

\begin{tabular}{|c|c|c|}
\hline $\mathrm{U}\left(\mathrm{H}_{2} \mathrm{PO}_{4}\right)^{30}$ & (IV) & (3) \\
\hline $\mathrm{U}\left(\mathrm{H}_{2} \mathrm{PO}_{4}\right)_{2}^{20}$ & (IV) & (3) \\
\hline $\mathrm{U}\left(\mathrm{H}_{2} \mathrm{PO}_{4}\right) \mathrm{j}^{\circ}$ & (IV) & (3) \\
\hline $\mathrm{U}\left(\mathrm{H}_{2} \mathrm{PO}_{4}\right)_{1}^{\circ}$ & (IV) & (3) \\
\hline $\mathrm{U}\left(\mathrm{H}_{1} \mathrm{PO}_{4}\right)_{8}$ & (IV) & (3) \\
\hline $\mathrm{U}\left(\mathrm{H}_{2} \mathrm{PO}_{4}\right)_{0}^{2-}$ & (IV) & (3) \\
\hline $\mathrm{U}_{2}\left(\mathrm{H}_{2} \mathrm{PO}_{4}\right)_{2}$ & (IV) & (3) \\
\hline $\mathrm{UO}_{2}\left(\mathrm{PO}_{4}\right)^{2-}$ & (v) & (3) \\
\hline $\mathrm{UO}_{2}\left(\mathrm{PO}_{4}\right)_{2}{ }^{2}$ & (v) & (3) \\
\hline $\mathrm{UO},\left(P O_{4}\right)_{3}^{\circ-}$ & (v) & (3) \\
\hline $\mathrm{UO}_{2}\left(\mathrm{PO}_{4}\right)_{4}^{11-}$ & (v) & (3) \\
\hline $\mathrm{UO}_{2}\left(\mathrm{PO}_{4}\right)_{8}{ }^{\mathrm{Ne}}$ & (v) & (3) \\
\hline $\mathrm{UO}_{2}\left(\mathrm{HPO}_{4}\right)^{\circ}$ & (V) & (3) \\
\hline $\mathrm{UO}_{2}\left(\mathrm{HPO}_{6}\right)_{2}^{2}$ & (v) & (3) \\
\hline $\mathrm{UO}_{2}\left(\mathrm{HPO}_{6}\right)_{3}^{3-}$ & (v) & (3) \\
\hline $\mathrm{UO}_{2}\left(\mathrm{HPO}_{4}\right)_{4}^{7 *}$ & (v) & (3) \\
\hline $\left.\mathrm{UO}_{2}(\mathrm{HPO})_{1}\right)^{\circ-}$ & (v) & (3) \\
\hline $\mathrm{UO}_{2}\left(\mathrm{H}_{1} \mathrm{PO}_{4}\right)^{\circ}$ & (v) & (3) \\
\hline $\mathrm{VO}_{2}\left(\mathrm{H}_{2} \mathrm{PO}_{4}\right)_{2}$ & (v) & (3) \\
\hline $\mathrm{UO}_{2}\left(\mathrm{H}_{1} \mathrm{PO}_{4}\right)_{3}^{2-}$ & (v) & (3) \\
\hline $\mathrm{UO}_{2}\left(\mathrm{PO}_{4}\right)^{\circ}$ & (VI) & (3) \\
\hline $\mathrm{UO}_{2}\left(\mathrm{PO}_{4}\right)_{2}{ }^{4-}$ & (VI) & (3) \\
\hline $\mathrm{UO}_{2}\left(\mathrm{PO}_{4}\right)_{3}{ }^{70}$ & (VI) & (3) \\
\hline $\mathrm{UO}_{2}\left(\mathrm{PO}_{6}\right)_{4}{ }^{100}$ & (VI) & (3) \\
\hline $\mathrm{UO}_{2}\left(\mathrm{PO}_{4}\right)_{5}{ }^{12}$ & (VI) & (3) \\
\hline $\mathrm{UO}_{2}\left(\mathrm{HPO}_{4}\right)^{\circ}$ & (VI) & (3) \\
\hline $\mathrm{UO}_{2}\left(\mathrm{HPO}_{4}\right)_{2}^{2-}$ & (VI) & (3) \\
\hline $\mathrm{UO}_{2}\left(\mathrm{HPO}_{4}\right)_{3}^{4-}$ & (VI) & (3) \\
\hline $\mathrm{UO}_{2}\left(\mathrm{HPO}_{4}\right)_{4}$ & (VI) & (3) \\
\hline $\mathrm{UO}_{2}\left(\mathrm{HPO}_{4}\right)_{5}^{8-}$ & (VI) & (3) \\
\hline $\mathrm{UO}_{2}\left(\mathrm{H}_{2} \mathrm{PO}_{4}\right)^{\circ}$ & (VI) & $(2),(3)$ \\
\hline $\mathrm{UO}_{2}\left(\mathrm{H}_{2} P \mathrm{O}_{1}\right)^{\circ}$ & (VI) & (3) \\
\hline $\mathrm{UO}_{2}\left(\mathrm{H}_{2} \mathrm{PO}_{6}\right)_{3}$ & (VI) & (3) \\
\hline $\mathrm{UO}_{2}\left(\mathrm{H}_{2} \mathrm{PO}_{4}\right)_{4}^{2 *}$ & (VI) & (3) \\
\hline $\mathrm{UO}_{2}\left(\mathrm{H}_{3} \mathrm{PO}_{4}\right)^{2+}$ & (VI) & (3) \\
\hline $\mathrm{UO},\left(\mathrm{H}_{3} \mathrm{PO}_{4}\right)\left(\mathrm{H}_{2} \mathrm{PO}_{4}\right)^{*}$ & (VI) & (3) \\
\hline $\mathrm{UO}_{2}\left(\mathrm{H}_{3} \mathrm{PO}_{6}\right)\left(\mathrm{H}_{2} \mathrm{PO}_{4}\right)_{2}^{\circ}$ & (VI) & (3) \\
\hline $\mathrm{UO}_{2}\left(\mathrm{HPO}_{4}\right)_{2}{ }^{2-}$ & (VI) & (2) \\
\hline $\mathrm{UO}_{2} \mathrm{H}_{2} \mathrm{PO}_{4}^{+}$ & (VI) & (2) \\
\hline $\mathrm{UO}_{2}\left(\mathrm{H}_{2} \mathrm{PO}_{4}\right)_{2}^{\circ}$ & (VI) & (2) \\
\hline $\mathrm{UO}_{2}\left(\mathrm{H}_{2} \mathrm{PO}_{4}\right)_{3}-$ & (VI) & (2) \\
\hline $\mathrm{UO}_{2}\left(\mathrm{H}_{3} \mathrm{PO}_{4}\right)\left(\mathrm{H}_{2} \mathrm{PO}_{6}\right)^{\circ}$ & (VI) & \\
\hline
\end{tabular}

Halide Complexes

$\begin{array}{lll}U F^{\circ} & \text { (IV) } & (2),(3) \\ U F_{2}^{20} & \text { (IV) } & (2),(3) \\ U F_{i}^{\circ} & \text { (IV) } & (2),(3) \\ U E_{6}^{\circ} & \text { (IV) } & (2),(3) \\ U E_{3}^{\circ} & \text { (IV) } & (2),(3) \\ U E_{0}^{2-} & \text { (IV) } & (2),(3)\end{array}$

\begin{tabular}{|c|c|c|}
\hline $\begin{array}{l}\mathrm{UO}_{2} \mathrm{~F}^{\circ} \\
\mathrm{UO} \mathrm{F}_{2} \\
\mathrm{UO}_{2} \mathrm{~F}_{3}^{2-} \\
\mathrm{UO}_{2} \mathrm{~F}_{4} \\
\mathrm{UO}_{2} \mathrm{~F}_{3}\end{array}$ & $\begin{array}{l}\text { (v) } \\
\text { (v) } \\
\text { (v) } \\
\text { (v) } \\
\text { (v) }\end{array}$ & $\begin{array}{l}(3) \\
(3) \\
(3) \\
(3) \\
(3)\end{array}$ \\
\hline UOF; & (VI) & (3) \\
\hline $\mathrm{UO}_{2} \mathrm{~F}^{+}$ & (VI) & $(2),(3)$ \\
\hline $\mathrm{UO}_{2} \mathrm{~F}_{2}{ }^{\circ}$ & (VI) & $(2),(3)$ \\
\hline $\mathrm{UO}_{2} \mathrm{~F}_{3}^{-}$ & (VI) & $(2),(3)$ \\
\hline $\mathrm{UO}_{2} \mathrm{~F}_{4}{ }^{2-}$ & (VI) & $(2),(3)$ \\
\hline $\mathrm{UO}_{2} \mathrm{~F}_{3}{ }^{2}$ & (VI) & (3) \\
\hline
\end{tabular}

$\mathrm{UCl}^{20}$ (III) (3)

UC1 (IV) (3)

$\mathrm{UCl}_{2}{ }^{\circ+} \quad$ (IV) (3)

UCl; (IV) (3)

$\mathrm{UCl}_{4}^{\circ}$ (IV) (3)

$\mathrm{UCl}_{3}^{-} \quad$ (IV) (3)

$\mathrm{VCl}^{2-} \quad$ (IV) (3)

UOCl (OH)

$\mathrm{UO}_{2} \mathrm{Cl}^{\circ} \quad$ (V) (3)

$\mathrm{VO}_{2} \mathrm{Cl}_{2}^{-} \quad$ (V) (3)

$\mathrm{UO}_{2} \mathrm{Cl}_{3}{ }^{2-} \quad$ (V) (3)

$\mathrm{UO}_{2} \mathrm{Cl}_{4}^{3 .} \quad$ (V) (3)

$\mathrm{UO}_{2} \mathrm{Cl}_{3} \times$ (V) (3)

$\mathrm{UO}, \mathrm{Cl}$ (VI) (2), (3)

$\mathrm{UO}_{2} \mathrm{Cl}_{2}^{\circ} \quad$ (VI) (3)

$\mathrm{UO}_{2} \mathrm{Cl}_{3}^{\circ} \quad$ (VI) (3)

$\mathrm{VO}_{2} \mathrm{Cl}_{4}^{2-} \quad$ (VI) (3)

$\mathrm{UO}_{2} \mathrm{Cl}_{3}^{3-} \quad$ (VI) (3)

UBr ${ }^{2+}$ (III) (3)

UBr ${ }^{30} \quad$ (IV) (3)

$\mathrm{UBr}_{2}^{20}$ (IV) (3)

$\mathrm{UBr}_{3}$ (IV) (3)

$\mathrm{UBr}_{4}^{\circ}$ (IV) (3)

$\mathrm{UBr}^{-}$(IV) (3)

$\mathrm{UBr}_{6}^{2-} \quad$ (IV) (3) 
Appendix E: Aqueous Complexus

\begin{tabular}{|c|c|c|}
\hline 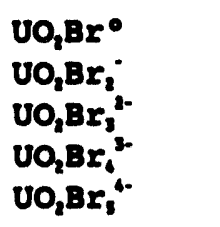 & $\begin{array}{l}\text { (v) } \\
\text { (v) } \\
\text { (v) } \\
\text { (v) } \\
\text { (v) }\end{array}$ & $\begin{array}{l}(3) \\
(3) \\
(3) \\
(3) \\
(3)\end{array}$ \\
\hline 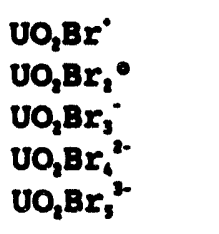 & $\begin{array}{l}\text { (VI) } \\
\text { (VI) } \\
(V I) \\
(V I) \\
(V I)\end{array}$ & $\begin{array}{l}(3) \\
(3) \\
(3) \\
(3) \\
(3)\end{array}$ \\
\hline $\begin{array}{l}\text { UI' } \\
U I_{2}^{20} \\
U I_{3}^{\circ} \\
U I_{4}^{\circ} \\
U I_{3}^{\circ} \\
U I_{6}^{2-}\end{array}$ & $\begin{array}{l}\text { (IV) } \\
\text { (IV) } \\
\text { (IV) } \\
\text { (IV) } \\
\text { (IV) } \\
\text { (IV) }\end{array}$ & $\begin{array}{l}(3) \\
(3) \\
(3) \\
(3) \\
(3) \\
(3)\end{array}$ \\
\hline $\begin{array}{l}\mathrm{UO}_{2} \mathrm{I}^{\circ} \\
\mathrm{UO}_{2} \mathrm{I}_{2}^{-} \\
\mathrm{UO}_{2} \mathrm{I}_{3}^{2-} \\
\mathrm{UO}_{2} \mathrm{I}_{4}{ }^{2-} \\
\mathrm{UO}_{2} \mathrm{I}_{3}^{4-}\end{array}$ & $\begin{array}{l}\text { (v) } \\
\text { (v) } \\
\text { (v) } \\
\text { (v) } \\
\text { (v) }\end{array}$ & $\begin{array}{l}(3) \\
(3) \\
(3) \\
(3) \\
(3)\end{array}$ \\
\hline $\begin{array}{l}\mathrm{UO}_{2} \mathrm{I}^{\circ} \\
\mathrm{UO}_{2} \mathrm{I}_{2}^{\circ} \\
\mathrm{UO}_{2} \mathrm{I}_{3} \\
\mathrm{UO}_{2} \mathrm{I}_{4}{ }^{2-} \\
\mathrm{UO}_{2} \mathrm{I}_{3}^{2-}\end{array}$ & $\begin{array}{l}\text { (VI) } \\
\text { (VI) } \\
\text { (VI) } \\
\text { (VI) } \\
\text { (VI) }\end{array}$ & $\begin{array}{l}(3) \\
(3) \\
(3) \\
(3) \\
(3)\end{array}$ \\
\hline 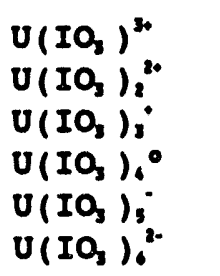 & $\begin{array}{l}\text { (IV) } \\
\text { (IV) } \\
\text { (IV) } \\
\text { (IV) } \\
\text { (IV) } \\
\text { (IV) }\end{array}$ & $\begin{array}{l}(3) \\
(3) \\
(3) \\
(3) \\
(3) \\
(3)\end{array}$ \\
\hline $\begin{array}{l}\mathrm{UO}\left(I O_{3}\right)^{\circ} \\
\mathrm{UO}_{2}\left(I O_{3}\right)_{2}^{-} \\
\mathrm{UO}_{2}\left(I O_{1}\right)_{3}^{2-} \\
\mathrm{UO}_{2}\left(I O_{1}\right)_{4}^{3-} \\
\mathrm{UO}\left(I O_{3}\right)_{3}^{6-}\end{array}$ & $\begin{array}{l}\text { (v) } \\
\text { (V) } \\
\text { (v) } \\
\text { (V) } \\
\text { (v) }\end{array}$ & $\begin{array}{l}(3) \\
(3) \\
(3) \\
(3) \\
(3)\end{array}$ \\
\hline 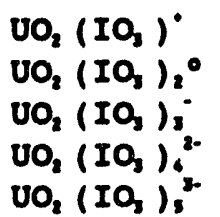 & $\begin{array}{l}\text { (VI) } \\
\text { (VI) } \\
\text { (VI) } \\
\text { (VI) } \\
\text { (VI) }\end{array}$ & $\begin{array}{l}\text { (3) } \\
(3) \\
(3) \\
(3) \\
(3)\end{array}$ \\
\hline
\end{tabular}

Nitrogen (Nitrate and Ammonlum) Complexes

\begin{tabular}{|c|c|c|}
\hline $\mathrm{U}\left(\mathrm{NO}_{3}\right)^{\mathrm{s}}$ & (IV) & (3) \\
\hline $\mathrm{U}(\mathrm{NO},)_{2}{ }^{20}$ & (IV) & (3) \\
\hline $\mathrm{U}\left(\mathrm{NO}_{3}\right)_{3}$ & (IV) & (3) \\
\hline $\mathrm{U}(\mathrm{NO},)_{4}^{\circ}$ & (IV) & (3) \\
\hline $\mathrm{U}\left(\mathrm{NO}_{3}\right)_{3}$ & (IV) & (3) \\
\hline $\mathrm{U}(\mathrm{NO},)_{0}^{2 \cdot}$ & (IV) & (3) \\
\hline $\mathrm{U}\left(\mathrm{NH}_{3}\right)^{40}$ & (IV) & (3) \\
\hline $\mathrm{U}\left(\mathrm{NH}_{3}\right)_{2}{ }^{4 *}$ & (IV) & (3) \\
\hline $\mathrm{U}\left(\mathrm{NH}_{3}\right)_{3}{ }^{40}$ & (IV) & (3) \\
\hline $\mathrm{U}\left(\mathrm{NH}_{3}\right)_{4}^{40}$ & (IV) & (3) \\
\hline $\mathrm{U}\left(\mathrm{NH}_{3}\right), \mathrm{g}^{*}$ & (IV) & (3) \\
\hline $\mathrm{U}\left(\mathrm{NH}_{3}\right)_{0}{ }^{*}$ & (IV) & (3) \\
\hline $\mathrm{UO}_{2}\left(\mathrm{NO}_{3}\right)^{\circ}$ & (V) & (3) \\
\hline $\mathrm{UO}_{2}(\mathrm{NO})_{2}$ & (v) & (3) \\
\hline $\mathrm{UO}_{2}\left(\mathrm{NO}_{3}\right)_{3}{ }^{2-}$ & (v) & (3) \\
\hline $\mathrm{UO}_{2}\left(\mathrm{NO}_{1}\right)_{4}^{3-}$ & (v) & (3) \\
\hline $\mathrm{UO}_{2}(\mathrm{NO})_{3} \mathrm{~s}^{* *}$ & (V) & (3) \\
\hline $\mathrm{UO}_{2}\left(\mathrm{NH}_{3}\right)^{\circ}$ & (V) & (3) \\
\hline $\mathrm{UO}_{2}\left(\mathrm{NH}_{3}\right)_{2}^{\circ}$ & (v) & (3) \\
\hline $\mathrm{UO}_{2}\left(\mathrm{NH}_{3}\right)_{3}$ & (v) & (3) \\
\hline $\mathrm{UO}_{2}\left(\mathrm{NH}_{3}\right)_{4}^{\circ}$ & (v) & (3) \\
\hline $\mathrm{UO}_{2}\left(\mathrm{NH}_{3}\right)_{3}^{\circ}$ & (v) & (3) \\
\hline $\mathrm{UO}_{2}\left(\mathrm{NO}_{3}\right)^{\circ}$ & (VI) & (3) \\
\hline $\mathrm{UO}_{2}\left(\mathrm{NO}_{3}\right)_{2}^{\circ}$ & (VI) & (3) \\
\hline $\mathrm{UO}_{2}\left(\mathrm{NO}_{3}\right)_{3}$ & (VI) & (3) \\
\hline $\mathrm{UO}_{2}\left(\mathrm{NO}_{3}\right)_{4}^{2-}$ & (VI) & (3) \\
\hline $\mathrm{UO}_{2}\left(\mathrm{NO}_{3}\right)_{5}^{3-}$ & (VI) & (3) \\
\hline $\mathrm{UO}_{2}\left(\mathrm{NH}_{3}\right)^{2+}$ & (VI) & (3) \\
\hline $\mathrm{UO}_{2}\left(\mathrm{NH}_{3}\right)_{2}{ }^{2+}$ & (VI) & (3) \\
\hline $\mathrm{UO}_{2}\left(\mathrm{NH}_{3}\right)_{3}{ }^{2+}$ & (VI) & (3) \\
\hline $\mathrm{UO}_{2}\left(\mathrm{NH}_{3}\right)_{4}^{2+}$ & (VI) & (3) \\
\hline $\mathrm{UO}_{2}\left(\mathrm{NH}_{3}\right)_{3}^{20}$ & (VI) & (3) \\
\hline
\end{tabular}

Sillcate Complexes

$$
\text { UO,SiO(OH); (VI) (3) }
$$

Possible Soll Organic Complexes

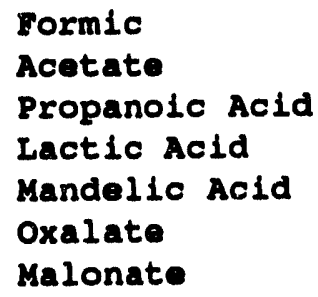


Appendix E: Aqueous Complexes

Mothyl Malonic Acld

Dimothyl Malonic acid sucolnate

Malelo Acld

Phthalio Acid

EDTA

Hydroxyacetic Acld

Mercaptoacotic acid

\section{Miscellaneous Complexes}

UC10,

$\mathrm{NO}_{2} \mathrm{ClO}_{2}^{\circ}$

$\mathrm{UO}_{2} \mathrm{ClO}_{3}$

UO,BrO,

$\mathrm{VO}_{2} 8 \mathrm{eO} \cdot$

(VI)

$\left(\mathrm{UO}_{2}\right)_{2}$ (OH) $\mathrm{SeO}^{\circ}$

$\mathrm{VO}_{2} \mathrm{Ni}^{\circ}$

(VI)

$\mathrm{UO}_{2}\left(\mathrm{~A}_{3}\right)_{2^{\circ}}^{\circ}$

$\mathrm{UO}_{2}\left(H_{3}\right)_{3}^{\circ}$

$\mathrm{UO}_{2}\left(\mathrm{~N}_{3}\right)_{4}^{2}$
(VI)

(VI)

(VI)

\section{References}

(1) Carnahan, C. L., "Some Effects of Database Variations on Numerical Simulations of Uranium Migration," Radiochimica Acta, 44/45:349-354, 1988.

(2) Langmuir, D., "Uranium Solution-Mineral Equilibria at Low Temperatures with Applications to Sedimentary Ore Deposits," Geochimica Cosmochimica Acta, 42:547-569, 1978.

(3) Wanner, H. and I. Forest, Chemical Thermodynamics of Unanium, Vol. 1, North Holland Publ., New York, 1992.

(4) Kramer-Schnabel, U., H. Bischoff, R. H. Xi and G. Marx, "Solubility Products and Complex Formation Equilibria in the Systems Uranyl Hydroxide and Uranyl Carbonate at $25^{\circ} \mathrm{C}$ and I=0.1 M." Radiochimica Acta, 56:183-188, 1992. 


\section{Appendix F: A Solubility-Ranking System to Describe the Relative Availability of Major Uranium Minerals and Uranium-Bearing Soil Phases}

\section{F.1 Background}

One task of this project was to attempt to develop a solubility-ranking system for the major uraniumbearing soil phases. Previously, Kalkwarf (1980) had applied a system that summarized the observed dissolution behavior of different uranium phases in terms of their kinetic dissolution rates. Rapidly dissolving phases were classified as $D$ (for day-long time-scales), phases with slower reaction rates were classified as W (for week-long time scales), and the most refractory phases were classified as $\mathbf{Y}$ (for yearlength time scales). The ranking scale provided a convonient method for estimating the relative risks that might be associated with different uranium bearing phases under a specific set of exposure conditions. Clearly, a similar ranking system would be used if it were extended to common soil phases, although the development of a classification scheme for soil phases poses difficulties because of the myriad effects that can enhance or suppress the kinetics of dissolution in the field.

The purpose of this appendix is to present the approach that we investigated as a possible classification scheme. "Solubility" can be conceptualized in a number of ways. Solubility has a thermodynamic interpretation, in which one can estimate the concentration of uranium in equilibrium with a solid phase if other solution parameters, such as $\mathrm{pH}$, pe, alkalinity, and sulfate concentrations, are known. In contrast, Kalkwarf (1980) employed an empirical, kinetically based definition for solubility. Soluble phases were those that reacted quickly to dissolve in water, regardless of their actual, thermodynamically defined solubility. This results in some apparent contradictions between the two systems. For example, in a soil environment, uranium tetrafluoride is thermodynamically unstable. That is, in an oxidizing, carbonate-rich environment, it should spontaneously convert to some form of a uranyl carbonate. However, the phase is slow to transform because of kinetic constraints on the oxidation from uranous to uranyl. Therefore, this highly unstable phase is classified as "Y" by Kalkwarf (1980) because of the slowness of the reaction.

In spite of this apparent limitation, the solubility ranking system we present is primarily thermodynamically based. Considerations are made for factors such as whether redox reactions are involved, but the system has severe limitations because of a lack of solid, kinetically based information on the relative rates of reactions of different uranium phases.
For tivis reason, we attempt to divide the classification along lines that are based on knowledge of reaction rates for known soil phases, but we avoid making specific estimates for the many phases for which little or no data are available.

\section{F.2 Methods}

The intent of this portion of the study was to establish a thermodynamically based solubility ranking for major uranium minerals. To accomplish this, $\log \left(\mathbf{K}_{\text {ep }}\right)$ values at $25^{\circ} \mathrm{C}$ for major uranium minerals and other phases investigated by Kalkwarf (1980) were extracted from the MINTEQ2A database. For the most part, these data are derived from the NEA database on uranium (see Wanner and Forest, 1992). Those species along with their respective $\log \left(\mathrm{K}_{\mathrm{p}}\right)$ values are listed in Table F.1.

Next, for each phase, the reaction of formation was written out in terms of the major components of the mineral. We then tabulated all the nonuranium species involved in the reactions of formation. For cach of these species, we assigned "representative" soil water activities. These values were based on a consensus agreement among the group members. The species and their "representative" activities are listed in Table F.2.

Then, we ranked the relative solubility of each mineral by estimating the uranyl ion activity that would be in equilibrium with that phase [assuming oxidation of U(IV) species], using the component ion activities listed in Table F.2. It is critical to recognize that this is not a rigorous computation. The effects of speciation and ion complexation were not considered, nor was the probability that, in many cases, other, more stable minerals would be forming spontaneously in the presence of the listed phase. Nonetheless, the procedure does provide an estimate of the relative solubilities of the different phases. Results from these computations are listed in Tables F.3, F.4 and F.5.

\section{F.3 Results and Discussion}

As already indicated, results from the computations are given in Table F.3. The seven species in Table F.3 are those species for which Kalkwarf (1980) provided a solubility classification. [Note that Kalkwarf (1980) gave a classification for ammonium diuranate -- $\left(\mathrm{NH}_{4}\right)_{2} \mathrm{U}_{2} \mathrm{O}_{7}$-- rather than for sodium diuranate, the species listed in Table F.1. The MINTEQ database did not have a value for the ammonium phase, so the sodium phase data are 
Appendix F: Solubility-Ranking System

Table F.1 Last of the mineral phases and solubility products taken from the MINTEQ2A database. Solubillty products are given as the $\log \left(\vec{K}_{-}\right)$; it as assumed that the product (mineral phase) is written on the right-hand slde of the equation.

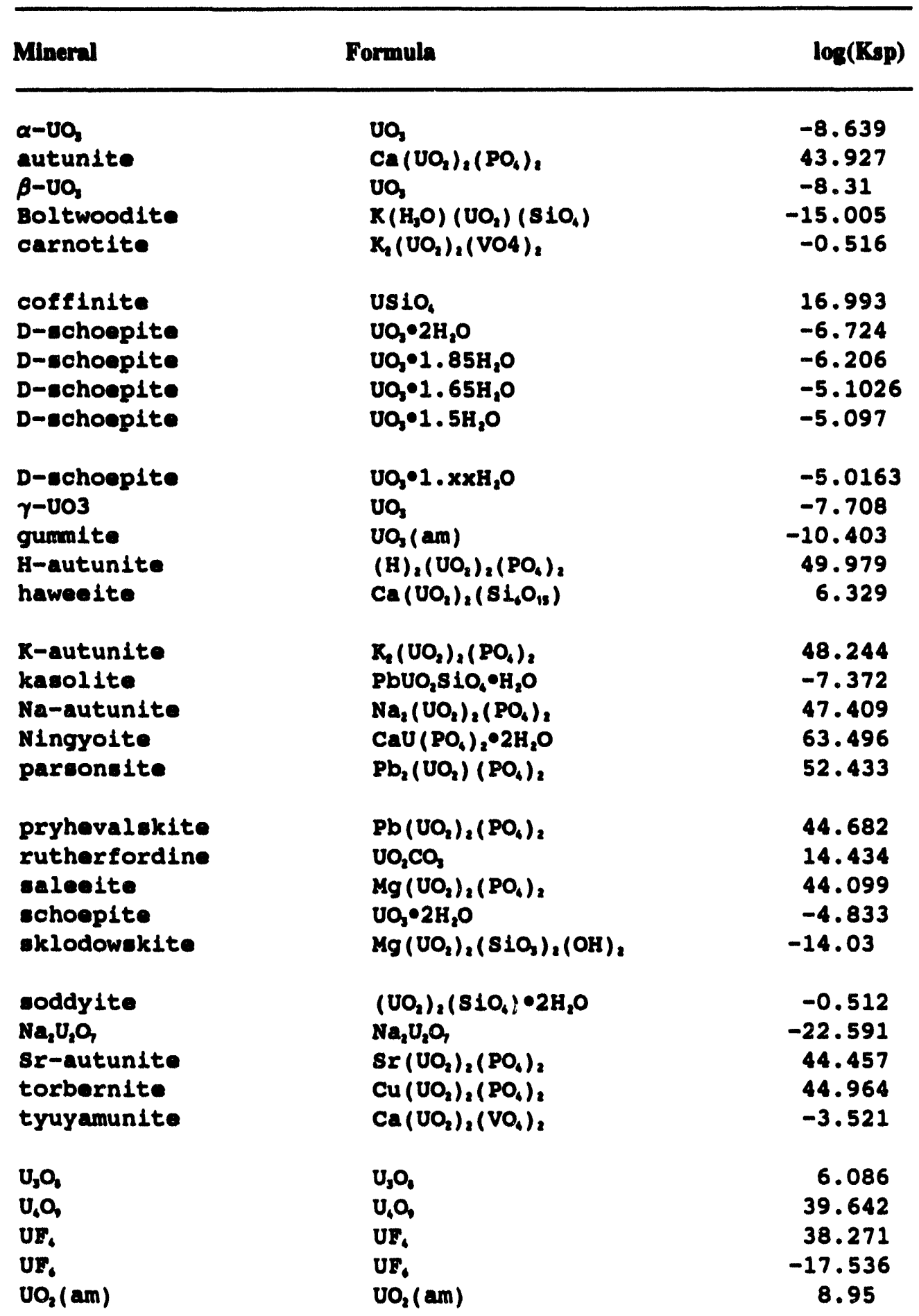


Table F.1 cout.

\begin{tabular}{|c|c|c|}
\hline Mlnaral & Formula & $\log \left(K_{\mathrm{sp}}\right)$ \\
\hline 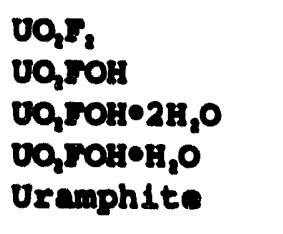 & 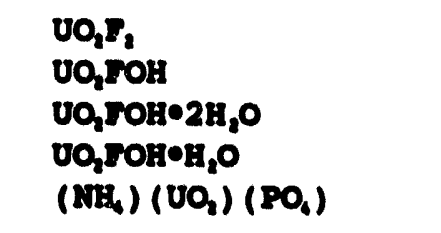 & $\begin{array}{r}7.237 \\
1.842 \\
2.659 \\
2.283 \\
51.749\end{array}$ \\
\hline $\begin{array}{l}\text { Uraninite } \\
\text { Uranocirolte } \\
\text { Uranophane } \\
\text { Weokeite }\end{array}$ & $\begin{array}{l}\mathrm{UO} \\
\left.\mathrm{Ba}(\mathrm{UO})_{2}\right)_{2}(\mathrm{POA})_{2} \\
\mathrm{Ca}\left(\mathrm{H}_{2} \mathrm{O}\right)_{2}(\mathrm{UO})_{2}\left(81 \mathrm{O}_{4}\right)_{2} \\
\left.\mathrm{R}_{2}(\mathrm{UO})_{2}\right)_{2}\left(81 \mathrm{O}_{3}\right)_{0}(\mathrm{OH})_{6}\end{array}$ & $\begin{array}{r}13.896 \\
44.448 \\
-17.524 \\
-16.0872\end{array}$ \\
\hline
\end{tabular}

Table F2 Lat of "representative" soll solution rpoctes setivities used to generate the relattve colubility randeren. $\mathbf{H}^{+}$and $e^{\circ}$ are given as the cegattive los of the setivity. All other species are liated as the los of the activity.

\begin{tabular}{|c|c|}
\hline Species & Activity \\
\hline $\begin{array}{l}\mathbf{r} \\
\bullet^{\circ}\end{array}$ & $\begin{array}{l}7.00 \\
1.00\end{array}$ \\
\hline $\begin{array}{l}\mathrm{Ba}^{20} \\
\mathrm{CO}^{2} \\
\mathrm{Ca}^{20} \\
\mathrm{Cu}^{20} \\
\mathrm{~F}^{\circ}\end{array}$ & $\begin{array}{l}-9.0 \\
-6.5 \\
-2.7 \\
-8.0 \\
-7.0\end{array}$ \\
\hline $\begin{array}{l}\mathrm{Te}^{20} \\
\mathrm{~K}^{\circ} \\
\mathrm{Mg} \\
\mathrm{Ma} \\
\mathrm{Na}^{20}\end{array}$ & $\begin{array}{l}-8.0 \\
-3.5 \\
-3.0 \\
-7.0 \\
-2.8\end{array}$ \\
\hline $\begin{array}{l}\mathrm{PO}^{2+} \\
\mathrm{Pb}^{20} \\
4 \mathrm{SSIO}_{4} \\
\mathrm{Sr}^{20} \\
\mathrm{VO}_{2}\end{array}$ & $\begin{array}{r}-10.5 \\
-10.0 \\
-2.7 \\
-6.0 \\
-10.0\end{array}$ \\
\hline
\end{tabular}

included for comparison.] Interestingly, the classification divides along oxidation-state lines rather than thermodynamic solubility lines. All of the uranous [U(IV)] phases are classified as "Y" (i.c., refractory to dissolution) by Kalkwarf (1980), in spite of the wide range in thermodynamic solubilities. This suggests that there are significant kinetic barriers to the oxidation of uranous phases in a SLF measurement. Of the other species in Table F.3, the ammonium diuranate is classified as 48\% "D" and 52\% "Y". All other phases, which are uranyl species, are classified as "D".

Table F.4 gives a listing of other uranyl mineral phases. Given the lack of specific kinetic information about these phases, we can only reviow the list and comment on the rankings in terms of certain expectations. In this context, the relative rankings offer both surprises and support for the expectations. For example, we expect the uranyl fluoride species to be among the more readily available of the uranium phases, and, indeed, they have some of the highest solubilities. Conversely, we expected the most common ore-forming minerals (c.g., carnotite, tyuyamunite, the autunites, and the silicate phases, such as haiweeite, soddyite, and weeksite) to be among the most stable. This expectation is supported by the relative rankings for the phosphate and vanadate phases, but the silicates do not follow this pattern. At this point, we believe that there is insufficient kinetic information to provide a reliable "solubility" classification along the lines of the classification used by Kalkwarf. We suspect that the phosphate and vanadate phases would eventially be classified as either "W" or " $Y$ " type phases, that many of the oxides would be classified as either "D" or "W" compounds, and that the silicates would generally 
Appendix F: Solubility-Ranking Syctem

Table F3 Luting of uranium minerals for which relative solubilities were computed and for which Kaikwarf solublitity claselacations are avallable.

\begin{tabular}{|c|c|c|c|}
\hline Mineral & $\log \left(\mathbf{X}_{\infty}\right)$ & $\begin{array}{l}\text { Relative } \\
\text { Ranking }\end{array}$ & $\begin{array}{l}\text { Kallwwre } \\
\text { Rankins }\end{array}$ \\
\hline \multicolumn{4}{|c|}{ U(VI) Minerals } \\
\hline $\begin{array}{l}\text { UR, } \\
\text { UO, } P_{2} \\
\gamma-\mathrm{UO}_{1} \\
\text { (Na), } \mathrm{U}_{2} \mathrm{O}_{1}\end{array}$ & $\begin{array}{r}-17.536 \\
7.237 \\
-7.708 \\
-22.591\end{array}$ & $\begin{array}{c}87.536 \\
6.763 \\
-6.292 \\
-6.9045\end{array}$ & $\begin{array}{c}D \\
D \\
D \\
482-D, 52-Y\end{array}$ \\
\hline \multicolumn{4}{|c|}{ U(IV) Minerals } \\
\hline $\begin{array}{l}\text { U., } \\
0 O_{1} \text { (am) } \\
0,0_{1}\end{array}$ & $\begin{array}{c}38.271 \\
8.95 \\
6.086\end{array}$ & $\begin{array}{l}19.729 \\
-6.95 \\
-10.70\end{array}$ & $\begin{array}{l}\mathbf{y} \\
\mathbf{y} \\
\mathbf{y}\end{array}$ \\
\hline
\end{tabular}

claseify as "W" or "Y" compounds. However, these projections are speculative, at best and must be verified by experimental determination.

Tablo F.5 presents a listing of uranous mineral phases not investigated by Kalkwarf (1980). At this point, we suegest that these phases would be classified as "Y" type phases in the classification scheme used by Kallwwarf (1980), because exch would need to undergo a redor process before releasing $\mathrm{UD}_{2}{ }^{\text {2+ }}$ to solution. Although there are circumstances under which such reactions can proceed rapidly, we suspset that they are not rapid for common uranous phases. This conclusion must be verified before a classification is applied to these species.

Lastly, in Table F.6, we present an alphabetical listing of uranium minerals, their chemical formulas, and references with more information about the minerals.

\section{F.4 Summary and Recommendations}

We have examined the relative solubility of a number of uranium minerals in "representative" soil solutions. The solubility values generated during this exercise should not be interpreted as strict thermodynamic solubilities, because a number of major solution processes, such as ion complexation, are not incorporated into the computation. The results for this solubility ranking do not correlate with the $\log \left(K_{\infty}\right)$ values, and is not a useful index of expected solubility behavior.
Comparison of the solubility rankings with those values reported by Kalkwarf (1980) suggest that the major controlling factor in uranium availability is the axidation state of the uranium in the solid phase. Uranous phases are classified as insoluble in Kalkwarf's scheme, and the uranyl phases, with the exception of the ammonium diuranate, are classified as soluble. Results obtained by Kalkwarf are for those phases that might be found in environments around uranium processing facilities, primarily oxides, and do not include phosphate, silicate, vanadate, or carbonate minerals.

We found no technically defensible method available for estimating the kinetic dissolution behavior of uranyl phases for which only thermodynamic information is currently available. As a result, we recommend that, for those phases currently thought to pose risks to individuals or the environment, studies be undertaken to assess relative rates of dissolution and weathering in typical soil environments.

\section{F.5 References}

Reference numbers correspond to those used in Table F.6.

(1) Powder Diffraction File: Alphabetical Index Inorganic Phases 1986, International Centre for Diffraction Data, Swarthmore, Pennsylvania, 1986. 
(2) Lanemuir, D., "Uranium Solution-Mineral Equilibria at Low Temperatures with Applications to Sedimentary Ore Deposits," Geochimica Casmochimice Acta, 42:547-569, 1978.

(3) Wanner, H. and I. Forest, Chemical Thermodynamics of Uranium, Vol. 1, North Holland Publ, Now York, 1992.
(4) Kalkwarf, D.R., NUREG/CR-1428, "Solubility Classification of Airborne Uranium Products from LWR-Fuel Plants," Pacific Northwest Laboratory, Richland, Washington, 1980. 

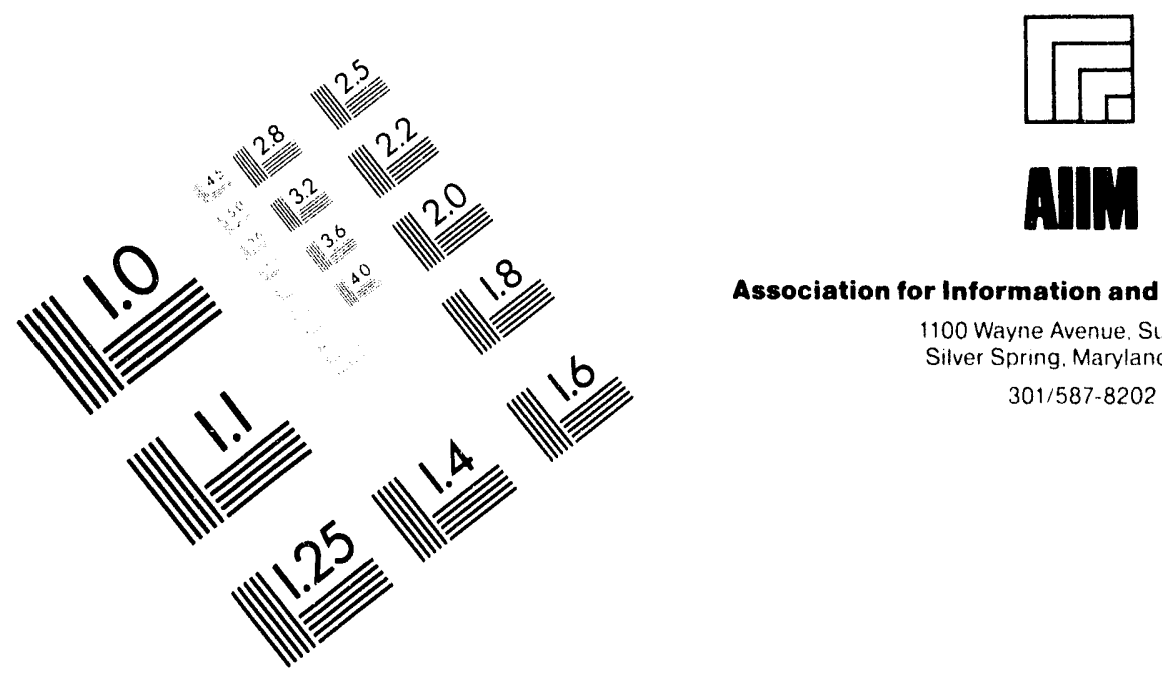

Association for Information and Image Management

1100 Wayne Avenue. Suite 1100

Silver Spring. Maryland 20910

301/587-8202

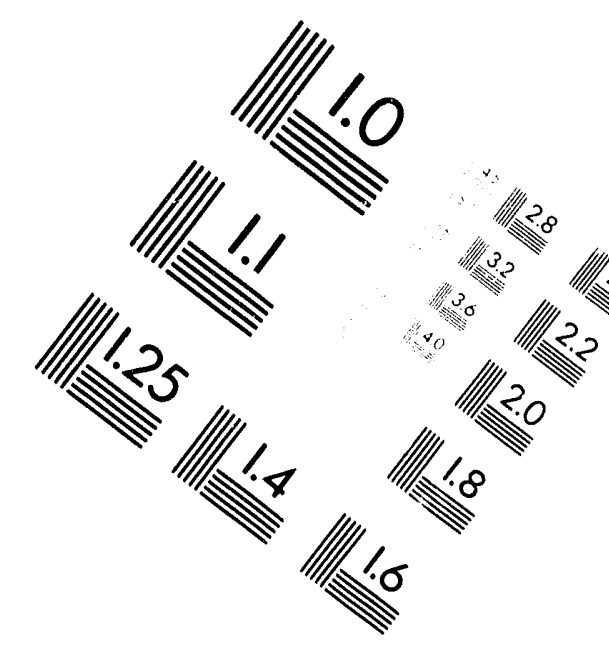

\section{Centimeter}

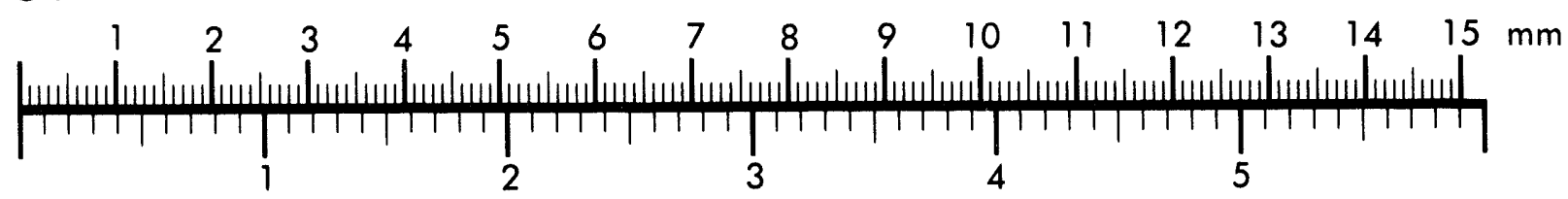

Inches
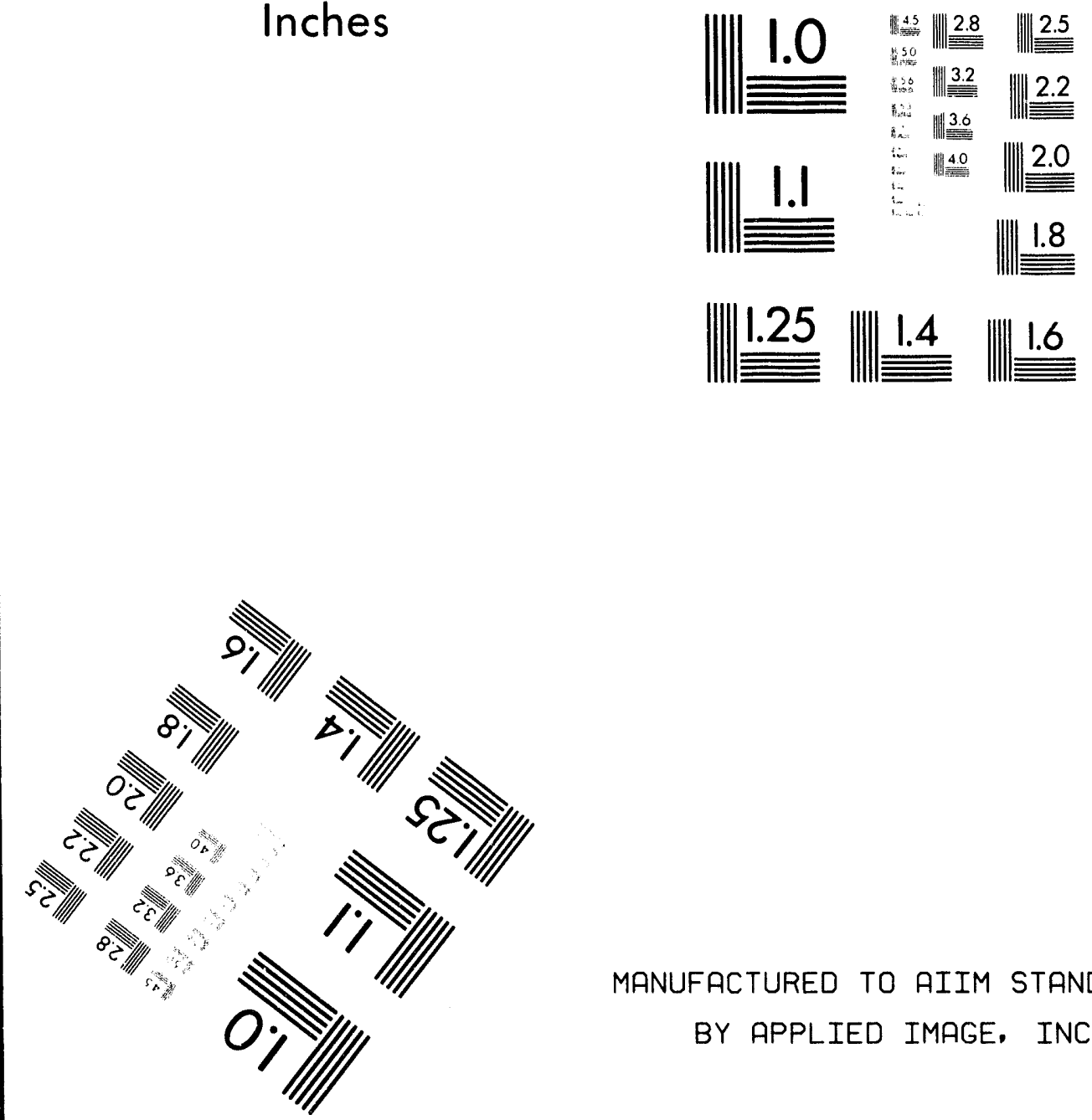

MANUFACTURED TO AIIM STANDARDS

BY APPLIED IMAGE, INC.

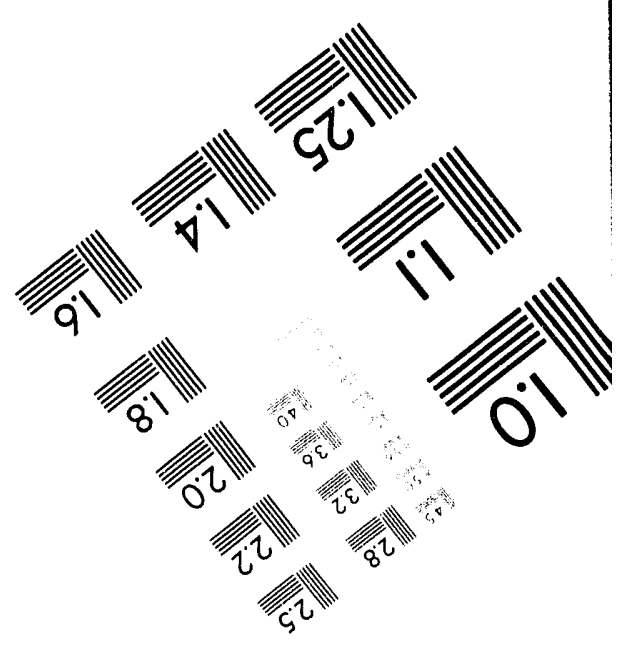



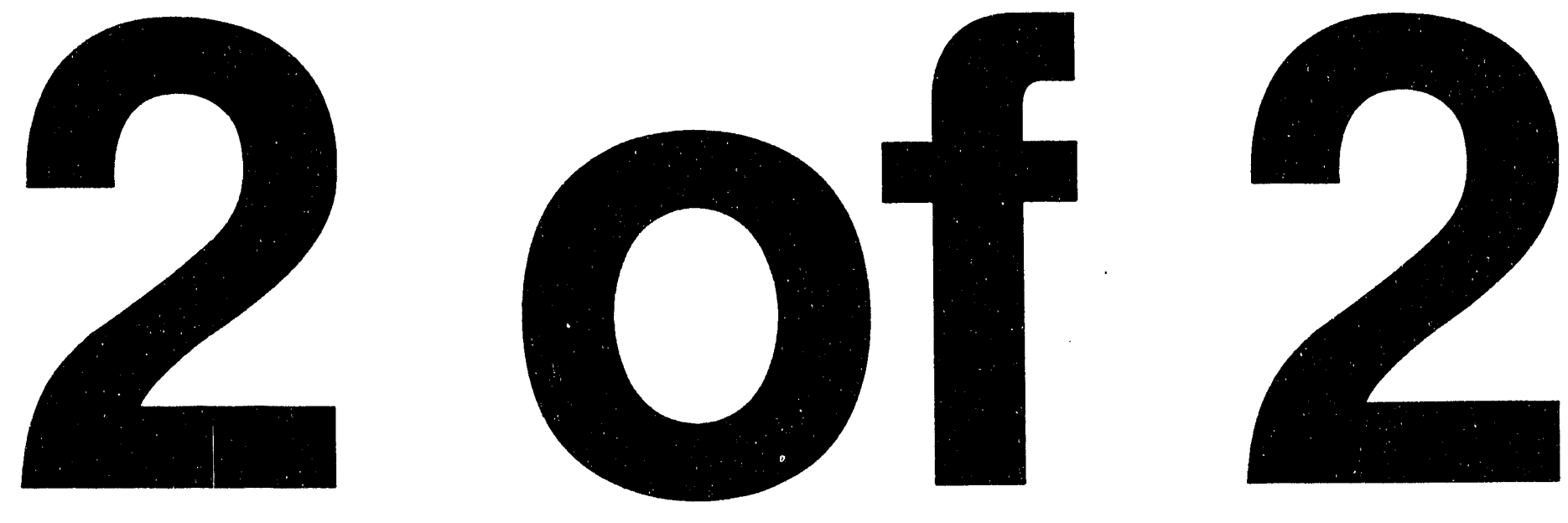
Appendix F: Solubility-Ranking System

Table F.4 Listing of the relative rankings of uranyl [Uranium (VI)] phases. The classification codes listed should be accepted as "best guess", based on observations made by Kalkwarf on related compounds, and on the apparent stability of the phases in ore deposits. Ustings in BOLD are taken from Table F.3.

\begin{tabular}{|c|c|c|c|}
\hline Mineral & $\log \left(K_{\boldsymbol{D}}\right)$ & $\begin{array}{l}\text { Relative } \\
\text { Ranking }\end{array}$ & Classincation \\
\hline $\begin{array}{l}\text { Ur. } \\
\text { UO, } \\
\text { Weeksite } \\
\text { UO,FOH } \\
\text { UO,FOH. } \mathrm{H}_{2} \mathrm{O}\end{array}$ & $\begin{array}{c}-17.536 \\
7.237 \\
-16.0872 \\
1.842 \\
2.283\end{array}$ & $\begin{array}{l}87.536 \\
6.763 \\
-1.3564 \\
-1.842 \\
-2.283\end{array}$ & $\begin{array}{l}\mathbf{D} \\
\mathbf{D} \\
\text { ? } \\
\mathbf{D} \\
\mathbf{D}\end{array}$ \\
\hline $\begin{array}{l}\text { UO, FOH. } 2 \mathrm{H}_{2} \mathrm{O} \\
\text { Boltwoodite } \\
\text { gummite } \\
\alpha-\mathrm{UO}_{3} \\
\beta-\mathrm{UO}_{3}\end{array}$ & $\begin{array}{r}2.659 \\
-15.005 \\
-10.403 \\
-8.639 \\
-8.31\end{array}$ & $\begin{array}{l}-2.659 \\
-3.295 \\
-3.597 \\
-5.361 \\
-5.69\end{array}$ & $\begin{array}{l}\text { D } \\
\text { ? } \\
\text { D } \\
\text { D } \\
\text { D }\end{array}$ \\
\hline $\begin{array}{l}\text { pryhevalokite } \\
\text { kasolite } \\
\gamma-\mathrm{UO}_{3} \\
\text { ( } \mathrm{Na})_{2} \mathrm{U}_{2} \mathrm{O}_{1} \\
\text { Uranocircite }\end{array}$ & $\begin{array}{r}44.682 \\
-7.372 \\
-7.708 \\
-22.591 \\
44.448\end{array}$ & $\begin{array}{l}-5.841 \\
-5.928 \\
-6.292 \\
-6.9045 \\
-7.224\end{array}$ & $488-D_{?}^{?} 528-Y$ \\
\hline $\begin{array}{l}\text { D-schoepite } \\
\text { parsonsite } \\
\text { H-autunite } \\
\text { Sr-autunite } \\
\text { D-schoepite }\end{array}$ & $\begin{array}{l}-6.724 \\
52.433 \\
49.979 \\
44.457 \\
-6.206\end{array}$ & $\begin{array}{l}-7.276 \\
-7.433 \\
-7.4895 \\
-7.7285 \\
-7.794\end{array}$ & $\begin{array}{c}D / W \\
? \\
? \\
? \\
D / W\end{array}$ \\
\hline $\begin{array}{l}\text { rutherfordine } \\
\text { torbernite } \\
\text { Uranophane } \\
\text { Uramphite } \\
\text { D-schoepite }\end{array}$ & $\begin{array}{c}14.434 \\
44.964 \\
-17.524 \\
51.749 \\
-5.1026\end{array}$ & $\begin{array}{l}-7.934 \\
-7.982 \\
-8.188 \\
-8.3745 \\
-8.8974\end{array}$ & $\begin{array}{c}D \\
? \\
? \\
? \\
D / W\end{array}$ \\
\hline $\begin{array}{l}\text { D-schoepite } \\
\text { D-schoepite } \\
\text { schoepite } \\
\text { sklodowskite } \\
\text { saleeite }\end{array}$ & $\begin{array}{l}-5.097 \\
-5.0163 \\
-4.833 \\
-14.03 \\
44.099\end{array}$ & $\begin{array}{l}-8.903 \\
-8.9837 \\
-9.167 \\
-9.785 \\
-10.0495\end{array}$ & $\begin{array}{l}D / W \\
D / W \\
D / W \\
? \\
?\end{array}$ \\
\hline $\begin{array}{l}\text { autunite } \\
\text { R-autunite } \\
\text { Na-autunite } \\
\text { soddyite } \\
\text { carnotite }\end{array}$ & $\begin{array}{l}43.927 \\
48.244 \\
47.409 \\
-0.512 \\
-0.516\end{array}$ & $\begin{array}{l}-10.1135 \\
-10.122 \\
-10.4045 \\
-12.394 \\
-13.984\end{array}$ & $\begin{array}{l}W / Y \\
W / Y \\
W / Y \\
W / Y \\
Y\end{array}$ \\
\hline $\begin{array}{l}\text { haweeite } \\
\text { tyuyamunite }\end{array}$ & $\begin{array}{r}6.329 \\
-3.521\end{array}$ & $\begin{array}{l}-14.7145 \\
-14.8895\end{array}$ & $\begin{array}{l}\mathbf{Y} \\
\mathbf{Y}\end{array}$ \\
\hline
\end{tabular}




\section{Appendix F: Solubility-Ranking System}

Table F.5 List of uranous [Uranium (IV)] minerals in MINTEQ database that have been assigned classification codes. Listings in BOLD are results taken from Table F3.

\begin{tabular}{lccl}
\hline Mineral & $\log \left(\mathrm{K}_{\mathbf{m}}\right)$ & $\begin{array}{c}\text { Relative } \\
\text { Ranking }\end{array}$ & Classification \\
\hline U.: & 38.271 & 19.729 & $Y$ \\
UO, (an) & 8.95 & -6.95 & $Y$ \\
Ningyoite & 63.496 & -9.796 & $Y$ \\
U., & 6.086 & -10.70 & $Y$ \\
Uraninite & 13.896 & -11.896 & $Y$ \\
U,O & 39.642 & -11.9105 & $Y$ \\
Coffinite & 16.993 & -12.293 & $Y$ \\
\hline
\end{tabular}


Appendix F: Solubility-Ranking System

Table F.6 Alphabetic listing of uranium minerals, their chemical formulas, and references.

\begin{tabular}{|c|c|c|}
\hline Name & Formula & Reference \\
\hline $\begin{array}{l}\text { Abernathyite } \\
\text { Agrinierite } \\
\text { Andersonite } \\
\text { Ankoleite-meta } \\
\text { Arsenuranospathite }\end{array}$ & 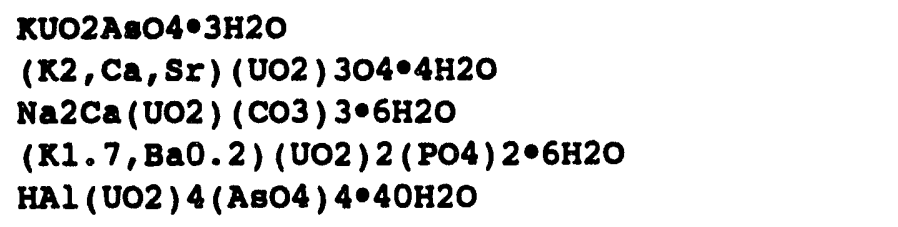 & $\begin{array}{l}(1),(3) \\
(1) \\
(1),(3) \\
(1),(3) \\
(1),(3)\end{array}$ \\
\hline $\begin{array}{l}\text { Arsenuranylite-Ca } \\
\text { Ashanite } \\
\text { Asselbornite } \\
\text { Autunite-Ca } \\
\text { Autunite-Ca-meta }\end{array}$ & $\begin{array}{l}\mathrm{Ca}(\mathrm{UO} 2) 4(\mathrm{AsO} 4) 2(\mathrm{OH}) 4 \cdot 6 \mathrm{H} 2 \mathrm{O} \\
(\mathrm{Nb}, \mathrm{Ta}, \mathrm{U}, \mathrm{Fe}, \mathrm{Mn}) 408 \\
(\mathrm{~Pb}, \mathrm{Ba})(\mathrm{UO} 2) 6(\mathrm{BIO}) 4((\mathrm{As}, \mathrm{P}) \mathrm{O} 4) 2(\mathrm{OH}) 12 \cdot 3 \mathrm{H} 2 \mathrm{O} \\
(\mathrm{Ca}, \mathrm{Sr})(\mathrm{UO} 2) 2(\mathrm{PO}) 2 \cdot 10.6 \mathrm{H} 2 \mathrm{O} \\
\mathrm{Ca}(\mathrm{UO} 2) 2(\mathrm{PO} 4) 2 \cdot 6 \mathrm{H} 2 \mathrm{O}\end{array}$ & $\begin{array}{l}(1),(3) \\
(1) \\
(1) \\
(1),(3) \\
(1)\end{array}$ \\
\hline $\begin{array}{l}\text { Autunite-Ca-pseudo } \\
\text { Autunite-H (syn) } \\
\text { Autunite-Na } \\
\text { Bassetite } \\
\text { Bauranoite }\end{array}$ & 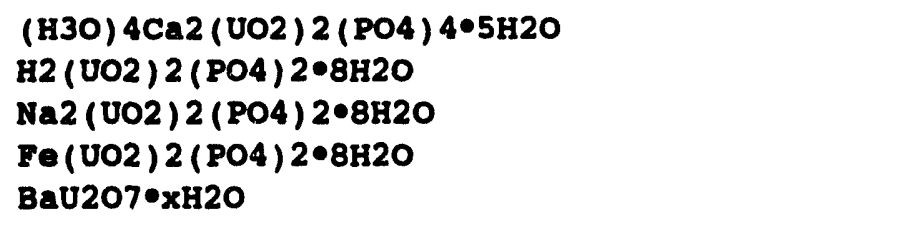 & $\begin{array}{l}(1),(3) \\
(1) \\
(1) \\
(1),(3) \\
(1),(3)\end{array}$ \\
\hline $\begin{array}{l}\text { Bayleyite } \\
\text { Becquerelite } \\
\text { Bergenite } \\
\text { Betafite } \\
\text { Betafite-ca }\end{array}$ & 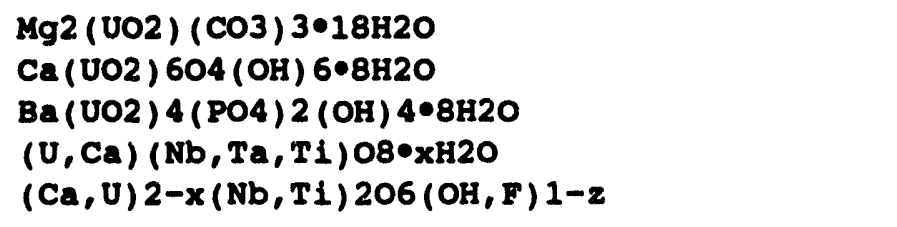 & $\begin{array}{l}(1),(3) \\
(1),(3) \\
(1),(3) \\
(1) \\
(1)\end{array}$ \\
\hline $\begin{array}{l}\text { Bijvoetite } \\
\text { Billietite (syn) } \\
\text { Boltwoodite } \\
\text { Boltwoodite-Na } \\
\text { Brannerite }\end{array}$ & 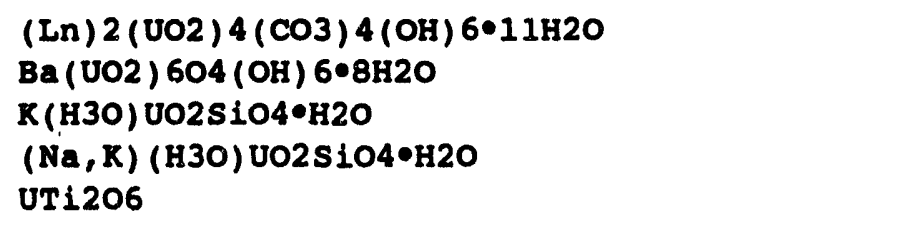 & $\begin{array}{l}(1) \\
(1),(3) \\
(1),(3) \\
(1) \\
(1)\end{array}$ \\
\hline $\begin{array}{l}\text { Brannerite-ortho } \\
\text { Calciouranoite } \\
\text { Calciouranoite-meta } \\
\text { Calcurmolite } \\
\text { Carnotite }\end{array}$ & 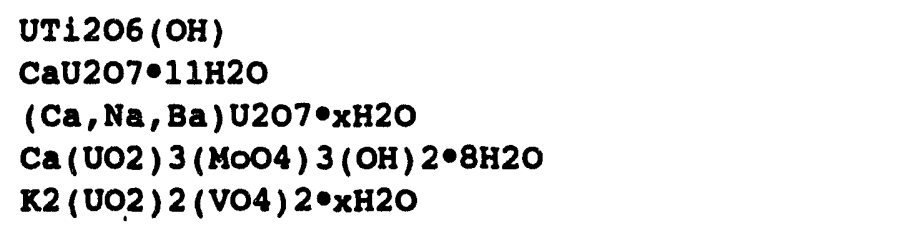 & $\begin{array}{l}(1),(3) \\
(1) \\
(1) \\
(1),(3) \\
(1),(3)\end{array}$ \\
\hline $\begin{array}{l}\text { Cheralite } \\
\text { Clarkeite } \\
\text { Cliffordite } \\
\text { Coconinoite } \\
\text { Coffinite }\end{array}$ & $\begin{array}{l}(\mathrm{In}, \mathrm{Th}, \mathrm{Ca}, \mathrm{U})(\mathrm{PO} 4, \mathrm{SiO} 4) \\
(\mathrm{Na}, \mathrm{Ca}, \mathrm{Pb}) 2 \mathrm{U} 2(\mathrm{O}, \mathrm{OH}) 7 \\
\mathrm{UTe} 309 \\
(\mathrm{Fe}, \mathrm{Al})(\mathrm{UO} 2) 4(\mathrm{PO} 4) 2(\mathrm{SO} 4) 2(\mathrm{OH}) \cdot 22 \mathrm{H} 2 \mathrm{O} \\
\mathrm{USIO} 4\end{array}$ & $\begin{array}{l}(1) \\
(1) \\
(1) \\
(1) \\
(1),(3)\end{array}$ \\
\hline $\begin{array}{l}\text { Coffinite, yttrian } \\
\text { Compreignacite } \\
\text { Cousinite } \\
\text { Cuprosklodowskite } \\
\text { Curienite }\end{array}$ & $\begin{array}{l}(\mathrm{U}, \mathrm{Ln}, \mathrm{Ca}, \mathrm{Mg})(\mathrm{SiO},(\mathrm{OH}) 4) \\
\mathrm{K2}(\mathrm{UO2}) 604(\mathrm{OH}) 6 \cdot 8 \mathrm{H} 2 \mathrm{O} \\
\mathrm{MgU} 2 \mathrm{MO} 2013 \cdot 6 \mathrm{H} 2 \mathrm{O} \\
\mathrm{Cu}(\mathrm{UO2}) 2(\mathrm{SiO} O \mathrm{OH}) 2 \cdot 6 \mathrm{H} 2 \mathrm{O} \\
\mathrm{Pb}(\mathrm{UO2}) 2 \mathrm{~V} 208 \cdot 5 \mathrm{H} 2 \mathrm{O}\end{array}$ & $\begin{array}{l}(1) \\
(1),(3) \\
(3) \\
(1),(3) \\
(1),(3)\end{array}$ \\
\hline
\end{tabular}


Table F.6 cont.

Name

Formula

Reference

Curite

Davidite

Demesmaekerite

Derriksite

Dewindtite

Dumontite

Fourmarierite

Francevillite-Ba (ayn)

Fritzcheite

rurongite

Grimselite (oyn)

Guilleminite

Gummite

Haiweelte

Hallimondite (eyn)

Heinrichite

Heinrichite-meta

Huegelite

Ianthinite

Iriginite

Johannite

Joliotite

Kahlerite

Kahlerite-meta

Kasolite

Rirchheimerite-meta

Kivuite

Lepersonnite

Liandratite

Liebigite

Lodevite-meta

Margaritasite- $(\mathrm{Cs}, \mathrm{K})$

Margaritasite-Cs

Marthozite

Masuyite

Mocterumite

Moluranite

Mourite

Mundite

Ningyoite
$\mathrm{Pb} 2 \mathrm{U} 507 \cdot 3 \mathrm{H} 2 \mathrm{O}$

(Fe, Ce, U) 2 ( TI, Fe) 5012

$\mathrm{Pb} 2 \mathrm{Cu} 5$ (UO2) 2 ( SeO3) 6 (OH) 6•2H2O

$\mathrm{Cu} 4$ ( $\mathrm{UO}^{2}$ ) ( $\mathrm{SeO} 3$ ) 2 (OH) 6

$\mathrm{Pb}$ (UO2) 3 ( PO4) 2 (OH) 2•3H2O

$\mathrm{Pb} 2$ ( $\mathrm{UO} 2$ ) 3 ( $\mathrm{PO} 4$ ) 2 ( $\mathrm{OH}$ ) 4 4 3 $2 \mathrm{O}$

$\mathrm{PbU} 4013 \cdot 4 \mathrm{H2O}$

$\mathrm{Ba}(\mathrm{UO2}$ ) 2V2O8.5H2O

$\mathrm{Mn}(\mathrm{UO} 2) 2$ (VO4) 2 4 H $2 \mathrm{O}$

Al13 (UO2) 7 ( PO4) 13 (OH) 14 -58H2O

K3NaUO2 (CO3) 3 ०H2O

$\mathrm{Ba}(\mathrm{UO} 2$ ) 3 ( $\mathrm{OH}$ ) 4 ( $\mathrm{SeO}$ ) 2 $23 \mathrm{H} 2 \mathrm{O}$

U03 (am)

$\mathrm{Ca}(\mathrm{UO2}) 2 \mathrm{Si}$ (6O15•5H2O

$\mathrm{Pb} 2$ (UO2) (A8O4) 2

$\mathrm{Ba}(\mathrm{UO2}) 2$ (AsO4) $2 \cdot 10 \mathrm{H} 2 \mathrm{O}$

$\mathrm{Ba}(\mathrm{UO2}) 2$ (AsO4) $2 \cdot 8 \mathrm{H} 2 \mathrm{O}$

$\mathrm{Pb} 2$ (UO2) 3 ( $\mathrm{ABO}$ ) 2 ( OH) 4 $4 \mathrm{H} 2 \mathrm{O}$

$\mathrm{UO2} .833 \cdot 2 \mathrm{H} 2 \mathrm{O}$

$\mathrm{U}$ ( $\mathrm{MOO} 4$ ) 2 (OH) $2 \cdot 2 \mathrm{H} 2 \mathrm{O}$

$\mathrm{Cu}(\mathrm{UO} 2) 2$ ( $\mathrm{SO} 4) 2$ ( OH) $2 \cdot 6 \mathrm{H} 2 \mathrm{O}$

(UO2) $\mathrm{CO} 3 \cdot 2 \mathrm{H} 2 \mathrm{O}$

$\mathrm{Fe}(\mathrm{UO} 2) 2$ (ABO4) $2 \cdot 12 \mathrm{H} 2 \mathrm{O}$

$\mathrm{Fe}(\mathrm{UO} 2) 2$ (AsO4) 2・8H2O

$\mathrm{Pb}(\mathrm{UO} 2)$ S $104 \cdot \mathrm{H} 2 \mathrm{O}$

$\mathrm{Co}(\mathrm{UO2}) 2$ (A8O4) 2・8H2O

( Th, Ca , Pb) H2 (UO2) 4 ( $\mathrm{PO} 4$ ) 2 (OH) $8 \bullet 7 \mathrm{H} 2 \mathrm{O}$

CaLn2 (UO2) 24 (CO3) $85 i 4012 \bullet 60 \mathrm{H} 2 \mathrm{O}$

$\mathrm{U}(\mathrm{Nb}, \mathrm{Ta}) 208$

$\mathrm{Ca} 2 \mathrm{UO}_{2}\left(\mathrm{CO}_{3}\right) 3 \cdot 10 \mathrm{H} 2 \mathrm{O}$

$\mathrm{Zn}(\mathrm{UO2}) 2$ (AsO4) $2 \cdot 10 \mathrm{H} 2 \mathrm{O}$

(Cs, K, H3O) ( UO2 ) 2 ( VO4 ) 2 คH2O

C82 (UO2) 2V2O8

$\mathrm{Cu}$ ( $\mathrm{UO} 2$ ) 3 ( $\mathrm{SeO} 3$ ) 3 (OH) 2 - $7 \mathrm{H} 2 \mathrm{O}$

$\mathrm{Pb}-\mathrm{UO} 3-\mathrm{H} 2 \mathrm{O}$

$\mathrm{Pb}$ ( $\mathrm{UO2}$ ) ( $\mathrm{TeO} 3$ ) 2

U4MO $7032 \cdot 2 \mathrm{OH} 2 \mathrm{O}$

UMO5O18.5H2O

Al ( $\mathrm{UO2}$ ) 3 ( $\mathrm{PO} 4$ ) 2 ( OH) 3•5 . $5 \mathrm{H} 2 \mathrm{O}$

$\mathrm{CaU}(\mathrm{PO} 4) 2 \bullet \mathrm{H} 2 \mathrm{O}$
(1), (3)

(1)

(1)

(1), (3)

(1), (3)

(1), (3)

(1), (3)

(1), (3)

(1), (3)

(1), (3)

(1), (3)

(1), (3)

(3)

(1), (3)

(1), (3)

(1)

(1), (3)

(1)

(3)

(1), (3)

(1), (3)

(1), (3)

(1), (3)

(1), (3)

(1), (3)

(1), (3)

(1)

(1)

(1)

(1), (3)

(1), (3)

(1)

(1)

(1), (3)

(1), (3)

(1), (3)

(1), (3)

(1), (3)

(1), (3)

(1), (3) 
Appendix F: Solubility-Ranking System

Table F.6 cont.

Name

Formula

Reference

Hovacek1te-20A (eyn)

Novacek1te-22A (syn)

Novacelite-meta

Ourainite

Parachoeplte

Pareonite

Petecheckite

Phosphurany 1 ite

Phuralumito

Phurcalite

Prshevalekite (syn)

Pyrochlore

Rabbittite

Rameauite

Ranunculito

Rauvite-Ca

Renardite

Richetite

Roubaultite

Rutherfordine

Sabugalite

saleeite

sayrito

schmitterite

schoopite

Schoepite-meta

schroeckingerito (घyn)

sedovite

senglerito

sharplto

sklodowskite

soddy 1 te

spinite-k

strelkinite

studtite

studt 1te-meta

swambolte

swartzite

Tanteuxenite

Thorogumite
$\mathrm{Mg}(\mathrm{UO2}) 2$ (A.004) 2.10H2O

$\mathrm{Yg}(\mathrm{UO2}) 2$ (A.04) $2 \cdot 12 \mathrm{H} 2 \mathrm{O}$

(1), (3)

$\mathrm{Mg}(\mathrm{UO2}) 2$ (As04) 2 -8H2O

(1)

(1)

(H3O) 2 (CO, $\mathrm{Kg}$ ) (UO2) 2 ( S1O4) 2 $3 \mathrm{H} 2 \mathrm{O}$

VO2. $86 \bullet 1.5 \mathrm{H} 2 \mathrm{O}$

(1)

(1)

Pb2002 (PO4) $20 \times 420$

$\mathrm{UFe}(\mathrm{Nb}, \mathrm{Ta}) 208$

$(1),(3)$

(1)

$\mathrm{Ca}(\mathrm{UO} 2) 3$ ( $\mathrm{PO} 4) 2$ (OH) 2 $6 \mathrm{H} 2 \mathrm{O}$

(1), (3)

(1), (3)

Al2 ( $\mathrm{UO2}$ ) 3 ( PO4) 2 (OH) 6.1 OH2O

(1), (3)

$\mathrm{Ca} 2$ ( $\mathrm{OO}^{2}$ ) 3 ( $\mathrm{PO} 4$ ) 2 ( OH) 4०4H2O

(1), (3)

$\mathrm{Pb}(\mathrm{OO} 2) 2$ ( $\mathrm{PO} 4) 2 \cdot 2 \mathrm{H} 2 \mathrm{O}$

( $\mathrm{Na}, \mathrm{Ca}, \mathrm{U}) 2$ ( $\mathrm{Nb}, \mathrm{Ta}) 206$ (OH, F)

(1)

Ca3Kg3 (UO2) 2 ( $\left.\mathrm{CO}_{3}\right) 6$ (OH) $4 \cdot 18 \mathrm{H} 2 \mathrm{O}$

K2Ca (UO2) 608・9H2O

$\mathrm{Al}$ (H3O) ( $\mathrm{OO2}$ ) (PO4) (OH) 3.3H2O

(1), (3)

(1), (3)

(1), (3)

$\mathrm{Ca}(\mathrm{UO} 2) 2 \mathrm{~V} 10028 \cdot 16 \mathrm{H} 2 \mathrm{O}$

(1), (3)

$\mathrm{Pb}(\mathrm{OO} 2) 4$ ( $\mathrm{PO} 4) 2$ (OH) 4०7H2O

(3)

(1)

(1), (3)

$\mathrm{Cu} 2$ ( UO2 ) 3 (OH) $1005 \mathrm{H} 2 \mathrm{O}$

002003

(1), (3)

HAl (UO2) 4 ( PO4) 4016H2O

$\mathrm{Mg}(\mathrm{OO} 2) 2$ ( $\mathrm{PO} 4$ ) 2 -xH2O

$\mathrm{Pb} 2$ (UO2) 506 (OH) $2 \cdot 4 \mathrm{H2O}$

(1), (3)

(1), (3)

(1)

U02T-03

$003 \cdot 2820$

(1), (3)

(1), (3)

$003 \cdot 2 \mathrm{H} 2 \mathrm{O}$

(1)

$\mathrm{NaCa}(\mathrm{OO} 2)(\mathrm{CO} 3) 3(\mathrm{SO} 4) \mathrm{F} \cdot 10 \mathrm{H} 2 \mathrm{O}$

(1), (3)

$\mathrm{U}(\mathrm{M} 0 \mathrm{O} 4) 2$

$\mathrm{Cu} 2$ (UO2) 2V2O8 (OH) 2 $\times \mathrm{H} 2 \mathrm{O}$

$\mathrm{Ca}(\mathrm{OO} 2) 6(\mathrm{CO} 3) 5(\mathrm{OH}) 4 \cdot 6 \mathrm{H} 2 \mathrm{O}$

(1), (3)

(1), (3)

(1), (3)

$\mathrm{Mg}(\mathrm{UO2}) 2$ (S1O3OH) 205H2O

(1), (3)

(002) 2 ( 5104$) \cdot 2 \mathrm{H} 2 \mathrm{O}$

(1), (3)

(UO2) HA $504 \cdot 4 \mathrm{H} 2 \mathrm{O}$

(3)

$\mathrm{Na2}$ (UO2) 2V2O8・6H2O

(1), (3)

004०4H2O

(1), (3)

U04.2H2O

(1)

UH6 (UO2S 104) 6•3OH2O

(1), (3)

$\mathrm{CaYg}(\mathrm{UO} 2)(\mathrm{CO} 3) 3 \cdot 12 \mathrm{H} 2 \mathrm{O}$

(1), (3)

$(\mathrm{U}, \mathrm{Fe}, \mathrm{V})(\mathrm{TI}, \mathrm{Sn}) 206$

(1)

$(T h, U, C e)(S 1 O 4) 1-x(O H) 4 x$ 
Appendix F: Solubility-Ranking System

Table F.6 cont.

Name

Formula

Reference

Thorutite

Threadgoldite

(Th, 0, Ca)T1206

(1)

Torbernite

Torbernite-meta

Triangulite

Al ( $\mathrm{OO2}$ ) ( POA) 2 ( OH) • $8 \mathrm{H} 2 \mathrm{O}$

(1), (3)

$\mathrm{Cu}(\mathrm{UO2}) 2$ ( $\mathrm{PO} 4) 2$ \%xH2O

(1), (3)

$\mathrm{Cu}(\mathrm{UO} 2) 2$ (PO4) 2 -8H2O

$\mathrm{Al} 3$ ( $\mathrm{OO2}$ ) 4 ( PO4) 4 (OH) 5•5H2O

(1), (3)

(1)

Tristramite

Iroegerite

Tyuyamunite-ca

Tyuyamunite-ca-meta

$(\mathrm{Ca}, \mathrm{O})(\mathrm{PO} 4) \cdot 2 \mathrm{H} 2 \mathrm{O}$

(1)

$\mathrm{UO2}$ ( $\mathrm{UO2}$ ) 2 (As04) 2 $12 \mathrm{H} 2 \mathrm{O}$

(1), (3)

$\mathrm{Ca}(\mathrm{UO2})$ 2V2O8.8H2O

(1), (3)

$\mathrm{Ca}(\mathrm{OO} 2) 2$ (VO4) $\bullet x \mathrm{H} 2 \mathrm{O}$

(1), (3)

Umohoite-17A

U02M0O4•4H2O

(1), (3)

Unnamed 2

Unnamed $\$ 12$

U-Mb-O

(1)

U03-\$102-H2O

3UO3-2SO3-9H2O

(1)

UО3०H2O

Unnamed $\$ 3$

$\mathrm{Ca}-\mathrm{Pb}-\mathrm{U}-\mathrm{A}=04-\mathrm{H} 2 \mathrm{O}$

(1)

Unnamed $\$ 1$

Ca-U-S1-04०H2O

(1)

Unnamed $\$ 6$

Unnamed $\$ 5$

(Ca, SI) 2U7O23 10 H2O

(1)

U-Si-0

(1)

Unnamed 7

$\mathrm{Pb}-\mathrm{U}-\mathrm{V}-\mathrm{O}-\mathrm{H} 2 \mathrm{O}$

(1)

Unnamed $\$ 10$

$\mathrm{Ca}-\mathrm{Yg}-\mathrm{Pb}-\mathrm{Fe}-\mathrm{UO} 4 \cdot \times \mathrm{H} 2 \mathrm{O}$

(1)

Unnamed $\$ 4$

Ca-Mg-U-SO4

(1)

Unnamed $\$ 8$

Ca-U-VO4-H2O

(1)

BaO-002-Aa205

(1)

Unnamed $\$ 11$

$\mathrm{Al}$ ( $\mathrm{OO2}$ ) 30 (OH) ( PO4) $2 \cdot 7 \mathrm{B2O}$

(1)

Upalite

Oramphite (ayn)

(NH4) ( VO2) (PO4) • $3 \mathrm{H} 2 \mathrm{O}$

(1), (3)

(1), (3)

Oraninite

0307

002.25

(1), (3)

Uraninite

002

Uranocircite

$\mathrm{Ba}(\mathrm{OO2}) 2$ ( PO4) $2 \bullet 10 \mathrm{H} 2 \mathrm{O}$

(1), (3)

(1), (3)

$\mathrm{Ba}(\mathrm{OO} 2) 2$ ( $\mathrm{PO} 4) 2 \cdot 6 \mathrm{H} 2 \mathrm{O}$

(1), (3)

Uranocircite-meta

$\mathrm{Ba}(\mathrm{OO} 2) 2$ ( $\mathrm{PO} 4) 2 \cdot 8 \mathrm{H} 2 \mathrm{O}$

(1)

Uranocircite-meta

(1), (3)

$\mathrm{Ca}(\mathrm{H} 3 \mathrm{O}) 2$ (UO2) 2 (SiO4) $2 \cdot 3 \mathrm{H} 2 \mathrm{O}$

(1), (3)

Uranopilite

(UO2) $6 \mathrm{SO} 4$ (OH) $10 \bullet 12 \mathrm{H} 2 \mathrm{O}$

(1), (3)

HAI (UO2) 4 ( PO4) $4040 \mathrm{H} 2 \mathrm{O}$

(1), (3)

Uranosphaerite

Bi2U209・3H2O

(1), (3)

Oranospinite

$\mathrm{Ca}(\mathrm{UO2}) 2$ (AsO4) $2 \cdot 10 \mathrm{H} 2 \mathrm{O}$

Oranospinite-17A-mota ( $8 Y n) \mathrm{Ca}(\mathrm{OO} 2) 2$ (AsO4) $2 \cdot 6 \mathrm{H} 2 \mathrm{O}$

(1), (3)

Uranospinite-9A-meta (oyn)

Oranospinite-ra

$\mathrm{Ca}(\mathrm{UO2}) 2(\mathrm{AsO}) \mathrm{H}) 2 \cdot 8 \mathrm{H} 2 \mathrm{O}$

(1)

(1)

$\mathrm{Ha2}$ (UO2) 2 (AsO4) $2 \cdot 5 \mathrm{H} 2 \mathrm{O}$

(1)

oranpyrochlore

$(\mathrm{U}, \mathrm{Ca}, \mathrm{Pb})(\mathrm{Mb}, \mathrm{Ta}) 207$

(1) 
Appendix F: Solubility-Ranking System

Table F.6 cont.

\begin{tabular}{|c|c|c|}
\hline Name & Formula & Reference \\
\hline Ureilite & $\operatorname{Mg} 2(U 02) 2 S 15016 \bullet 9 H 2 O$ & (1) \\
\hline Uvanite & U2V6021・15H2O & (1) \\
\hline Vandenbrandeite & CuU04•2H2O & $(1),(3)$ \\
\hline Vandendriesecheite & $\mathrm{PbU7022 \cdot 12 \textrm {H } 2 \mathrm { O }}$ & $(1),(3)$ \\
\hline Vanmeersecheite-meta & $\mathrm{U}(\mathrm{UO2}) 3(\mathrm{PO} 4) 2(\mathrm{OH}) 6 \cdot 2 \mathrm{H} 2 \mathrm{O}$ & $(1),(3)$ \\
\hline Vanmmeerescheite & U ( UO2 ) 3 ( PO4) 2 (OH) 6.4H2O & $(1),(3)$ \\
\hline Vanuralite-Al & $\mathrm{Al}(\mathrm{UO2}) 2 \mathrm{~V} 2 \mathrm{OB}(\mathrm{OH}) \cdot 11 \mathrm{H} 2 \mathrm{O}$ & $(1),(3)$ \\
\hline Vanuralite-Al-meta & $\mathrm{Al}(\mathrm{VO} 2) 2(\mathrm{VO} 4) 2(\mathrm{OH}) \cdot 8 \mathrm{H} 2 \mathrm{O}$ & $(1),(3)$ \\
\hline Vanuralite-H & $(\mathrm{H} 3 \mathrm{O})(\mathrm{UO2}) 2 \mathrm{~V} 2 \mathrm{O} \cdot 3 \cdot 3 \mathrm{H} 2 \mathrm{O}$ & (1) \\
\hline Voglite & $\mathrm{Ca} 2 \mathrm{Cu}\left(\mathrm{UO}^{2}\right)\left(\mathrm{CO}^{2}\right) 4 \cdot 6 \mathrm{H} 2 \mathrm{O}$ & $(1),(3)$ \\
\hline Walpurgite & Bi4(UO2) (ABO4) 2O4.3H2O & $(1),(3)$ \\
\hline Weeksite & $\mathrm{K} 2(\mathrm{UO} 2) 2(\mathrm{Si} 2 \mathrm{O} 5) 304 \mathrm{H} 2 \mathrm{O}$ & $(1),(3)$ \\
\hline Widenmannite & $\mathrm{Pb} 2 \mathrm{UO}_{2}(\mathrm{CO} 3)_{3}$ & $(1),(3)$ \\
\hline Woeleendorfite & $(\mathrm{Pb}, \mathrm{Ca}) \mathrm{U} 207 \cdot 2 \mathrm{H} 2 \mathrm{O}$ & (1) \\
\hline Wyartite-17A & $\mathrm{Ca}-\mathrm{U}-\mathrm{CO} 3 \bullet \mathrm{H} 2 \mathrm{O}$ & (1) \\
\hline Wyartite-21A & $\mathrm{Ca} 307 \mathrm{C2O} 22(\mathrm{OH}) 16 \cdot 4 \mathrm{H} 2 \mathrm{O}$ & (1) \\
\hline zellerite-ca & CaUO2 (CO3) $2 \cdot 5 \mathrm{H} 2 \mathrm{O}$ & $(1),(3)$ \\
\hline zellerite-meta (syn) & $\mathrm{CaUO} 2\left(\mathrm{CO}_{3}\right) 2 \cdot 3 \mathrm{H} 2 \mathrm{O}$ & $(1),(3)$ \\
\hline Zeunerite & $\mathrm{Cu}(\mathrm{OO} 2) 2(\mathrm{AsO} 4) 2 \cdot 16 \mathrm{H} 2 \mathrm{O}$ & (1) \\
\hline zeunerite-meta & $\mathrm{Cu}(\mathrm{UO2}) 2(\mathrm{AsO}) 2 \cdot 2 \cdot \mathrm{H} 2 \mathrm{O}$ & (1) \\
\hline Zippeite & $(\mathrm{UO2}) 3$ ( SO4) 2 (OH) $2 \cdot 8 \mathrm{H} 2 \mathrm{O}$ & (1) \\
\hline Zippeite-Co (eyn) & $\mathrm{CO}\left(\mathrm{WO}_{2}\right) 6(\mathrm{SO} 4) 3(\mathrm{OH}) 10 \cdot 16 \mathrm{H} 2 \mathrm{O}$ & $(1),(3)$ \\
\hline Iippeite-K & $\mathrm{K} 4(\mathrm{UO} 2) 6(\mathrm{SO} 4) 3(\mathrm{OH}) 10.4 \mathrm{H} 2 \mathrm{O}$ & $(1),(3)$ \\
\hline 2ippeite-Mg & $\mathrm{Mg}(\mathrm{UO} 2) 6(\mathrm{SO} 4) 3(\mathrm{OH}) 10 \cdot 16 \mathrm{H} 2 \mathrm{O}$ & $(1),(3)$ \\
\hline zippeite-Na (syn) & $\mathrm{Na} 4(\mathrm{UO} 2) 6(\mathrm{SO} 4) 3(\mathrm{OH}) 10.4 \mathrm{H} 2 \mathrm{O}$ & $(1),(3)$ \\
\hline zippeite-Ni (ayn) & $\mathrm{Ni}(\mathrm{UO2}) 6(\mathrm{SO} 4) 3(\mathrm{OH}) 10 \cdot 16 \mathrm{H} 2 \mathrm{O}$ & $(1),(3)$ \\
\hline zippeite-zn (syn) & $\ln 2\left(\mathrm{UO}_{2}\right) 6(\mathrm{SO} 4) 3(\mathrm{OH}) 10 \cdot 16 \mathrm{H} 2 \mathrm{O}$ & $(1),(3)$ \\
\hline
\end{tabular}




\section{Distribution}

No. of

Copies

\section{QFFSITE}

Rateb Abu-Eid

U.S. Nuclear Regulatory Commission

Office of Nuclear Material Safety and Safeguards

Mailstop TWFN-7F-27

Washington, DC 20555

Andrew C. Campbell

U.S. Nuclear Regulatory Commission

Office of Nuclear Material Safety and Safeguards

Mailstop TWFN-7D-13

Washington, DC 20555

Daniel T. Huang

U.S. Nuclear Regulatory Commission

Office of Nuclear Material Safety and Safeguards

Mailstop TWFN-8A-23

Washington, DC 20555

Michael Weber

U.S. Nuclear Regulatory Commission

Office of Nuclear Material Safety and Safeguards

Mailstop TWFN-7F-27

Washington, DC 20555

John H. Austin

U.S. Nuclear Regulatory Commission

Office of Nuclear Material Safety and Safeguards

Mailstop TWFN-7F-27

Washington, DC 20555

Malcolm R. Knapp

U.S. Nuclear Regulatory Commission

Office of Nuclear Material Safety and Safeguards

Mailstop TWFN-7J-9

Washington, DC 20555

John T. Greeves

U.S. Nuclear Regulatory Commission

Office of Nuclear Material Safety and Safeguards

Mailstop TWFN-7J-9

Washington, DC 20555

John J. Surmeier

U.S. Nuclear Regulatory Commission

Office of Nuclear Material Safety and Safeguards

Mailstop TWFN-7J-9

Washington, DC 20555
No. of

Copies

Timothy C. Johnson

U.S. Nuclear Regulatory Commission

Office of Nuclear Material Safety and Safeguards

Mailstop TWFN-7F-27

Washington, DC 20555

Larry Bell

U.S. Nuclear Regulatory Commission

Office of Nuclear Material Safety and Safeguards

Mailstop TWFN-7F-27

Washington, DC 20555

Bill Lahs

U.S. Nuclear Regulatory Commission

Office of Nuclear Material Safety and Safeguards

Mailstop TWFN-7F-27

Washington, DC 20555

David Fauver

U.S. Nuclear Regulatory Commission

Office of Nuclear Material Safety and Safeguards

Mailstop TWFN-7F-27

Washington; DC 20555

Heather Astwood

U.S. Nuclear Regulatory Commission

Office of Nuclear Material Safety and Safeguards

Mailstop TWFN-7F-27

Washington, DC 20555

Nick Orlando

U.S. Nuclear Regulatory Commission

Office of Nuclear Material Safety and Safeguards

Mailstop TWFN-7F-27

Washington, DC 20555

Jack Parrott

U.S. Nuclear Regulatory Commission

Office of Nuclear Material Safety and Safeguards

Mailstop TWFN-7F-27

Washington, DC 20555

Sam Nalluswami

U.S. Nuclear Regulatory Commission

Office of Nuclear Material Safety and Safeguards

Mailstop TWFN-7F-27

Washington, DC 20555

Mark Thaggard

U.S. Nuclear Regulatory Commission

Office of Nuclear Material Safety and Safeguards

Mailstop TWFN-7D-13

Washington, DC 20555 
Distribution

No. of

Copies

Fred Ross

U.S. Nuclear Regulatory Commission

Office of Nuclear Material Safety and Safeguards

Mailstop TWFN-TD-13

Washington, DC 20555

Margaret Federline

U.S. Nuclear Regulatory Commission

Office of Nuclear Material Safety and Safeguards

Mailstop TWFN-TD-13

Washington, DC 20555

Joseph J. Holonich

U.S. Nuclear Regulatory Commission

Office of Nuclear Material Safety and Safeguards

Mailstop TWFN-7J-9

Washington, DC 20555

Michael J. Bell

U.S. Nuclear Regulatory Commission

Office of Nuclear Material Safety and Safeguards

Mailstop TWFN-7C-6

Washington, DC 20555

John Bradbury

U.S. Nuclear Regulatory Commission

Office of Nuclear Material Safety and Safeguards

Mailstop TWFN-TD-13

Washington, DC 20555

Virginia Colten-Bradley

U.S. Nuclear Regulatory Commission

Office of Nuclear Material Safety and Safeguards

Mailstop TWFN-TD-13

Washington, DC 20555

Richard Codell

U.S. Nuclear Regulatory Commission

Office of Nuclear Material Safety and Safeguards

Mailstop TWFN-TD-13

Washington, DC 20555

Tony Huffert

U.S. Nuclear Regulatory Commission

Office of Nuclear Material Safety and Safeguards

Mailstop TWFN-TF-27

Washington, DC 20555

George E. Powers

U.S. Nuclear Regulatory Commission

Office of Nuclear Regulatory Research

Mailstop TWFN-9C-24

Washington, DC 20555
No. of

Copies

Cynthia G. Jones

U.S. Nuclear Regulatory Commission

Office of Nuclear Material Safety and Safeguards

Mailstop TWFN-8F-5

Washington, DC 20555

William Radcliffe

U.S. Nuclear Regulatory Commission

Office of Nuclear Material Safety and Safeguards

Mailstop TWFN-8F-5

Washington, DC 20555

Christine M. Daily

U.S. Nuclear Regulatory Commission

Office of Nuclear Regulatory Research

Mailstop TWFN-9F-39

Washington, DC 20555

George Birchard

U.S. Nuclear Regulatory Commission

Office of Nuclear Regulatory Research

Mailstop TWFN-9C-24

Washington, DC 20555

Phil R. Reed

U.S. Nuclear Regulatory Commission

Office of Nuclear Regulatory Research

Mailstop TWFN-9C-24

Washington, DC 20555

Ed O'Donnell

U.S. Nuclear Regulatory Commission

Office of Nuclear Regulatory Research

Mailstop TWFN-9C-24

Washington, DC 20555

Paul. M. Bertsch

Savannah River Ecology Laboratory

Drawer E

Aiken, SC 29802

David E. Morris

INC-14; MS C-345

Los Alamos National Laboratory

Los Alamos, NM 87545

Michael H. Ebinger

EES-15, MS J-495

Los Alamos National Laboratory

Los Alamos, NM 87545 
No. of

Copies

Mark P. Elless

P. O. Box 2008

Building 3504, MS 6317

Oak Ridge National Laboratory

Oak Ridge, TN 37831

Chet W. Francis

P. O. Box 2008

Building 3504, MS 6317

Oak Ridge National Laboratory

Oak Ridge, TN 37831

Suk Y. Lee

P. O. Bax 2008

Building 1505, MS 6038

Oak Ridge National Laboratory

Oak Ridge, TN 37831

Gary T. Jacobs

P. O. Box 2008

Building 1505, MS 6038

Oak Ridge National Laboratory

Oak Ridge, TN 37831

Hank R. Westrich

P. O. Box 5800

Sandia National Laboratories

Albuquerque, NM 87185-0750

James L. Krumhansl

P. O. Box 5800

Sandia National Laboratories

Albuquerque, NM 87185-0975

Lee K. Holder

Golder Associates, Inc.

4104-148th Ave, NE

Redmond, WA 98052
QN-SITE

50 Pacific Northwest Laboratory

RJ Serne K6-81

AR Felmy K6-82

JE Amonette K6-82 (19)

GR Holdren K6-81 (5)

KM Krupka K6-81 (2)

CW Lindenmeier K6-79

VL LeGore P8-37

CC Ainsworth K3-61

JP McKinley K3-61

DR Kalkwarf P7-35

KJ Cantrell K6-81

DI Kaplan K6-81

D Rai K6-82

L Rao K6-82

LE Thomas P8-15

OT Farmer P8-08

KB Olsen K6-96

EJ Wyse P8-08

TW Wietsma K6-81

JR Freeman-Pollard H6-03

JG Woolard H6-05

Publication Coordination

Technical Report Files (5) 


\begin{tabular}{|c|c|}
\hline $\begin{array}{l}\text { U.S. NUCLEAR REGULATORY COMMISSION } \\
\text { BIBLIOGRAPHIC DATA SHEET } \\
\text { (SNo instructions on the roverse) }\end{array}$ & 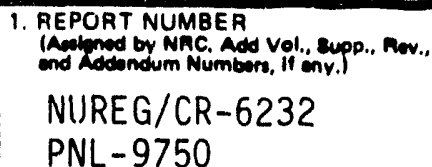 \\
\hline \multirow{4}{*}{$\begin{array}{l}\text { 2. TITLE AND SUBTITLE } \\
\text { Assessing the Environmental Availability. of Uranium in } \\
\text { Soils and Sediments }\end{array}$} & \\
\hline & DATE REPORT PUBLISHED \\
\hline & \begin{tabular}{l|l} 
MONTH & YEAA \\
June & 1994
\end{tabular} \\
\hline & 4. FIN OR GRANT NUMBER \\
\hline \multirow{2}{*}{$\begin{array}{l}\text { 5. AUTHOA(S) } \\
\text { J. E. Amonette, G. R. Holdren, Jr., K. M. Krupa, } \\
\text { C. W. Lindenmeier }\end{array}$} & $\begin{array}{l}\text { 6. TYPE OF REPORT } \\
\text { Technical }\end{array}$ \\
\hline & $\begin{array}{l}\text { 7. PEAIOD COVERED (Imelusive Doses/ } \\
1993-1994\end{array}$ \\
\hline
\end{tabular}

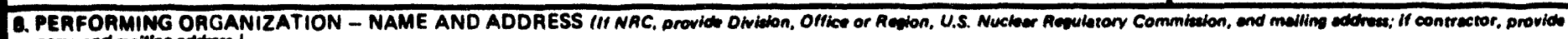
neme end meition entras)

Pacific Northwest Laboratory

Richland, WA 99352

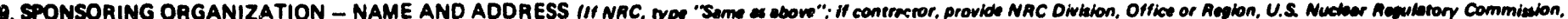
and maiming entrat

Division of Waste Management

Office of Nuclea: Material Safety and Safeguards

U.S. Nuclear Regulatory Commission

Washington, DC 20555-0001

10. SUPPLEMENTARY NOTES

11. ABSTRACT 1200 mords or masl

This report reviews existing approaches to determine their potential for assessing the environmental availability (i.e., aqueous solubility) of uranium in bulk soils or sediments. Direct empirical approaches that involve extractions by aqueous solutions provide estimates of the solubility of operationally defined components. Alternately, indirect approaches based on advanced instrumental techniques can be used to identify specific forms of uranium; the contribution of each form to the solubility is then inferred from geochemical equilibrium and kinetic models. At present, the direct empirical approaches are more likely to provide useful estimates of environmentally available uranium at reasonable costs. For the long term, we recommend development of a flow-cell procedure that incorporates dissolution-rate information into the assessment of environmental availability. In the interim, we recommend development of a batch wet-chemical procedure based on a combination of standard and nonstandard methods. Both procedures require laboratory testing and correlation with field data before being used for regulatory purposes. Lastly, we have tabulated literature data on the aqueous complexes of uranium and major uranium minerals, shown that the environmental availability of uranium cannot be predicted from thermodynamic solubility data alone, and compiled a list of laboratories capable of performing environmental availability determinations.

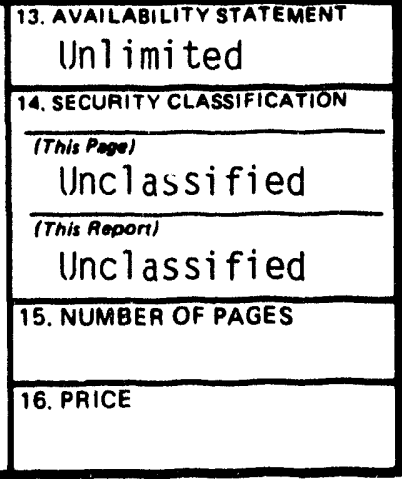



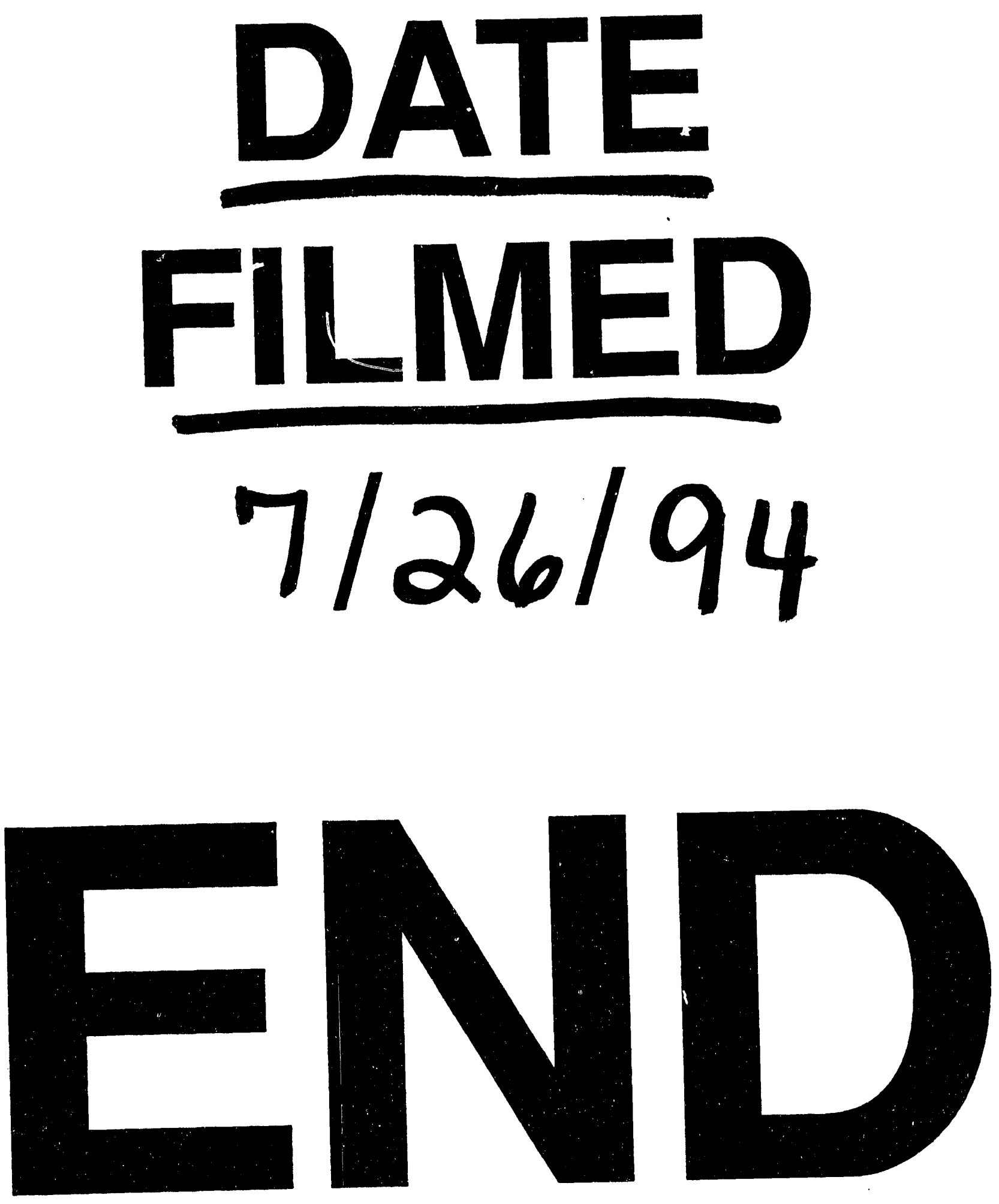
